\title{
ON THE MORAL SIDE \\ OF ENTERPRISE
}

The Complexities, Perils and Promises of Organizational Character and Integrity

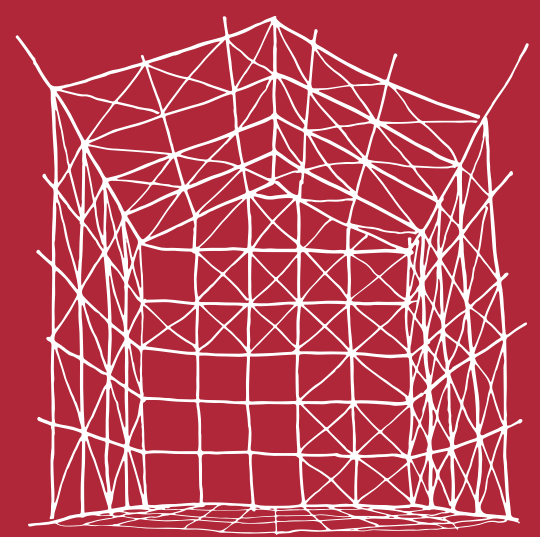

TIMO FIORITO 



\section{ON THE MORAL SIDE OF ENTERPRISE}

THE COMPLEXITIES, PERILS AND PROMISES OF ORGANIZATIONAL CHARACTER AND INTEGRITY

Timo Laurenzo Fiorito 
Cover design: Camillo Fiorito

Printed by: Ipskamp Printing

Lay-out: Douwe Oppewal

ISBN: $\quad$ 978-90-365-5224-0

DOI: $\quad 10.3990 / 1.9789036552240$

URL: $\quad$ https://doi.org/10.3990/1.9789036552240

() 2021 Timo Laurenzo Fiorito, The Netherlands. All rights reserved. No parts of this thesis may be reproduced, stored in a retrieval system or transmitted in any form or by any means without permission of the author. Alle rechten voorbehouden. Niets uit deze uitgave mag worden vermenigvuldigd, in enige vorm of op enige wijze, zonder voorafgaande schriftelijke toestemming van de auteur. 


\title{
ON THE MORAL SIDE OF ENTERPRISE
}

\section{THE COMPLEXITIES, PERILS AND PROMISES OF ORGANIZATIONAL CHARACTER AND INTEGRITY}

\section{DISSERTATION}

\author{
to obtain \\ the degree of doctor at the Universiteit Twente, \\ on the authority of the rector magnificus, \\ prof. dr. ir. A. Veldkamp, \\ on account of the decision of the Doctorate Board \\ to be publicly defended \\ on Friday 1 October 2021 at 16.45 hours
}

by

\section{Timo Laurenzo Fiorito}

born on the 16th of March, 1990 in Amsterdam, The Netherlands 
This dissertation has been approved by:

Supervisor

prof. dr. ir. P.C. de Weerd-Nederhof

Co-supervisors

dr. M.L. Ehrenhard

dr. mr. ir. R.J. Hoff 


\section{Graduation Committee:}

Chair / secretary prof. dr. T.A.J. Toonen

Supervisor

Co-supervisors

prof. dr. ir. P.C. de Weerd-Nederhof dr. M.L. Ehrenhard

dr. mr. ir. R.J. Hoff

Committee

Members prof. dr. ir. A. Bruggink prof. dr. ir. O.A.M. Fisscher prof. dr. C.M. van Praag prof. dr. L. Paape prof. mr. dr W. Huisman
Universiteit Twente

Universiteit Twente

Universiteit Twente

De Nederlandsche Bank

Universiteit Twente

Universiteit Twente

Vrije Universiteit Amsterdam

Nyenrode Business Universiteit

Vrije Universiteit Amsterdam 


\section{Contents}

Contents $\quad$ VI

List of Tables $\quad$ IX

List of Figures $\quad$ IX

Acknowledgement $\quad \mathrm{X}$

1. Introduction 1

1.1 Organizational Actorhood: Character and Integrity 3

1.1.1 Organizational Character 4

$\begin{array}{ll}\text { 1.1.2 Organizational Integrity and Values } & 6\end{array}$

1.2 The Perils of Integrity: Corporate Irresponsibility and Misconduct 8

1.3 Research Objectives, Scope, Methods and Questions 10

$\begin{array}{ll}\text { 1.3.1 Research Objectives } & 10\end{array}$

1.3.2 Scope and Methodological Considerations 11

$\begin{array}{ll}\text { 1.3.3 Research Questions } & 16\end{array}$

$\begin{array}{ll}\text { 1.3.4 Dissertation Outline } & 17\end{array}$

2. Unpacking the Complexities of Organizational Integrity: An Institutional $\begin{array}{ll}\text { Perspective } & 21\end{array}$

2.1 Introduction $\quad 21$

2.2 What is Integrity? $\quad 24$

2.3 Integrity and the Organizational Actor 26

2.3.1 Defining Organizational Integrity 28

2.3.2 Organizational Integrity: Espoused, Embedded and Enacted Values $\quad 29$

2.4 An Institutional Perspective of Organizational Integrity 32

2.4.1 Institutional Pluralism and Organizational Identities 33

2.4.2 The Perils of Organizational Integrity 35

2.4.2.1 How Pluralism Moderates Values Espousal and Embedding by Leadership $\quad 36$

2.4.2.2 How Pluralism Moderates Values Embedding 40

2.4.2.3 How Pluralism Enables Decoupling between Embedded and Enacted Values 43

2.5 Discussion and Conclusion $\quad 44$

2.5.1 Toward a Theory of Organizational Integrity 44

2.5.2 Integrity of the Organizational Actor $\quad 45$

2.5.3 The Complexities of Organizational Integrity 47 
3. Settle Down or the Struggle Within: Exploring Character and Corporate Responsibility in Two Financial Enterprises 51

3.1 Introduction $\quad 51$

3.2 Theoretical Background: Organizational Identity and Character 53

3.3 Research Context and Method $\quad 55$

3.3.1 Case Overview $\quad 55$

3.3.2 Data Collection $\quad 55$

3.3.3 Data Analysis $\quad 56$

3.4 Findings $\quad 58$

3.4.1 Stretching $\quad 58$

3.4.2 Struggling $\quad 62$

$\begin{array}{ll}3.4 .3 \text { Stabilizing } & 65\end{array}$

$\begin{array}{ll}\text { 3.4.4 Settling } & 69\end{array}$

$\begin{array}{lll}3.5 & \text { Discussion and Conclusion } & 72\end{array}$

4. The Persistence of Organizational Misconduct: The Case of Anti-Money Laundering in the Financial Industry, 2005-2020 77

$\begin{array}{lll}4.1 & \text { Introduction } & 77\end{array}$

$\begin{array}{lll}4.2 & \text { Theoretical Background } & 79\end{array}$

4.2.1 Social Control Agents and Labeling of Misconduct 79

4.2.2 The Path Dependence of Misconduct: Organizational Learning $\begin{array}{ll}\text { and Decoupling } & 81\end{array}$

4.3 Research Setting and Method $\quad 82$

4.3.1 Case Study: Noncompliance with Anti-Money Laundering Regulations $\quad 82$

4.3.2 Data Collection $\quad 83$

$\begin{array}{ll}\text { 4.3.3 Data Analysis } & 84\end{array}$

4.4 Findings $\quad 88$

4.4.1 Episode 1: Emerging Complacency (2005-2013) 88

4.4.2 Episode 2: Confronting Complacency (2013-2017) 93

4.4.3 Episode 3: Coercing Acquiescence (2017-2020) 99

4.5 The Materialization, Persistence and Remediation of Misconduct 103

$\begin{array}{lll}4.6 & \text { Discussion and Conclusion } & 105\end{array}$

4.6.1 Perverse Learning and the Emergence of Complacency:

The Role of Social-Control Agents 106

4.6.2 The Effects of Complacency on Organizational Responsiveness $\quad 107$

4.6.3 The Implications of Salient Events on Acquiescence 109 
5 Building Character through Adversity: Organizational Work in Response to Integrity Failure in a Financial Enterprise

5.1 Introduction

5.2 Theoretical Background

5.2.1 Integrity Failures and Organizational Character $\quad 115$

5.2.2 Rebuilding Character through Organizational Work 117

5.3 Research Setting and Method 119

5.3.1 Empirical Setting 119

$\begin{array}{ll}\text { 5.3.2 Data Collection } & 119\end{array}$

$\begin{array}{ll}\text { 5.3.3 Data Analysis } & 121\end{array}$

5.4 Findings 124

5.4.1 Phase 1: Reevaluating Organizational Character (2007-2009) 125

5.4.1.1 Experiencing an Integrity Failure $\quad 125$

5.4.2 Phase 2: Reshaping Organizational Character (2010-2015) 129

5.4.2.1 Neutralizing Character Work 129

5.4.2.2 Accentuating Character Work 133

5.4.3 Phase 3: Anchoring Organizational Character (2016-2020) 136

$\begin{array}{lll}\text { 5.4.3.1 Legacy Engagement } & 136\end{array}$

5.4.3.2 Legacy Embracement 140

5.5 A Model of Rebuilding Character through Adversity 144

$\begin{array}{lll}5.6 & \text { Discussion and Conclusion } & 147\end{array}$

5.6.1 The Coalescence of Distrust and Uncertainty:

$\begin{array}{ll}\text { An Impetus for Rebuilding Character } & 148\end{array}$

5.6.2 The Role of Character Work in Adapting to Integrity Failure $\quad 150$

5.6.3 The Importance of Legacy for Organizational Character 152

6 Discussion and Conclusion $\quad 155$

6.1 Summary of Key Findings 156

6.1.1 Key Findings Chapter 2: Unpacking the Complexities of $\begin{array}{ll}\text { Organizational Integrity } & 156\end{array}$

6.1.2 Key Findings Chapter 3: Character Development and Corporate Responsibility 157

6.1.3 Key Findings Chapter 4: Complacency and the Normalization of Misconduct 158

6.1.4 Key Findings Chapter 5: Character Work in the Wake of Integrity Failures $\quad 160$

6.2 Main Theoretical Contributions 161

$\begin{array}{ll}\text { 6.3 Implications for Practice } & 165\end{array}$

6.4 Research Reflections and Limitations 168

6.5 Suggestions for Future Research 172

$\begin{array}{ll}\text { Bibliography } & 177\end{array}$

Summary: On the Moral Side of Enterprise 203

Samenvatting: Over de Morele Kant van Ondernemen 207

$\begin{array}{ll}\text { About the Book } & 211\end{array}$ 


\section{List of Tables}

Table 1. 1 Summary of the Studies $\quad 12$

Table 3. 1 Overview of Interview Data $\quad 57$

Table 4. 1 Data Source Material $\quad 84$

Table 5. 1 Empirical Material $\quad 121$

\section{List of Figures}

Figure 1. 1 Schematical Dissertation Outline $\quad 18$

Figure 2. 1 An Institutional Perspective of Organizational Integrity 32

Figure 3.1 Data Structure $\quad 59$

Figure 3. 2 A Model of Character Development $\quad 72$

Figure 4. 1 Data Structure $\quad 86$

Figure 4. 2 Timeline with Key Events 87

Figure 4. 3 The Materialization, Persistence and Erosion of Misconduct: A Model 104

Figure 5. 1 Data Structure $\quad 123$

Figure 5. 2 A Model of Rebuilding Character through Adversity $\quad 145$ 


\section{Acknowledgement}

The book before you is the outcome of more than four years of hard work, perseverance and personal growth. In retrospect, having been given the opportunity to pursue my $\mathrm{PhD}$ degree within both academia and practice has been a great experience, one which made my journey as special as it was. Many people have been part of this journey. Many read part of the manuscript or said things about it that were helpful to me in some way. And many more have listened diligently while I was trying to grasp my own line of thought. The scholars I met at conferences, the practitioners I spoke to in the field and the colleagues who have come and gone throughout the years have all been meaningful in some way or another. However, there are some that I would like to thank explicitly.

I would like to express my gratitude to my supervisors. From the day Petra welcomed me into the group, she believed in me. Although I may not have had a very clear idea what pursuing a doctoral degree entailed, Petra showed her faith in me by pushing me to put myself out there and to explore the possibilities that academia has to offer. At the same time, she gave me the freedom to carve my own path, pursue my own research ideas and mature to the scholar I am today. I am truly grateful for that.

Michel introduced me to the wondrous world of academia in all its facets and helped me improve my thinking, writing and presentation skills. His support for and critical reflection on my ideas along the way, as well as the enthusiasm with which he allowed me to seek my own niche within organizational theory, have been meaningful contributions to the formative years of my academic carrier. Our talks on politics, business and sports were always enjoyable and thought-provoking, while sometimes-the view that Ajax owes its success to players and trainers transferred from FC Twente-even hilarious. My thanks for being such a dedicated supervisor.

Richard had the ability to make me feel right at home at De Nederlandsche Bank. With his down-to-earth attitude, Richard was often able to pull me down from the "ivory tower" that academia can sometimes be, pushing me to always look for the practical relevance of my research. Giving me the opportunity to experience the complexities of the financial sector in a way that would not have been possible through a purely academic lens was truly enriching.

Although not officially a member of my supervisory committee, Olaf has been an important force behind this research collaboration and was always curious what I had been up to and willing to constructively challenge my thoughts in order for me to become a better researcher. These talks were always inspiring.

Many thanks to all my colleagues at the Entrepreneurship and Technology Management (ETM) department of University of Twente. Our occasional talks, weekly department seminars and research bootcamps helped me shape my thoughts and knowledge on a wide variety of topics. To my fellow doctoral students I met along the way, Anna, Andres, Igors, Jin, Koen, Lisa, Marlies, Shuijing and Xander, thank you for giving me a great time in 
Enschede. Having a group of like-minded and equally ambitious individuals has been very inspiring indeed and motivated me to take the weekly commute from Amsterdam to Enschede.

A special thanks goes to Tamara and Yasin. My afternoon walks with Tamara, initially on campus but later in Amsterdam, Utrecht and Zutphen, during which we often talked about family, health and relationships, helped me to put things in perspective and made me realize that there are more important things than the pursuit of a $\mathrm{PhD}$ degree. As office mates, Yasin and I often had in-depth discussions about ethnographic research, while also enjoying our shared passion for rock classics from the ' 70 s and ' 80 s. The summer school we spent brushing up our methodological skills at the University of Essex was truly the pinnacle in my doctoral education and I sometimes long for those simpler times.

Many thanks to my colleagues at De Nederlandsche Bank. The support, knowledge, and ever-recurring question of when I would finally finish writing my "scriptie" were both heartwarming and extremely motivating. I am truly glad I can now actually call you my real colleagues. Ali, David, Ernestine, Evert, Leon, Leonard, Lonneke, Petra, Melvin and Nathan, in particular, were always there to talk about the current developments in the field relevant to my research-and perhaps just as important in times of stress and uncertainty, to discuss topics far removed from it. Special mention to Remy for being an important sparring partner from the get-go and for being a welcoming force when the UT delegation came to Amsterdam. I want to thank you all for making this happen.

Additionally, a big thanks to all the friends who were able to keep me sane along the way and for providing me with necessary breaks and distance from my work. With some of them, I could even share the joys and sorrows of doing doctoral research. To have friends who were going through the same experience was truly encouraging. Special thanks to my two paranymphs, Camillo and Nathan, for making the journey to this doctoral dissertation, each in their own way, a very pleasant time. Camillo, to have a brother with whom I could share my perfectionism, but who could also complement me in my relative lack of artistic talent, is a true gift. Over the years, Nathan was always there to give me advice when I was struggling and to correct some overly complex paragraph I had written.

Silvia has been the most supportive girlfriend one could wish for. She was always caring and patient, especially in the last part of my journey, giving me the space to do what needed to be done while at the same time knowing how to cheer me up when I was down. Finally, I want to thank my parents, Beniamino and Susy, for your unconditional love and support throughout the process. There were times when I was at a loss, but you always knew how to motivate me to keep going. Without your ever-present faith in me, I would not have been able to do this. Thank you for everything!

\section{Timo Fiorito}

Amsterdam, The Netherlands, August, 2021 



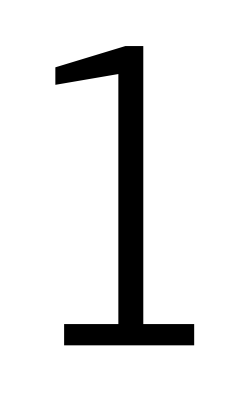

\section{Introduction}

Organizations are often described as behaving either courageously or ruthlessly, as being motivated by either the pursuit of profit or social responsibility, as displaying high-minded ethical principles or few at all. This reflects our tendency to attribute human qualities, traits and behaviors to organizations (Ashforth et al., 2020; Shepherd \& Sutcliffe, 2015), as we do when we praise organizations for addressing social challenges or, alternatively, when we condemn the moral character and integrity of important institutions following misbehavior (Bundy et al., 2021; Connelly et al., 2016; Paruchuri et al., 2021). There is, for instance, an abundance of examples of financial firms acting irresponsibly and even violating their own standards of organizational integrity. The 2007-2008 global financial crisis revealed how organizations and institutions-both large and small-had transgressed if not the law, expectations of responsible corporate and institutional behavior. At its core, this episode exemplified financial organizations' gradual drift away from their founding values towards opportunism and wealth accumulation.

Although the financial crisis was largely ignored by organization and management scholars (Munir, 2011; Starkey, 2015), more recent studies have signaled an enduring state of conflicting values, interests and logics within many of these institutions (Almandoz, 2014; Beunza, 2019; Leaver \& Reader, 2019; Palermo et al., 2016). Consequently, the previous decade has seen numerous examples of flagrant failures of integrity, including the manipulation of key interest rates, deficiencies in anti-money laundering controls, sanctions breaches and the cross-selling of fake accounts. Although the list is far from exhaustive, global financial institutions such 
as Deutsche Bank, HSBC, Wells Fargo and ING have time and again shown that, even in the best case, they were repeatedly unable to detect, mitigate or prevent misconduct within their boundaries and, in the worst case, deliberately created an environment in which the pursuit of profit came before compliance with laws and regulations.

Other questionable practices by financial enterprises that have evoked widespread indignation by customers, activist groups, politicians and the wider public, while not unlawful, include excessive executive pay, investments in harmful industries, and tax avoidance. Although strategic and aggressive tax planning is not always prohibited by law, the Panama Papers scandal exposed how some financial institutions had facilitated and enabled crime, corruption and other wrongdoing, denying corporate tax income to countries and thereby increasing poverty and inequality across parts of the world (Obermayer \& Overmaier, 2016). In the Netherlands, the parliamentary inquiry that followed in the wake of the Panama Papers scandal revealed how an array of financial facilitators, including tax advisors and corporate service providers, had created a "paper reality" that made effective supervision by financial and tax authorities difficult and sometimes even impossible.

Consequently, such instances of corporate irresponsibility and misconduct abound have cast doubt on the financial firms that are, in large part, responsible for the proper management of our national wealth (Algan \& Cahuc, 2013; Cohn et al., 2014). Public uproar and further loss of trust in these organizations and their executives have led to a large number of citizens and interest groups calling for action by financial regulators, law enforcement authorities and politicians. More importantly, the persistence of conduct that deviates from important ethical values, norms and regulations has stained the image of financial firms and significantly shaped the "institutional legacy" of their industry (Greve \& Rao, 2012; Roth \& Kostova, 2003) for years to come.

However, at the same time, these high-profile cases of corporate irresponsibility and the moral outrage that emerged in the wake of these transgressions, have led numerous firms to directly confront or escape this contentious legacy and to signal their adherence to institutional norms and values. Such enterprises are pressured to do so, organizational scholars argue, as many for-profits are increasingly subjected to multiple, and sometimes contradictory, societal demands (Greenwood et al., 2011; Kraatz \& Block, 2008; Pache \& Santos, 2010; Thornton et al., 2012). The combination of rising regulatory requirements relating to risk management and compliance (Boston Consulting Group, 2018), normative demands for corporate responsibility, sustainability and transparency, and the culturalhistorical legacy of the financial crisis have given rise to a profound complexity within many of the financial enterprises we regularly interact with. Although maximizing shareholder value remains the main imperative for these firms, both members and key constituents increasingly expect them to demonstrate that their profitability and growth is achieved in both responsible and sustainable ways, and in accordance with their stated purpose and values (Henderson, 2020; Margolis \& Walsh, 2003).

In short, firms are increasingly finding that value creation by the business and the values, norms and rules of the societies in which they operate are intertwined-albeit in a complex 
and often perilous way (Ehrenhard \& Fiorito, 2018). It is therefore all the more remarkable that organization and management theories do not provide a well-developed vocabulary to talk about and explain "how organizational actors come to be, how they come to represent certain values or interests, and how they consequently translate those into action" (King, 2015: 150). However, understanding how organizations build character and (often fail to) maintain integrity is crucial, both for the academic debate about the moral responsibility of collective entities (Orts \& Smith, 2017) and for those societal actors that seek collective solutions to ethical and societal problems (Ferraro et al, 2015; George et al., 2016). This dissertation engages with these daunting challenges and explores the complexities, perils and promises of organizational character and integrity.

\subsection{Organizational Actorhood: Character and Integrity}

Why did Triodos Bank come to represent principles of "sustainability and transparency" and to promote "quality of life and human dignity for all" (Reijngoud, 2009)? How did ABN Amro, once a proud national symbol of probity, transform from "the hunter to the prey" and eventually become replete with "distrust, quarrels and complacency" (Bökkering \& Couwenbergh, 2020; Smit, 2012)? Likewise, why did SNS Reaal alter from an "upright, provincial savings bank" to an institution permeated by "arrogance and blind ambition" (Van der Boon et al., 2013)? These are immensely intriguing questions that reflect our propensity to portray organizations as embodying values, traits and identities of their own, as possessing particular evolutionary trajectories, and as being capable of persistently staying true to self-imposed commitments-or, in some cases, straying far away from them. More importantly, they point to the rising academic interest in how organizations behave, function, mature and are evaluated as unique social actors in their own right (Bromley \& Meyer, 2015; Drori et al., 2009; Greenwood et al., 2014; Halgin et al., 2018; Hwang \& Colyvas, 2020; King et al., 2010; Meyer \& Bromley, 2013).

Actors are loosely defined as "social constructs, possessing institutionally defined identities including capacities, rights, and responsibilities [while] the types of actors include individual actors and collective actors" (Scott, 2014: 228). By viewing organizations as social actors, scholars emphasize their unique and distinct character, and their capacity for responsibility, moral agency, and purposive action. Importantly, because of their attributed "actorhood" (Bromley \& Sharkey, 2017: 12), organizations are increasingly expected to project a multiplicity of institutionally derived identities, roles and duties. As summarized by Kraatz and Block (2017: 544), "Organizations are required to make normative commitments and claims (i.e., to say what they value and what they contribute to society)". Consequently, we tend to evaluate actions in and by organizations by referring to such organization-specific expectations, praising those that persistently follow-through on their commitments and conferring on them legitimacy, resources, and status. 
Although we often anthropomorphize organizations linguistically to portray them in a positive way-"my company is friendly", "my company is trustworthy"-by treating organizations as social actors we not only acknowledge that they are "capable of rational action but also vulnerable to irrational drives and pathologies" (Hatch \& Schultz, 2002: 1005). That is, organizational actors are susceptible to a broad range of maladaptive and dysfunctional processes (e.g. myopia, hubris or complacency) that will drive their behavior towards their environment and potentially hinder the realization of self-imposed goals and responsibilities. Organizations that have fallen prey to such syndromes and fail to behave in line with their history of espoused commitments, values and actions, risk being perceived as lacking integrity or, at the very least, as acting out of character.

Organizational integrity, character, responsibility, commitment, and values are core concepts underpinning sociologist Philip Selznick's thinking. Selznick was concerned with organizations as both social and moral actors, and described the dual nature of organizations as both economic and technical collectives, aiming to achieve efficiency, as well as social and value-laden entities whose activities are important ends in themselves (Selznick, 1949, 1957, 1992, 2008). Throughout his lengthy academic career, Selznick was profoundly sensitive to the inherent tensions between these two facets of the organizational institution and the potential challenges they present. Recent work by Kraatz and colleagues (2009, $2010,2015,2020$ ) has reinvigorated Selznick's dormant sociological concepts, including the nature, source and perils of organizational character (Ansell et al., 2015; King, 2015) and integrity (Chandler, 2015; Goodstein, 2015), as well as the importance of values and ideals, both within and surrounding organizations (Besharov \& Khurana, 2015; Kraatz \& Flores, 2015).

\subsubsection{Organizational Character}

As organizations become committed to a particular set of ideals and values (Cornelissen et al., 2020; Cuyper et al., 2020), understood as "human beliefs about the things that are worth having, doing, and being" (Kraatz \& Flores, 2015: 356), they form a distinct and unique "human-like personality or character" (Cornelissen et al., 2016: 204). Since important ideals and values, such as transparency, solidarity, responsibility and reliability, "fix the assumptions as to the nature of the enterprise, its distinctive aims, methods, and role in the community" (Selznick, 1957: 55), organizational character tends to function as an internal normative logic for managerial decision-making and future activities (Sasaki et al., 2019; Steele \& King, 2011) and for the evaluation of organizational conduct by both internal and external constituents such as employees, customers, suppliers and regulators (Love \& Kraatz, 2009; Mishina et al., 2012). Although there will be much to say about these intriguing themes in this dissertation, two preliminary insights are worth mentioning in this introductory chapter.

First, since character is a "historical product" (Selznick, 1957: 38), the sources of the values and beliefs that make an organization distinct and unique can self-evidently be found in the past. More specifically, an organization's "historically accreted character" (Kraatz et 
al., 2010: 1529) is the result of critical and identity-defining moments in the organization's life course. Since the "past relates to and embodies the character of an organization" (Foster et al., 2020: 263), organizations' present and future choices, behaviors, culture and strategies must be seen in light of their unique history, strife and evolutionary trajectories. In What Happened to Goldman Sachs, Steven Mandis (2013: 10) aptly describes the historical processes that led the Wall Street bank to drift from its vaunted values and principles to create the corporate juggernaut it is today:

The story of what happened at Goldman after 1979 is messy and complex. Many seemingly unrelated pressures, events, and decisions over time, as well as their interdependent, unintended, and compounding consequences, slowly changed the firm's culture. Different elements of its culture and values changed at different times, at different speeds, and at different levels of significance in response to organizational, regulatory, technological, and competitive pressures. But overall, what's apparent is that Goldman's response to these pressures to achieve its organizational goal of being the world's best and dominant investment bank was to grow-and grow fast. Seemingly unrelated or insignificant events, decisions, or actions that were rationalized to support growth then combined to cause unintended cultural transformation.

This example suggests that, similarly to individuals, history matters if we are to understand an organization's character strengths and imperfections. Historical developments, such as leadership changes, internal power shifts, and employee turnover, while seemingly insignificant in themselves, may collectively have a lasting impact on an organization's normative composition and, consequently, its propensity to be trustworthy and reliable (Fombrun, 1996) or opportunistic and selfish (Selznick, 1992) in its interaction with stakeholders.

Studies on organizational character would therefore benefit from the "historic turn" (Clark \& Rowlinson, 2004; Suddaby, 2016) in organizational research and to be especially mindful of organizations' unique life courses. As such, whether through the preservation of historical imprints at the time of founding (Cuyper et al., 2020), the recovery of dormant values and ideals (Kraatz et al., 2020), experiential learning (Christianson et al., 2009), or the perpetuation of collective memories (Foroughi et al., 2020), critical events and disruptions in an organization's life course, such as its founding, failures or crises, offer ideal-yet rarely charted avenues-for the study of corporate character formation or alteration.

Second, contemporary institutional scholars have emphasized that studies of organizational character should aim to "situate organizations within their macroinstitutional environment" (Kraatz \& Flores, 2015: 365). Character has been shown to shape an organization's responses to environmental pressures and changes while, at the same time, the character of an organization takes form as it adapts and responds to influences and changes in its external environment (Besharov \& Khurana, 2015; Cuyper et al., 2020; Waeger \& Weber, 2019). 
When organizations adopt and diffuse commitments, practices and policies that advocate some societal objective, for instance, concerning corporate responsibility (McWilliams \& Siegel, 2001), business ethics (Chandler, 2014), and sustainability (Kok et al., 2019), they admit new values, new responsibilities and new objectives within their boundaries. This creates both a normative guide for decision-making and, maybe more importantly, specific expectations projected towards key audiences. As a result, their character becomes increasingly solidified and irreversible, and profound departures from the values inscribed in this character may come only at the cost of extreme uncertainty and distrust. Given the multiplicity of commitments organizations make and the challenges that poses, it is critical to understand the process of character development because increasingly for-profit organizations articulate their commitment to addressing societal concerns and grand challenges.

\subsubsection{Organizational Integrity and Values}

Our enduring vision of helping customers succeed financially, which unites us as One Wells Fargo. Our five values, which articulate what's most important to us: What's right for customers, people as a competitive advantage, ethics, diversity and inclusion, and leadership (Wells Fargo, 2014)

We believe in our vision and values just as strongly today as we did the first time we put them on paper and staying true to them will guide us toward continued growth and success for decades to come. As you read more about our vision and values, you will learn about who we are, where we're headed, and how every Wells Fargo team member can help us get there (Wells Fargo, 2015)

Despite their explicit formulation and communication, the U.S.-based bank Wells Fargo failed miserably in realizing its value commitments when it was revealed that employees had secretly opened two million unauthorized accounts in a cross-selling scheme, landing customers with over $€ 2$ million in fees. This makes Wells Fargo a striking example of when an organization's espoused values and reality do not match. John Stumpf, the disgraced CEO of Wells Fargo, captured this misalignment in a letter to employees when he observed that "the employees' actions were inconsistent with the values and culture we strive to live up to every day" (Stumpf, 2016). Unfortunately, Wells Fargo is just one example of organizations that fail to meet the legitimate expectations of responsible corporate and institutional behavior and violate their self-prescribed standards for appropriate conduct.

What binds together the increasing societal expectations for responsibility, reliability and trustworthiness is the notion of organizational integrity. Selznick used the concept of integrity throughout his institutional work and defined it as "fidelity to self-defining principles" (Selznick, 1992: 322). In this context, fidelity can be understood as faithfulness to embraced obligations, rules, duties or roles, and is concerned with firmly realized commitment to certain ideals, purpose and goals. Selznick argued that integrity concerns 
"the persistence of an organization's distinctive values, competence and role" (1957: 57) and, whether related to individuals or organizations, it is "the centerpiece of morality and the main concern of the moral actor" (1992: 212).

Although the notion of integrity has many layers and is difficult to define, contemporary scholars have asserted that integrity pertains to acting in accordance with the espoused values, an alignment between individuals' or collective actors' words and deeds (Leroy et al., 2012; Simons, 2002), and adhering to sound moral and ethical principles (Parry \& ProctorThomson, 2002; Colquitt \& Rodell, 2011). Waddock and colleagues (2002: 145) provide a more comprehensive definition and assert that organizational integrity comes down to:

Meeting stakeholders' demands that companies be honest, firmly adhere to their stated codes and values, be healthy, whole, and sound financially and in other ways relevant to specific stakeholders, and essentially that the reality of company actions and impacts match company rhetoric.

Although management research on organizational integrity remains remarkably scarce, the burgeoning literature on values within and surrounding organizations provides us with some important conceptual insights (Besharov, 2014; Gehman et al., 2013; Kraatz \& Flores, 2015; Kraatz et al., 2020; Vaccaro et al., 2015; Wright et al., 2020). This line of research emphasizes that values and ideals provide meaning and purpose, distinctiveness, and social cohesion, and thus have significant positive implications for organizational life. However, as values are "only one part of the institutional fabric" (Kraatz \& Block, 2017: 543), they tend to be in constant tension with other normative, regulative and cognitive influences. Moreover, some organizational values are precarious and, when not well protected from conflicting imperatives and private interests, are susceptible to "displacement, attenuation and corruption" (Selznick, 1992: 244), while others can give rise to intra-organizational conflict and fragmentation, opportunistic behavior and even wrongdoing.

Therefore, a core premise of a Selznickian approach to organizational integrity is that important values need "congenial, sustaining social structures if they are to be realized" (Kraatz et al., 2010: 1523). For an organization to live up its espoused commitments, values must be made real in organizational practices and internal power structures, in the way employees and leaders interact with one another and with their environment, and the way management balances multiple values with stakeholder demands. However, prior research on organizational integrity has treated its primary subject as isolated from its increasingly complex institutional environment. As a result, although researchers have tended to attribute integrity to an entity "if that party is consistent with its past actions and if [their] actions comply with preceding promises" (Eberl et al., 2015: 1206), the literature is not clear what integrity entails when organizations are confronted with institutional pluralism and, consequently, have selves that comprise multiple distinct goals, values, interests and responsibilities. 


\subsection{The Perils of Integrity: Corporate Irresponsibility and Misconduct}

As the introduction of this chapter has already mentioned, this dissertation also aims to explore the "dark side of organizations" (MacLean \& Behnam, 2010; Vaughan, 1999); more specifically, the antecedents, processes and consequences of organizational misconduct. If the multitude of corporate scandals and integrity failures tells us anything, it is that misconduct is ubiquitous in modern organizational life. Organizational misconduct is understood as "behavior in or by an organization [that is judged] to transgress a line separating right from wrong" (Greve et al., 2010: 56). Scholars have linked misconduct to a host of adverse outcomes (Greve et al., 2010; Zahra et al., 2005) that elicits a multitude of stakeholder responses (Hersel et al., 2019; Palmer, 2012). Not surprisingly, both the antecedents and the remediation of misconduct, as well as efforts from institutional actors to curtail misbehavior, remain important subjects for scholars and practitioners alike.

With the preliminary insights on organizational character and integrity in mind, their linkage to notions of corporate irresponsibility and misconduct may seem self-evident. Integrity pertains to faithfulness to accepted ethical, regulatory and normative principles, whereas integrity failures constitute the violation of such principles, often resulting in the "situation wherein the firm's motives, honesty, and/ or character fall short" (Connelly et al., 2016: 2136).

As for-profits are increasingly expected to adopt and enact a host of institutionally derived roles, duties and responsibilities (e.g. financial firms' obligation to combat money laundering and terrorist financing)(Kraatz \& Block, 2017; Pache \& Santos, 2010), the challenges inherent in remaining faithful to mutually conflicting commitments and goals become obvious. The decision to produce and market a new financial product or invest in a particular industry, enter a new market or accept a new customer, while in line with an organization's commercial goals, may be perceived as irresponsible, unethical or even unlawful when they are in violation with the firm's espoused principles. In short, when actions are not in line with the character of an organization-that is, its history of past commitments and the values flowing from sch commitments-audiences may question its integrity and trustworthiness. Two preliminary insights are worth mentioning here.

First, while for-profit organizations increasingly adopt commitments to societal concerns in their pursuit of both legitimacy and distinctiveness (Suchman, 1995; Zhao, et al., 2017), scholars who have acknowledged the pluralism within modern organizations have also characterized their inner life by a great many internal complexities and inconsistencies, "sometimes involving conflict, sometimes simple decoupling and hypocrisy" (Bromley \& Meyer, 2015: 23). For instance, tensions between profit and corporate responsibility can create internal contestation over what constitutes legitimate behavior (Besharov, 2014; Smith et al., 2013), which can escalate into ongoing and often intractable conflicts (Fiol et al., 2009; Battilana and Dorado, 2010). Research has suggested that such internal complexities and tensions can, if left unchecked, lead to opportunism and mission drift (Grimes et al., 
2019; Selznick, 1949), disrupt or subvert organizational institutions (Kraatz, 2009), and make an enduring commitment to organizational integrity difficult to sustain (Besharov \& Khurana, 2015; Gallagher \& Goodstein, 2002).

Organizations are increasingly expected to espouse their commitment to important values, norms and regulations, both to signal their moral character and to gain legitimacy from key audiences. Consequently, if we for instance observe that a financial firm has a tendency to violate governmental regulations, we might assume that this is due to a deficiency in its character, which is perhaps manifested in its incentive plan, power relations or a leadership that prioritizes profit over adherence to institutional values, norms and regulations.

Research has shown that organizations may respond to institutional demands for responsible behavior by only symbolically conforming to commitments, policies and structures, while decoupling them from daily operations if they are in conflict with core organizational goals (Bromley \& Powell, 2012). Due to the irreversible expectations organizations create by espousing their commitments to institutional prescriptions, flagrant instances of decoupling, such as between corporate ethics or compliance programs and core business activities (MacLean \& Behnam, 2010; Weaver et al., 1999) or between adopted ESG standards and actual investment practices (Lyon \& Maxwell, 2011), are increasingly "likely to be seen as a moral and operational failure" (Bromley \& Powell, 2012: 198), and thus as serious threats to organizational integrity.

Second, rather than an abnormality or deviation, misconduct is increasingly regarded as a "normal" aspect of modern organizational life (Ashforth \& Anand, 2003; Earle et al., 2010; Vaughan, 1996). This perspective, which has been popularized by Donald Palmer and colleagues $(2010,2012)$, centers around the "inevitability of organizational wrongdoing" (Weick, 2013: 292). Specifically, the pluralistic institutional landscape moves our analysis of misconduct from rational choice by individual decision-makers to a social control agent perspective (Dewan \& Jensen, 2020; Greve et al., 2010; Heese et al., 2016; Mohliver, 2019), as wrongdoers are now increasingly assumed to stray from appropriate behavior "in a mindless and boundedly rational way, subject to the influence of their immediate social context, slipping into wrongdoing in a crescive way, without ever developing a positive inclination to do so" (Palmer, 2012: 268).

The regulatory, normative and cultural-cognitive complexities that have arisen amplify ambiguity and uncertainty among organizational members and outside constituents in identifying and determining what behavior constitutes acceptable behavior and what misconduct. Organizations increasingly engage in multiple communities, countries and cultures, each with different values, norms and rules. As a result, members and key audiences, including social-control agents, face challenges in identifying appropriate behavior because of blurred ethical boundaries (Palazzo et al., 2012). In the regulatory aspect, frequently changing laws increase the inherent complexity and ambiguity in defining the criterion for wrongdoing (or "rightdoing"). This is reinforced when countervailing and regulatory constraints decrease or become ambivalent (e.g., deregulation, ineffective monitoring) 
(Gillespie \& Dietz, 2009). This trend of perceiving misconduct potentially emerging from ambiguity and uncertainty, value pluralism, and deficiencies in controls calls for a strategic attention to business ethics, risk management and regulatory compliance.

\subsection{Research Objectives, Scope, Methods and Questions}

Having provided some preliminary insights on organizational character, integrity and misconduct, in the following section we lay out the research objectives, the scope of this dissertation and some methodological considerations, and the central research questions.

\subsubsection{Research Objectives}

In the previous sections we attempted to carefully lay the groundwork for the main body of this dissertation. In short, we described how organizations, as distinct social and moral entities, tend to have a unique history, purpose and values, are capable of demonstrating valuable traits such as moral discipline, trustworthiness and reliability, while also being attentive to the prevalence of hypocrisy, dishonesty and misbehavior within many organizations. In essence, these matters pertain to organizational character and integrity. The objective of this research is to increase our understanding of the organizational and institutional processes through which financial enterprises form character, sustain integrity and remediate misconduct. In doing so, this dissertation has three main objectives.

First, the studies presented in this dissertation aim to help scholars better understand the modern organization as a particular social and moral actor. Neither micro-scholars nor macro-scholars have been particularly interested in studying the origins, distinctive features and actions of organizational actors, as aptly encapsulated by King and colleagues (2010: 291):

The ontological status of the organization as a distinct kind of social entity is not well theorized given the present focus on social phenomena above or below the organizationlevel line of sight and the associated focus on verb-oriented organizational processes.

Our aim is to bridge this research gap by conceptually and empirically exploring how organizations form character and (often fail to) maintain integrity. Despite the obvious opportunities to move the level of analysis from individual to collective entities (Bauman, 2013; Palanski \& Yammarino, 2007; Wright \& Goodstein, 2007), management scholars who have put the organizational actor at the center of their scientific inquiry have paid scant attention to the peculiarities and challenges of organizational character and integrity (Goodstein, 2015; King, 2015). By theorizing the precariousness of integrity in situations of institutional pluralism and empirically investigating the historical sources-as well as the present and future implications of character for organizational life-this dissertation is 
particularly relevant for organizational theorists who have begun to examine the origins and functions of values within organizations (Kraatz et al., 2020) as well as the importance of the organizational actors in tackling grand challenges (Ferraro et al, 2015; George et al., 2016).

Second, we seek to provide important insights on the antecedents, processes and consequences of organizational misconduct. Although organizational scholars' interest in misconduct is slowly but steadily gaining ground (e.g. Castro et al., 2020; Greve et al., 2010; Hersel et al., 2019), we still have a long way to go in understanding the nature, emergence and persistence of "normalized" misconduct (Ashforth \& Anand, 2003) as well as how organizations successfully adapt to-or fail to adjust to-integrity failures (Connelly et al., 2016; Mishina et al., 2012; Paruchuri et al., 2021). This is essential if we accept the increasingly influential idea that misconduct is ubiquitous within many modern organizations and that much misconduct, rather than intentional in nature, is perpetuated unintentionally and mindlessly (Perrow, 1999; Vaughan, 1999), thus requiring a more comprehensive understanding of how organizations and outside actors successfully adjust or fail to adapt to such failures.

Although traditional perspectives on misconduct, such as "bad apples" or "bad barrels" approaches (Kish-Gephart et al., 2010; Palmer, 2012; Trevino \& Youngblood, 1990), have provided important insights on the individual and organizational factors that may enable misconduct, these perspectives have been shown to be less useful in understanding the institutional processes that facilitate the materialization and persistence of misconduct among a broader group of organizational actors.

Third and finally, this dissertation aims to help business leaders better understand how they can build a valued character and retain the integrity of their organization. Ensuring the integrity of organizations, that is to say, their soundness, wholeness and incorruptibility (Merriam-Webster, 2021), is essential if we are to promote their resilience and that of the wider institutional system of which they are part (Waddock, 2012; Williams et al., 2017). On the other hand, our intention is to also suggest important managerial and regulatory implications and make recommendations for those societal actors that are confronted with the challenge of detecting, preventing and reducing organizational misconduct.

\subsubsection{Scope and Methodological Considerations}

In the following section, we set out the scope of this dissertation and elaborate on our methodological approach. By doing so, we place attention on the boundary conditions of our empirical studies. It goes without saying that because our main interest is in how financial firms as distinct social and moral entities form character, maintain integrity and (fail to) remediate misconduct, the primary unit of analysis is the individual firm. Moreover, as the goal of this dissertation requires the rigorous exploration of organizations' inner workings, a profound appreciation of their informal social structures and unique evolutionary trajectories, and the various ways they respond to and interact with their external environmental, the research methods applied throughout this dissertation reflect these assumptions. 


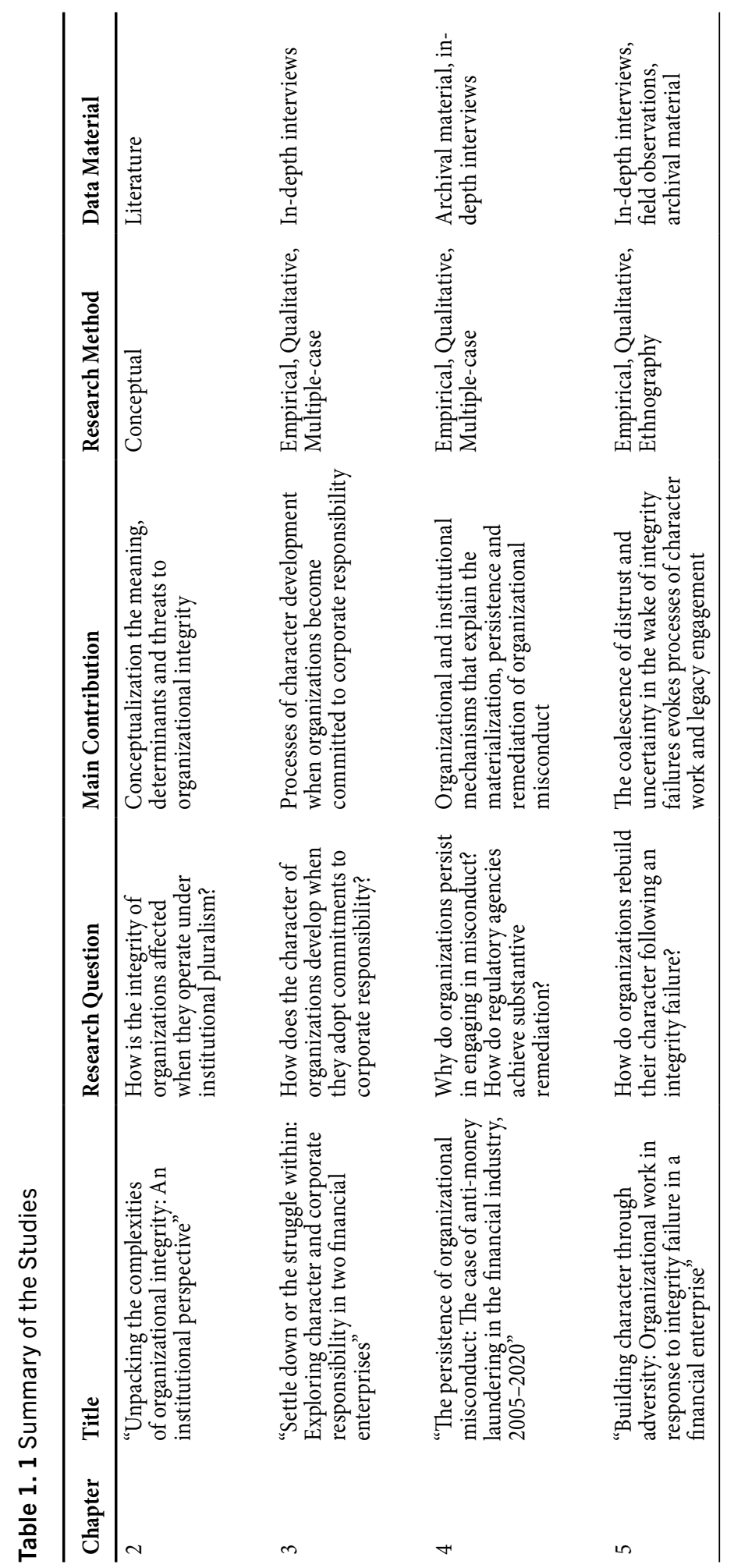


Although the primary aim of Chapter 2 is to familiarize and "prime" ourselves through engaging with the relevant organization and management literature, the subsequent chapters are deeply empirical in nature. Consequently, in our goal to flesh out a fine-grained understanding of the complexities, perils and promises of character and integrity, we grounded our inquires mainly on in-depth case studies. As noted above, our methodological approach was profoundly phenomenon-driven, taking the peculiarities and anomalies we encountered in our empirical setting as the point of departure and granularly exploring them "to fashion theoretical lenses that allow us to see the world as it might be" (Suddaby, 2014: 408). In other words, rather than pursuing generalized answers for some a priori set of questions, our research aim was to develop a theoretical abstraction of specific organizational phenomena through immersion, discovery and interpretation.

In our predominantly grounded theory approach to theory development (Corbin \& Strauss, 1990; Strauss \& Corbin, 1998), we iterated back and forth between our collected data material and the existing literature to develop probable and theoretically informed explanations for the phenomena we were interested in. This generative process of theorybuilding, known as "abduction" (Saetre \& Van de Ven, 2021), meant that we began our research project with general research questions informed by a number of initial interests and curiosities, and a broad survey of the literature. For instance, we were initially intrigued by the empirical observation that some financial firms are able to successfully adapt and, in some cases, even realize profound positive change following integrity failures, while others were reluctant or even resisted normative and regulatory pressures in the wake of uncovered misconduct. In the process of conversing with informed actors in our empirical field, including managers, executives, regulators and other industry experts, various hunches and ideas surfaced which led us to repeatedly adjust our research questions, to exchange emerging ideas with fellow researchers and to draw in overlooked literature to help make sense of our data.

During this process, we became increasingly sensitive to the ontological status of organizations as social actors (King, 2015; Selznick, 1992). Although one could argue, as many scholars have already done, that actorhood can only be attributed individuals (see Orts \& Smith, 2017), we were deeply captivated by the "organizational actorhood" perspective (Bromley \& Meyer, 2015; Bromley \& Sharkey, 2017; King et al., 2010). Individuals bring with them their own values, beliefs, preferences and interests when joining an organization and these personal characteristics tend to have significant influence on both individual behavior and organizational actions (Battilana, 2006; Hallett \& Ventresca, 2006; Kraatz et al., 2020).

Yet Selznick's assumptions about organizations also reminds us that these collective entities are semi-independent of their members and have path-dependent characters around which (future) members and leaders deliberate and make important strategic decisions. Furthermore, in everyday life we are inclined to treating organizations as if they are human-like. Therefore, in Chapter 3 and 5 we engaged with specific members who were able to inform and convey to us their personal experiences in making sense of external 
stimuli and that led them to govern their organization accordingly, such as senior managers, policymakers and executives, as these are considered "key carriers of organizational actorhood" (Bromley \& Sharkey, 2017: 24), representing the larger collective and enacting the strategic posture of the organization (Pratt \& Kraatz, 2009).

However, if we are to understand the character and integrity of organizational actors more comprehensively, we realized we had to look beyond the individual employee, manager or executive, and examine organizations' particular evolutionary trajectories and struggles, their informal social structures and 'political' disagreements. As an example of such immersive scholarship, Beunza (2019: 275) went onto the floor of a Wall Street derivatives trading room to explore "the relationship between economic models on morality in financial organizations". What is most notable about that work was the importance of his extensive engagement with traders, managers and executives in their daily activities, interactions and routines. The combination of ethnographic field visits and oral history interviews proved indispensable to the understanding of how the culture of financial organizations changes in order for them to remain healthy, even in times of crisis.

In an-admittedly ambitious-attempt to parallel these methodological endeavors and provide a thick description of our empirical cases (Geertz, 1973), in Chapter 5 we complement our in-depth interviews with field material, including recurrent and prolonged visits to our case organization, immersion within everyday activities, and direct observations of group conversations, meetings and presentations. The detailed fieldnotes we gathered during the research visits, together with interviews of key informants and extensive archival material, gave us opportunity to rigorously ground our empirical phenomena up close and over time.

Since character and integrity have important social and evaluative properties (Greve et al., 2010; Selznick, 1992; Wright \& Goodstein, 2007), we were especially keen to situate our primary units of analysis within their broader institutional environment and historical context. For instance, the character of an organization emerges over time as leaders adapt to formative processes throughout the organization's life-course and it responds to the various opportunities and challenges presented to it by the external environment. Similarly, broader environmental changes, including regulatory, technological, social movement and political shifts, require substantive responsiveness that are potentially incongruent with existing organizational arrangements, including previously taken-for-granted values, norms and practices (Greenwood et al., 2011; Oliver, 1991; Pache \& Santos, 2010). Such changes tend to "create unique challenges for the maintenance of organizational integrity" (Dacin et al., 2002: 53), and this forces us to remain aware of the external environment if we are to comprehensively understand corporate misbehavior. Acknowledging these assumptions requires us to take the historic turn in the management literature seriously and to apply a "developmental and diachronic lens" to our organizational analysis (Kraatz et al., 2010: 1529). 
In Chapter 4, for instance, we draw on rich archival material spanning a 15-year period and complemented those documents with retrospective interviews with regulators to investigate offending firms' various responses to increasing regulatory pressures for compliant behavior. Extending this developmental lens, in Chapter 5 we were interested in the work organizational members engage in as they rebuild the "tainted" character of their organization in the wake of an integrity failure. In this study, we were greatly informed by historical archival material and oral history interviews as they provided us with the longitudinal data material needed to apply our developmental lens.

As we gathered and processed our interview, field and archival data, we were conscious of the confidentiality and sensitivity of our empirical material. Therefore, informants were told that the data that emerged from our conversations would be included in our analysis. We also used member-checking, giving our informants the opportunity to reflect on the content of the interview transcripts, and asking whether our interpretations of the empirical material was consistent with theirs. We anonymized our case organizations and refrained from blending public and private data, so as to prevent the identification of the firms discussed our cases. Furthermore, we used secure hardware to store and secure software to analyze our data.

Such an historically sensitive approach to organizational analysis is particularly suited for the empirical setting of this dissertation. We chose the financial industry as our setting because our excellent access to this sector, the institutions within it, the individuals that work within these firms and the governmental agencies that regulate them, provided an ideal avenue to empirically explore themes of character and integrity. Although financial enterprises have been widely criticized by key constituents and audiences for their lack of integrity (Munir, 2011; Starkey, 2015), the 2007-2008 global financial crisis has increased the societal pressures for business ethics and regulatory compliance. Such pressures have induced many firms and their leaders to confront their legacy head-on and reshape the character of their organization, albeit in some cases only symbolically. Furthermore, customers, activist groups, legislators and regulatory agencies increasingly expect financial firms to substantially improve their commitments to corporate social responsible and sustainability and to effectively manage and control their internal and external integrity risks. Simultaneously, however, practice shows that increased normative and regulatory pressures do not automatically lead to a sense of shared ownership, or to sound and responsible organizational behavior. Recent high-profile scandals have demonstrated that financial firms are still reluctant to fully comply and remediate following rule-breaking or worse. 


\subsubsection{Research Questions}

Based on the aforementioned research goals, scope and methodological considerations, we have formulated the following central research question:

Central research question: What are the organizational and institutional processes through which organizations (re)form character, sustain integrity and remediate misconduct?

To be able to address this central question and realize our research objectives, we put forward several underlying research questions. Four research questions form the basis for the studies presented in this dissertation. Table 1.1 outlines the content of this dissertation by summarizing the individual chapters, their corresponding research questions, the main contributions of each study, and the research methods and data material that are being used to answer the research questions. Below, the individual chapters and their corresponding research questions will be elaborated on in more detail.

In Chapter 2 we provide conceptual insights on what it means for an organization to act with integrity. Although much of organization and management literature deals with the individual-level of analysis of integrity, such as behavioral integrity (e.g. Simons, 2002), scholars have "not taken up in a central and sustained way the problems of organizational integrity" (Goodstein, 2015: 176). We acknowledge this research gap and recognize that more clarity and focus is needed on the meaning, determinants and challenges of organizational integrity. Therefore, we theoretically explore how competing institutional pressures may affect a sustained commitment to organizational integrity. Our theorization will provide a conceptual framework and a set of corresponding propositions that, although not specific for financial firms, will be a guiding tool in the rest of this dissertation.

Research Question 1: How is the integrity of organizations affected when they operate under institutional pluralism?

Building on the presented propositions, in Chapter 3 we explore how the character of organizations is altered when they adopt and diffuse normative commitments within their boundaries. Research has shown that when organizations become committed to social issues, such as sustainability, corporate responsibility or business ethics, their moral character becomes increasingly solidified and irreversible (Kraatz \& Flores, 2015; Selznick, 1957), as both inside and outside actors evaluate an organization's actions while referring to its character. At the same time, however, organizations pursue goals that may conflict with these commitments and values inscribed therein. As such, character alteration is often characterized as "a collective process of negotiation, compromise, and conflict over values and beliefs" (King, 2015: 166). In this chapter we draw on in-depth interviews with executives, senior managers and policymakers of two financial firms that have become increasingly committed to corporate responsibility to answer the following research question: 
Research Question 2: How does the character of organizations develop when they adopt and diffuse commitments to corporate responsibility?

Although first-time integrity failures may constitute mere incidental acts, the tendency of organizations to persist in misbehavior is likely to be rooted the character of the organization. However, scholars have also suggested that to fully understand the causes of misconduct in and by organizations, one must understand how vigorously and successfully "social-control agents" enforce the legal rules (Greve et al., 2010: 81). Taking this approach, we follow recent work (Dewan \& Jensen, 2020; Heese et al., 2016; Mohliver, 2019) that emphasizes that the actions (or inactions) of regulatory or law enforcement agencies need to be included in the study of the materialization, persistence and remediation of misconduct. Compounding these assumptions, in Chapter 4 we examine the phenomenon of persistent organizational misconduct, exploring the interplay between organizational processes and institutional influences. In exploring these intriguing themes, we undertake three in-depth case studies of noncompliance with anti-money laundering regulations by European financial firms over a 15-year period (2005-2020). We pose the following research question:

Research Question 3: Why do organizations persist in engaging in misconduct? How do regulatory agencies achieve substantive remediation?

Finally, Chapter 5 delves into the process of how organizations rebuild character in the wake of integrity failures. Selznick (1957: 59) hypothesized that as organizations adapt to critical and identity-defining moments in the course of their lives, they become infused with values and develop a "distinctive unity and character". Recently, scholars have begun to explore both the nature and source (Cornelissen et al., 2020; Cuyper et al., 2020) as well as the present and future implications (Kraatz et al., 2010; Sasaki et al., 2019) of this historically accreted character. Integrating these streams of research, Chapter 5 examines the organizational work that members engage in as they attempt rebuild character following integrity failure. Drawing on longitudinal data (in-depth interviews, field observations and archival material) of a successful European financial enterprise that was nationalized during the 2007-2008 global financial crisis, we pose the following question:

Research Question 4: How do organizations rebuild their character following an integrity failure?

\subsubsection{Dissertation Outline}

Figure 1.1 summarizes schematically the individual chapters and corresponding research questions. As indicated by the dotted line, in Chapter 2 we provide a conceptualization of organizational integrity and propose a theoretical model. The following three chapters are empirical in nature. In Chapter 3, we explore how the character of an organization develops when it becomes committed to corporate responsibility. Chapter 4 examines 
three case studies of persistent organizational misconduct, exploring the interplay between organizational processes and institutional influences. In Chapter 5, we investigate indepth and over time how organizations build character in the wake of integrity failures. Finally, Chapter 6 brings together and discusses the overall findings of this dissertation, the main theoretical contributions, implications for practice, research reflections and limitations, and suggestions for future research.

Figure 1. 1 Schematical Dissertation Outline

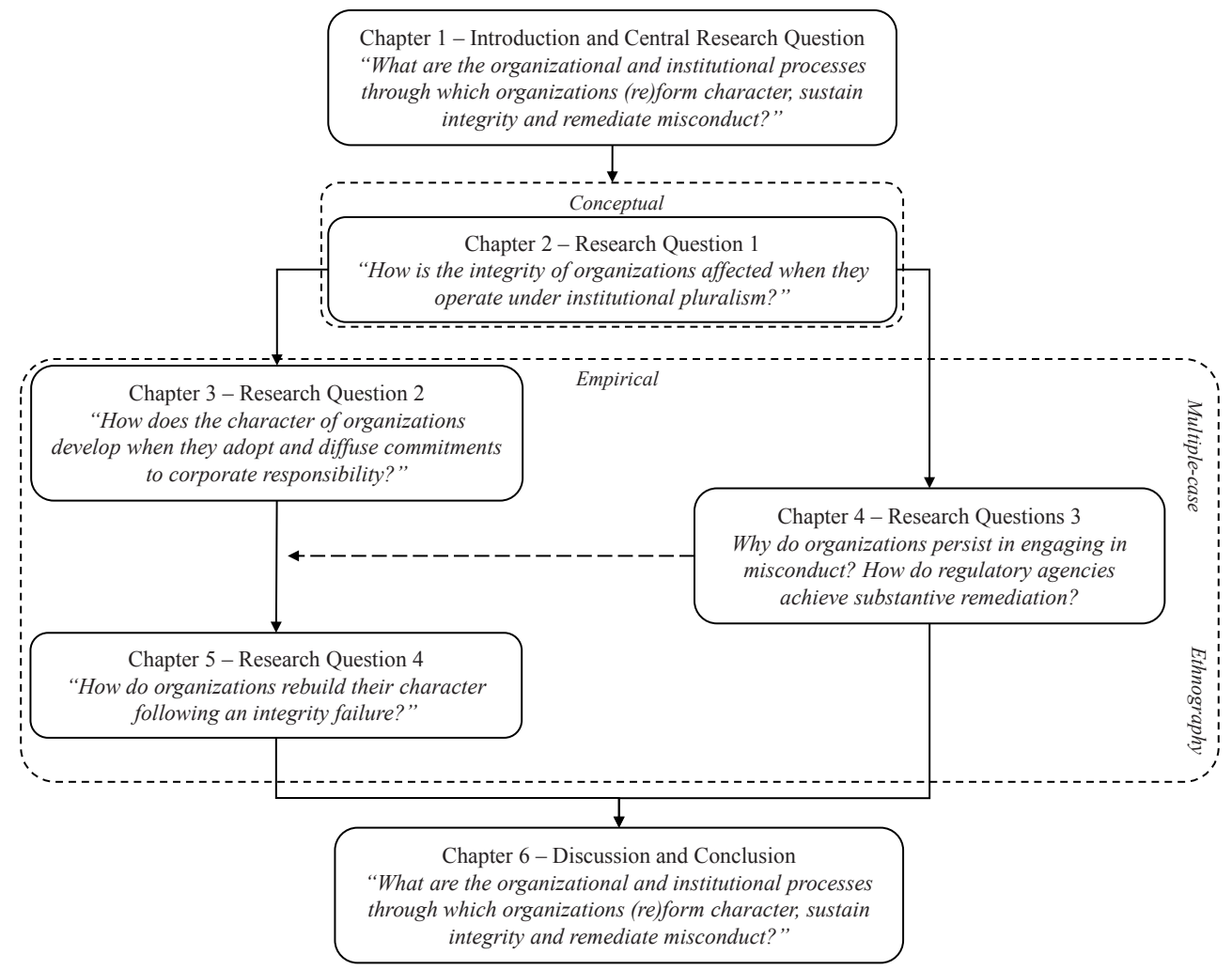


Introduction | 19 



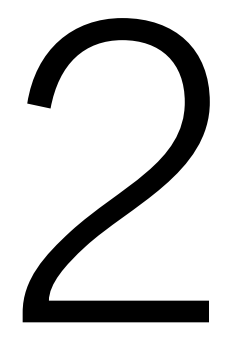

\section{Unpacking the Complexities of Organizational Integrity: An Institutional Perspective}

\subsection{Introduction}

Organizational integrity is commonly understood as organizational actions that are in accordance with embraced moral or socially accepted values, and the demonstration of value-attuned responsiveness to its external environment (Swanson, 1999; Selznick, 1992). However, since most values are inherently "precarious" and susceptible to distortion, in the absence of their substantive anchoring within organizational boundaries, they are at risk of being subverted or just ignored (Clark, 1956; Grimes et al., 2019; Selznick, 1957). Therefore, organizational integrity requires that values are not only symbolically espoused but are also deeply embedded within the technical operations and informal social structures of the organization (Besharov \& Khurana, 2015; Ebrahim et al., 2014; Kraatz et al., 2010). Therefore, we have conceptualized organizational integrity as the 'wholeness' of the formally espoused moral values set by top management (Bourne et al.,

Previous versions of this chapter were presented at the 34th EGOS Colloquium, July 5-7, 2018 in Tallinn, Estonia, and the 79th Annual Meeting of the Academy of Management, August 9-13, 2019, in Boston, Massachusetts, USA. A previous version of this chapter was the finalist for Best Environmental and Social Practices Paper Award, Organization and Management Theory division of the Academy of Management, and was published as Fiorito, T. L. and Ehrenhard M. L. (2019). Understanding organizational integrity from an institutional perspective. Academy of Management Proceedings. 
2019), the embedded values, reflected in the formal organizational structures and systems (i.e. organizational design)(Amis et al., 2002) and shared by its members in organizational routines, beliefs and symbols (i.e. organizational culture)(Schein, 1985), and the values enacted in organizational actions (Gruys et al., 2008).

In contrast to individual integrity (Becker, 1998), the concept of organizational integrity takes the collective entity and its internal workings as the focus of moral scrutiny and scientific inquiry (Kaptein \& Wempe, 2002; Krygier, 2012; Selznick, 2008). Ample evidence from empirical studies has shown how a strong commitment to core values and purpose, institutionalized and embedded in internal processes and social structures, has a positive effect on employee commitment (Ostroff et al., 2005), issue response (Bansal, 2003), the relationship with external constituents (Voss et al., 2000), post-merger performance (Cording et al., 2014), the ethical conduct of employees (Paine, 1994), and long-term firm profitability (Collins \& Porras, 1994). In contrast, a misalignment between espoused values and organizational actions can have numerous negative consequences, including loss of reputation and legitimacy, lawsuits and sanctions, and even organizational demise (Eberl et al., 2015; Heugens et al., 2008; Love \& Kraatz, 2009).

Organizational actors tend to increasingly portray themselves as internally consistent and integrated wholes, holding coherent identities and making collective statements about their goals, commitments and purpose (Drori et al., 2009; King et al., 2010; Halgin et al., 2018). Importantly, this creates organization-specific expectations against which constituents evaluate their behavior (Bromley \& Sharkey, 2017; Mishina et al., 2012). Simultaneously, institutional scholars have come to emphasize how modern organizations often hold multiple, and sometimes conflicting, goals, interests, values and identities (Ashforth \& Reingen, 2014; Battilana \& Dorado, 2010; Smith \& Besharov, 2019). Whereas many traditional business organizations have adopted commitments to sustainability and corporate social responsibility, there is a tendency for not-for-profits to combine their social ends with economic values such as efficiency and expediency.

Consequently, the inner life of many of these organizations has become characterized by a great many internal complexities and inconsistencies, "sometimes involving conflict, sometimes simple decoupling and hypocrisy" (Bromley \& Meyer, 2015: 23). Research has shown that these internal tensions, if maintained unchecked, may lead to value subversion or mission drift (Grimes et al., 2019), may disrupt organizational institutions (Kraatz, 2009), and can thus make an enduring commitment to organizational integrity difficult to sustain (Besharov \& Khurana, 2015; Gallagher \& Goodstein, 2002).

Despite significant scholarly attention to individual integrity in relation to employee and leadership behavior (see Bauman, 2013; Palanski \& Yammarino, 2007; Simons et al., 2015), the concept of organizational integrity has been largely ignored in the organizational and management literature (Dacin et al., 2002; Goodstein, 2015; Selznick, 2000). This research gap is troubling, considering that organizations as unique social actors are increasingly becoming the subject of moral scrutiny (Orts \& Smith, 2017). Specifically, the limited scholarly work on organizational integrity has treated its primary subject as 
isolated from its increasingly complex and ambiguous institutional environment. Although researchers have tended to attribute integrity to an entity "if that party is consistent with its past actions and if [their] actions comply with preceding promises" (Eberl et al., 2015: 1206), the literature is not clear what integrity entails when organizations are confronted with institutional pluralism and, consequently, have selves that comprise multiple distinct goals, interests, values and identities. As scholars tend to view organizational values as unitary, coherent and collectively shared, we lack a conceptual understanding of how an increasingly complex environment may manifest itself in internal incoherence, and thus undermining a sustained commitment to organizational integrity.

To better grasp the profound complexity of modern organizations, research needs to consider how organizations fail to cultivate integrity when their "selves are crosscut by multiple identities" (Caza et al., 2018: 704). Therefore, we are interested in understanding how competing institutional pressures may affect a sustained commitment to organizational integrity, and so, we pose the following research question: How is the integrity of organizations affected when they operate under institutional pluralism? We develop a conceptual model that allows us to better understand how field-level forces interact with intra-organizational dynamics in either strengthening or weakening organizational integrity (Goodstein, 2015; Kraatz, 2009). To do this, we move beyond the "view of organizations as unitary and tightly integrated entities making univocal decisions" (Pache \& Santos, 2010: 456; Greenwood et al., 2014; King, 2015) and recognize the complexity of intra-organizational arrangements, processes and social structures. Such an approach involves a central role for the internal and external mechanisms by which organizational values and purposes are either sustained or subverted and is based on the notion that organizations are deeply affected by their environments.

This paper offers two theoretical insights. First, we offer renewed attention to the notion of organizational integrity. We believe that a theoretical endeavor to better understand this concept and its challenges is needed because organizational integrity as a "unified, crossdisciplinary research subject [that] is only beginning to come of age" (Breakey et al., 2015: 37; Huberts, 2014). By integrating the recently reinvigorated literature on values (Gehman et al., 2013; Kraatz et al., 2020) with that of organizational identity (Haslam et al., 2017; Whetten \& Mackey, 2002) in our conceptualization of integrity, we acknowledge the potential dangers of normative fragmentation within organizations. Moreover, by conceptualizing integrity at the organizational level, we attempt to answer the recent calls by organizational scholars who underscore the need for "understanding, explicating and researching the enduring, noun-like qualities of the organization" (King et al., 2010: 290). Second, while institutional pluralism has become a vibrant research area (Kraatz \& Block, 2019; Radoynovska et al., 2019), institutional plurality has seldom been explicitly discussed in research related to organizational morality and values (Heugens \& Scherer, 2010). Therefore, we contribute to institutional theory by theorizing about how the increasingly pluralistic societal landscape may challenge a sustained commitment to organizational integrity. 


\subsection{What is Integrity?}

Before exploring the concept of organizational integrity in more detail, we believe it is first necessary to define integrity at the individual level of analysis. Extant research has indicated the concept's many conceptual layers and definitional difficulties (Bauman, 2013; Bakker, 2007). Based on their systematic literature review on the uses and definitions of integrity in organization and management research, Palanski and Yammarino (2007: 171) observe that the literature on integrity "suffers from significant problems," including "too many definitions and too little theory". In the following we describe the most common conceptualizations of integrity: (1) wholeness and integration; (2) identity-conferring commitments; (3) authenticity; (4) behavioral consistency; and (5) integrity and morality. Each is described below.

Integrity as wholeness and integration. Some of the underlying meanings of integrity can be found in the Latin term integritas, denoting "wholeness", "completeness", and "purity". This meaning of integrity does not only imply that the focal individual is undivided, unimpaired, and incorruptible, as suggested by Merriam-Webster dictionary, but also connotates the state of being unbroken, coherent, and of one piece (Kaptein, 2019; Maak, 2008). Some scholars have adopted this notion and have suggested that individual integrity is related to wholeness of thoughts, attitude, words, and behavior across time (Archer, 2017; Lowe et al., 2004; Worden, 2003). For instance, Srivastra and Cooperrider (1988: 5) note that as "a unifying process leading to a state of wholeness, completeness, or undividedness", integrity hinges on the integration of opposing forces of conviction and pleasure.

Integrity as wholeness presumes that rather than being torn apart by conflicting desires, the integrated self behaves in line with its own convictions (Wolfe, 1998: 142; Solomon, 1999). Integrity, in the sense of wholeness, implies integration and connectedness of the individual in all of one's beliefs and relations and involves "coming to grips with multiple values in a sort of multivalency" (Worden, 2003: 23). Moreover, integrity as wholeness and integration "has as much to do with one's coherent connections and relationships with other people and institutions as it does with one's relation to oneself" (Solomon, 1999: 39). In sum, such unity then reflects the seamless integration of the self with its environment (Wolfe, 1988).

Integrity as identity-conferring commitments. Some scholars have equated integrity with "adherence to one's character" (Cox et al., 2018: 29) and have claimed that a person with integrity stays true to those self-ascribed values, principles and beliefs that confer on the individual a distinct character or identity (Bauman, 2013; Calhoun, 1995). In a similar vein, McFall (1987) argues "that personal integrity requires unconditional commitments" that ascribes to that person a distinct and unique identity. These identity-conferring commitments are those values, beliefs and principles with which a person is "deeply and extensively involved and identifies", and thus defining for the individual self (Smart \& Williams, 1973: 116). In exploring leadership integrity, Bauman (2013) notes that integrity requires a reliable and consistent course of action in line with the identity-conferring 
commitments to principles that make the person who he or she is. The central thesis that these authors converge on is that, in order to be an individual of integrity, a person must identify with some values to such an extent that it makes losing his or her integrity possible, or to quote McFall (1987): "In order to sell one's soul, one must have something to sell".

Integrity as authenticity. Integrity is often equated in some sense with the notion of authenticity. Authenticity is concerned with an individual consistently acting according to his or her own conscience and convictions. Several authors have linked integrity to this sense of understanding and owning one's own set of values and acting accordingly (Cox et al., 2018; Avolio \& Gardner, 2005). For instance, Lowe et al., (2004) note that integrity is related to the concept of authenticity in that an individual acts in accordance with personal experience. In a similar vein, Ibarra and Barbulescu (2010: 140) assert that authenticity constitutes "the integrity of the self and behavior within and across situations", implying a self-consistent and continuous adherence to those distinctive features that are central to the self. Leroy and colleagues (2012) link integrity as authenticity-being true to oneself-to the notion of behavioral consistency, defined here as the perceived alignment between words and actions.

Integrity as behavioral consistency. An important dimension of integrity is a sense of consistency between promises and behaviors over time. The alignment between espoused principles and realized practices, i.e. "walking the talk", has been the preferred conceptualization when measuring and testing integrity at the individual level (Leroy et al., 2012; Simons, 2002). First coined by Simons (2002: 19), behavioral integrity is defined as "the perceived pattern of alignment between an actor's words and deeds", and reflects individuals' consistently keep promises and enacting the principles they espouse. Therefore, it is associated with perceived promise-keeping, trustworthiness and honesty. Scholars have used the concept of behavioral integrity to study a wide array of topics, including followers' commitment and performance (Leroy et al., 2012), employee citizenship and deviant behavior, team virtues and performance (Palanski et al., 2010) and the relationship between regulatory focus and impression management (Kacmar \& Tucker, 2016). Interestingly, however, scholars who adhere to this meaning note that "integrity is not fundamentally a moral concept" (Bauman, 2013: 414).

Integrity and morality. Although the notion of behavioral consistency is morally neutral-the principles an individual consistently adheres to may be perceived as unethical by some audiences but not others-other scholars have included a general conceptualization of morality in their definition of integrity (Archer, 2017; Badaracco \& Ellsworth, 1989; Becker, 1998; Parry \& Proctor-Thomson, 2002). In their view, integrity has an important normative component: attributions of integrity presuppose fundamental moral decency and soundness (Cox et al., 2018; Selznick, 1992). According to this view, integrity involves more than the adherence to some arbitrary set of principles embraced by a particular group of individuals or larger collective, nor is mere behavioral consistency enough. Integrity may only be ascribed to an actor, these scholars argue, if the principles that the actor consistently adheres to are morally acceptable to the wider community in which that actor operates 
(Bauman, 2013; Selznick, 1992). Therefore, integrity “involves fidelity to one's endorsements" (Calhoun, 1995: 244), but not just any endorsements-an unbroken commitment in action to a recognizable set of morally justifiably values (McFall, 1987).

In short, while often equated with behavioral consistency, there is an argument to make that integrity entails more than the mere alignment between words and deeds. Having integrity means that the individual stands for something and exhibits fidelity in action to self-ascribed values and principles (Becker, 1998; Calhoun, 1995). Such commitments are identity-defining because they represent one's deepest held values and principles, create moral identity, and cannot be dismissed without profound internal crisis. Since integrity is generally regarded as a morally valuable trait, the beliefs that are identity-conferring must self-evidently be morally justifiable (Archer, 2017; Smart \& Williams, 1973). In other words, because such self-ascribed commitments are constitutive of who one is as a person, for integrity to hold the individual must adhere to them in a self-consistent and integrative manner.

\subsection{Integrity and the Organizational Actor}

Above, we presented some of the most commonly used definitions of individual integrity. In the following, we put forward the notion of "organizational actorhood" (Bromley \& Sharkey, 2017; Halgin et al., 2018) and tease out some of the central tenets of organizational integrity. Organizational scholars have come to portray the modern institutional landscape as one in which formal collectives are socially constructed as actors in their own right, denoting bounded autonomy, decision-making capacity and sovereignty (Hwang \& Colyvas, 2020; Scott, 2014). That is, organizations are increasingly treated as "human-like entities authorized to engage in social intercourse as a collective and possessing rights, obligations and responsibilities as if the collective were a single individual" (Whetten \& Mackey, 2002: 395). Such treatment of organizations as actors is possible because of their increasing tendency to make self-claims to actorhood by articulating their distinct contributions, roles and obligations in and to society (Bromley \& Sharkey, 2017; Halgin et al., 2018) while also being held responsible by their external environments for a growing range of economic, social and environmental concerns.

Perhaps the most elaborative interpretation of the social actor perspective of organizations is that proposed by King and colleagues (2010). According to those scholars, the social actor perspective incorporates two central assumptions. First, the external attribution of action assumption delineates how the properties that grant organizations actorhood-such as sovereignty, the capability for autonomous actions, and ascribed responsibility-are attributed to them by their principal constituents. We treat the organizations we interact with as capable of deliberate and goal-oriented actions, while also holding them accountable for their behaviors (and omissions). In other words, organizations are social actors because 
"society, not only legally but also practically and linguistically, grants them that status" (King et al., 2010: 292). Second, the internal attribution of intentionality assumption presumes that organizational actors have goals and intentions that are quasi-independent of the values, beliefs, and desires of their members and constituents-that is, organizations are not mere social aggregates or collectives of the members that comprise them, but rather posses unique properties, including distinct histories, cultures and decision-making structures, that guide members' behaviors and thus conveys collective responsibility and agency (Steele \& King, 2011; Tollefsen, 2002).

Notably, both assumptions emphasize the centrality of identity in the treatment of organizations as social actors. Scholars have come to understand organizational identity as those self-defining characteristics (e.g. values) that describe what is central, enduring, and distinctive about the organization (Albert and Whetten, 1985). Although research on organizational identity has proliferated, covering a diverse set of perspectives (see Haslam et al., 2017), the social actor perspective of organizational identity is most obviously connected with the notion of organizational actorhood (Gioia et al., 2013; Whetten, 2006; Whetten \& Mackey, 2002). This perspective broadly asserts that "organizational identity is a set of external legitimizing claims and behavioral commitments, which are pathdependent and binding, and therefore provide organizations with central, enduring, and distinctive characteristics" (Haslam et al., 2017: 324). In other words, the identity of an organizational actor is essentially a collection of identity claims that explicitly articulate who the organization is, what it represents and how it will behave (e.g. through purpose and mission statements)(Gioia et al., 2013; Haslam et al., 2017; Whetten \& Mackey, 2002) providing meaning for collective sensemaking, prioritization and interpretation among members and thus binding the organization to a particular course of action.

Importantly, the two assumptions behind organizational actorhood reflect the view of organizations as agentic as well as constrained by environmental opportunities, pressures and prescriptions. Such internal and external attribution also recognizes that the identity of organizations is an institutionalized accomplishment. That is, the organizational actor is both "real, semi-autonomous, and independent of individual actors" who constitute the organization, and "legally and institutionally endowed with agency, rights and responsibilities" (Haslam et al., 2017: 325; Meyer \& Bromley 2013; Steele \& King 2011). More importantly for our argument, because the identities that constitute the organizational self comprise a blend of an organization's unique beliefs, values and traits, as well as its distinct connection with and obligations to the society in which it is embedded, they are profoundly "value-based" (Kraatz \& Block, 2017: 548; Selznick, 1992). Consequently, identity claims of organizational actors provide moral agency, purpose and justification for action (Kraatz et al., 2020; Steele \& King, 2011) as well as a reference point for judgement and evaluation by key constituents (Love \& Kraatz, 2009; Mishina et al., 2012). Therefore, organizations are considered to be not only social actors, but indeed also moral actors. 


\subsubsection{Defining Organizational Integrity}

Having described the underlying assumptions for the treatment of organizations as both social and moral actors, in the following we present some of the commonly used definitions of organizational integrity. Selznick defined organizational integrity as "fidelity to selfdefining principles" (1992: 322). Similarly to the notion of organizational actorhood, Selznick saw organizations as moral entities capable of purposive actions and asserted that integrity arises from their consistent commitment to moral values and purpose. Organizational integrity, in this view, presumes at least "a core of morally justifiable commitments" and is associated with moral coherence, both between actions and selfdefining values and in terms of its connection to the external environment (Selznick, 1992: 322). The central features Selznick attributed to integrity are reflected in the various conceptualizations provided in organization and management literature, including (1) wholeness and integration; (2) behavioral consistency and authenticity; and (3) morality.

Organizational integrity as wholeness and integration. Applied to organizations, integrity as 'wholeness' relates to "a unity that makes a differentiated constellation of parts held together as one" (Srivastra \& Cooperrider, 1988: 5). To the extent that an organization has integrity, it is a complete, rather than fragmented, whole in and of itself (Archer, 2017; Maak, 2008; Waddock et al., 2002). The maintenance of organizational integrity, in this sense, is expressed in the efforts localized in organizational policies and structures that lead to 'wholeness' and integration of the various values, norms, and ideals that motivate action, so that no part of the organizational self has an absolute primacy over the others (Bakker, 2007; Besharov \& Khurana, 2015; Pratt \& Kraatz, 2009). Such view is consistent with the Corporate Integrity Theory developed by Kaptein and Wempe (2002); according to these authors integrity denotes that the organization is predominately unfragmented and remains whole as members in their behavior are loyal to the multivalency of values that are constitutive of the identity of their organization.

Organizational integrity as behavioral consistency and authenticity. Others have extended Simons and colleagues' $(2002,2015)$ writings on behavioral integrity and have applied their notion of behavioral consistency to the analysis of organizations. Such a perspective is consistent with the view of authenticity on the organizational level (Cording et al., 2014; Ibarra and Barbulescu, 2010). These studies consistently advance the idea that an organization that displays authenticity is one that is willing to take action based on the values is espouses (Paine, 1994). In this view, organizations are perceived as acting with integrity when their articulated values and commitments are followed through in organizational actions and decisions-making (Colquitt \& Rodell, 2011; Eberl et al., 2015).

For example, Cording and colleagues (2014: 38) defined organizational authenticity as "consistency between a firm's espoused values and realized practices" and showed that a lack thereof reduces an organization's trustworthiness and can consequently leads to lower productivity. Likewise, in their study of trust repair following organizational-level integrity violations, Eberl and colleagues (2015) argue that "integrity is attributed if a party is consistent with its past actions and if these actions comply with preceding promises". 
Organizational integrity as morality. Scholars have emphasized that integrity requires the organization to engage in value-attuned responsiveness towards the external environment (Selznick, 1992; Swanson, 1999). Such responsiveness is morally bounded and constrained through taking into account community and institutional values that are grounded in the organization's implicit contract with society and the roles, duties and responsibilities the particular society confers on the organization (Gallagher \& Goodstein, 2002 Heugens et al., 2008). As such, organizational integrity demands moral legitimacy (Goodstein, 2015; Suchman, 1995; Selznick, 1992). This moral responsiveness and integration of the self with the external environment precludes morally illegitimate values and mission as a base for organizational integrity. Only if the values of an organization are morally or socially acceptable will integrity be attributed. Thus, this integrated organizational self encompasses the coherence in "the sense of mission, its various stakeholder obligations and interests and its sense of social responsibility and social values" (Solomon, 2004: 1035).

\subsubsection{Organizational Integrity: Espoused, Embedded and Enacted Values}

Organizational integrity assumes that consistent lines of action are reasonably aligned with accepted moral or socially prevalent values. This understanding of organizational integrity fits well with the growing number of studies that examine values within and surrounding organizations (see Kraatz et al., 2020). Scholars have commonly referred to values as "conceptions of the good-ideals about what is worth having, doing, and being" (Kraatz \& Block, 2017:20; Grimes et al., 2019). By virtue of their normative weight, values play an important role in the context of organizing in that they constitute, in part, the identities of organizations, provide direction, meaning, and purpose for members, and function as reference points for social evaluation.

Within the context of organizations, values can take various forms. For instance, organizational values may refer to the values explicitly and formally espoused by the leadership (Bourne et al., 2019; Kabanoff et al., 1995), the values attributed to the organization or that is aspires for (Bourne \& Jenkins, 2013), shared among organizational members (Parson, 1956; Schwartz, 1999), or embodied in strategic decision-making (Gehman et al., 2013; Gruys et al., 2008). In this section, we discuss the three forms of organizational values that we consider central to our conceptualization of organizational integrity.

Espoused organizational values. Organizations, as purposive and autonomous social actors, increasingly make normative commitments and claims regarding their beliefs, intentions and responsibilities (Bourne et al., 2019; Kraatz \& Block, 2017; Meyer \& Bromley, 2013). Therefore, espoused values can be understood as the values determined and sanctioned by top management (Bansal, 2003), often communicated verbally or written down in "mission statements" (Blair-Loy et al., 2011) and formal corporate documents, such as codes of conduct and corporate ethics statements (Bartkus \& Glassman, 2008). Consequently, the espoused values embodied in such claims are what the organization, as a distinct social and moral actor, professes to stand for. 
Internally, espoused values are intended to guide individual and organizational actions, to help employees make sense of and justify everyday interactions and behavior, and to ensure that alternative choices are on the basis of the organization's value system. Externally, because "organizations enhance their legitimacy by espousing values that are in fact congruent with their cultural milieu" (Kabanoff \& Daly, 2000: 286), espoused values play an important role in delineating the intentions, goals and purpose of the organization, communicating its identity, and thus for impression management, fostering reputation, legitimacy and image (Ashforth \& Gibbs, 1990).

While scholars have questioned whether espoused values are actually shared by members (Bourne \& Jenkins, 2013), these values make salient the organization's embraced ethical commitments, obligations and responsibilities. Because of their explicit nature, espoused values are more costly to ignore, irreversible and are thus more likely to be perceived by audiences as characterizing the organization's true self (King et al., 2010; Steele \& King, 2011). Despite much cynicism concerning mission statements, the articulation of values has become commonplace in organizations (Bourne \& Jenkins, 2013; Gehman et al., 2013; Kraatz et al., 2020). By espousing their values and principles, organizations create implicit contracts with key constituents (Cording et al., 2014; Heugens et al., 2008), and such claims thus become normative standards against which their subsequent actions are evaluated (Love \& Kraatz, 2009; Mishina et al., 2012). As a result, when organizations make their values explicit to key constituents, "obvious contradictions between espoused values and the actions of organizations [are likely] to be exposed" (Bourne at al., 2019: 135). These expectations, and the values and beliefs implied therein, are therefore "a necessary starting point for meaning-creating iterations and ethical behavior" in the form of organizational integrity (Jonson et al., 2015: 338).

Embedded organizational values. As argued above, an increasing array of organizations claim to be 'doing the right thing' by espousing a set of moral or socially preferred values, yet for many of these organizations the impact is restricted to an embraced philosophy that has limited influence on actual business operations (Bartkus \& Glassman, 2007; Bromley \& Powell, 2012; Brunsson, 2002). Since the means by which embraced ends are achieved reflect the organization's underlying integrity and character, substantive attention to the social structures and processes is necessary to prevent ends from being corrupted (Chandler, 2015; Kraatz et al., 2010; Krygier, 2012). In other words, the challenge for any organization attempting to stay true to their values is to find meaningful ways to embed their principles into the "driving systems" of the organization (Paine, 1994: 112; Gruys et al., 2008).

Organizational values are embedded when they are "expressed in the operational structures and systems of organizations, or when they are shared to the extent that that members are able to anticipate other members' actions, behaviors and expectations" (Bourne \& Jenkins, 2013: 502). Once accepted values have been embedded, they guide, motivate and steer organizational agents to act in accordance with such commitments and to restrain actions that might violate them (Goodstein, 2015; King, 2015; Selznick, 2000). With regard to our conceptualization of organizational integrity, we distinguish between those values that are embedded in organizational design and those in organizational culture. 
First, values are formally embedded when they are reflected in substantive organizational systems and structures more typically associated with organizational design, such as reward and incentive systems; practices of recruitment, promotion, and removal; and decisionmaking processes and control mechanisms (Schein, 2004). Scholars suggest that the values embedded in these formal organizational structures, such as socialization and hiring policies (Battilana \& Dorado, 2010) and governance mechanisms (Ebrahim et al., 2014) can determine who is admitted to and dismissed from the organization, control the behavior of members through rules, rewards and sanctions, and, consequently, shape the organization's behavior towards their external environment. As organizational actors hold sovereignty and intentionality, the values embodied in organizational structures and systems are important drivers and predictors of organizational actions (Amis et al., 2002; Hinings et al., 1996; Perkmann \& Spicer, 2014).

Second, values are informally embedded when they are shared among organizational members and reflected in beliefs, routines, symbols and ideals. Shared values are the aggregation of the values of the organization's members and constitute an organizational value system (Parson, 1956). In this view, shared values are closely aligned with what many would describe as organizational culture (Rokeach, 1973; Schwartz, 1999) such that, when meaningfully internalized by the actors in a social system, shared values "should ensure that each actor wants what it should want, and acts as it should [wish to act]" (Nohria \& Ghoshal, 1994: 493). Shared values may therefore function as a source of social control within organizational boundaries (Ouchi, 1980). In other words, organizational values should not be merely espoused, but shared among a significant proportion of the organizational membership so that such values are the basis for behaviors and actions.

Enacted organizational values. Although espoused values denote the values that are formally communicated by the organization and its leadership, the enacted values are the values reflected in organizational actions and strategic decision-making (Bourne \& Jenkins, 2013; Ostroff et al., 2005; Schein, 1985). Specifically, enacted values are understood as "the values and norms actually converted into employee, managerial and organizational behavior" (Howell et al., 2012: 734) and involve a "theory-in-use that explains behavior, which neither the institution nor the individuals may explicitly understand" (Schuh \& Miller, 2006: 721). Variation in values enactment therefore depends on how closely an organization's specific actions aligns with a particular set of explicitly espoused organizational values (Gruys et al., 2008). In summary, organizational integrity then hinges on the extent to which the organization holds true to and enacts the values it has espoused. Thus, we propose the following:

Proposition 1a: Organizations are more likely to act with integrity when the espoused organizational values are shared among organizational members (informal embedding).

Proposition 1b: Organizations are more likely to act with integrity when the espoused organizational values are reflected in an organization's operational structures and processes (formal embedding). 
Figure 2. 1 An Institutional Perspective of Organizational Integrity

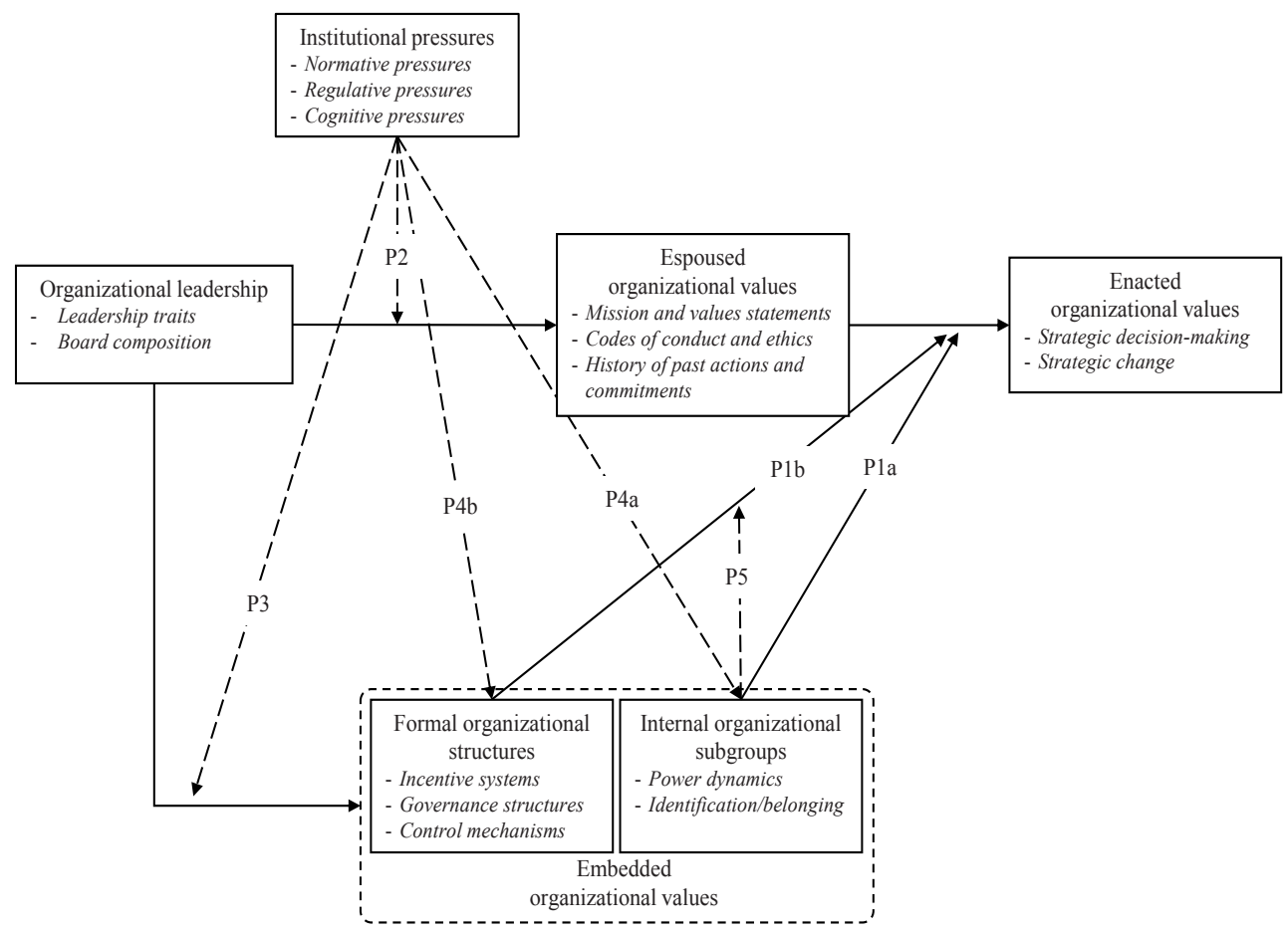

\subsection{An Institutional Perspective of Organizational Integrity}

In the previous section we asserted that organizations are more likely to maintain integrity when the values espoused by organizational leadership and the values embedded in formal structures (i.e. organizational design) and shared among members (i.e. organizational culture) are congruent. However, extant research has emphasized that a variety of endogenous and exogenous influences may create normative fragmentation and contestation within organizational boundaries (Greenwood \& Hinings, 1996; Oliver, 1992). Profound organizational and institutional changes, such as corporate expansions, acquisitions and mergers (Marquis \& Lounsbury, 2007), employee turnover (Morrel et al., 2004), changes in leadership (Kraatz \& Moore, 2002) or shifts in the regulatory or competitive environments (Armanios \& Eesley, 2021) are likely to significantly influence the internal cohesion, composition and relative salience of organizational values. Our focus on these internal complexities is consistent with institutional theory, which highlights how external forces may give rise to persistent intra-organizational contradictions (Ashforth \& Reingen, 2014; Smith \& Besharov, 2019), with the potential to create uncertainty, contestation, and conflict (Fiol et al., 2009; Glynn, 2000). 
Specifically, when these institutional prescriptions lead organizations to adopt commitments, practices or structures that are ostensibly incompatible with the dominant values, this may result in the loss of normative consensus or agreement among members. This may subsequently challenge the alignment between the values formally espoused and communicated by the organization as a whole and the embedded values that motivate managerial and strategic decision-making (Amis, et al., 2002; Bourne \& Jenkins, 2013). In the following sub-section, we show that when organizations are confronted by institutional pluralism, they often come to hold multiple value-based identities, which may undermine a sustained commitment to organizational integrity.

\subsubsection{Institutional Pluralism and Organizational Identities}

The main premise of institutional theory is that formal organizations are fundamentally dependent on and affected by the social institutions in their external environment. Therefore, institutional scholars have highlighted the degree to which organizational commitments, structures, processes and behaviors "are driven by sets of socially constructed beliefs, norms and rules negotiated and enforced" by macro-institutional forces, including normative, regulative and cultural-cognitive elements (DiMaggio \& Powell, 1983; Scott, 2014; Thornton et al., 2012). Consequently, organizations and their members are understood to be working to secure status, legitimacy and access to resources which requires their conformity to social rules, norms and regulations established in fields, communities and societies (Meyer \& Rowan, 1977; Suchman, 1995).

Importantly, this environment is constitutive of organizations and thus provides organizations with various institutional prescriptions about what organizations should say (i.e. espouse), how they should be internally structured and designed (i.e. embed) and what they should do (i.e. enact). Although this institutional environment has been traditionally characterized as homogenous, more and more studies emphasize the heterogeneity of the institutional environment.

Institutional pluralism. Recent institutional studies have noted how the societal field has become increasingly ambiguous and heterogeneous with multiple-often mutually incompatible-prescriptions that result in competing pressures for conformity (Greenwood et al., 2011; Kraatz \& Block, 2008; Thornton et al., 2012). This environment is characterized by multiple institutional demands and stakeholder expectations, resulting in organizations having to pursue diverse and often conflicting goals, roles, commitments and responsibilities (Ashforth \& Reingen, 2014; Pache \& Santos, 2010; Smith \& Besharov, 2019). Scholars have come to examine this phenomenon of multiple institutional pressures under the label of institutional pluralism, understood as the situation in which organizations "are subject to multiple regulatory regimes, embedded within multiple normative orders, and/or constituted by more than one cultural logic ... [they] thus possesses multiple, institutionally derived identities which are conferred upon it by different segments of its pluralistic environment" (Kraatz \& Block, 2008: 243). Recent efforts to infuse institutional theory with organizational identity processes have popularized the idea that identities are-for the major part-derived from this increasingly pluralistic environment. 
The social actor perspective of organizational identity corresponds directly to the institutional literature. This perspective generally assumes that the normative, regulative and cognitive forces present in the institutional environment serve as identity templates, constraints or prescriptions. In other words, institutions enable identity construction by "supplying organizations and their leaders [with] a set of possible legitimate identity elements with which to construct, give meaning to, and legitimize identity claims and symbols" (Glynn, 2008: 413). Therefore, an organization's identity is seen as formed through the process of "institutional bricolage", in which an organization's members, and in particular its leaders, actively draw on institutional material to construct organizational identity (Besharov \& Brickson, 2016; Raffaeli \& Glynn, 2014). Consequently, institutionally informed studies on organizational identity have elaborated on how organizations construct their identity through the adoption of commitments, public statements, and legitimizing claims to constituents and audiences within the external environment (Glynn, 2008; Kraatz et al., 2016; Haslam et al., 2017). This is what makes organizations within the same organizational field tend to share a broad range of characteristics.

Multiple organizational identities. Acknowledging the basic idea that organizations are shaped in part by the institutions in their field, scholars have suggested and empirically demonstrated that institutional pluralism has the effect of imposing multiple identities on an organization and requiring it-though sometimes only symbolically-"to be multiple things to multiple people" (Kraatz \& Block, 2008: 21). Consequently, identity scholars have gone on to emphasize that, as a result of such pluralism, organizational identities tend to include multiple, and sometimes incompatible, attributes and claims (Albert \& Whetten, 1985; Pratt \& Foreman, 2000), including "the values, goals, beliefs, traits, abilities that constitute an organization's central, enduring, and distinct features" (Besharov, 2014: 1485).

Importantly, when we take the moral dimension of the institutional landscape seriously, we come to understand that institutionally derived identities are not only representative of group membership or attachment. The various identities that society ascribes to organizations do not just direct them to demonstrate symbolic conformity to external prescriptions or adopt culturally appropriate practices and structures. Instead, because these identities are profoundly value-based (Kraatz et al., 2020; Selznick, 1992), when an "organization admits a new member into its coalition of identities" (Kraatz \& Block, 2017: 545), it is also accepting new responsibilities, new obligations and new objectives. Therefore, these role identities compel organizations to declare commitments to normative values and ideals, take on various new duties, and are expected to deliver upon these embraced ends in a meaningful way.

Extant scholarship has indicated how many modern organizations have hybrid identities that are "composed of two or more types that would not normally be expected to go together" (Albert \& Whetten, 1985: 270). Empirical examples of such "multiple identity" organizations abound. In the not-for-profit sector, many organizations have identities that combine societal values that emphasize cultural or ideological principles with economic values. In recent decades, identities that combine divergent values have also become 
common in the for-profit sector, with the rise of business organizations that explicitly address social and environmental concerns (Henderson, 2020; Margolis \& Walsh, 2003; Smith et al., 2013). Even traditional corporations increasingly have identities that include multiple and potentially contradictory values, as they operate in global markets, have a diverse employee population, and engage in ongoing efforts to win the support of diverse constituents (Smith \& Lewis, 2011).

Importantly, these disparate identities "are all present inside the organization" in the form of distinct subgroups, departments or divisions (Pratt \& Kraatz, 2009: 394), each with their own set of values. Although there will be much overlap in these identity attributes within the same organization, contradictory interests, desires and norms anchored in these identities are likely to prescribe diverging courses of action.

Implicit in this stream of research are the challenges these organizations face resolving the tensions that emerge from their multiple identities. Although organizations will always experience some incoherence in these identities and their associated goals, most leaders are capable of finding common ground (Raffaelli \& Glynn, 2015; Radoynovska et al., 2019; Selznick, 1957). Recent work has elaborated on the various organization-level strategies, structures and practices (Battilana \& Dorado, 2010; Pratt \& Foreman, 2000) as well as the various group and individual dynamics (Ashforth \& Reingen, 2014; Smith \& Besharov, 2019) that are deployed to successfully manage multiple identities. For instance, Kraatz \& Block (2008) theorize four ways to manage multiple identities, including aggregating the identities associated with institutional constituents, integrating them in a coherent whole, compartmentalizing them or completely deleting some identities.

\subsubsection{The Perils of Organizational Integrity}

Though scholars have asserted that the 'wholeness' of multiple selves is a key element of integrity (Cox et al., 2018; Kraatz, 2009; Raffaelli \& Glynn, 2015), organizational actors that have adopted multiple value-based identities are likely to espouse and embed competing values within their boundaries (Quinn \& Rohrbaugh, 1981). Such values-based complexity, characterized by "the prevalence of multiple, independent, yet interacting and continuously changing values" (Grimes et al., 2019: 821), has been shown to lead to diverging courses of action and is thus likely to complicate consistent organizational behavior.

Although values have the potential to function as a "cohesive force" within collectives (Kraatz et al., 2020: 491), creating shared identity and common purpose, researchers have gone on to embrace the study of this complexity and also the ensuing conflicts and ethical dilemmas (Grimes et al., 2019; Kraatz \& Block, 2017; Smith et al., 2013). When uncertainty and ambiguity are pervasive over which value-based identity and associated roles, responsibilities and obligations to prioritize, this can cause conflict and contestation between internal subgroups that hold contradictory values, norms and interests (Glynn, 2000), precipitate or derail strategic change (Dutton \& Dukerich, 1991) and challenge the sustained adherence to accepted ethical, regulatory and normative principles (Connelly et al., 2016). 
Although goal disagreement, power struggles and competition over scarce resources between identity groups is the normal state of affairs in most organizations (Huy et al., 2014; King et al., 2010), their very integrity depends on members' collective ability to resolve conflicts between values and mitigate the destructive tensions inherent in pursuing competing goals as they formulate strategy and make key decisions. Organizations with multiple identities must fulfill the expectations, responsibilities and obligations associated with each adopted identity in its entirety, as "anything less will be viewed as compromising [their] integrity" (Whetten et al., 2014: 487).

When the mismanagement of multiple value-based identities leads to organizational actions that diverge from previously observable patterns of commitments and promises, organizations are likely to be perceived as have compromised their integrity (Connelly et al., 2016; Bundy et al., 2021; Paruchuri et al., 2021). For instance, while scholars have suggested compartmentalization as a legitimate tactic to manage multiple value-based identities, in which two or more important but antithetical identities are maintained separately and operate relatively independent from each other, this strategy might become a focal point for scrutiny if audiences find that there is an illegitimate decoupling of organizational practices (Bromley \& Powell, 2012; MacLean \& Behnam, 2010; Weaver et al., 1999). Similarly, intentionally deleting or "marginalizing" an institutionally derived identity, together with the responsibilities and obligations associated with it-in favor of commercial interests-may signal to important audiences an abandonment of accepted ethical, regulatory and normative principles.

Since corporations are increasingly expected to say what they contribute to society beyond their core commercial goals, the key challenge for integrity arises because "conflicting influences are transmitted down into organizations that are supposed to be coherent actors" (Meyer \& Bromley, 2013: 377). Given that "obvious disconnects between rhetoric and subsequent actions is often regarded as the very antithesis of organizational integrity" (Kraatz \& Block, 2008: 322), we speculate that having multiple, disparate identities is likely to create diverging organization-specific normative standards against which subsequent actions are judged. Therefore, when organizations make identity claims to which their own behavior does not conform, their actions may be perceived as hypocritical in the eyes of stakeholders. Although scholars have suggested that deliberate mission drift can be an effective strategy for organizations to deal with "several conflicting values simultaneously" (Brunsson, 2002: xiii; Grimes et al., 2019), audiences are likely to view such actions as inauthentic, dishonest and morally illegitimate and to question the trustworthiness and integrity of such organizations (Harrison et al., 2009; Love \& Kraatz, 2009; Mishina et al., 2012). Based on our theorizing, in the following sub-section we formulate several propositions.

\subsubsection{How Pluralism Moderates Values Espousal and Embedding by Leadership}

Extant research has suggested that ensuring a sustained commitment to organizational integrity requires "attention to the particularly complex institutional environment in which leaders and managers operate" (Radoynovska et al., 2019: 33). Specifically, when we 
situate organizations within their pluralistic and ever-changing environments, the content of their espoused values tends to reflect the dual influence of both institutional pressures for conformity (Bartkus \& Glassman, 2008; Suchman, 1995) and the historical patterns of prior commitments, promises and actions that make each organizations distinctive (Blair-Loy et al., 2011; Zhao et al., 2017). Scholars have suggested that organizational leadership is of particular importance in this regard, as leaders are seen as symbolizing the organization in that they function "as key carriers of organizational actorhood" (Bromley \& Sharkey, 2017: 24), embodying the strategic and normative stance of their organization, defining espoused value sets and governing their organization accordingly. As leaders serve as the carriers of institutional values and the guardians of integrity (Selznick, 1957; Solinger et al., 2020), they are responsible for embedding espoused values in informal social and formal structures and systems.

As a result, espoused values are primarily the manifestations of the leadership's concern for the effective functioning of their organization and, therefore, are required to cater to the needs, expectations and pressures of both their members and other stakeholders. Such leaders are increasingly engaged in symbolic and rhetorical work to attain and maintain trust and support from investors, employees, customers and governments regulators. From this perspective, the espousal of values is a primarily a matter of legitimacy in that congruence between the espoused values and the organization's wider social system wherein it operates can assist in gaining support, status and access to resources, and so can be essential for organizational survival (Ashforth \& Gibbs, 1990). Since organizational actors increasingly display their capabilities for autonomous and rational action on many fronts while, at the same time, becoming enmeshed in a web of roles, responsibilities and obligations to multiple constituents, the espoused values of any organization are thus likely to include combinations that compete in the sense that they would not typically sit together in the value systems of individuals (Quinn \& Rohrbaugh, 1981; Schwartz, 1999). That is to say, the structure of an espoused values set may contain elements of both compatibility and conflict among them (Bourne et al., 2019; Kabanoff et al., 1995).

Contrary to the common view that the sole goal of business organizations is to maximize shareholder value, for-profits face increased societal pressures for environmental responsibility, transparency and ethical behavior. In this context, normative and regulatory pressures emanating from the organization's institutional environment will likely compel leadership to publicly espouse its commitment to engage in societal concerns. For instance, pressures by activist groups to adopt sustainability principles and standards (Carlos \& Lewis, 2017; Wright \& Nyberg, 2017) and demands by regulators to demonstrate substantive compliance with requirements regarding environmental pollution (Armanios \& Eesley, 2021; Edelman, 1992) have led many corporations to make normative and enduring commitments in these areas. Importantly, however, these values are likely to compete with purely economic values. The adoption and espousal of governmental mandates rules, norms and principles is likely to restrict managerial discretion in a commercial environment, and this will likely lead to a broad range of strategic responses. Bartkus and Glassman (2008), 
for instance, show that some elements of organizational value statements are the product of firms' need to secure external legitimacy but then only loosely couple these statements to their formal operations. Consequently, the fragmented and pluralistic environment causes, at least on the surface, organizational actors to espouse contradictory values. Thus, we propose the following:

Proposition 2: When organizations face institutional pluralism and consequently hold multiple identities, organizational leadership is more susceptible to espousing competing values, increasing the risk of integrity failures

The coexistence of contradictory espoused values is bound to cause much confusion over which value claims to prioritize and, consequently, what constitutes legitimate behavior in the eyes of key audiences. Although organizations increasingly espouse ostensibly competing values, the degree to which such values-based complexity is successfully managed and consistent organizational action is ensured, is to a large degree dependent on the individuals within the organization who have normative, cognitive and motivational affinity for such embraced values (Battilana \& Dorado, 2010; Hallett \& Ventresca, 2006; Pache \& Santos, 2010). The literature on organizational leadership suggests how the institutional context is an important factor in shaping leadership characteristics that, in turn, influence organizational processes, structures and outcomes (e.g. Yamak et al., 2014).

As organizations are said to, in part, reflect of their leadership, including their beliefs, traits and assumptions (Hambrick \& Mason, 1984; Kraatz \& Moore, 2002; Raffaelli \& Glynn, 2015), the values internalized by top management and decision-makers are likely to be mirrored in the social structures of the organization. For instance, Almandoz (2014) shows that financial firms with founding teams that prioritize economic values were associated with the higher use of risky financial instruments in comparison with teams that had internalized community values. Likewise, Berson and colleagues (2008) study the process through which CEO dispositions and values relate to organizational culture and find that CEO self-directiveness is associated with an innovation-oriented culture, whereas benevolence values is characteristic of supportive organizational cultures. Combining these assumptions, we argue that institutional pressures and changes may in part work through leadership in determining which values are embedded within the organization.

Within institutionally embedded organizations, leadership is responsible for recognizing and acknowledging the external demands and integrating multiple roles, responsibilities and obligations within the same collective entity. Such leadership is generally in the best position to manage conflicts between various social roles and find ways to redirect tensions between values to more productive ends (Besharov \& Khurana, 2015; Kraatz, 2009; Raffaelli \& Glynn, 2015; Selznick, 1957). Leaders must embed the multivalency of values within the social structures of their organization, so that members are provided with clear meaning, orientation and guidance to navigate critical decision-making situations (Besharov \& Khurana, 2015; Smith \& Besharov, 2019). 
In this vein, Pratt and Kraatz (2009) recognize leaders' roles in portraying the organization as a consist, coherent entity through blending competing values in speech, symbols and narratives to secure support from competing subgroups. Importantly, this work is decidedly structural and quasi-integrative in nature. By granting the various identity groups sufficient influence and resources, leaders are able to construct a "constitutional system of checks and balances" (Kraatz, 2009: 76), while simultaneously preventing any subgroup from gaining control over the whole organization. This demands, for instance, certain governance mechanisms that ensure that "representatives of each side of competing demands can keep one side from dominating" (Besharov \& Smith, 2019: 28). Such boundary-defining work is an ongoing and evolutionary process, with leaders having to adapt to the ever-changing moral landscape and "remodel" governance arrangements accordingly as they take on new social roles and consider constituents' demands. This integrative and responsive leadership, Solinger and colleagues (2020) suggest, involves continuously updating and adjusting the moral course of the organization as it espouses new values, adopts new commitments, and takes on new responsibilities.

Alternatively, when the leadership does not identify with the values of the organization, leaders may be reluctant to embed embraced values in the social structures of the organization or embed values that polarized espoused values. This may be the case in situations of changes in leadership or board composition. In their study of executive migration, for instance, Kraatz and Moore (2002: 139) show that new leadership may forcefully advocate alternative values that "promote and facilitate the adoption of illegitimate, contra-normative changes" when their personal values are antithetical to those formally espoused or when they come from organizations with a history of nonconformity. The reluctance to embed may also be a cynical ploy used by an unethical leadership to give off a false appearance of conformity to societal prescriptions or to "corrupt" the internal character of the organization by illegitimately prioritizing the demands of constituents at the expense of others (i.e. to "coopt”)(Kraatz et al., 2010; Zahra et al., 2005). As illustrated by Lencioni's (2002) analysis of the 'empty' values statements used by the US energy conglomerate Enron, attempts by leaders to espouse a set of values that are not supported by policies and procedures nor shared among members have potentially destructive implications for the integrity of organizations. Therefore, if the leadership is not representative of such espoused values sets, they will be less like to resolve tensions arising from the embedded structures of the organization. Therefore, we propose:

Proposition 3: When organizations face institutional pluralism and consequently hold multiple identities, espoused values are less likely to be embedded when not all values are internalized by leadership, increasing the risk of integrity failures 


\subsubsection{How Pluralism Moderates Values Embedding}

As noted above, ensuring consistent organizational action requires that embraced values are embedded into both the formal and informal social structures of the organization. However, pluralism in the institutional environment has the effect of creating contradictions between the values espoused by leadership and those embedded in operational structures and shared by organizational members. Organizations that are able to adequately integrate their various identities so that associated values and beliefs "are widely shared and densely articulated among members" (Ashforth et al., 2008: 328) are likely to strengthen organizational identification. Such strong identification has been shown to guide, orient, and unify members in engaging in collective action, and provides the means to interpret and prioritize competing institutional pressures (Besharov \& Brickson, 2016; Dutton \& Dukerich, 1991; Greenwood et al., 2011).

In this vein, Raffaelli and Glynn (2014: 548) assert that “an organization's identity filters perceptions about the relevance and appropriateness of practices; practices that align with the organization's identity are perceived to be more appealing and legitimate and, in turn, more likely to be adopted". When members coherently identify with their organization's espoused values, they are more likely to adopt institutional practices and structures that reinforce these commitments. In contrast, disidentification or normative fragmentations will likely lead to undesirable behaviors. Based on these assumptions we advance several propositions.

First, the distinctive feature of the institutionally embedded organization is that is often composed of multiple identity groups that hold incompatible values, beliefs and ideals (Smith \& Besharov, 2019; Battilana \& Dorado, 2010; Pache \& Santos, 2010). Such internal groups tend to reflect both the distinct values, needs and interests of organizational membership as well as external concerns, resulting in a "multiplicity of values" within the organizational boundaries (Hinings et al., 1996: 888). Consider a bank as an example, where the investment bankers that provide services for large corporations and institutional investors are likely to hold values that differ somewhat from their colleagues in the Legal department or those within the HR department. The diverse roles, needs and interests of these organizational subgroups are likely to elicit markedly different modes of conduct.

The creation and maintenance of integrity, in the sense of 'wholeness' in disparate values, requires finding common ground among the groups and external coalitions identified who hold potentially competing values (Ashforth \& Reingen, 2014; Besharov \& Khurana, 2015; Kraatz, 2009). The creation of such "political compromise" is necessary if leaders are to establish social cohesions and come to a semi-common view among members of what is distinct, central and enduring about their organizations. In their study of reinsurance trading in Lloyd's of London, for instance, Smets et al. (2015: 933) observed overt competition between brokers who held community values and those who prioritized market values, yet also discovered various balancing practices within the organization that led members to "show 'gentlemanliness' among competitors and prioritize long-term relationships over short-term profits”. Similarly, Dutton and Dukerich's (1991) study of the 
Port Authority of New York and New Jersey revealed that organizational agents were more likely to respond to external pressures to address social concerns relating to the homeless when they identified with their organization's social commitments. These studies highlight that members' identification increases their attention to and responsiveness toward matters related to the organization's espoused values.

In contrast, however, when specific internal subgroups do not identify with subsets of espoused values or hold radically contrasting values to be important, tension is likely to be pervasive. Extant research suggests that such a profound misalignment between the espoused values by organizational leadership and the values shared by specific segments of the organization can signal an explicit lack of belonging (Tracey \& Phillips, 2016; Smith \& Lewis, 2011) or disidentification with specific features of an organizational identity (Ashforth et al., 2008; Besharov, 2014). When such intractable conflicts run rampant (Fiol et al., 2009; Glynn, 2000), powerful subgroups that do not identify with some subsets of their organization's espoused values may purposefully resist their enactment in practice. For instance, in their study of middle managers' reactions to the implementation of a radical change program initiated by a recently appointed top management team, Huy and colleagues (2014) show how shifting legitimacy judgement of the change agents elicited emotional responses that fueled mounting resistance to change efforts.

Alternatively, subgroups that hold sufficient power, status and authority may unobtrusively enact values that are antagonistic towards those espoused by their leadership. Although leaders can embed the values they envision for the organization in operational structures and processes to encourage or coerce members to enact the espoused values, they do not have complete control over all social processes and interactions within the organization. Organizational leadership is "reliant upon key members who possess the knowledge, skills or professional qualifications" to enact these embraced values in organizational actions (Bourne \& Jenkins, 2013: 508). In contrast, when the espoused values are not sufficiently shared among members and the organization- through its leadership-is unable to establish a shared purpose within the organization through finding common ground among internal subgroups that hold divergent values, organizational integrity is likely to be significantly at risk. Therefore, we propose the following:

Proposition 4a: When organizations face institutional pluralism and consequently hold multiple identities, internal subgroups (informal embedding) that only identify with a subset of espoused values will only enact this subset or resist the enactment of values they do not identify with, increasing the risk of integrity failures

Second, the institutional environment conveys to organizations specific prescriptions regarding the appropriate processes, structures and strategies to enact espoused values, such as hiring procedures, incentive systems and decision-making processes. These institutionally derived practices, and the values embedded therein, have important implications for everyday organizational life in that they guide behavior and control strategic decision-making. Importantly, as these organizational structures and rules 
become institutionalized and taken-for-granted among members, they have the propensity to override individual perception of what constitutes appropriate behavior. In this vein, the bourgeoning literature on misconduct has suggested that when unethical norms and values are embedded in formal organizational routines, structures, and systems, boundedly rational members are likely to take them for granted and assume that misconduct provides an appropriate way to reach organizational goals (Greve et al., 2010; Habersang et al., 2019; Palmer, 2012).

Concretely, while governance practices and incentive systems may reinforce an ethical culture by stimulating behaviors that are congruent with an organization's self-defining principles (Gallagher \& Goodstein, 2002; Paine, 1994), incentives can also work in opposition to culture, especially when they "reward employees for achieving a metric without regard to the actions they took to achieve that metric" (Graham et al., 2016: 19). For instance, while Wells Fargo's espoused values statement included "what is right for customers" and "ethics", the 2016 cross-selling scandal revealed that management had adopted and diffused throughout their organizations a compensation system that promoted cross-selling as a performance metric and thus rewarded behaviors that were incongruent with the bank's espoused values (Tayan, 2019).

As noted above, a coherent organizational identity, and consequently greater identification, is an important factor in determining members' responsiveness to institutional pressures (Greenwood et al., 2011; Pache \& Santos, 2010; Schilke, 2018). Organizations are less likely to adopt controversial business and governance practices that are incongruent with an organization's espoused values when members do not identify with specific subsets of espoused values (Bednar et al., 2015; Mohliver, 2019). For instance, Kraatz et al. (2010) demonstrate that the adoption of enrollment management systems in liberal arts colleges undermines the autonomy of organizational members charged with maintaining specific organizational values. Importantly, the systems' adoption suddenly exposed the colleges to market values, which clashed with long-standing values associated with academic instruction and support. This example illustrates how the adoption of "mundane administrative arrangements" (Selznick, 1957: 14) that are ostensibly incongruent with espoused values have the potential to "override" individual behavior. When organizational decision-makers do not identify with their organization's espoused values and, consequently, the associated duties, responsibilities and obligations, they are more likely to resist institutional pressures for the adoption of practices, processes and structures. In integrating these arguments, we propose the following:

Proposition 4b: When organizations face institutional pluralism and consequently hold multiple identities, organizational members are less likely to adopt processes and structures (formal embedding) that are fully in line with all espoused values when members only identify with subsets of values, increasing the risk of integrity failures 


\subsubsection{How Pluralism Enables Decoupling between Embedded and Enacted Values}

Extending our theorizing in the previous section, in the following we build on the assumption that the degree to which members identify with their organization's identity influences whether processes and policies are actually enacted in practice. While many organizations adopt formal processes and policies to secure legitimacy, avoid sanctions and ensure that behavior is in accordance with espoused values, studies have suggested that such structures are often not fully implemented in day-to-day, central, task-related operations of the organization.

Since pressures to adopt externally legitimated structures and policies may be in direct conflict with their core goals, organizations are likely to resort to decoupling by adopting visible structures that show attentiveness to constituents' demands and values but avoid full implementation to protect the technical requirements of the organization, such as corporations' profit-maximizing activities. Such decoupling, as the process through which organizations separate their normative structures from their operational structures (Boxenbaum \& Jonsson, 2017; Meyer \& Rowan, 1977), is ubiquitous in organizations and has been traditionally theorized as an important instrument to communicate adherence to institutional prescriptions (Bromley \& Powell, 2012; Tilcsik, 2010).

However, in contrast to earlier depictions that decoupling has external legitimacy benefits, scholars have gone on to characterize decoupling between policy and practice, or symbolic adoption, as "a moral and operational failure" (Bromley and Powell, 2012: 498), especially when organizations have decoupled those structures that are externally imposed by important constituents, such as regulatory agencies, lawmakers or standards setting organizations (Deephouse \& Suchman, 2008; Wijen, 2014). Therefore, symbolic adoption is often perceived by audiences as "window dressing", as when corporations have ceremonially gained environmental certification but engage in widespread pollution practices (Carlos \& Lewis, 2017; Lyon \& Maxwell, 2011). MacLean and Behnam (2010) provide an example of such illegitimate decoupling between embedded and enacted values. In their study of widespread deceptive sales practices at a large financial services firm, the authors demonstrate how the organization decoupled its formal compliance program from core business activities to create a "legitimacy façade" towards key constituents. However, such decoupling eventually enabled the institutionalization of misconduct within the organization and, consequently, the loss of external legitimacy.

Although these studies attest to the pervasiveness of misalignment between embedded structures and their implementation in organizational activities, decoupling is not an inevitable response to institutional pressures that are in conflict with core goals. Indeed, studies have suggested how decoupling behavior is more likely when there is a lack of external monitoring and enforcement or when institutional norms, rules and laws are ambiguous (Edelman, 1992; Lehman \& Ramanujam, 2009). Importantly for our argument, the degree of decoupling is also influenced by the views, interests and values of powerful organizational members (Binder, 2007; Crilly et al., 2012; Westphal \& Zajac, 2001). What 
is implied in these studies is that the integration of multiple values-based identities, and thus shared values, may function as compensation for holding a decoupled system together and is likely to both resolve uncertainty and facilitate coordination among organizational insiders in soundly implement adopted policies and structures (Orton \& Weick, 1990).

In contrast, we suggest that a fractured organizational identity is likely to create normative fragmentation and weakened identification. Therefore, decoupling behavior is more likely when "adopted policies conflict with or are not central to the interests or beliefs of internal parties" (Bromley \& Powell, 2012: 496). Since internal power dynamics have been shown to be in important determinant in decoupling behavior (Boxenbaum \& Jonsson, 2017; Westphal \& Zajac, 2001), decoupling is more likely when powerful internal subgroups do not identify with a subset of espoused values. For example, Weaver and colleagues (1999) found that while corporations may experience external pressures for socially responsible business processes, formal corporate ethics programs may become decoupled from daily practices if there is a lack of management commitment. Similarly, in his study of a postCommunist government agency, Tilcsik (2010) observed that inconsistencies between the values embedded in formal structures and the values and ideological beliefs of powerful decision-makers about how the organization should be run may result in decoupling behavior. While leaders may embed values in formal structures, in the absence of shared values among organizational members then competing institutional pressures may result in decoupling behavior. Based on our theorization, we propose the following:

Proposition 5: When organizations face institutional pluralism and consequently hold multiple identities, the values represented in formal organizational processes and structures (formal embedding) are more likely to be decoupled from enacted values when powerful internal subgroups (informal embedding) only identify with a subset of espoused values, challenging a sustained commitment to organizational integrity

\subsection{Discussion and Conclusion}

\subsubsection{Toward a Theory of Organizational Integrity}

Practitioners and scholars alike increasingly reference the integrity of organizations. Extant research has highlighted the numerous positive outcomes for organizations when they follow-through on their values and commitments (Henderson, 2020; Mackey \& Sisodia, 2014). Purpose-driven organizations such as Unilever, DSM and Triodos Bank are admired and prized by their audiences for their ability to consistently put their embraced principles into practice despite changing organizational, regulatory, technological, and competitive circumstances. In contrast, recent integrity failures, such as Wells Fargo's cross-selling of fake accounts, the Volkswagen emission scandal, and the BP Deepwater Horizon oil spill, exemplified a glaring disregard of accepted ethical, regulatory and normative principles. Such violations of self-imposed commitments have been shown to 
damage reputations, harm employee morale, increase regulatory costs, and evoke investor divestment (Bundy et al., 2021; Paruchuri et al., 2021; Mishina et al., 2012).

However, there is still a lot of ambiguity and inconsistency surrounding how organizational integrity is conceptualized and used. Despite the social and economic costs of integrity failures (Connelly et al., 2016; Greve et al., 2010), organization and management theory have not developed in tandem with these transgressions as scholars have not yet taken up the meaning, determinants and processes of integrity in a unified and sustained way (cf. Dacin et al., 2002; Goodstein, 2015). In fact, scholars have viewed organizational integrity predominantly as the sum of members' ethical or unethical behavior, but have mostly ignored the fact that organizations have legal status as actors and possess distinct properties that make them behave semi-autonomously and independently from their individual members. Moreover, most studies on integrity have treated the organizational actor as isolated from its institutional context, while this increasingly complex and fast changing environment has been shown to create unique challenges for organizations and their ability to consistently adhere to their self-defining principles.

In this dissertation, we set out to pay renewed attention to the important concept of organizational integrity and, in doing so, proposed an institutional perspective. Specifically, we define integrity as the 'wholeness' of espoused, embedded, and enacted values. In our social actor approach to organizational analysis, we integrate the literature on values and identity to theorize on the complexities and challenges of organizational integrity. We have developed a theoretical model and a number of associated propositions that suggest the possible dynamics between competing institutional pressures and intra-organizational influences that may cause tension between the espoused, embedded and enacted values, and subsequently, threaten the integrity of organizations. Our article aims to make two primary contributions to our understand of integrity as it relates to existing scholarship on organizational values, organizational identity and institutional pluralism.

\subsubsection{Integrity of the Organizational Actor}

The topic of organizational integrity is key not only because it draws attention to questions about the overlap or gaps between organizations' espoused, embedded and enacted values, but also because this construct reflects scholars' growing interest in how organizations behave, function, mature and are evaluated as unique social actors in their own right (Bromley \& Sharkey, 2017; Greenwood et al., 2014; Halgin et al., 2018; King et al., 2010). As recent research has suggested, theories on organizational behavior tend to overemphasize the positive outcomes, neglecting the possibility that these same theories can also predict or explain cynical, undesirable or even immoral organizational behavior (Greve et al., 2010; Palmer, 2012). Our work addresses this research gap in organizational studies by spotlighting the potential negative outcomes of theoretical models and thus explores the "dark side of organizations" (MacLean \& Behnam, 2010: 1517). More specifically, by examining the integrity of organizational actors with the aid of the established literature on organizational values and identity (Gioia et al., 2013; Kraatz et al., 2020; Whetten \& 
Mackey, 2002), we were able to construct a more fine-grained framework for understanding the distinctive intra-organizational processes of organizational integrity.

First and foremost, as we theorize on the integrity of organizational actors, we answer the recent calls by organizational scholars to better "understand, explicate and research the enduring, noun-like qualities of organizations" (King et al., 2010). Scholars have suggested that building theory through anthropomorphizing-imbuing human characteristics, motivations and intentions to non-human entities-is a "critically important tool for developing influential theories in organization studies" (Shepherd \& Sutcliffe, 2015: 97; Ashforth et al., 2020). The bourgeoning literature on organizational identity (Albert \& Whetten, 1985; Gioia et al., 2013) and organizational memory (Anteby \& Molnár, 2012; Foroughi et al., 2020) attest to the usefulness of such approach in advancing our understanding of organizational phenomena. In our study, we began with surveying the existing literature on individual integrity to come to a basic understanding of its meaning, processes and challenges. In extending these assumptions to the organizational level, we propose a social actor conception of organizational integrity and put the organization at the center of our scientific and moral analysis.

The model we proposed resembles what has been termed behavioral integrity (i.e., the congruence between organizational talk and action)(Leroy et al., 2012; Palanski et al., 2012; Simons, 2002). We have taken this definition of integrity as our point of departure because integrity as consistency has received the most scholarly attention at the individual level (see Simons et al., 2015). However, an important contribution of our study is that we are also sensitive to some of the alternative meanings of integrity like wholeness and soundness. By incorporating the degree of fragmentation versus integration of organizations' multiple identities in our conceptualization of integrity (Besharov \& Brickson, 2016; Pratt \& Foreman, 2000), we highlight the importance of understanding how identity attributes (e.g. values, interests and beliefs) are actually embedded within formal and informal social structures of organizations. This sensitivity to intra-organizational processes is an answer the call for organizational theorists to "dig into the inner workings of organizations" (Greenwood et al., 2014: 1211). While lofty mission statements may accrue organizations legitimacy and status benefits, we believe that when leaders are unable to manage and integrate a fractured organizational identity, consistent organizational actions in congruence with espoused values is unlikely to achieved.

Moreover, because we asserted that organizational identities and values are in part institutionally derived, we are also attentive to the important moral component of integrity (Archer, 2017; Selznick, 1992). By building on the idea that organizations are capable of purposive, intentional and autonomous actions, the values-based commitments organizations adopt when they take on a new role identity imbues them with moral agency. That is, the institutionally derived identities that organizations adopt are not mere indicators of field membership. Since identities are profoundly value-based, the roles, responsibilities and obligations that organizations adopt and espouse are likely to create normative expectations (Mishina et al., 2012; Love \& Kraatz, 2009), whereas obvious departures from 
these moral duties are likely to be perceived by key constituents as failures of integrity end evoke extreme distrust and disengagement.

Although we have argued that organization-specific expectations surface as organizations engage in values espousal to secure legitimacy, such expectations are also shaped by an organization's historical pattern of previous actions and commitments. Indeed, organizational integrity is closely related to the notion of character, often understood as an organization's clear commitments and distinctive approaches to meeting those commitments (Cornelissen et al., 2020; Cuyper et al., 2020; King, 2015). Such organizational character tends to function as a normative backdrop, both 1) internally, as a selection and deliberation device for managerial behavior, and 2) externally, via audiences' assessment of an organization's actions. In juxtaposing these two concepts, Whetten (2006: 223) highlights the "logical interface between organizational integrity and the normative conception of organizational character" in that they both focus on the important historical frame of reference.

Importantly, constituents evaluate organizational actions as an indicator of the character of the organization. Consequently, when behaviors are profoundly inconsistent with an organization's history of past commitments and actions, audiences are likely to perceive the organization as lacking integrity and trustworthiness in its interaction with stakeholders, and they may come to question its character (Bundy et al., 2021; Park \& Rogan, 2019). Flagrant integrity failures that signal a dissonance between espoused, embedded and enacted organizational values have the potential to "blemish" the character of an organization (Connolly et al., 2016; Paruchuri et al., 2021: 565). Importantly, obvious dissonance between espoused and enacted values is likely to lead members to dissociate themselves from the tainted organization and no longer identify with its espoused values (Ashforth et al., 2008; Besharov, 2014; Elsbach \& Bhattacharya, 2001). Alternatively, we might reasonably expect that when members strongly oppose the values and mission of their organization, they may well respond by espousing the opposite values and beliefs. Some integrity failures have to potential to "create extreme uncertainty and distrust" (Paruchuri et al., 2021: 565) and force internal change agents to attempt to implement radical change.

\subsubsection{The Complexities of Organizational Integrity}

The very idea of integrity implies the 'wholeness' of values, desires and actions. However, organization are rarely unitary or tightly integrated entities, but rather consist of subgroups that hold competing needs, beliefs and interests. Although organizations increasingly portray themselves integrated wholes, they are simultaneously internally fragmented and imbued with inconsistencies and tensions as a result of competing institutional demands. This fact of modern organizational life, we believe, poses significant challenges for the maintenance of organizational integrity. The literature on institutional pluralism deepens our collective understanding of how internal tensions are manifested within the individual organization and how leaders may struggle with such normative fragmentation. Specifically, our conceptualization of integrity encompasses a tripartite of organizational 
values forms and highlights both the challenges of preserving their joint 'wholeness' and the implications if and when specific values hold primacy over others.

When we consider how organizational values systematically affect how organizations adapt to external stimuli (Bansal, 2003; Perkmann \& Spicer, 2014; Schilke, 2018), it becomes clear that their degree of embeddedness influences the nature of responsiveness to institutional pressures. Specifically, external demands to respond to environmental and social concerns, such as climate change, racial discrimination or gender inequality, are more likely to result in substantive actions when such demands are congruent with the principles already embedded in the organization's formal design and culture (Amis et al., 2002; Besharov \& Khurana, 2015; Hinings et al., 1996). In contrast, due to much of the ceremonial symbolism inherent in the espousal of values (Bromley \& Powell, 2012; Bourne et al., 2019), we expect that these are less likely to predict organizational responses to institutional pressures than are the values embedded in a integrated organizational identity. For instance, organizations that define themselves as committed to making "sustainable living commonplace" are likely to be organized, act and respond to external pressures differently than those that present themselves as aiming to be "the most profitable".

Alternatively, when the values held by top management or among powerful internal subgroups advocate interests or goals that are diametrically opposed to external pressures in relation to a specific social concern, these "values may serve as anchors that bind the entity to its past and prevent needed change from occurring" (Kraatz et al., 2020: 500). In other words, profound changes in normative standards or governmental regulations that are incongruent with core organizational goals are likely to elicit a great deal of resistance and symbolic responsiveness (Bromley \& Powell, 2012; Huy et al., 2014; Oliver, 1991). For instance, U.S. and European banking regulators are increasingly demanding compliance with anti-financial crime prevention requirements. Recent studies show that major financial firms are required to spend about $€ 1$ billion per annum on financial crime operations, with offending firms having to pay a staggering $€ 28$ billion since 2008 in fines in relation to money laundering and sanctions violations (Leopold et al., 2020). However, even after they were prosecuted or fined for their wrongdoing, banks such as JPMorgan Chase, HSBC, Standard Chartered, and Deutsche Bank continued to tacitly facilitate money laundering. Although this phenomenon of repeat corporate offending indicates profound disconnects between, on the one hand, institutional norms and rules, and on the other hand, the values embedded within organizational boundaries, our model suggests that the leaders of these financial conglomerates have been unable to integrate their organizations' multiple valuebased identities and associated duties.

Finally, our model suggests that when internal groups do not identify with or share the values that leadership has espoused for the organization, the sustained commitment to organizational integrity is at risk. This problem will be particularly salient when organizational subgroups are distanced from the corporate center, challenging direct steering or control, and holding values flowing from to their local cultures but that differ significantly from the values espoused by the organizational collective (Bourne et al., 2019; 
Hofstede, 1998). For instance, as organizations increasingly operate cross-border, cultural distance between subunits, functions and divisions and the corporate center has increased dramatically. Similarly, the growth or expansion of organizations through corporate acquisitions or mergers may result in the situation in which the acquired members hold radically different values than those espoused for the organization as a whole. This does mean that, by default, all multinationals will experience integrity failures. However, when leadership is reluctant or unable to integrate multiple identities into a coherent whole, members will not be guided, oriented, and unified to engage in collective action, nor have the means to interpret and prioritize institutional pressures that are inconstant with espoused values (Besharov \& Brickson, 2016; Dutton \& Dukerich, 1991; Greenwood et al., 2011).

Also, our conceptual study focusses attention on potential strategic efforts to implement opaque disconnects. As such, local organizational practices in a host country, while potentially legitimate in that country's particular culture, may be dissonant with what the organization professes to stand for as a whole. For instance, while Royal Dutch Shell's bribery payments in Nigeria were normalized and accepted business practice in the host country and aligned with embedded values of Shell's foreign subsidiaries, they were incongruent with Shell's proclaimed General Business Principles. In a similar vein, although Dutch beer brewing conglomerate Heineken has a tendency to present itself as having achieved remarkable feats in the area of corporate social responsibility, recent revelations of sexual harassment and low pay at its breweries in Africa have demonstrated the obvious dissonance between corporate talk and strategic choices (Van Beemen, 2018). Within our model, such actions to credibility dissociate the enacted and embedded values from espoused values is likely to reduce disproval by audiences. Scholars have asserted that such transference of socially irresponsible practices from its headquarters to its overseas subsidiaries, where the degree of institutional enforcement and sanctions for noncompliance is low, constitute strategic efforts to create plausible deniability for senior managers (Crilly et al., 2012; Surroca et al., 2013). 



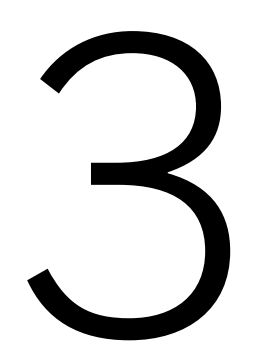

\section{Settle Down or the Struggle Within: Exploring Character and Corporate Responsibility in Two Financial Enterprises}

\subsection{Introduction}

Scholarly interest in how organizations function as social actors is growing (Bromley \& Sharkey, 2017; Halgin et al., 2018). Viewing organizations as social actors emphasizes their capacity for responsibility, collective intentionality and purposive action (King et al., 2010; Lawrence \& Phillips, 2019). In this vein, when organizations develop a conception of self, they take on a unique set of commitments and core values, and form a "distinctive unity and character" (Selznick, 2008, p. 59). This "historically accreted character" (Kraatz et al., 2010, p. 1529) is the result of critical and identity-defining moments in the organization's life course and emerges from "a collective process of negotiation, compromise, and conflict over values and beliefs" (King, 2015, p. 166). Research has shown that this moral character functions as the normative backdrop for organizational decision-making (Sasaki et al., 2019; Steele \& King, 2011) and the evaluation of organizational conduct by outside actors (Mishina et al., 2012; Park \& Rogan, 2019).

Pervious versions of this chapter were presented at the 35th EGOS Colloquium, July 4-6, 2019 in Edinburgh, Scotland, and at the 80th Annual Meeting of the Academy of Management, August 7-11, 2020. 
As organizations adopt and diffuse normative commitments within their boundaries, for instance, concerning corporate responsibility (McWilliams \& Siegel, 2001), sustainability (Kok et al., 2019), and business ethics (Chandler, 2015), their moral character becomes increasingly solidified and irreversible (Kraatz \& Flores, 2015; Selznick, 1957). However, at the same time, even though they portray themselves as coherent actors with discernable characters (Bromley \& Sharkey, 2017; Pratt \& Kraatz, 2009), in practice organizations pursue goals that may conflict with their normative commitments. Consequently, scholars characterize the inner life of modern organizational actors by a great many internal complexities and inconsistencies, sometimes involving conflict (Fiol et al., 2009; Glynn, 2000) and sometimes simple decoupling and hypocrisy (Bromley \& Powell, 2012; Brunsson, 1989). These conditions heighten the risk that actions become perceived as being at odds with historically accreted commitments, and thus, as out-of-character acts (Love \& Kraatz, 2009; Mishina et al., 2012). Therefore, research has emphasized the importance of building adopted commitments into the social fabric of the organization through, for instance, the articulation and routinization of core values (Tsoukas, 2018), the preservation of valued organizational imprints over time (Cuyper et al., 2020) and collective experimentation with and integration of a hybrid organizational identity (Cornelissen et al., 2020).

Although resembling the "social actor conception of organizational identity" (Whetten \& Mackey, 2002, p. 394), organizational character has received far less empirical attention despite being a striking example of theory that emphasizes how collective commitments made by an organization over its life course reinforces particular practices and routines (Birnholtz et al., 2007; Cohen, 2007). Moreover, given their socially embedded nature, organizations build character as they respond to issues that emanate from their institutional environment. However, a key-yet undertheorized-problem is that these commitments are transmitted downwards in organizations that are supposed to behave as coherent social entities. Given the multiplicity of commitments that organizations make and challenges that creates, it is critical to understand the process of character development as organization adopt normative commitments.

We aim to build theory that allows us to better understand the development process of character when organizations adopt commitments to corporate responsibility, defined as "actions that appear to further some social good, beyond the interests of the firm and that which is required by law" (McWilliams \& Siegel, 2001, p. 117). To provide a more finegrained understanding of this process, we explore the intra-organizational arrangements and processes as organizations adopt new commitments (Ashforth \& Reingen, 2014; Smith \& Besharov, 2019). Our case organizations are two financial firms that have undergone considerable change following the 2007-2008 global financial crisis. Although both firms have fallen under public ownership due to profound operational and financial challenge, both have become increasingly committed to corporate responsibility. We conducted in-depth interviews with executives, senior managers and policymakers to address the following research question: How does the character of organization develop when they adopt and diffuse corporate responsibility commitments? 
This paper will make the following contributions. First, we put the organization at the center of our scientific analysis, as we currently lack holistic accounts of how organizations are structured, managed and behave as distinctive social actors. To achieve this goal, we pay renewed attention to the notion of organizational character. We believe that an empirical endeavor to better understand this concept and its underlying mechanisms is essential because organizational character as a unified, cross-disciplinary research subject is only beginning to come of age (Cornelissen et al., 2020; Cuyper et al., 2020; King, 2015). Second, our paper contributes to the "performative understanding of values" (Daskalaki et al., 2018: 1742) both within and surrounding organizations (Besharov, 2014; Gehman et al., 2013). By integrating this normative dimension in our conceptualization of organizational character by investigating the diffusion of corporate responsibility practices, we respond to calls (Heugens \& Scherer, 2010; Lawrence et al., 2013) for organizational research to engage beyond the academic community and connect to practical concerns so that such research would be expected to increase in practical relevance in addressing grand challenges.

\subsection{Theoretical Background: Organizational Identity and Character}

Organizational scholars increasingly treat organizations as distinctive and sovereign social entities capable of purposive and intentional action (Bromley \& Sharkey, 2017; King et al., 2010). This status as social actors enables organizations "to behave in a cohesive, self-referential manner, while also giving them tremendous political, economic and social influence and responsibility" (King, 2015, p. 150). As a result, scholars have started to study the conditions under which organizational actors possess agency (Battilana, 2006) and, in doing so, have singled out organizational identity (Whetten, 2006) and organizational character (King, 2015) as the sources of such actorhood (Bromley \& Sharkey, 2017).

Scholars who have taken the social actor conceptualization of identity have characterized organizations as unique social entities with historically accreted personalities and enduring identity attributes (Gioia et al., 2013; King et al., 2010; Whetten, 2006), including, for instance, their collective goals, values, beliefs and traits. Specifically, Haslam and colleagues (2017) define the social actor perspective of organizational identity as referring to "a set of external legitimizing claims and behavioral commitments which are path-dependent and binding, and in this way provide the organization with central, enduring and distinctive characteristics" (p. 324).

The social actor view of identity holds that organizations have some degree of historical continuity, both with regards to identity stability over time and as regarding the alignment between such collective identity, and its associated normative commitments, and its strategies and actions (King et al., 2010). As such, obvious disconnects between identity and organizational conduct may be perceived by audiences as violating the expectations 
that emerge from identity characteristics and are thus evaluated as inauthentic behavior (Grimes et al., 2018). As an organization's identity outlines the collective goals and values of an organization (Haslam et al., 2017), its content is important because it offers a blueprint for managerial decision-making (Steele \& King, 2011). More recently, scholars have begun to treat organizational identity as a filter that shapes how organizational leaders and members perceive, interpret, and respond to competing institutional demands (Glynn, 2008) and functions as a 'sensemaking device' through which to evaluate the relevance and appropriateness of organizational actions (Greenwood et al., 2011).

Resembling the social actor conceptualization of identity is Selznick's notion of organizational character. According to Selznick (1957), organizations become institutions as they become infused with values, commonly understood as "human beliefs about the things that are worth having, doing, and being" (Kraatz \& Flores, 2015, p. 356). As these organizational institutions accept long-term commitments, defined as "choices which fix the assumptions as to the nature of the enterprise, its distinctive aims, methods, and role in the community" (Selznick, 1957, p. 55), a distinctive organizational character starts to be formed.

These commitments, whether in the form of actions, public statements or both, represent an organization's deeply held beliefs and values and the irreversible choices it makes over time (Sasaki et al., 2019). More specifically, they reveal the enduring and essential properties of an organization, which guide members' actions and inform the external evaluations of the appropriateness of organizational conduct (King, 2015; March \& Olsen, 2004). Although some commitments, such a as statement of purpose, ethical codes, or explicit identity statements (Ybema, 2010) may only symbolically reflect the intended character of an organization in order to foster legitimacy in the eyes of important stakeholders, they create expectations for audiences and reinforce existing expectations about the organization's being and its actions (Love \& Kraatz, 2009; Mishina et al., 2012; Park \& Rogan, 2019).

The social processes that generate irreversible commitments, including the organization's unique history, moments of conflicts and compromise, and values articulation work performed by its leaders (Gehman et al., 2013; Tsoukas, 2018), shape the character of an organization. Once these commitments are integrated in taken-for-granted routines and practices, character shapes particular ways of acting (Narduzzo et al., 2000) and organizational responses to an organization's external environment (Tsoukas, 2018), thus promoting behavioral consistency over time (Birnholtz et al., 2007; Lockwood, 2013). As commitments "represent the way through which values are actually built in the social structure of the organization", their adoption tends to function as character-defining moments in an organization's life course (Selznick, 1957, p. 56). The commitments that have organizations embraced are therefore a "mixed blessing" (Kraatz \& Flores, 2015, p. 358) as they "crystallize [organizational] purpose and keep the organization on track, avoiding potential drifts, but narrowing down future paths" (Sasaki et al., 2019, p. 5). 
Similarly to the social actor conceptualization of identity, underlying the concept of organizational character is the assumption that organizations are motivated to take action by internal self-reflection (Steele \& King, 2011). Groups and individuals within the organization that want to promote their values and interests must seek to do so in a way that aligns these values with the broader character of the organization. Thus, organizational character tends to function as a focal point around which leaders and members carry out their work, resolve conflicts and tensions, and respond to institutional demands (King, 2015). Consistent with the social actor conception of organizational identity, character influences internal coherence by creating a "strong context that heavily anchors group deliberation, shapes the framing of individuals' expression of their own interests, and provides for the framework for goal setting and strategic decision-making" (Steele \& King, 2011, p. 65).

\subsection{Research Context and Method}

\subsubsection{Case Overview}

Our exploration of the process of character development is grounded in a qualitative, inductive approach that is well suited for developing new theory (Van Maanen, 2011). A qualitative, inductive approach was suitable because our goal was to build theory about a phenomenon-organizational character development-that is currently not well explained by the existing literature. To develop a rich understanding of the intra-organizational processes of character development, we employed a multiple case-study design (Yin, 1994). This design is common in studies that require in-depth data collection. We conducted case studies at two financial firms, "FinanceCo" and "CapitalGroup" (pseudonyms). Both organizations underwent considerable change leading up to and following the 2007-2008 global financial crisis, notably, being brought into public ownership and large-scale corporate restructuring. Additionally, FinanceCo and CapitalGroup have increasingly presented themselves to the outside world as socially responsible alternatives to their competitors. Each firm has over 3.000 employees, had a balance sheet figure of over $€ 55$ billion in 2017 and offer a wide range of financial products to both companies and individuals, with FinanceCo focusing on retail banking and CapitalGroup on insurance activities. Although FinanceCo was still government-owned at the time of data collection, CapitalGroup was recently fully moved back into the private sector.

\subsubsection{Data Collection}

Within our cases, we used a qualitative research design. The lead author conducted in-depth interviews with the top management members, including executives, directors, senior managers and policymakers, over a 7-month period. Interviewees were selected based on purposive criteria (Miles \& Huberman, 1994) related to their role in both construing the 
external image of the firm and implementing associated practices within organizational boundaries. We identified relevant informants during preliminary interviews with the CEOs both of FinanceCo and CapitalGroup, especially senior management as they can be considered "key carriers of organizational actorhood" (Bromley \& Sharkey, 2017, p. 24), representing the larger collective and enacting the strategic posture of their organization (Pratt \& Kraatz, 2009). As our data collection and analysis unfolded, and to extend our sample of relevant informants beyond those identified by the CEO's in the preliminary interviews, we used theoretical sampling to gain additional information (Glaser \& Strauss, 1967).

In total, 31 organizational members were interviewed. After the first round of these semi-structured interviews and after reaching provisional conclusions, 21 informants were approached for a second interview to elaborate on the preliminary findings. The interviews ranged between 60 and 90 minutes in length. Most were recorded and subsequently transcribed verbatim. Table 3.1 contains an overview of the interview data. Interview questions broadly focused on the organizational members' roles in their respective organizations and questions about each organization's history, commitments, strategies, and practices. However, our focus changed somewhat as we analyzed our data and we added questions regarding dilemmas and conflicts, and individual and organizational responses to the inevitable tensions.

\subsubsection{Data Analysis}

We used a grounded theory approach for our data analysis (Charmaz, 2006; Glaser \& Strauss, 1967). Following the main principles of this approach, we began our analysis as we collected the data, iterating between our individual interpretation of the data, emerging theoretical arguments and the literature in order to theoretical ground our emerging findings (Glaser \& Strauss, 1967; Strauss \& Corbin, 1998). This analysis consisted of three distinct steps (Gioia et al., 2013). We categorized our raw data into empirical firstorder concepts, abstracted and grouped these empirical concepts into conceptual secondorder themes, and finally, categorized these conceptual themes in aggregated dimensions. These conceptual categories formed the building blocks for our theoretical framework that explains the process of organizational character development. Figure 3.1 shows the data structure that contains these three steps. Throughout the analysis process, we used Atlas.ti research software to group, categorize, compare and contrast our codes. Below, we describe our steps in detail.

First, we sought to develop first-order codes that describe the emergent empirical topics, process, ideas and actions we found in our data. As we went through the textual materials, we were conscious to use the terminology that was used by our informants, because our aim was to stay as close to the empirical data as possible (Strauss \& Corbin, 1998). As overarching clusters of codes surfaced, we compared those within and across the interview transcripts. Once a stable set of codes had surfaced, we went back through all relevant passages of the transcripts to see if they fitted the themes. We repeated this process of 
Table 3.1 Overview of Interview Data FinanceCo and CapitalGroup

\begin{tabular}{|c|c|c|c|}
\hline Informant & Organization & Position & \# Interviews \\
\hline D1 & FinanceCo & Director & 1 \\
\hline D2 & FinanceCo & Supervisory Board Member & 1 \\
\hline D3 & FinanceCo & Chief Executive Officer & 1 \\
\hline D4 & FinanceCo & Senior Manager & 2 \\
\hline D5 & FinanceCo & Chief Operation Officer & 2 \\
\hline D6 & FinanceCo & Brand Director & 2 \\
\hline D7 & FinanceCo & Brand Director & 3 \\
\hline D8 & FinanceCo & Brand Director & 2 \\
\hline D9 & FinanceCo & Senior Manager & 1 \\
\hline D10 & FinanceCo & Director & 1 \\
\hline D11 & FinanceCo & Director Balance Sheet Management & 1 \\
\hline D12 & FinanceCo & Director Financial Markets & 2 \\
\hline D13 & FinanceCo & Tax Manager & 2 \\
\hline D14 & FinanceCo & General Counsel & 2 \\
\hline D15 & FinanceCo & Director Audit & 1 \\
\hline I1 & CapitalGroup & Chief Executive Officer & 2 \\
\hline $\mathrm{I} 2$ & CapitalGroup & Director Audit & 3 \\
\hline I3 & CapitalGroup & Corporate Secretary & 1 \\
\hline I4 & CapitalGroup & Chief Risk Officer & 2 \\
\hline I5 & CapitalGroup & Chief Financial Officer & 2 \\
\hline I6 & CapitalGroup & Supervisory Board Member & 2 \\
\hline I7 & CapitalGroup & Brand Director & 3 \\
\hline I8 & CapitalGroup & Senior Manager & 2 \\
\hline I9 & CapitalGroup & Director Sustainability & 1 \\
\hline I10 & CapitalGroup & Brand Director & 1 \\
\hline I11 & CapitalGroup & Director & 1 \\
\hline I12 & CapitalGroup & Brand Director & 1 \\
\hline I13 & CapitalGroup & Brand Director & 2 \\
\hline I14 & CapitalGroup & Senior Manager & 2 \\
\hline I15 & CapitalGroup & Senior Portfolio Manager & 1 \\
\hline
\end{tabular}

relaying and comparing our first-order codes with our empirical material, relabeling and merging codes in the process, until we reached saturation of first-order codes (Glaser \& Strauss, 1967).

Second, we engaged in "axial coding" (Gioia et al., 2013; Strauss \& Corbin, 1998), in which we searched for commonalities and connections between and among the categories of first-order codes. By doing so, we assembled our empirical categories into more abstract second-order themes. As we iterated between our empirical codes and the identity and character literature, we were able to construct increasingly theoretically well-grounded concepts.

Finally, we began to cluster these theoretically informed second-order themes in overarching aggregate dimensions. During this stage, we attempted to conceptualize the 
emerging theoretical themes and reconnect them to previous literature on organizational identity and character. These aggregate dimensions formed the base of our empirically grounded model that represents the process through which organizational character develops.

\subsection{Findings}

In the following section we briefly present our findings structured around the four aggregated themes we abstracted from our cases, as shown in Figure 3.1: (1) stretching, (2) struggling, (3) stabilizing, and (4) settling. These four main dimensions will form the input for our theoretical model of character development.

\subsubsection{Stretching}

As organizations mature and respond to challenges and opportunities in their environment, they become committed to a particular set of values and refine a desired future image. By stretching we refer to the antecedents through which an organization's external image is formed and becomes manifested in an organization-specific purpose and associated commitments. Below, we set out three specific themes relating to how organizational stretch characterized our informants' experiences.

Problematic past evokes commitments. Highly relevant for organizational identity and commitments was an organization's history. Specifically, the organizations' problematic past (if any) affected the way the organization matured and evoked commitments. This reflective sense of temporality arose from the collective realization for the need for selfreferential meaning creation after major critical events and past experiences, including systemic mismanagement or misconduct before an during the 2008-2009 global financial crisis. Specifically, these salient events led leadership to make commitments to societal values that began to define the character of their organization.

FinanceCo was nationalized as a result of large-scale fraud and mismanagement in one of its subsidiaries. When we talked about this episode in the company's history, a majority of our informants indicated how they experienced nationalization as a "wake-up call" (D6), which brought with it a "sense of tranquility" (D5). Reflecting on the nationalization of FinanceCo, a subsidiary director explained: "Ultimately, when we got nationalized, we had a sense of shame, especially towards our customers-But I also saw a certain solidarity arise. Apparently, we needed a kind of urgency that made us start thinking about these kinds of existential questions" (D7). Another subsidiary director who had been working at FinanceCo for over 20 years, and who experienced both the IPO of the organization and its later nationalization first-hand, summarized the way these had affected the organization: 

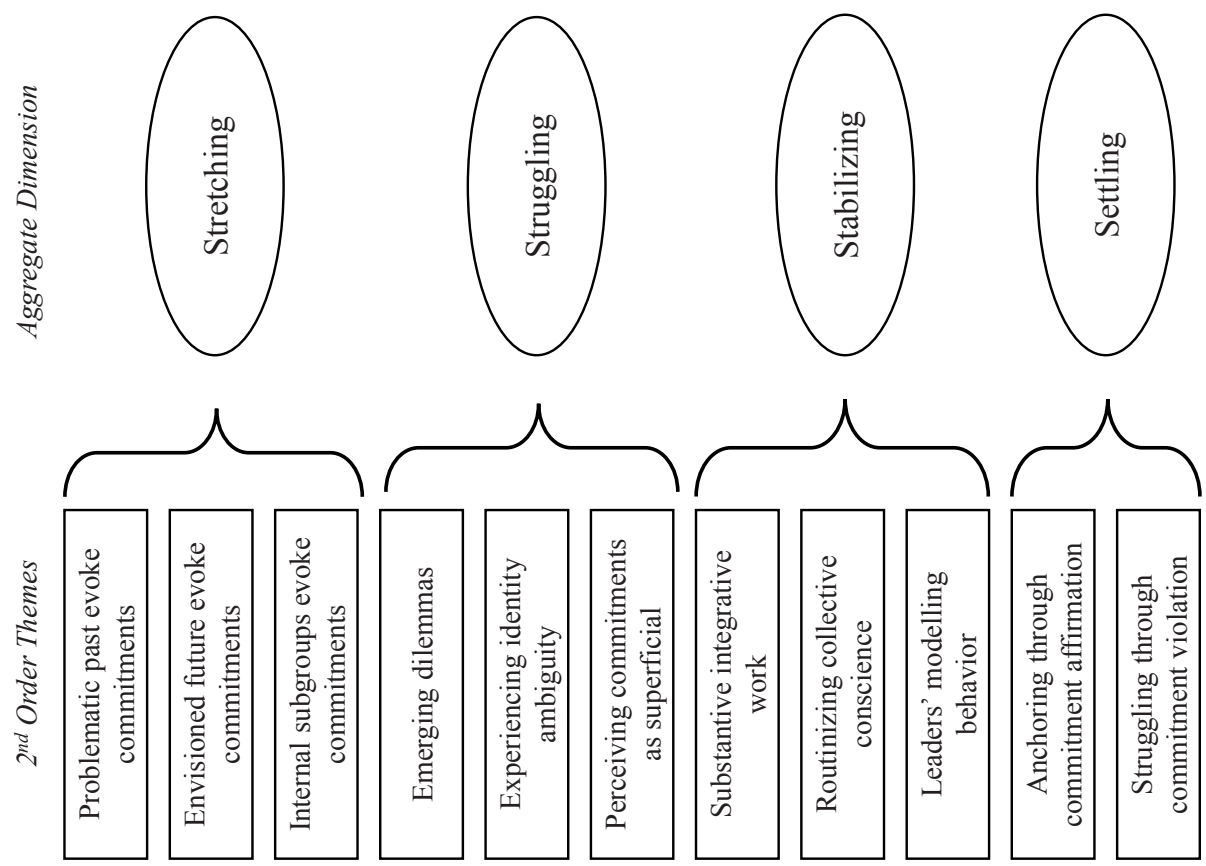


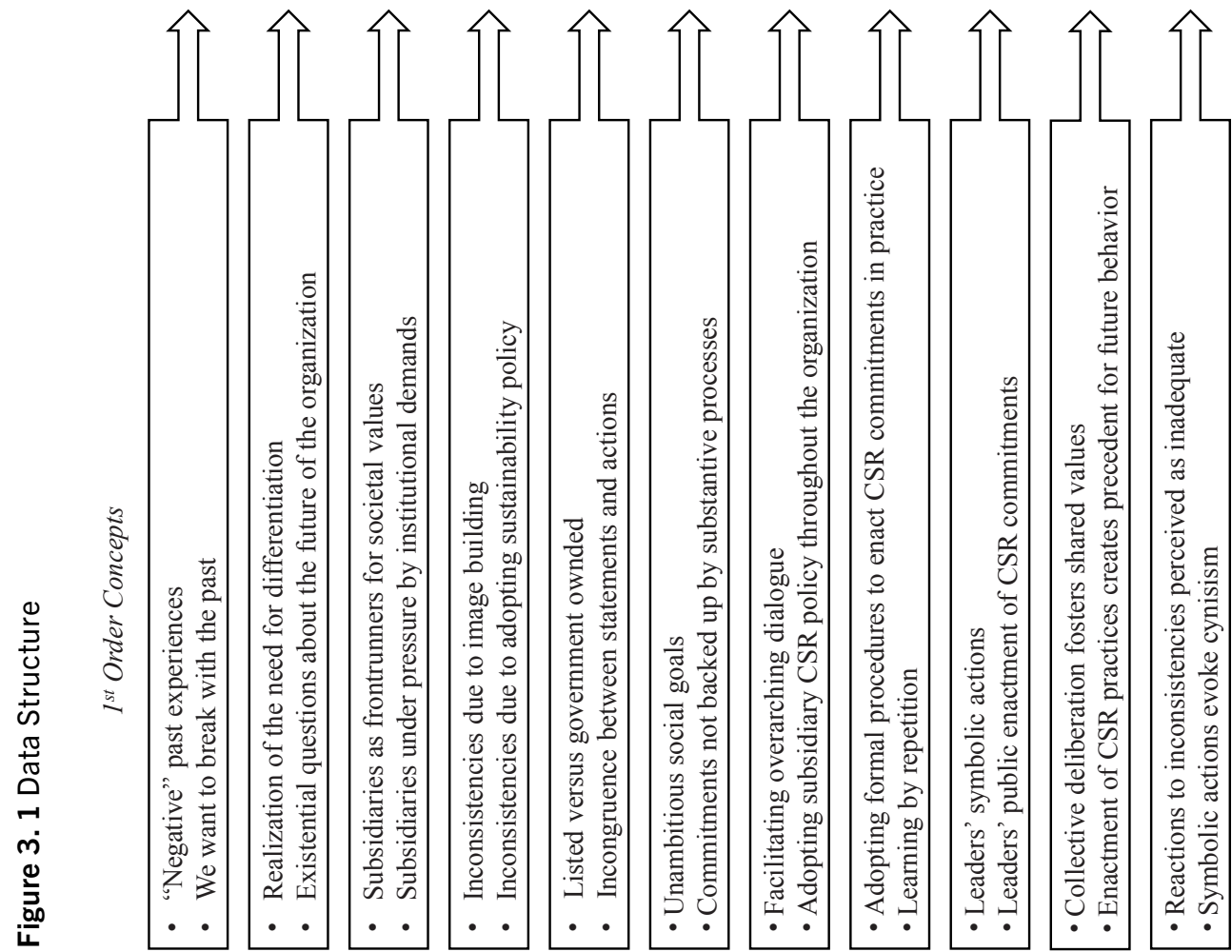
With the IPO we took a wrong turn. And now we are trying to get back on the road from which we came. And that's why I'm still here ... Because if I hadn't felt comfortable with the movement back, I would have left. But I like to help with the resuscitation-that's how I saw it ... I've always believed in those old values of the bank ... They are now becoming very explicit. Where they were very implicit in the company before the IPO, they are now being made much more explicit. That's our manifesto commitment to 'banking with a human touch' (D8)

Our informants shared the belief that while FinanceCo's societal values were dormant and obfuscated by market pressures before the nationalization, falling into state hands had made the leadership team decide to embed them in its organizational purpose and its new strategic direction. FinanceCo's manifesto was introduced because of the perceived importance for providing an answer to the question "what is the reason of our existence?" (D3). Reflecting on the process of making such societal values more explicit, internally through 'sensegiving' by organizational leadership and externally through significant branding efforts, the CEO emphasized that "there is a big difference between a marketing trick and our manifesto, or 'banking with a human touch', because we actually started to describe the latent values and behavior which were already in the organization ... looking back over the years-and that has resulted in 'this is who we are" (D3).

For CapitalGroup, a similar process unfolded as the organization was nationalized before to the financial crisis due to several failed acquisitions by its parent company. The company's asset management director recalled that this event had triggered a period of selfreflection: "Slowly but surely in 2007 we went into the financial crisis. Our parent company was a kind of company that said, 'let the balance sheet sweat', and they went down hardWe've learned from that ... We started to acknowledge that we had a social role to play, because this just wasn't right" (I11). In an attempt to differentiate CapitalGroup as a socially responsible financial firm, the leadership team decided to initiate a significant branding effort that signaled a clear break from the past. Elaborating on this, the corporate website states that "CapitalGroup's raison d'être is to help people by doing. If we do that right, we'll have a healthy future".

Envisioned future evokes commitments. An additional and complementary manifestation of temporality arose from the collective realization of the need for differentiation. FinanceCo's problematic past led to existential questions about the future of the organization and its existing practices and structures. This existential void caused the company to forgo practices that were previously deemed questionable. For FinanceCo this meant renouncing all forms of variable-pay and a focus on a range of simple and lowrisk financial products and services, mainly savings and mortgages, but also an overall strategic overhaul in the direction of a more socially-driven organization. Although our informants reflected on this mantra as echoing the underlying identity of the organization, it also functioned as a significant branding effort to differentiate the organization from its competitors. As our informants acknowledged, this need for differentiation in the current corporate landscape was one of the motivations for FinanceCo's strategic direction. This 
perceived urgent need for differentiation was heavily rooted in comparison with its peer financial firms and a perceived need to be significantly different in order to stay commercially viable. Consider the director of the financial markets department, who explained the new direction FinanceCo had taken:

... we were nationalized for reason. We also need have a raison d'être, a right to exist, a reason for being. It makes no sense to be a second Bank X. With regards to deposits, small SME loans and mortgages-Bank X does that, so does Bank Y, so does Bank Z ... We had to go in a different direction, so we started looking how we could differentiate ourselves from our competitors (D12)

During our conversation with the CEO of CapitalGroup about the company's branding efforts, he claimed that, "we started that campaign because we thinkit's right and responsible. It's also a way to differentiate ourselves" (I1). Most of our informants expressed their belief that these branding efforts had a strong intrinsic strength, reflecting CapitalGroup's identity and societal values as being "that other insurer" (I2), differentiating it from bigger competitors. Others also acknowledged that these branding efforts represented an effort to actively manage impressions, directly for external audiences and indirectly for insiders. CapitalGroup's commitments to corporate responsibility, centered around the responsible investment strategy of its investment branch, articulated and externally expressed through its marketing campaigns, focusing strongly on not serving specific industries that are perceived as harmful, such as modern armament manufacturers, tobacco, child labor and nuclear energy.

Internal subgroups evoke commitments. A recurring theme in our conversations was the influence of specific internal subgroups as frontrunners to address, propagate and integrate societal values throughout the organization. We found that the asset management departments at both our cases fulfilled such a function. As these subsidiaries were commercially successful, institutional pressures to adopt responsible investment practices increased and as top management recognized their distinctive capabilities, these subsidiaries were provided with autonomy, more resources, and buy-in from the leadership team to develop. Over time, the societal values underlying the subgroup identities of these subsidiaries permeated throughout the rest of the organizations.

One specific way how stretch was reflected in FinanceCo's purpose and structure can be traced back to the initiation of 'Project Together', in which the company went from holding four separate banking licenses to one. In particular, the SocioBank subsidiary functioned as a frontrunner for social and environmental sustainability. One subsidiary director recalled how the social values of SocioBank concerning responsible investment became increasingly embedded throughout the whole organization since the initiation of 'Project Together'. As FinanceCo started to realize the potential of these social values and sustainability principles, both commercially and as a way to differentiate the organization from its competitors, the former director of SocioBank recalled how the company saw the relevance and importance of its 'responsible and sustainable' subsidiary in the aftermath of nationalization: 
Things did not go well at FinanceCo. And then what I saw was that there was increasing interest in the principles that we applied. And it became increasingly clear that it was not just about where the money from SocioBank customers should be invested-Our leadership was also very much interested in how we dealt with our stakeholders, how we dealt with employees, how we dealt with customers, and of course most importantly, how we dealt with our environment (D5)

In a similar vein, one pervasive narrative was CapitalGroup's stance on corporate responsibility represented in accounts of its environmental and social activities both internally, communicating with its own employees, and external, in the local community. CapitalGroup's asset management department has had a major influence on the company's commitments regarding responsible investment. CapitalGroup's leadership team eventually saw the commercial need to significantly includes these in their branding efforts and marketing campaigns.

\subsubsection{Struggling}

Above we set out to describe how organization's external image is formed and becomes manifested in an organizational purpose and associated commitments, often as a result of a problematic past and an envisioned future, and often pressure from internal subgroups. However, as these commitments became increasingly explicit, managers began to experience struggles. Below, we set out the specific themes relating to the struggle between the external representation and its self-conception characterized our informants' experiences

Emerging dilemmas. As our case organizations became committed to new sets of societal values, certain dilemmas emerged between the external construed image and their self-views. A senior manager summarized this sense of incongruency by acknowledging, "CapitalGroup is positioning itself as a social and sustainable company ... and as we move in that direction, more and more dilemmas arise, and they become more complex-actually, we are only now starting to recognize that there is a contradiction between what we say and who we are and what we actually do" (I8). Perhaps the strongest and most intractable set of dilemmas expressed in our interviews were those concerning the company's customer onboarding practices. CapitalGroup's responsible investment commitments, articulated and externally expressed through its branding efforts, focus strongly on the exclusion of specific companies and industries seen as harmful from its investment portfolio. However, as the company began to move into new industries, its insurance branch was increasingly offered contracts from firms that were excluded from its investment portfolio. CapitalGroup's CRO summarizes this predicament as follows:

We don't invest in tobacco, but does that also mean that we don't offer people who work there, who are employees in the tobacco industry, a retirement plan? Or that we do not insure them against incapacity for work? If we do that, we will receive premium, and what happens with that money? That is invested-So, although we do not invest directly in the tobacco industry, we do invest money from the tobacco industry (I5) 
Furthermore, because of its status as being a state-owned company, CapitalGroup was unable to significantly raise the pay of its executives. However, as the government sold its remaining shares following the company's recent IPO, pressures from its shareholders regarding executive compensatio, began to grow. This made apparent the obvious contrasts between stakeholders' demands. Although the company's mainly 'Anglo-Saxon' shareholder base demanded increased financial alignment of the executive board, CapitalGroup remained a local organization with an exclusively national customer base, operating in an environment with tough rules on pay and in which all sorts of bonus structures for executives are increasingly seen as irresponsible. The CFO of CapitalGroup explained the tension between values:

Our shareholders expect financial alignment. They can't imagine we are doing this work if we can't get very rich-“Why on earth would you do that?" And that's a deeprooted cultural difference that you will never resolve completely (I5)

At FinanceCo, the company adopted the CSR principles of SocioBank, by many of our informants considered the frontrunner for social and environmental practices, into its common purpose. This adoption led to a range of challenges within other departments as the newly adopted commitments did not always match with FinanceCo's goals. For instance, FinanceCo's financial markets department still had various financial instruments in certain financial institutions and countries that did not fit within the CSR policy of SocioBank, including U.S. ("they still administer the death penalty", D7) and Japanese ("their government have not signed the treaty again the fabrication of cluster bombs", D12) government bonds.

Experiencing identity ambiguity. We found that the severity of the emerging dilemmas was largely determined by the degree of identity ambiguity experienced within the organizations. Within FinanceCo there was a strong degree of identity clarity. This was reflected in the similarity of statements made about the convictions of the bank, including 'we are a simple bank', 'we are different', 'we are improving the diversity of [our national] banking sector' and 'we want to change the way of banking. These articulations of 'who we are' as organization were present throughout the various subsidiaries and subunits of FinanceCo, indicating a distinct and collective sense where the organization stood for and what actions would reflect that identity. However, subtle struggles over the organization's identity remained, particularly within the financial departments, as these had to keep the organization commercially viable while also accepting the new social image projected by the executive board.

In contrast, as CapitalGroup started to actively position itself as a responsible insurer by means of comprehensive branding efforts, employees started to experience a rising sense of ambiguity in relation to the company's identity. As we conducted our interviews, we began to notice subtle tensions between multiple views about 'who the organization is' and 'what the organization stands for', especially as the result of a visible incongruence between how the organization presented itself and its actual practices. Illustrative of this ambiguity 
of CapitalGroup's identity were the antithetical views of the $\mathrm{CEO}$ and the $\mathrm{CFO}$ regarding the company's social commitments. While the CEO strongly believed that societal and commercial values were mutually reinforcing, CapitalGroup's CFO was more skeptical, stating, "We are still a commercial company ... Our goal is just to make money, and it is not our goal to make society better" (I5). Consider an example given by the CFO regarding CapitalGroup's decision to introduce CSR targets within the organization:

We have given our employees CSR targets. [Our CEO] thinks it's very important. And I don't really think that is our goal ... I like the signal, but we are a commercial companyMy point is: then what? What kind of targets? Everyone has to do it, but some people fill in something nonsensical. My target is to encourage socially responsible investing. That's in my portfolio. I drive a Land Rover. And my COO fills in that he drives a more fuel-efficient car than his boss ... he has certainly achieved his goal (I5)

These underlying tensions became even more apparent in our conversations with our informants when we discussed CapitalGroup's projected external image regarding its responsible investment policy and its customer onboarding practices. As a senior audit manager noted:

On the one hand, we are the type of company that says: "we do not invest in the weapons industry but in the pharmaceutical industry" ... That's what we commit to publicly. But we do not make it more concrete in the sense that we don't sign contracts with Shell, or with Thomas Industries, or with parts of Siemens, one of the largest arms suppliers in Europe. And there may be some inconsistency in that (I2)

Moreover, we found that identity ambiguity increased as a result of an increased pressure on organizational growth following the company's IPO. Consider an example given by a senior manager, the director of the retirement subsidiary of CapitalGroup, about the growth of her business unit and the opportunities she is given as a result of the growth of her business unit:

We are getting opportunities from large companies, we are growing so we are more involved ... with big deals. In my business unit, because we are growing so much, we are given a lot of opportunities-Tobacco and weapons may still be a bit trivial, but there is also a whole group which are not excluded by our investors, but still doesn't feel quite right. But if we can make money out of it ... as a pension company we're not one of the biggest, we need growth. So there definitely is a commercial issue (I7)

Perceiving commitments as superficial. The commitments articulated may become perceived as ambiguous or even superficial by employees. Managers at FinanceCo indicated that when the executive board began to formulate the company's purpose, they actually started to describe the values and behaviors already present within the organization. However, some departments that were not directly involved with customers, especially financial departments, found it difficult to put 'banking with a human touch' into daily practice. As the senior staff 
director explained: "Some people are not used to it ... people have to start thinking outside the box-But they are sometimes very traditional ... they do not always understand it. Those are the hardcore bankers" (D13). Challenges to these convictions were not appreciated: employees who challenged these convictions were for example, portrayed by others as "not sufficiently understanding or committed to [our] mission" (D7).

In CapitalGroup, some managers were skeptical about their organization's branding efforts. Specifically, some indicated that the organization was making superficial commitments and setting goals without substantive processes and resource allocation. Some managers expressed their concern the that external image construed by CapitalGroup's executive board lacked an implicit anchoring in its business operations and practices, resulting in some of our informants voicing their concern regarding the authenticity of their organization's commitment.

Our goals are not ambitious ... Because the moment we set a target which we will not achieve, we have a real problem with our shareholders. This is understandable from a financial point of view, but it is deadly for sustainability. Because we will only become more sustainable if we move outside our comfort zone ...We have a new mobility policy, we have calculated that we can save $82 \%$ in $\mathrm{CO}_{2}$ with our new policy. But we set the target at $50 \%$, so that we have $32 \%$ slack. Not very challenging right? That's not in the mindset, that's culture (I12)

Our informants expressed their belief that too much attention was paid to the construed external image, while the processes and structures that were meant to deliver on these commitments were often not in place. The director of one of CapitalGroup's subsidiaries offered an illustrative example of this misalignment between espoused commitments and enacted practices:

Our head of marketing always liked a good marketing campaign ... He also made promises we couldn't live up to. Committing to something must be embedded in the soul of the organization, that you have chosen, what you are going for, and for which processes are in place and the risks assessed. It has to be a consequence of who we are, and in this organization, it often starts with making promises (I9)

\subsubsection{Stabilizing}

Managers saw the need for a common language and a set of shared understandings among employees as a first step to achieve stability between the organizations' externally projected image and its self-definition. Our informants simultaneously acknowledged that construing and communicating an organizational purpose was not sufficient to provide guidance for "fork in the road" decisions in everyday situations. To resolve the struggles within their boundaries and to create a sense of unity and consistency in conduct, our case organizations initiated various stabilization efforts. 
Substantive integrative work. FinanceCo had set out to implement substantive structures that would facilitate and guarantee consistency between the organization's business activities and its social commitments. As SocioBank's principles became a core component of FinanceCo's purpose, the leadership team recognized the need to find ways integrate these principles throughout the organization. To achieve this goal, FinanceCo implemented various governance practices that would facilitate the implementation of the firm-wide CSR policy and internal dialogue over CSR aspects. Furthermore, SocioBank's senior management was given considerable power and support by the leadership team to further diffuse its social commitments throughout the organization. Consider this example given by FinanceCo's CEO regarding his decision to adopt SocioBank's CSR policies throughout the whole organization:

Our subsidiary does not invest in U.S. government bonds because the US still has the the death penalty. That is a principle, the death penalty is not in accordance with the Universal Declaration of Human Rights ... The [UDHR] is guiding the sustainability policy of our subsidiary, and they are very consistent with that. You cannot be idealistic in one part of the bank and not in another part... So, if we state that is the right thing, we will adopt it throughout the whole organization (D3)

Structural differentiation and radical autonomy allowed some parts of CapitalGroup to operate with little regard for other parts and indeed with the commitments made by the organization as a whole. As a result, the leadership team recognized the need for various integrative practices to overcome internal tensions between the various subunits and to resolve the perceived ambiguity. For instance, when a subsidiary director grappled with a range of new and existing customers within CapitalGroup's insurance branch that had been excluded from the company's investment portfolio, she approached the CEO for support. He recognized the need for an overarching dialogue between various subunits, especially between CapitalGroup's investment and insurances branches. The CSR taskforce which was subsequently created facilitated an overarching dialogue between the directors of the various organizational subunits, integrating and coupling a range of expertise, interests and knowledge. This forum was seen by many as an important tool to guide decision-making in resolving emerging dilemmas, especially because senior management "was not yet accustomed to dealing with clear conflicts between social commitments and commercial responsibilities" (I11).

Routinizing a collective conscience. Notwithstanding the importance of substantive integration work, leaders understood that their company's projected image should also be reflected in a set of shared beliefs, ideas, and attitudes that provides "a common view of what we can and cannot do in the light of who we are" (I9). Managers and executives routinized their societal commitments by implementing formal policies to enact their organization's purpose, thereby embedding societal commitments in the collective conscience. 
FinanceCo's leadership team introduced and implemented a decision-making model based on shared values, through which the organization ensured that optimum choices were made that reflected FinanceCo's commitments. Specifically, for each managerial decision a 'cover sheet' was included on which managers had to indicate to what extent each individual proposal contributed to FinanceCo's shared values strategy, that is, a proportional commitment to customers, employees, shareholders, and society. Through the repetitive use of this process, this strategy had found its way into the minds of the managers and other employees. As one senior manager noted, "We are all forced, and I mean that in a positive sense, to always go through that process ... I'm not saying it's easy, but precisely because it's not easy, it is going to live. And step by step we are becoming consciously competent" (D1). Managers recognized the process involved a certain learning capacity based on repetition which taught them how to properly implement 'banking with a human touch' in day-to-day activities. FinanceCo's General Counsel explained this process of learning and repetition in the intersection between the executive board and senior management:

What people now know is that if you want to have a proposal dealt with by the executive
board, you have to include "banking with a human touch" in your proposal. If you
haven't looked at it until you have to attend the board meeting, you're obviously too
late because it won't be embedded in the proposal. It just doesn't have a chance of
succeeding ... I see that people have really thought about it in advance now ... Our
CEO has been here for some time now, so I think we have been educated in what the
chances of success are (D14)

We encountered a similar process of learning and habituation at CapitalGroup. To routinize the collective conscience, the company's management reacted to a series of inconsistencies in its client onboarding practices through an adaptive learning process, forming what several managers termed 'moral jurisprudence'. This moral jurisprudence was established because there was a need "to create a sort of unequivocalness within CapitalGroup whenever we are discussing a dilemma, that in what we do, in our attitude and behavior, there is a kind of common thread" (I1). For instance, while CapitalGroup made explicit commitments not to invest in the tobacco industry, it did acquire a pension insurance contract from British American Tobacco because, as stated by CapitalGroup's CEO, "employees shouldn't be victims of their employer" (I1). Conversely, a proposal for property insurance for the local factory of DuPont was declined because of the company's perceived lack of concern for its social and natural environments, including chemical spillages and pollution. One directors explained how the development of this moral jurisprudence helped her and her department in her daily practice:

We have made this fundamental choice in our CSR policy ... The discussion we had about DuPont, you could actually feel that it was in there, but no one could explicitly explain why it would be inconsistent if we say we don't want to be associated with that company, but we do offer them property insurance ... It's all about trying to get to the surface of what the logic is that employees have, unspoken, and to make it discussable, and eventually an organization develops a common vision of what is 'right' (I7) 
Leaderships' modelling behavior. Senior managers ascribed an essential role to the leadership in the stabilization process between the organization's image as committed to corporate responsibility and its internal self-definition. Specifically, managers indicated the leadership teams' modelling behavior is to achieve stability and overcome sources of struggle. Some of these behaviors were symbolic actions towards external stakeholders that reaffirmed and reestablished the company's commitments. For example, the leadership team of FinanceCo experienced significant pressure from the government to implement substantial cost reductions through layoffs and to simultaneously increase its returns in order to increase its stock price. A senior manager prized his CEO's perseverance in staying true to FinanceCo's purpose:

... leadership also has to do with the fact that [our CEO] has the courage to go to [our shareholder] and say that we have a manifesto, we have translated that manifesto into a strategy of shared values and we think that it is important to stay true to that purpose (D8)

FinanceCo's leadership team made a concerted effort to promote behaviors that they thought would match the company's purpose of 'banking with a human touch'. The belief was that by "walking the walk as well as talking the talk" (D2), they could increase understanding and buy-in, both internally from managers and employees and externally from stakeholders. This was explained by one subsidiary director, who indicated that his CEO was "constantly looking for ways to put the organizational vision into practice" (D8) by providing social cues that link the organization's activities to values and ideals, both in actions and in statements. Such cues were provided to convey information about the organization's deeply held values and thus contributed to the development of the internal blueprint for managers' decision-making. For instance, a major decision FinanceCo made to reaffirm its way of doing business was to take back control of its debt collection which had previously been outsourced to commercial debt collection agencies. FinanceCo's CEO explained that in the long run this would match with the bank's character-defining commitment to 'bank with a human touch':

The translation of 'banking with a human touch' into practice continually require decisions that affirm this commitment. When you are committed to "banking with a human touch", it does not really 'fit' to transfer debt files to a debt collection agency. We say we want a good relationship with our customers. However, these collection agencies have no eye for the needs of the customer at all. They only want to collect debts and charge as much as possible. That does not match, it is not consistent, with who we want to be (D3)

This decision was often advanced by our informants as the prime example of FinanceCo's CEO ability to "make the painful decision which are nonetheless in line with our purpose" (D9), thereby reaffirming the organization's commitments.

CapitalGroup's CEO made a similar observation, stating that "it is the message we convey and the image we provide, the way we talk to our employees and express our values, 
as well as how we present ourselves as role models" (I1). The leaders' modelling behavior also became apparent in the involvement of CapitalGroup's CEO in the CSR taskforce, albeit it in a mainly symbolical manner: "In the end, he attended the sessions only once, but that's not the point. It's about how he carries it when he is present" (I7).

\subsubsection{Settling}

The practices described above influenced how managers identified with their organization's efforts to overcome struggles, thereby further anchoring organizational commitments in the character of the organization. We found that adaptive behavior could include commitment affirmation, wherein actions confirmed the organization's values and active deliberation occurred about what was appropriate behavior for the company. However, stabilizing behavior could also include commitment violation and set in motion recurring struggles because such actions were perceived as incongruent with the organization's espoused commitments.

Adaption through commitment affirmation. Adaption through commitment affirmation occurred when managers perceived the commitments their organization made were upheld or stabilizing practices led to active deliberation and shared understanding of what constituted appropriate behavior in specific situations. Our informants described how integrative work, routinizing a collective conscience and leaders' modelling behavior set in motion active deliberation about what constituted appropriate behavior for the company and what did not, creating precedents for future behavior and further anchoring commitments in organizational character.

First, challenges and inconsistencies in CapitalGroup's customer onboarding practices provided an opportunity for the organization to promote an overarching dialogue between the various subunits, providing an opportunity for learning and mutual deliberation. Over time, resolving emerging dilemmas resulted in a collective view about what was deemed appropriate action when new customers presented themselves. One senior manager explained: "when you talk about it, you generally get more supported solutions which also meet the values you stand for as organization" (I9). Although a majority of our informants at CapitalGroup acknowledged that while the processes that would support the commitments and resolve inconsistencies "had only been partially crystalized" (I7), articulating and communicating commitments functions as the first step. An example was given by the CFO of CapitalGroup, about acquiring a retirement administrator and the subsequent integration of its asset management, a part of which was the retirement fund of British American Tabacco:

We as CapitalGroup do not invest in the tobacco industry. So the question is, what do we do with that? We've taken over this client, and there's a retirement fund in it from a company we wouldn't invest in. Should I drop the acquisition? ... in the end, we acquired the [pension] fund ... We wouldn't invest in British American Tabacco, but the employee who has his pension doesn't have to suffer. We deliberately made the decision, which we consider to be an acceptable one. And by making this decision we set precedent for future behavior (I4). 
Second, routinizing a collective conscience by enforcing formal procedures and creating informal guidelines for enacting the social commitments sent a powerful symbolic message to employees, who interpreted routinizing as a signal that the commitment and values inscribed therein were being upheld. Finally, leaders' modelling behavior signaled to employees and managers alike which values and behaviors were appreciated and congruent with the organization's commitment.

As explained in the previous section, both small and large decisions by the leadership that reflect FinanceCo's purpose helped employees in their daily activities. For example, an senior manager described reassuringly: "[the CEO] shows a type of leadership in which he makes very clear what 'banking with a human touch' means for him and how we could give it shape and form, that it is very important. If you look at the internal messages, you see responses from colleagues and they are talking about pride, so that they are proud of decisions like that" (D11). Similarly, a director of a subsidiary emphasized: "So if there is another comment like, 'you work at a bank?', you can at least indicate which bank you work for, what the mission of that bank is, and how they implement it. And that helps people enormously" (D7).

Anchoring through commitment violation. Some stabilizing efforts were perceived as violating the organization's espoused values commitments. Importantly, clear incongruity between the organization's externally expressed commitments and its actions brought about especially strong feelings of cynicism and skepticism among our informants, leading to a process of recurring struggle. At FinanceCo, commitment violations became apparent as a result of various strategic decisions the organization made in preparation for its IPO. Central to the IPO strategy were major cost reduction programs. Faced with a range of low-risk financial products and a moderate return for its government shareholder together with governmental pressure for a high stock price, the leadership team understood that the only way FinanceCo could achieve cost reductions was through layoffs and significant pay decreases for the remaining employees. Consequently, FinanceCo suffered a major decrease in employee satisfaction.

In contrast to FinanceCo, at CapitalGroup recurring struggles as a result of perceived commitment violations was fostered by all three stabilizing practices. Managers expressed their frustration and dissatisfaction with the organization's efforts to react to perceived inconsistencies in its onboarding practices, resulting in significant internal criticism directed at CapitalGroup's leadership. Managers clearly became cynical about the lack of leadership commitment and resources allocation, seeing the taskforce as a 'symbolic management' practice (Bromley \& Powell, 2012). Similarly, a senior manager commented on CapitalGroup' commitment: 
We miss the expertise or the commitment to take a specialist on CSR away from our competitor to translate it for us. That is apparently something we are reluctant to do, and that is something which makes us very vulnerable (I13)

This eventually led to some managers becoming disillusioned about the company social commitments, as one director of a subsidiary noted: "I will stick to my own responsibilities, but that's it" (I14).

Although managers did not perceive the acceptance of customers that who excluded from CapitalGroup's investment portfolio as immoral or unethical, they did perceive it as detrimental to CapitalGroup's image and therefore incongruent with the commitments the company had made. Some managers rationalized the acquisition of corporate clients that were excluded from CapitalGroup' investment portfolio. However, more idealistic managers were clearly critical of this approach taken by the executive board, as a senior manager noted:

What you have to watch out for is that we are going to come up with a 'socially legitimate' argument for winning such a contract. Ultimately, the argument is that it is a nice customer to have it, commercially. And then it is a question of conscience. Are you sincere, or are you just looking for the limit, which doesn't really match what we stand for' (I2).

Perceived commitment violations also arose as a result of actions taken by the executive board to appease the demands of certain stakeholders, resulting in diminished identity clarity within the organization. For example, the pay increase for the board of executives led, both internally and externally, to considerable criticism and confusion over the organization's identity. A senior manager summarized this notion:

In our [marketing] campaign we also say things like: 'we don't want sky-high bonuses'. And then there is a big salary increase for the executive board. I notice that it just doesn't resonate with our stakeholders ... It doesn't fit with our story. I think that when we talk about wanting to be a different insurer, that we are no longer that party of the past, and we are no longer doing this and that, and where we are really going to a higher future in which the company is more and more subordinate to our environment, I wonder whether such a salary increase fits with that (I8)

Managers were skeptical about this decision from the board of directors, perceiving it as incongruent with the CapitalGroup' professed commitments. Furthermore, various customers also saw it as a movement back to CapitalGroup' bad old days, causing additional struggles within the organization's boundaries. 
Figure 3. 2 A Model of Character Development

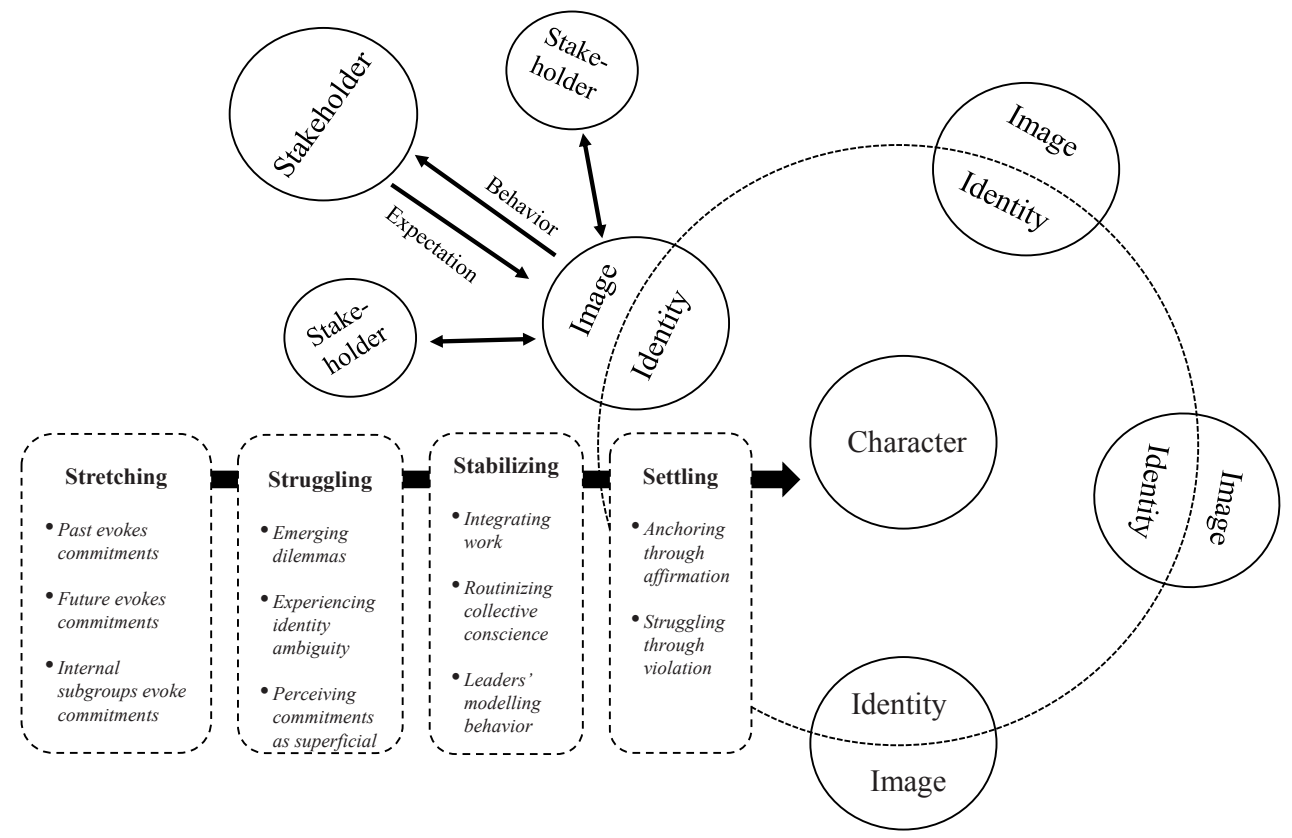

\subsection{Discussion and Conclusion}

We examined the process of character development through a qualitative study of two financial enterprises that have become increasingly committed to corporate social responsibility. In Figure 3.2 we present the theoretical model that emerged from our findings. Our model shows that when organizations adopt and articulate normative commitments, which we termed "stretching", they gradually begin a new image for the organization. We found that commitments become evoked as result of an often problematic past, envisioned future, and pressure from internal subgroups. While values ordinarily exist in a dormant state (Kraatz et al., 2020), we demonstrate that leaders can purposefully retrieve and espouse latent values after critical events in order to offer members a "bright light" (Hitlin, 2008), provide strategic direction and regain legitimacy from core stakeholders. In the wake of such critical adverse events, efforts to recover are significantly strengthened through the process of what scholars have labeled "anchoring in origins" of the firm (Basque \& Langley, 2018, p. 1687) and thus emphasizes the relevance of organizational history in identity saliency (Anteby \& Molnár, 2012; Schultz \& Hernes, 2013).

The process of stretching resonates with Tsoukas' (2018) notion of "values articulation work", that is, the actions through which purpose and relevant values are constructed and reaffirmed (Gehman et al., 2013). This articulation work has been shown to help carve 
out an image for the organization (Gioia et al., 2013), provide direction and an internal blueprint for managerial decision-making (King, 2015) and externally as a post-hoc evaluative mechanism of organizational conduct (Love \& Kraatz, 2009; Mishina et al., 2012). In accordance with the social actor perspective of organizational identity (King et al., 2010; Whetten \& Mackey), we find that this articulation work assists the communication of the central and enduring attributes of an organization, while simultaneously differentiating the collective from other referent entities.

When firmwide commitments are made salient to managers within the organization, tensions between ostensibly contradictory commitments become exposed, leading to a process we term "struggling" (See Kok et al., 2017). This process is composed of three interrelated dynamics. First, these normative commitments become increasingly salient to managers and executives alike, resulting in emerging dilemmas. Second, the severity of these emerging dilemmas is, by and large, significantly determined by the degree of identity ambiguity within the organizations. We find that identity ambiguity (Corley \& Gioia, 2004), as a collective state wherein organizational members "find themselves without a good sense of who we are as an organization" (p. 178) can be particularly pervasive when commitments are perceived as superficial.

To resolve internal struggles, organizations perform "stabilizing" practices. These stabilizing efforts provide the opportunity for further anchoring commitments in the character of the organization. We term this process as "settling". However, at the same time, stabilizing efforts that are perceived to be inconsistent with an organization's identity may evoke a sense of 'organizational sacrilege' (Harrison et al., 2009), wherein actions "directly contradict sacred ideals, values, beliefs and so on espoused by the organization" (p. 255). When commitments are perceived to be violated, there is a risk of recurrent struggles and a failure to fully diffusing such commitments throughout the organization.

First, while substantive integrative work may foster an overarching dialogue between subgroups to come to a shared understanding of interests, values and needs (Ashforth \& Reingen, 2014; Smith \& Besharov, 2019), over time skepticism may arise as some managers experience these efforts as merely symbolic management practices (Bromley \& Powell, 2012; Brunsson, 1989), leading to perceived commitment violation.

Second, the character of an organization is more than the espousal of lofty principles or purpose to improve an organization's image (such as in a mission statement), but rather "the coherent patterning of recurring actions and practices" (Ansell et al., 2015, p. 95) that "shapes its responses to its external environment" (Tsoukas, 2018, p. 13). In this vein, Selznick (1957) recognized that commitments depend on "congenial though often mundane administrative arrangements" (p. 14) in order to be sustained in practice. Therefore, we emphasize the critical importance of embedding and routinizing the espoused organizational values into organizational procedures and to develop, in Durkheimian's phrase, "a sense of collective conscience" (Starkey, 1998, p. 126), through which value commitments are habituated and integrated in an organizational character. 
Finally, while organizational scholars have rightly acknowledged that institutional leadership relies on the infusion of meaning and value in the social structure of the organization, (Golant et al., 2015; Solinger et al., 2020), our findings suggest that successful leaders must also internalize their espoused values within themselves, publicly represent them in one's behavior towards others and enact them in organizational actions. Consistent with the view of organizational identity as an ongoing accomplishment (Cornelissen et al., 2020; Schultz \& Hernes, 2013), we find that leaders' modelling behaviors and recurrent and public enactment of corporate responsibility initiatives contributes to "the appearance of cross-temporal consistency" (Kraatz, 2009, p. 80) of the organization's espoused values, through which commitments are anchored in the character of the organization.

Our study makes two important contributions. First, our aim was to put the organization at the center of our scientific analysis, providing a holistic account of how organizations are structured, managed and behave as distinctive social actors. In engaging in this empirical endeavor, we answer the recent calls by organizational scholars to once again "research the enduring, noun-like qualities of organizations" (King et al., 2010, p. 290). By doing so, we offer renewed attention to the notion of organizational character, as we recognize that organizational character as a unified, cross-disciplinary research subject is only beginning to come of age and forms "a useful starting point for rejuvenating the study of organizational actors" (King, 2015, p. 167). Figure 3.2 shows how the concept of character is distinct from other organization-level constructs, such as image and identity. Organizational character and identity are not often equated by scholars, who see identity as "more subject to fluctuation and reversal than Selznick suggested of character" (King, 2015, p. 159). Therefore, the core distinction between the two concepts concern questions about enduringness and malleability (see Whetten, 2006). Recognizing that the "more often an identity is (re)enacted, the more enduring it might prove" (Anteby \& Molnár, 2012, p. 516), to both inside and outside stakeholders, our study demonstrates that recurrent enactment of commitments becomes anchored in the character of an organization.

Second, our paper contributes to the growing number of studies that consider the "performative understanding of values" (Daskalaki et al., 2018, p. 1742) within and surrounding organizations (e.g. Besharov, 2014; Gehman et al., 2013). We do so by incorporating this normative dimension in our conceptualization of organizational character through the investigation of the adoption and diffusion of corporate social responsibility commitments. Practice scholars (Narduzzo et al., 2000; Tsoukas, 2018) show that as practitioners collectively and repetitively experience and resolve emergent inconsistencies and ambiguities, they develop their own distinct and habitual ways of working. In responding to these complexities, we show that through routinizing and modeling behaviors, collective commitments become habitually "built into the social structure of the enterprise and become part of its basic character" (Selznick, 1957, p. 141). Habituation creates precedent for future organizational decision-making and guides practitioners' performance (Lockwood, 2013) which helps the firmwide commitments to 
become embedded through routines. The repetitive nature of this decision-making process eventually leads employees and managers alike to gain a collective view of what to expect from each other and from the organization as a whole. 



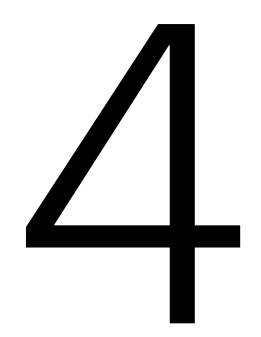

\section{The Persistence of Organizational Misconduct: The Case of Anti-Money Laundering in the Financial Industry, 2005-2020}

\subsection{Introduction}

In 2012, global banking giant HSBC entered into a deferred prosecution agreement and paid a $\$ 1.9$ billion fine for laundering vast sums of dirty money for Mexican and Columbian drug cartels. Court documentation and media reporting revealed how HSBC had been engaged in these illicit activities since the turn of the century and that everyone with influence over the firm, from board members and shareholders to compliance officers and regulators, appeared to have been complacent. However aberrant the HSBC case may seem, this example of persistent corporate misconduct is not abnormal. Misconduct is ubiquitous in modern organizational life (Castro et al., 2020; Lehman \& Ramanujam, 2009; Palmer, 2012) and is linked to a host of adverse outcomes (Hersel et al., 2019; Zahra et al., 2005) eliciting a multitude of stakeholder responses (Gangloff et al., 2016). Not surprisingly, both the antecedents and (failures in) remediation of misconduct (Greve et al., 2010; Vaughan, 1999) as well as efforts from both inside and outside actors to curtail misconduct (Gray \& Silbey, 2014; Misangyi et al., 2008), remain important subjects for organizational research.

Previous versions of this chapter were presented at the 36th EGOS Colloquium, July 2-4, 2020 in Hamburg, Germany, and at the 81st Annual Meeting of the Academy of Management, 24 July-4 August 10, 2021. A version of this chapter is under review for an edited volume on organizational misconduct, corruption and scandals in Research in the Sociology of Organizations 
Extant research has shown that while some first-time offenses may constitute mere incidental acts, the tendency of organizations to violate ethical values, norms and rules in a repeated fashion may be the result of deficiencies in their character or culture (Love \& Kraatz, 2009; Mishina et al., 2012). However, the persistence of misconduct may also result from institutional influences, including taken-for-granted professional practices (Muzio et al., 2016), peer misconduct (Gonin et al., 2012), and legal ambiguity (Edelman, 1992). Moreover, organizations vary considerably in their responsiveness to external pressures or enforcement actions (Chandler, 2014; Crilly et al., 2012; Raaijmakers et al., 2015), and may thus also differ in the extent to which they remedy misconduct and remediate noncompliance. Although these studies attest to a vibrant area of research, a central puzzle among organizational scholars remains "how [such] transgressions materialize and how they persist" (Roulet, 2019: 1439).

Whereas recent studies have taken the perspective of social-control agents (Clemente \& Gabbioneta, 2017; Dewan \& Jensen, 2020; Heese et al., 2016; Mohliver, 2019) and have highlighted their role in "creating and labeling misconduct" (Greve et al, 2010: 55 ), the process through which regulatory agencies may inadvertently contribute to the materialization and persistence of misconduct remains poorly understood. Previous research has typically involved thorough examination of single instances of misconduct (Gabbioneta et al., 2013; Graffin et al., 2013; MacLean \& Behnam, 2010), but studies fall short in explaining why organizations continue to engage in misconduct even following regulatory enforcement. Existing research has provided some preliminary insights on these issues, including organizations' inability to learn from failures (Anand et al., 2012; Haunschild et al., 2015; Lehman et al., 2019) or their tendency to only respond symbolically to coercive pressures (Bromley \& Powell, 2012; Chandler, 2014; MacLean \& Behnam, 2010). However, these lines of research have not yet been consistently addressed to the puzzle of persistent misconduct.

Our aim in this study is to address is research gap. Greve and colleagues (2010: 81) assert that to fully understand the causes of misconduct one must understand how vigorously and successfully social-control agents enforce the legal rules. Taking this approach, we follow recent work (Dewan \& Jensen, 2020; Heese et al., 2016; Palmer, 2008, 2017) that emphasizes that the actions (or inactions) of social control agents need to be included in the study of misconduct. As such, we posed the following research questions: Why do organizations persist in engaging in misconduct? How do regulatory agencies achieve substantive remediation? We undertook in-depth case studies of noncompliance with anti-money laundering regulations by three European financial firms over a 15-year period (2005-2020). This context is particularly appealing because of the endemic nature of this regulatory matter within the global financial system and the intensifying narrative of criminalizing gatekeepers. Based on our inductive, qualitative analysis, we elucidate three stages of escalating contestation between offending financial firms and regulatory authorities.

Our study offers several theoretical insights. First, adding to research on organizational misconduct, we adopt a novel social-control agent perspective and add to our understanding 
of how regulatory authorities may inadvertently create and sustain misconduct. In doing so, this study responds to the assertion that "rigorous use of a social-control agent definition of misconduct, paired with empirical research on the behavior and influence of socialcontrol agents, would be a major contribution to research on organizational misconduct" (Greve et al., 2010: 57). Specifically, we show how regulatory leniency and ambiguity towards normalized noncompliance (Ashforth \& Anand, 2003; Earle et al., 2010; Vaughan, 1996) may foster the emergence of complacency among regulated firms. Second, our research untangles the underlying mechanisms and enablers of organizational resistance to external pressures for conformity by elucidating how complacent organizations enact novel symbolic responses. Third, we contribute to the emerging literature on organizational scandals (Graffin et al., 2013; Clemente \& Gabbioneta, 2017), specifically by showing how salient critical events (Chandler, 2014; Hoffman \& Ocasio, 2001) may be leveraged by social-control agents to challenge complacency and enforce substantial responsiveness.

\subsection{Theoretical Background}

\subsubsection{Social Control Agents and Labeling of Misconduct}

Organizational misconduct can be understood as "behavior in or by an organization [that is judged] to transgress a line separating right from wrong” (Greve et al., 2010: 56). In our study, we focus on misconduct as determined by regulatory officials, regardless of intent and immediate outcome. Therefore, misconduct, whether intentional or unintentional, is understood as a property imposed on conduct when a social-control agent labels the focal behavior as misconduct. Studies of organizational misconduct have covered an extensive array of enabling and precipitating antecedents. Traditional approaches for studying organizational misconduct include, for example, corporate culture (Coleman \& Ramos, 1998), social networks (Greve et al., 2010), organizational-level strain (Simpson, 2002) and rational choice (Palmer, 2012). Others have paid attention to corrective actions (Hersel et al., 2019) and consequences of misconduct (Rhee \& Haunschild, 2006).

Apart from research on antecedents, corrective actions and consequences, scholars have begun to examine misconduct through adopting a labeling perspective (Clemente \& Gabbioneta, 2017; Murphy et al., 2017). This labeling approach describes how misconduct is constructed by actions (or inactions) by authority figures. Partly informed by institutional theory (Meyer \& Rowan, 1977; DiMaggio \& Powell, 1983), this approach describes how institutions-the regulative, normative and cognitive structures that shape the behavior of organizations and their members in a delaminated field (Scott, 2014)-may curtail, countenance, stimulate, sustain, shape and enable misconduct by or within organizations. 
According to this stream of research, such "social control agents"-political leaders, governmental agencies, and the media-effectively "create" the very notion of misconduct by deciding where the line falls between good and bad behavior (Greve et al., 2010: 79), or by failing to enforce that line (Graffin et al., 2013; Heese et al., 2016). Such entities thus have the "institutional role" (Clemente \& Gabbioneta, 2017: 287) of drawing the line that defines what is legally, ethically or socially irresponsible, and enforcing such standards when that line is crossed. For instance, Mohliver (2019) demonstrates that once the institutional environment became more stringent following the enactment of the Sarbanes-Oxley Act in 2002, auditors, as specific social-control agents, began eliminating the practice of stockoption backdating among their clients. Exploring the effects of the same U.S. federal law, Pozner and colleagues (2019) found that this legislation led to increased CEO accountability and media reporting of misconduct, causing firms to make more visible and costly corrective action following the announcement of an earnings restatement. Prevalent in these studies is the notion that different actors-those involved in wrongdoing, those who are harmed, and social control agents labeling the wrongdoing-may not view the focal act in the same way, and that shifts in social-control agents' attitude towards misconduct may bring about changes in a firm's behavior (Greve et al., 2010; Palmer, 2017).

However, decisions by these social-control agents are not simply "a straightforward implication of a set of laws, ethical principles, and/or social norms" (Greve et al., 2010: 56). As social-control agents have interests of their own and are subject to various constraints (Palmer, 2012), their decisions to enforce are shaped by a complexity of internal and external influences (Dewan \& Jensen, 2020; Greenwood et al., 2011; Heese et al., 2016). Yet we know little about the specific antecedents of these labeling actions by social control agents (e.g. why some deviant practices are penalized and thus labeled as misconduct but others are not). Social control agents uncover and judge instances of misconduct based on various factors, including self-interest, bureaucratic routines, and political and societal pressures.

Governmental entities as a specific social control agents, such as regulatory agencies and public prosecutors, represent collectivities that enforces rules and norms and have the legal authority to bring a charge of misconduct against an organization for its alleged violation, that is, to label an alleged violation as misconduct (Wiesenfeld et al., 2008). Governmental agencies are boundedly rational actors (March \& Simon, 1958) by virtue of their political entrenchment (Dewan \& Jensen, 2020) and budgetary resource constraints (Greve et al., 2010). Consequently, even when allegations of misconduct are pervasive and unambiguous, social control agents can only investigate a limited number of organizations. For instance, Heese et al. (2016) show that complex and fragmented external environments tend to be mirrored within the regulator's internal structure and reporting patterns, leading to inconsistencies in regulatory enforcement actions. As a result, social control agents have the discretion to respond to some instances of misconduct but not others. Therefore, there is a persistent need to consider what is optimum is terms of cost efficiently and in line with their social and political interests to enforce rule violations (Correira, 2014; Kedia \& Rajgopal, 2011). 


\subsubsection{The Path Dependence of Misconduct: Organizational Learning and Decoupling}

Research on path dependence highlights the notion that organizations' continuous misconduct depends on "the corporate path of previous states, actions, and decisions" (Page, 2006: 88). Early misconduct alters the preconditioning for corporate decisions and establishes a particular behavioral pattern that is efficacious for organizations to then follow. Once a path of noncompliance has been taken, organizations are inclined to engage in repeated rule violations. Two schools of research that may inform our thinking about the persistence of misconduct are theories on organizational learning and decoupling.

Although rarely integrated with the literature on regulatory compliance and rulebreaking (Desai, 2016; Haunschild \& Rhee, 2004), research on organizational learning provides an ideal window through which to examine responses to regulatory enforcement following misconduct (Cyert \& March, 1963; Gavetti et al., 2012; March \& Olsen, 1975). Noncompliance with a given rule, once initiated, is likely to be repeated. The mechanisms by which social-control agents provide feedback (i.e. inspection reports, sanctions) occur infrequently and are often ambiguous, and the potential adverse outcomes of noncompliance are generally only loosely coupled with the violated rule (Lehman \& Ramanujam, 2009). Consequently, without sanctions or enforcement actions, organizational members tend to "learn from noncompliance in a perverse way; namely they learn that it is acceptable" (Greve et al., 2010: 73). In other words, firms are more likely to break rules when organizational decision makers perceive that the benefits of illegal actions outweigh the costs (Mishina et al., 2010).

As organizational members enjoy immediate benefits of noncompliance but delayed negative consequences, if any at all, "perverse organizational structures and processes become subject to inertia and the same actions are repeated over time" (Lehman et al., 2019: 9; Anand et al., 2012). For instance, Lehman \& Ramanujam (2009) show that initial violations may be routinized in the absence of adverse outcomes that can be directly linked to the violation. Such conditions may contribute to the emergence of routinized noncompliance or normalized corruption (Ashforth \& Anand, 2003; Vaughan, 1996). If deviant practices are allowed to continue unchecked and become routinized, they become ordinary, acceptable, and mindlessly enacted, and increasingly hard to change (Earle et al., 2010).

Remediation of noncompliance is often a matter of learning-driven refinement of routines. The routines associated with legal rules are repositories of organizational memory (Gavetti \& Levinthal, 2000) that enable organizations to capture the lessons of experience (Zollo \& Winter, 2002), such as previous rule violations. Repeated noncompliance is thus more likely to occur when an organization fails to update the actions of a routine associated with a particular rule in response to feedback from the regulatory regime (Lehman et al., 2019). Extant research has explored the barriers towards organizational learning, including a lack of corporate responsibility on the part of the organization (Smith \& Elliott, 2007), inadequate communication (Schilling \& Kluge, 2009) and external rules that are both complex and ambiguous (Cannon \& Edmondson, 2001) may thus foster repeated rule violations 
Repeated rule violations, or a failure to remediate then, may also result from ceremonial or symbolic conformity to institutional pressures, such as regulatory scrutiny following initial misconduct (Oliver, 1991; Raaijmakers et al., 2015). Meyer and Rowan (1977) proposed that organizations decouple their practice from their formal or espoused structures when institutional and task environments are in conflict, or when they are facing conflicting institutional pressures. Recent work by Hersel and colleagues (2019) on the corrective actions organizations pursues following misconduct shows how organizations often recidivate because they had not made substantive changes to prevent further misconduct. Thus, if policy changes following regulatory scrutiny are enacted but then easily decoupled, or are proposed but without action, these responses are likely to lead to repeated rule violations (Bromley \& Powell, 2012).

Studies suggest that organizations decouple if they experience strong coercive pressure to implement a new practice, and more so if they distrust the actor that imposes pressure on them (Kostova \& Roth, 2002). Decoupling is also more frequent among organizations that do not fully believe in the efficacy of the practice in question (Boxenbaum \& Jonsson, 2017) or if these practices are seen to lack normative legitimacy (Sonenshein, 2016). In other instances, according to MacLean and Behnam (2010), some organizations may decouple formal control systems from organizational processes completely to create "a façade of legitimacy" among external stakeholders while maintaining a culture that facilitates repeated noncompliance or the institutionalization of misconduct.

Recent studies have also highlighted that coupling is only a temporary phenomenon, describing it as a process (Crilly et al., 2012). For example, Chandler (2014) demonstrates how the societal expectations regarding business ethics may ebb and flow over time, resulting in a recurrent process of re- and decoupling. This process also highlights the notion that while organizations may initially adopt practices to satisfy regulatory pressures, making commitments, resource allocation and controls may decline over time (Anand et al., 2012; Haunschild et al., 2015). Overall, although existing theories of decoupling are largely silent on organizational learning, decoupling can be the outcome of deficient organizational learning efforts that are fraught with complexity under conditions of inconsistent-and rapidly changing-stakeholder pressures, which may lead to the persistence of misconduct.

\subsection{Research Setting and Method}

\subsubsection{Case Study: Noncompliance with Anti-Money Laundering Regulations}

One of the key weapons in the global fight against financial and economic crime-such as money laundering, corruption and tax evasion-is the 'responsibilization' (Wakefield \& Fleming, 2009) of commercial, non-state actors, such as banks and other financial institutions. In this vein, financial firms are increasingly expected to act as 'gatekeepers' 
(Coffee, 2006) and to play a fundamental role in maintaining the integrity and stability of the broader financial system. The European Supervisory Authorities (EBA, ESMA and EIOPA) state that money laundering and terrorist financing (ML/TF) undermine the integrity of Europe's financial sector. Firms have a central role to play in the fight against $\mathrm{ML} / \mathrm{TF}$, and so are required by law to establish and maintain effective policies, controls and procedures to identify, assess and manage ML/TF risks, and to report suspicious transactions to the relevant authorities. More specifically, this societal role requires financial institutions to have strict customer due diligence (CDD) and know your customer (KYC) practices to promote high ethical and professional standards in the financial sector and prevent financial firms from being used-intentionally or unintentionally-for criminal activities (Basel Committee on Banking Supervision, 2016).

Noncompliance with such regulations is a widespread organizational phenomenon. Recent scandals, such as the prosecution and sanctioning of various European and U.S. banks for money laundering and facilitating terrorist financing, have demonstrated an emerging trend towards criminalizing gatekeepers' roles. In the period 2009-2017, banks around the world have paid $€ 304$ billion in fines for an abundance of regulatory failings including money laundering, market manipulation and tax evasion (Boston Consulting Group, 2018). For instance, HSBC Holdings' 2012 agreement to pay a $€ 1.5$ billion fine to U.S. regulators and enter into a deferred prosecution agreement for lack of adequate anti-money laundering controls and BNP Paribas' $2014 € 6.5$ billion settlement over allegations of sanctions violations highlighted the gravity of these transgressions and signaled a changing political and societal discourse regarding such misconduct. Due to regulatory scrutiny following these scandals, financial firms are increasingly pressured to intensify their investments in KYC/AML policies, controls and procedures.

\subsubsection{Data Collection}

We have studied how financial firms repeatedly violated KYC/AML regulations over a period of 15 years. The three case organizations we used for this study are three European financial firms, "EastCo", "SouthBank" and "WestGroup" (pseudonyms). These cases were theoretically sampled (Yin, 2003) for their repeated regulatory noncompliance and their broad similarities in size, international scope and history. This focus helped us formulate fine-grained theoretical explanations for the phenomenon under scrutiny. We use a unique longitudinal dataset of organizational noncompliance with KYC/AML regulations, which was collected to cover the period from 2005 to 2020, dating back to the moment the first regulatory audit in relation to noncompliance by one our case study firms was conducted.

We collected data from three types of source-archival data, interviews and media datathus creating a rich and reliable data set. For each case, we systemically collected a wealth of archival material from the domestic regulatory authorities. This included regulatory audit reports, interview transcripts, statements of facts, remediation action plans, annual reports (from firms and their regulatory authorities) and press releases from governmental agencies. We thus compiled a body of textual data (225 documents) spanning the 15-year time period (see Table 4.1). 
We complemented our documentary data with retrospective and semi-structured interviews with informants who were purposefully sampled for their unique insights into the problem of repeated noncompliance with KYC/AML regulations. Particularly insightful were those interviews we conducted with seven financial crime regulators (FCR1-7) responsible for conducting various regulatory audits over the years. During these interviews, we asked each respondent to reflect on the historical developments of financial crime regulations by their regulatory authority before exploring how these changes had impacted the regulatory strategy vis-à-vis our focal case study organizations. Each interview lasted between 60 and 120 minutes, was recorded and then fully transcribed.

Table 4. 1 Data Source Material

\begin{tabular}{|c|c|c|}
\hline Organization & Documents & Interviews \\
\hline EastCo & $\begin{array}{l}\text { Annual reports 2008-2019; Regulatory } \\
\text { conversation transcripts; Regulatory audit } \\
\text { findings; Enforcement documentations; } \\
\text { Management statements; Internal audit reports; } \\
\text { Objection to enforcement decisions; Reactions } \\
\text { to regulatory findings } \\
\text { (86 documents; } 1,442 \text { pages) }\end{array}$ & \\
\hline SouthBank & $\begin{array}{l}\text { Annual reports 2006-2019; Regulatory } \\
\text { conversation transcripts; Internal audit reports; } \\
\text { Reaction to regulatory findings; Regulatory } \\
\text { audit findings; Settlement agreement; } \\
\text { Statement of facts; Validation reports } \\
\text { (69 documents; } 1,112 \text { pages) }\end{array}$ & \\
\hline WestGroup & $\begin{array}{l}\text { Annual reports 2007-2019; Regulatory } \\
\text { conversation transcripts; Reactions to } \\
\text { regulatory findings; Regulatory audit findings; } \\
\text { Remediation action plans; Validation reports; } \\
\text { (68 documents; 1,364 pages) }\end{array}$ & \\
\hline Regulatory agency & $\begin{array}{l}\text { Annual (strategy) reports 2010-2019; } \\
\text { Enforcement and sanction decisions; } \\
\text { Intervention strategies; Reports of internal } \\
\text { meetings; Parliamentary inquiry findings; } \\
\text { Supervisory strategy change action plans; } \\
\text { Timelines of regulatory actions } \\
\text { (26 documents; } 765 \text { pages) }\end{array}$ & $\begin{array}{l}\text { Department head financial crime } \\
\text { regulation (2); senior regulator } \\
\text { financial crime (5) (FCR) }\end{array}$ \\
\hline Total & 224 documents; 4,683 pages & 7 interviews; 108 pages of transcript \\
\hline
\end{tabular}

\subsubsection{Data Analysis}

The exploration of why organizations continue to repeatedly engage in misconduct and the role of social-control agents in this process was grounded in a qualitative, inductive approach that is well suited for developing new theory (Pratt, 2016). This kind of approach is suitable because the goal of this study was to build theory about a phenomenon that is not well explained by the existing literature. We applied the Gioia-methodology following the standard procedure described in the literature (Gioia et al., 2013). Figure 4.1 represents 
the data structure that emerged from our analysis of how the case study organizations responded to rising regulatory scrutiny, illustrating the first-order categories, the secondorder themes, and the aggregate dimensions that served as the foundation of our model. For the sake of clarity, we describe our analysis as a sequence of four discrete steps.

The first stage of data analysis involved a detailed reading of the collected textual materials across the three cases and the regulatory authority, which enabled us to develop a longitudinal narrative account. We started the analysis with a visual map of key events (Langley, 1999), bracketing our stream of longitudinal data into separate time periods. Following the event timeline and drawing on our various data sources, we developed an increasingly rich and comprehensive description of our cases. As we constructed the timelines and important events, we noticed two salient themes: (1) regulatory enforcement and sanctioning had changed over time, from only incidental to increasingly stringent; and (2) despite being scrutinized for earlier transgressions, firms repeatedly continued to violate rules and failed to remediate. As we delved into the literature on organizational misconduct, learning and decoupling, we were influenced by the notion that social-control agents may inevitably "create" organizational misconduct (Palmer, 2017); for instance, by "changing the enforcement of the line between acceptable and unacceptable behavior" (Greve et al., 2010: 79).

During the second stage of data analysis, we returned to our empirical material and began the process of "open coding" (Corbin \& Strauss, 1990). We used the qualitative data analysis software Atlas.ti to code for first-order empirical topics around the organizational deviant practices and regulatory actions that we had identified in the textual material. Iterating between researchers and reading the texts multiple times, we merged the initial codes into 90 first-order empirical codes. These codes represented descriptions of organizational characteristics that may enable or promote repeated rule violations (e.g. "attention and priority senior management", "regulations lacking legitimacy" and "underestimating risks"), regulatory enforcement strategies (e.g. "limited enforcement", "increasing internal support", "responsibilizing senior management") and descriptions of remedial efforts (e.g. "resource commitments", "fragmented repair" and "reluctance to remediate").

During the third stage, we used axial coding (Strauss \& Corbin, 1998) to categorize the first-order codes into second-order themes. As we started to develop the various processes and relationships between second-order themes, we started to ask informed actors followup questions. This was not to confirm our narrative, but to ask how they would describe the various episodes and regulatory scrutiny over time. These second-order themes represented deviant organizational practices ("normalizing noncompliance", "symbolic remediation" and "isolated remediation"), regulatory processes ("regulatory restraint" and "regulatory amplification") and broader societal events ("normative coupling"). Information provided by interviewees thus helped us in the active construction of categories. For instance, as we came up with the notion of 'complacency', one interviewee described the attitude of one of our case organizations during one episode as complacent. This helped us to better construct the timeline, but also prompted us to look back at how this behavior had emerged over time. 

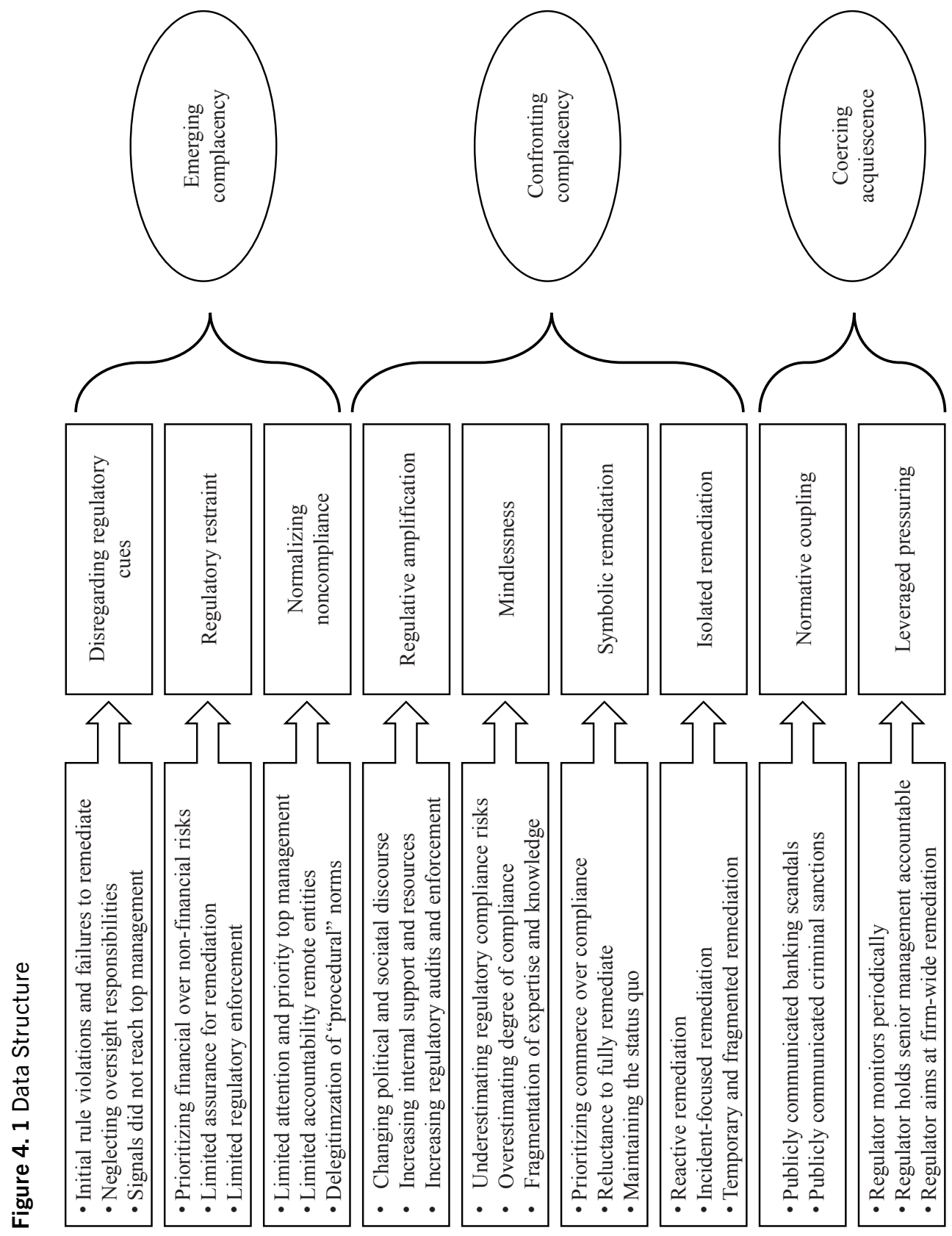


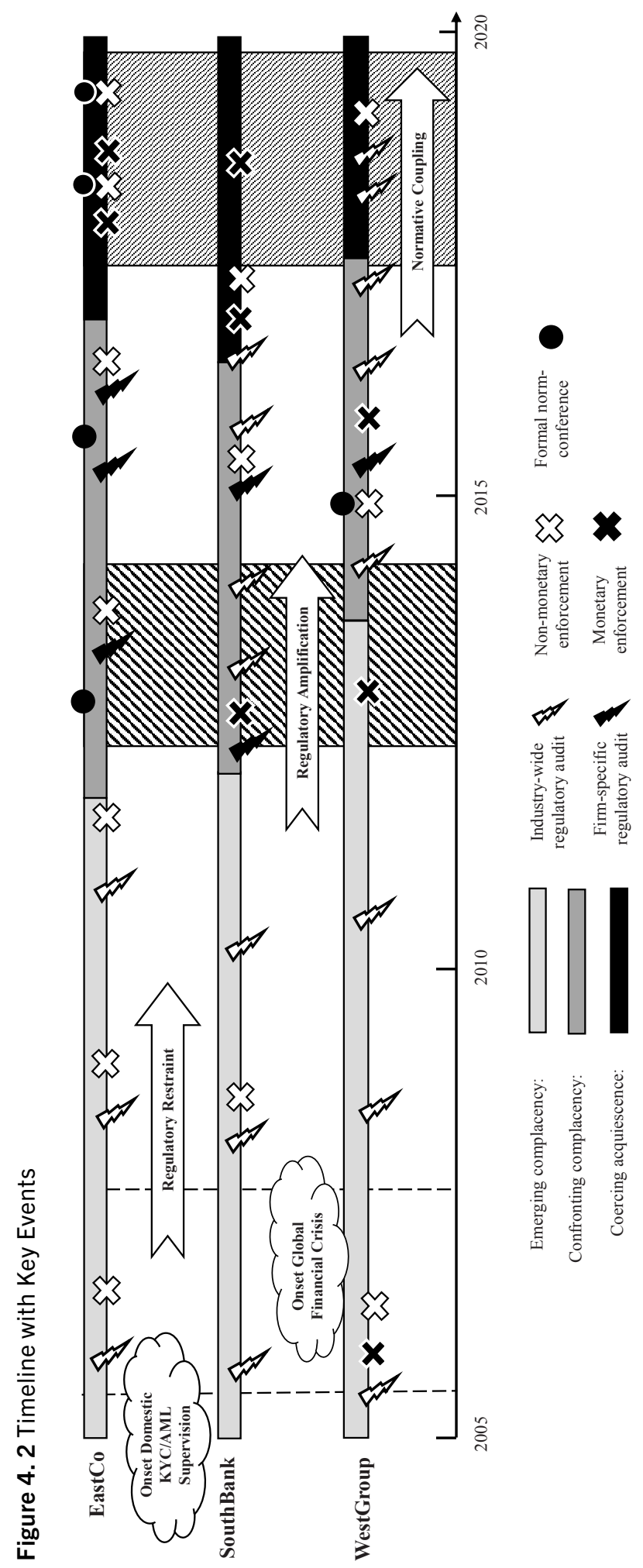


Finally, we applied these second-order themes back to the regulatory changes and our case histories of the three organizations to discern how these interacted with each other. By mapping the second-order themes to the case histories of our firms, parallel to the regulatory changes, we identified three distinct episodes creating, confronting and curbing organizational misconduct: (1) emerging complacency; (2) confronting complacency; and (3) coercing acquiescence. The first episode depicts the interactive framing and labeling processes through which noncompliance became increasingly normalized. In the second episode, the regulatory authority began to confront the complacency and firms responded strategically through various activities. The third episode involved critical salient events that enabled to the regulatory authority to leverage firms' acquiescence actions. In Figure 4.2, we show a simplified timeline of the key events. This illustrates how the grounded analysis maps onto the case histories in explaining how misconduct in created, confronted and curbed over time.

\subsection{Findings}

In the following section, we summarize the key patterns and events that unfolded between 2005 and 2020 in each of the three case organizations. Furthermore, we discuss the relevant developments in the supervisory practices and enforcement strategy of regulatory authorities. The case narratives are structured according to our aggregate dimensions, in which we discuss our second-order themes and provide representative supporting data. We divide our narrative account into the three episodes that we identified in our data analysis: (1) emerging complacency; (2) confronting complacency; and (3) coercing acquiescence.

\subsubsection{Episode 1: Emerging Complacency (2005-2013)}

In this first episode, spanning the period 2005-2013, each of our three case organizations began to receive signals from national and foreign oversight authorities that they were not compliant with the relevant KYC/AML regulations, standards and requirements. Although warnings emanating from foreign authorities were often urgent, regulatory auditing and enforcement by the national regulatory authorities remained limited in all three cases. Moreover, external and internal scrutiny led to only limited corrective actions by the case organizations themselves, as reflected by the structural inattention by senior management and the normalization of rule violations.

Disregarding regulatory cues. As shown in Figure 4.2 , each of our three case organizations were caught up in industry-wide regulatory inquiries. These exploratory inquiries evaluated firms' implementation of its KYC/AML policies and monitoring controls, often through offsite assessments. Although these initial inquiries exposed various oversight and quality assurance concerns, these cues were often disregarded and did not receive substantive follow-up. 
At EastCo, regulatory feedback that the organization was noncompliant was either disregarded or not considered as requiring attention or priority by senior management. For instance, an industry-wide regulatory inquiry revealed inadequacies in policies and procedures regarding customer due diligence. Regulators found that unequivocal accountability for customer due diligence at the highest echelon of EastCo was insufficient and a system of independent checks for compliance was inadequate. Overall, the regulatory authority identified that "awareness regarding customer due diligence risks-at both the executive and operational levels-was below the required level" (EastCo: regulatory audit report, 66:1). Responding to these findings, EastCo emphasized how remedial actions, including the hiring of temporary staff, would negatively impact the financial performance of the firm. In a follow-up audit several years later, regulators concluded that EastCo had been unwilling to adequately correct its shortcomings.

Regulatory cues also emanated from foreign oversight authorities. For instance, a foreign regulatory authority found that a remote entity of EastCo had systematically and repeatedly violated various KYC/AML requirements, which resulted in the willful facilitation of money laundering. In a regulatory audit concerning these transgressions, regulators concluded that:

... the subsidiary was aware in advance of explicit warnings from the foreign regulatory authority about the impact of third country AML regulations and the increased money laundering risks that this would entail ... The subsidiary did not report this to EastCo, nor did EastCo itself pick up these warnings (EastCo: regulatory audit report)

Likewise, SouthBank was repeatedly warned by both domestic and foreign regulatory authorities about shortcomings in the implementation of its KYC/AML policies and practices. In its response to findings of an industry-wide regulatory inquiry into the working of its customer due diligence practices, SouthBank recognized the importance of having robust customer due diligence practices but noted that it was already under extreme pressures to meet other regulatory financial requirements.

Over the years, SouthBank has been warned by various external bodies, namely the national regulatory authority and the European Central Bank, about shortcomings and risks in the implementation of its KYC/AML policy. Internally, it has also been established at several times that the required KYC/AML policy was completely insufficiently implemented. However, all these signals did not lead to material changes (SouthBank, regulatory audit report)

Regulatory restraint. During this first episode, regulatory authorities began to scrutinize firms on the effectiveness of their KYC/AML practices through exploratory industry-wide inquiries, as shown in Figure 4.2. However, the intrusiveness and pervasiveness of these regulatory audits, and especially the enforcement of rule violations, remained limited. Both before and during the 2007-2008 global financial crisis, regulatory authorities primarily considered solvency and liquidity risks with a focus on evaluating and monitoring firms' 
ability to remain solvent, devoting disproportionally less attention, capacity and resources to non-financial risks (European Commission, 2019). Even when regulators did reveal rule violations, hardly any assurance of remediation was demanded from the offending firms, as reflected on by a regulator:

Firms did not get the impression from us that a great deal of action was expected and that the regulator considered this issue important. And conversely, the regulator did not perceive [noncompliance] as very problematic against the background of the financial issues that were significant during that period (FCR2)

Importantly, since the regulatory agencies prioritized firms' solidity and solvency, they perceived the material consequences of a monetary sanction for non-financial noncompliance to be potentially detrimental to the financial stability of firms. Thus, and in the light of more urgent financial pressures affecting the entire financial sector, sanctioning of KYC/AML noncompliance was only authorized if there was clear and unambiguous evidence of the criminal offence of money laundering. The mere violations of so-called procedural norms, e.g. deficiencies in client identification and monitoring practices, aimed at preventing money laundering and other financial crimes, did not elicit stringent regulatory enforcement or sanctions. Specifically, regulators indicated they often felt opposition from their senior management, particularly when they thought sanctioning was necessary to communicate to firms the severity and risks for future rule violations:

We can keep blaming the [offending] firms, but we also made mistakes: capacity issues, attention, the way we gave feedback following on-site visits, the threat we communicated through our feedback. Because the truth is, if our senior management had gone to their CEO and had said: 'you have to solve these issues', the impact would have been much greater (FCR5)

Consequently, regulatory inquiries lacked pervasiveness and initial irregularities did not unequivocally lead to stringent enforcement actions. For instance, responding to regulatory noncompliance at a bank branch of EastCo, the regulatory authority served the firm with an order, charging EastCo with ensuring that all its entities were in compliance with the procedural requirements outlined in the applicable legislation. In a series of annual investigations, EastCo's internal auditing team repeatedly uncovered similar irregularities at various of its entities. Although such irregularities were repeatedly communicated to the regulatory authority, the regulator did not take any formal enforcement actions. In a meeting between senior managers of EastCo and its regulators, regulators informed the firm that they did not intend to sanction EastCo for its repeated noncompliance, primarily because they did not want to interfere with EastCo's restructuring process:

If an order imposed by us is not complied with, the usual next 'intervention step' is a regulatory fine. We have decided not to do this ... The importance of an improved governance structure, and consequently an improved internal organization, currently 
outweighs a formal measure in response to the internal audit reports showing that member banks achieved unsatisfactory scores (EastCo: regulatory audit interview).

Regulatory restraint during this episode was also reflected in the inability of regulators to draw lessons from individual irregularities to help inform their broader supervisory practice. For instance, regulators were aware that EastCo did not sufficiently monitor its large retail portfolio. However, these signals did not entice regulatory authorities to audit other firms for similar violations, as explained by one senior regulator:

At that time, we did not think: 'wait a minute, let's take a look at the other large banks to see how they deal with their retail portfolio'-even only to level the playing field, to look at how the others were doing ... We did not do that, because if we had, we would have known that compliance was also substandard at [other companies] as well (FCR3)

By contrast, foreign regulatory authorities sanctioned one of our case organizations for multiple compliance deficiencies, including facilitating money laundering through one of its remote entities. However, regulatory authorities only served the firm with an order to remediate these transgressions. Following this order, the case organization implemented various comprehensive remedial actions to improve its KYC/AML practices and monitoring framework. After finishing these projects, the regulatory authority validated these remediation efforts and assured the case organization that it had successfully resolved all the major regulatory compliance concerns. Reflecting on this period, interviewees indicated that, in hindsight, validation efforts were often not sufficient and too limited in scope to have concluded that all structural problems had been sufficiently resolved. Even more significantly, as regulators perceived "the supervision on foreign remote entities as a responsibility for local authorities" (FCR1), oversight deficiencies by the firms included in our research, specifically in the head offices of these firms, became increasingly more exacerbated and perceived as "normal".

Normalized noncompliance. For all three cases, both initial violations and failures to sufficiently remediate were met with regulatory restraint. Although negative outcomes of regulatory inquiries were always communicated back to firms, substantial enforcement actions and sanctions were infrequent, and actual noncompliance was rarely communicated to the wider public. Since regulatory authorities were reluctant to sanction firms' procedural shortcomings, only focusing on cases of actual money laundering, noncompliance became increasingly framed as a deficiency in the procedural execution of regulations, rather than as significant financial crime. As we went through our data, we came to understand that our case organizations experienced these procedural requirements as 'red tape' and as disproportionately burdensome. Moreover, because regulators were reluctant to penalize noncompliance, procedural norms became increasingly perceived as illegitimate, explained by a senior regulator: "We saw [regulatory noncompliance] as 'administrative sloppiness' as well. Otherwise you cannot explain why we did not penalize irregularities" (FCR1). As a result, firms came to believe that they could prioritize commercial goals over regulatory compliance. 
There was no (or insufficient) control from the head office on the implementation and compliance with global KYC/AML standards at EastCo's remote entities. Senior management has put the responsibility for oversight on implementation to the entities themselves and believes (to date) that it may do so ... There is a high degree of severity, over a long period of time ... and with regard to the largest client populations structurally insufficient customer due diligence is carried out, particularly motivated by commercial considerations (cost savings) (WestGroup, regulatory audit report)

In communicating its findings of an industry-wide customer due diligence inquiry, regulators termed EastCo's violations as a "financial crime", urging the firm to remediate its shortcomings. However, this talk about urgency for remediation was not back up with actual enforcement or sanctioning. More importantly, because regulatory cues were either disregarded or did not reach senior management, EastCo did not perceive these concerns as demanding resolute action. For instance, one senior regulator reflected on a conversation he had with a manager following an industry-wide inquiry that had revealed serious shortcomings:

We asked him why they were unable to remediate, and he answered "We get ten priorities from [our] head office. And anti-money laundering is number nine. The top five priorities are really the 'must does', the 'must haves'. And well, [preventing money laundering] is a 'nice to have' (FCR5)

At SouthBank, regulators discovered a discrepancy between the high number of transactions monitored and the low number of alerts generated and suspicious transactions reported. In practice, this tended to indicate that the firm did not sufficiently monitor and review its clients' transactions, a core component of any sound and robust KYC/AML system. Although the regulatory authority advised SouthBank "to take a close look at these irregularities and the effectiveness of the transaction monitoring system" (SouthBank: regulatory audit report, 190:1), it did not order or enforce remediation. More importantly, the firm itself did not respond to these warnings nor did it follow up on these irregularities. Since these irregularities were not addressed, they accumulated to create significant violations in the firm's transactions' monitoring practices. After being sanctioned for routinely missing suspicious and illegal transactions, its CEO acknowledged that "in hindsight, these non-financial risks did not receive the required attention and priority at the boardroom table" (SouthBank: regulatory audit interview).

In summary, while regulatory agencies signaled the importance of sound $\mathrm{KYC} / \mathrm{AML}$ practices and structures, noncompliance was primarily framed as a deficiency in the execution of procedural requirements. The procedural emphasis of KYC/AML regulations heavily affected managerial discretion, causing these requirements to be increasingly seen as illegitimate. Importantly, as initial violations did not lead to substantive corrective actions or sanctioning, firms' disregard of regulatory cues led to the "normalization" of noncompliance. We termed this as the emergence of complacency. 


\subsubsection{Episode 2: Confronting Complacency (2013-2017)}

As a result of the processes described concerning the previous episode, each of our three case organizations had become increasingly complacent. During the second episode, spanning the period 2013-2017, this sense of complacency became increasingly contested as regulators increased their coercive pressures. However, complacency among firms caused them to structurally underestimate their operational risks and overestimate their degree of regulatory compliance. As a result, firms were reluctant to respond substantially to increasing coercive pressures, and even in cases where firms did respond to regulatory scrutiny, remediation was often merely symbolic or isolated in nature.

Regulatory amplification. At this point, regulatory authorities started to redefine their supervisory roles and strategies, as shown in Figure 4.2. These developments paralleled a shifting political and societal discourse reflecting increasing public pressures for responsible and ethical conduct by financial firms in the wake of the financial crisis. These developments were substantially fueled by multiple state-commissioned reports evaluating the (dis)functioning of the various regulatory authorities in the build build-up to the 200708 global financial crisis. These evaluations assessed that while, overall, the oversight of solvency, liquidity and capital was adequate, authorities had not sufficiently and vigorously enforced non-financial, behavioral, governance and internal control issues. Specifically, these reports concluded that regulatory authorities should have addressed transgressions earlier (and perceived them as more serious), that they overestimated the expertise of directors and executives and were reluctant to vigorously enforce deficiencies in 'checks and balance' requirements.

These findings were consistent with various reports commissioned by supranational organizations. In 2010, for instance, the International Monetary Fund published a note assessing the industry's compliance and stressed the importance of a more intrusive and skeptical approach to supervision, increased resources and skilled staff for national regulators, and the development of a "will to act" on regulatory concerns (IMF, 2010).

Following these critical evaluations, regulators began to advocate for a more stringent and intrusive regulatory and enforcement strategy. This applied not only to traditional parts of supervision such as of solvency and liquidity risks. Regulatory authorities asserted that a sustainable business model and an ethical organizational culture, supported by balanced governance structures, were of great importance for the effective functioning of financial firms. Therefore, their supervisory strategy and organization would have to reflect this new approach, as stated in a strategy report:

Intrusive supervision means that we will also have to dig deep into these less tangible areas, address firms for transgressions and ensure that shortcomings are remediated. This means more attention to the governance structure of firms, the composition and quality of boards of directors and supervisory board, integrity and remuneration policy. This will lead to more interventions and enforcement in these areas (Regulatory authority: internal documentation) 
Senior regulators stressed that these external developments were increasingly accompanied by substantial internal support and increased resources for stricter enforcement of noncompliance. These developments mirrored the more stringent enforcement actions of foreign authorities in relation to KYC/AML noncompliance, particularly from various U.S. regulatory authorities. During this episode, financial crime prevention became an increasingly compulsory part of supervision. Over the years, the specialized department responsible for policymaking, auditing and enforcing of financial crime risks- in particular anti-money laundering, corruption and fraud-significantly expanded in size, introducing new regulatory instruments and taking on responsibilities. During the period of 2014-2019, this financial crime department grew by more than $60 \%$, reflecting increased priority by senior management.

As can be seen in Figure 2, while the number of investigatory audits only increased slightly in comparison to those during the previous episode, these inquiries were more intrusive and pervasive. Moreover, as the regulatory validation of remedial actions became common practice, firms had to repeatedly demonstrate that they had sufficiently addressed shortcomings. More importantly, regulatory authorities began to more strictly enforce good conduct and sanction firms that were noncompliant. As regulatory authorities amplified their coercive pressure to further increase compliance with KYC/AML regulations, overt conflicts between regulators and firms started to emerge.

Mindlessness. Having structurally disregarded regulatory cues, firms were operating in a rigid and mindless fashion. This reduced attention and awareness prevented senior management from fully grasping the underlying regulatory compliance matters within their organizations and understanding what had to be remediated. Internal and external signals that were incongruent with beliefs established during the previous episode were misinterpreted or not recognized at all as demanding either attention or priority. Since actual money laundering rarely materialized, firms were structurally unaware of the regulatory risks that had emerged and their senior management was thus unable to effectively govern these risks:

Firms experience little threat with regard to financial crime risks. At the same time, the regulator sees that where threats are underestimated, the degree of control is overestimated. The chance that risks materialize is not estimated as high enough to trigger action on the part of firms. The impact (damage) of potential risks also does not seem large enough for the firms to tackle the issue (Regulatory authority: Internal documentation)

Our data suggest that this mindlessness emerged from the fragmentation of knowledge, expertise and awareness of money laundering risks throughout the organization. For instance, while EastCo established a dedicated anti-financial crime department to meet rising regulatory pressures, this department was largely compartmentalized away from the core business. Tasks and responsibilities regarding the management of customer integrity risks and transaction monitoring were allocated to various departments. This internal 
buffering' between subunits inhibited the effective communication of compliance risks to senior management and led to the diffusion of responsibilities. That is, the core business departments regarded this financial crime department as responsible for all customer due diligence activities, and thus did not perform any due diligence activities themselves. Illustrative in this regard were the findings of a regulatory audit on the oversight activities of EastCo's headquarters. Regulators discovered that the headquarters of EastCo had systematically failed to recognize or misinterpreted internal warnings about money laundering at remote entities. Describing these deficiencies, senior regulators concluded that:

It was generally understood by EastCo head office that there were risks involved in operating branches of its remote entity, but (as EastCo emphasized) "with hindsight" it was not fully understood what these risks actually implied for the firm (EastCo: regulatory audit report)

Compartmentalization of tasks and responsibilities also hindered the flow of information to senior management. For instance, regulatory authorities noted that within SouthBank's 'three lines of defense' structure, managers "felt limited responsibility for the whole which led to compartmentalization, whereby everyone had eyes only for their own demarcated role and thus lacked ownership of the entire process" of preventing money laundering (SouthBank: regulatory audit report). As a result, important shortcomings that were known about at the operational level, did not reach senior management. Importantly, the lack of information about shortcomings confirmed the senior management's ingrained belief that all forms of noncompliance had been resolved.

For WestGroup, deficiencies in oversight and quality assurance from the head office caused senior management to remain unaware of the operational risks that the firm faced. As a result, oversight of both domestic and foreign remote entities fell short, and signals of noncompliance were not recognized by senior management. For instance, during an audit at one of its remote entities, regulators found that several employees had willfully carried out various illegal business transactions for wealthy clients. However, signals of these violations were not recognized by head office:

The monthly compliance reports from the remote entity to the head office contains limited information and are largely blank. The reports do not contain issues with regard to [specific] customer due diligence, suspicious transactions or other issues regarding money laundering risks (WestGroup: regulatory audit report)

These finding were remarkable, as these concerns did indeed exist and were later identified by WestGroup itself following an internal audit investigation. The fact that the reports from the remote entity were almost blank did not alarm headquarters, nor did WestGroup's head office conduct any on-site inquiry.

Symbolic remediation. While regulatory authorities significantly increased its coercive pressures, our three case organizations responded only through deliberate efforts to 
maintain the status quo. Firms often perceived these regulatory demands to be in conflict with their commercial priorities, and thus only adopted KYC/AML policies and monitoring practices symbolically.

Following multiple regulatory findings of transgressions, regulators imposed an order on EastCo. In responding to this enforcement action, senior management repeatedly assured regulators that EastCo intended to fully correct its shortcomings and implement suitable and effective KYC/AML measures to be "in control". However, over the years EastCo remained reluctant to fully remediate as "formal deadlines for remediation set by the regulatory authority were repeatedly exceeded and annual internal auditing inquiries identified continuing transgressions" (EastCo: regulatory audit report). However, this resistance did not lead to any substantive enforcement actions or sanctions. Senior managers at EastCo and its regulators often disagreed about to what degree the order's requirements should be met. Illustrative were concerns over EastCo's client identification practices within its retail customer segment stemming from Episode 1. Over time, as this incorrectly identified client segment came to make up a significant portion of EastCo's total customer base, senior management became increasingly reluctant to retroactively review those customers:

EastCo does not appear to intend to make a thorough recovery on this sizeable portfolio. Despite a large number of discussions between regulators and executives of EastCo, there is still a difference of opinion about what is necessary to meet the mitigation order (EastCo: regulatory audit interview).

The perceived magnitude of client identification requirements and resource commitments necessary to resolve these shortcomings inhibited EastCo's senior management from taking resolute actions.

As for SouthBank, having completed several remedial actions, senior management was convinced that all underlying compliance issues were sufficiently resolved. This notion was partly fueled by feedback from the regulatory authority, which (as described above) had positively validated SouthBank's remedial efforts. At the same time, senior regulators indicated that because of this ingrained belief, SouthBank had developed a complacent attitude that became embedded in the interaction with regulators. As a result, subsequent regulatory audits that uncovered serious violations were met with a defensive attitude by senior managers, as a regulator noted:

During the period from 2012 to the end of 2016, SouthBank took on this kind of complacent attitude towards us, saying: "you can tell us whatever you want, but we have it all figured out"... almost to the point of arrogance (FCR6)

A recurring pattern revealed by the regulatory audits was the observation that repeated violations-or failures to remediate-were primarily motivated by commercial imperatives. SouthBank had structurally invested too little in meeting its legal obligations because, over a long period of time, compliance was considered less important than commercial 
considerations. As a result, the compliance monitoring positions were significantly understaffed, and were thus unable to function as countervailing power over commercial departments:

SouthBank focused mainly on the profitability of the organization and the achievement of its commercial objectives. The lack of investment in the required capacity, both in terms of personnel and technology, has contributed to the emergence and continuation of serious irregularities and rule violations (SouthBank: regulatory audit report)

Likewise, and despite increased regulatory pressures, WestGroup failed to remediate. Explaining WestGroup's attitude, a senior regulator noted: “They felt that they had already identified and resolved all relevant compliance issues ... They actually thought they were doing well, and they complained that we were stressing form over substance" (FCR4). This 'form over substance' belief became evident during visits from WestGroup's internal control officers to the firm's remote entities. Regulators revealed that these audits did not include a review of client files, while audits were limited to determining whether client files fell 'technically' short of the procedural requirements, without a thorough assessment of the substance. Addressing these violations, regulators noted:

We stress that the shortcomings as identified in client files ... should not be considered as 'sloppiness', as implied by you during the last meeting ... but do in fact constitute serious violations of relevant laws and regulations (WestGroup: regulatory audit report)

Reflecting on these transgressions, regulators noted that WestGroup's managers repeatedly stressed commercial motives for failing to meet the regulatory requirements, particularly to prevent the erosion of its competitive position in relation to other financial firms. For instance, over a number of years, WestGroup had structurally classified new customers into its lowest risk category, using an arbitrary but unjustifiable high threshold "approved by senior management ... on the basis of commercial considerations only" (WestGroup: regulatory audit report). As a result, due diligence on these customers was minimized to cut back on monitoring costs, thus risking suspicious transactions being undetected.

Isolated remediation. Despite increased regulatory pressure, firms continued to resist and remained unwilling to recognize and act upon the underlying causes of noncompliance as reflected in the continuing absence of tailor-made risks analyses. Partly owing to procedural emphasis in KYC/AML regulations, substantive compliance meant firms had to retroactively improve their client identification. As a result, resource and personnel commitments were primarily allocated to reviewing client files with a view to ensuring the completeness of documentation present in the files. In conjunction with increased regulatory pressures to focus on immediate ad-hoc remediation, this led to remedial actions often being only temporary and fragmented in nature. However, these actions failed to address the embedded organizational norms, beliefs and assumptions that were the cause of violations. 
With regards to the temporality of remediation, although awareness of money laundering risks appeared to develop across the firms during this episode, attention repeatedly ebbed off over time as the focus of senior management shifted to other subjects, as regulators noted:

A pattern that the regulator is confronted with is that financial institutions adjust their investment agendas because of internal commercial pressures ... as a result, investments in customer due diligence and in the compliance function tend to fall over time. In practice, this means that the regulator, after following up on previous supervisory investigations, must again enforce the restoration of ethical business operations (Regulatory authority: internal documentation).

This meant that although policies and standard operating procedures were improved following regulatory inquiries, they were insufficiently implemented in practice and often decayed over time. Even if individual divisions or branches within our case organizations discovered solutions that were suitable for resolving shortcomings, managerial attention was often focused on the local situation rather than the joint situation, and this impeded replication of effective processes in other parts of the organization.

Across the board, EastCo was persistently reluctant to remediate following violations at its remote entities. In addition to the lack of specific procedures to ensure that global customer due diligence policies were actually implemented, senior managers often characterized transgressions at its remote entities as matters that should be resolved by the local management. Despite persistent pressure by regulators, they maintained the belief that foreign legislation did not apply to the operations of the head office. Our analysis suggests that the extensive period of neglected oversight over remote entities prevented EastCo from addressing the root cause of its repeated noncompliance, as summarized in the following data segment:

Over the years, EastCo has not taken sufficient responsibility for what happened outside the central organization. As a result, control of local and foreign entities was insufficient. The energy and attention required to manage these problems, combined with addressing the ever-emerging incidents, is a particularly time-consuming matter that detracts from addressing the underlying causes [of the rule violations] (Regulatory authority: internal communication)

SouthBank was confronted with a significant rise in regulatory audits following the regulatory strategic changes, as shown in Figure 4.2. However, after completing various remedial actions during the first episode, subsequent regulatory audits revealed that SouthBank had significantly cut down on its monitoring and compliance practices. Regulatory audits revealed that "over an extensive period, SouthBank did not invest sufficiently in personnel capacity and quality" (SouthBank: regulatory audit report). Specifically, the responsibility for remedial actions was repeatedly entrusted to lower levels management and staff departments, and the firm depended heavily on external parties, such as specialized consultancy firms, for large-scale remedial projects. As soon as these 
remedial actions were completed, the costly short-term compliance projects that were set up to correct operations disbanded, leading knowledge and expertise to decay followed by the recurrence of noncompliance.

WestGroup repeatedly exhibited an inability to learn from previous rule violations and subsequent enforcement actions. The firm was often too occupied with resolving individual irregularities, "without conducting a thorough analysis of why it was unable to comply with KYC/AML regulations adequately" (WestGroup: regulatory audit report). For instance, regulators validated a remedial project but concluded that the remediation was "mainly focused on the actual repair of client files in terms of documentation and evidence but paid no attention to the root causes underlying the misconduct" (WestGroup: regulatory audit report). In a subsequent root cause analysis conduct by the firm itself, WestGroup concluded that senior management mainly reacted to external pressures from the regulatory authority:

During the last five years, KYC/AML related issues seem to have mainly been addressed reactively in a project management mode, i.e. to remediate observed gaps with shortterm goals. Priorities given by the executive levels seem to have been influenced by external pressures, i.e. the regulators' findings, and less by a proactive, systematic, riskbased analysis (WestGroup: internal documentation)

In general, WestGroup did not effectively translate remediation measures into daily practices while corrective actions were often terminated before they were sufficiently embedded in the daily operations. Moreover, on the supervisory and executive boards no one was specifically responsible for firm-wide KYC/AML remediation and monitoring processes (Regulatory authority: internal documentation). For instance, although WestGroup had made significant improvements following initial rule violations, regulators concluded that "in recent years, WestGroup has cut down on its compliance positions again, while the results of the recent regulatory audits did not give rise to this" (WestGroup: regulatory audit interview). Reflecting on these remedial actions, WestGroup confirmed these struggles:

While we conducted several actions and remediation plans in different business units, the firm has not been able to instill a strong change management from remediation to structural solutions to embedded action into day-to-day processes for business units, with a bank-wide vision (WestGroup: documentation from bank)

\subsubsection{Episode 3: Coercing Acquiescence (2017-2020)}

Unlike during the two earlier episodes, various salient critical events and several highprofile financial scandals in the period 2017-2020 profoundly infused the discourse around KYC/AML noncompliance with public outrage. Together with amplified firmspecific pressures led to regulators to become increasingly empowered to break down complacency within firms, which we termed "coercing acquiescence". Within this episode, we identified two main activities: normative coupling and leveraged pressuring. 
Normative coupling. An important step in this final episode involved the process of normative coupling, which followed various salient critical events and a changing societal and political discourse toward KYC/AML noncompliance. These critical events, including some high-profile financial scandals at various major European financial firms, attracted substantial political and public condemnation of any KYC/AML rule violations. Furthermore, for the senior management of our case organizations, who had repeatedly demonstrated a lack of accountability and awareness, these events served to emphasize the financial and reputational repercussions of KYC/AML rule violations.

Normative coupling was also driven by other developments throughout the global financial industry. During the period 2017-2019, financial firms were confronted with several high-profile corporate scandals. For instance, the $€ 20-80$ billion Russian Laundromat scheme, involving the movement of money out of Russia through a network of global banks, the Danske Bank money laundering scandal, and the $€ 775$ million settlement with ING for failing to spot money laundering caused increasing centralization and intensification of financial crime supervision at the European level (European Commission, 2019), adding to the widespread acceptance that the effectiveness of the performance of firms' gatekeeper function had to be increased. These highly publicized scandals thus irrevocably signaled the gravity and severity of KYC/AML noncompliance, generating significant societal and political traction.

Importantly, these events challenged the collectively settled consensus that rulebreaking would not elicit any substantial social or economic sanctions. Regulatory inquiries during this episode revealed the impact these salient critical events had on the senior management of our case organizations, which started to show more ownership of the subject and demonstrate both the urgency and the willingness to tackle the problem. For instance, executives at one of our case organizations told regulators that following the societal and political outrage, they had used the publicly disclosed statements to announce an extensive analysis of possible weaknesses with their own organization.

These industry-wide developments enticed regulators to strengthen their KYC/AML supervision. Supervisory examinations began to show improvements in compliance with AML regulations. For instance, regulators concluded that, partly in response to the publication of the Panama Papers:

... SouthBank has visibly made improvements to its control measures to prevent involvement in financial and economic crime arising from aggressive tax planning and customer anonymity (SouthBank, regulatory audit report).

Although previous sanctions for corporate-facilitated money laundering cases had been considerable (e.g. €6.5 billion for BNP Paribas, €1.5 billion for HSBC), this episode was characterized by a significant and global rise of sanctions for KYC/AML rule violations. The $€ 9$ billion of fines in the recent 15-month period contrasts with the period of 2008 to 2018 when the total for the entire decade amounted to \$23 billion (Fenergo, 2020). The surge in fines stemmed in part from geopolitics, as regulators-especially those in the 
U.S.-levied much stiffer penalties on foreign firms operating in the U.S. versus those in their own country.

Simultaneously, senior regulators told us that European regulatory authorities and public prosecutors began to mirror this punitive approach. Indeed, the changing societal and political discourse towards corporate-facilitated money laundering coincided with increasingly pervasive regulatory enforcement efforts. These scandals, sanctions and the political ramification thus signaled to executives the significance of KYC/AML noncompliance and ramification for firms' profitability if they were to be sanctioned. As the cultural values and beliefs implicit in KYC/AML regulations became increasingly salient as a result of these highly publicized corporate scandals, government-mandated regulations gained legitimacy among the leaders of our case organizations. Regulatory authorities skillfully utilized this public outrage and the shifting discourse of criminal sanctioning to leverage more comprehensive remediation efforts and substantive resource commitments.

Leveraged pressuring. Firms interpreted industry-wide critical events and political developments as signals of "an intensified regulatory focus on money laundering" (EastCo) and "increased reputational risk" (SouthBank). Although industry-wide events signaled the negative financial and reputational consequences of rule-breaking, by themselves they proved ineffective in achieving substantial compliance. However, these events provided opportunities and momentum for the regulatory authorities to intensify firmspecific pressures, particularly through stressing executives' legal responsibilities, stricter monitoring of remedial actions and demanding firmwide rather than ad-hoc remediation. As a result, the regulators became increasingly empowered to break down the collectively settled consensus between firms and regulatory authority.

One of the key developments in achieving compliance was the recent change in legislation in many countries regarding governance arrangements within organizations with a view to fostering compliance with KYC/AML regulations. This led to increased personal responsibility of policy makers of financial firms, and strengthened public and political scrutiny of these "captains" of the financial industry. Although previous attempts to remediate noncompliance were primarily handled by middle managers, this new amendment required each firm to assign a board members specifically responsible for ensuring the firm's compliance with KYC/AML regulations. In practice, this was reflected in more frequent meetings between the firms' senior management and the domestic regulator, and increased reporting about compliance matters in the boardroom.

At EastCo, regulators learned from the approach taken from criminal investigations to leverage senior management to substantially comply with the requirements set out in a mitigation order. Similarly to agreements made with management of criminally sanctioned financial firms, this leveraged pressure concerned "addressing the CEO and chairman of board of directors of EastCo directly to their personal responsibilities" (FCR4). To enforce the remediation efforts, progress interviews were held with the CEO and chairman of the supervisory board every six months and regulators demanded a six-monthly progress report from EastCo's CEO. In their conversations with the firms' executives, regulators began to 
emphasize the possible consequences of persistent KYC/AML noncompliance, including new sanctions and a re-assessment of the responsible executives on their reliability and suitability. A similar trend was evident at WestGroup, where leveraged pressuring became evident in the regulators' move to hold senior executives strictly responsible for the substantial remediation of KYC/AML deficiencies. In communicating its findings following a regulatory inquiry, senior regulators stressed:

We hold the CEO and the chairman of the board of WestGroup personally responsible for the realization of the required remediation ... We expect both CEO and chairman to report periodically on the progress of the recovery and the improvements, and thereby giving openness about any bottlenecks and newly identified problems (WestGroup: regulatory audit report)

In this context, regulators demanded that WestGroup's CEO to report in writing biannually and subsequently explain the current position verbally to the senior management of regulatory authority. Subsequently, the chairman of the board of directors was invited to periodically set out the progress and supervision exercised by the board on the remediation and improvements.

Leveraged pressure in conjunction with industry-wide events prompted senior management to publicly commit to resolving regulatory compliance concerns and acknowledge that robust customer due diligence practices were essential for a firm's 'license to operate'. Particularly salient during this episode were the substantial resource commitments firms made and their subsequent adoption of new practices and structures. In 2019, our case organizations cumulatively invested an estimated $€ 1$ billion in fighting financial crime, including the prevention of corporate-facilitated money laundering. For instance, EastCo invested substantially in customer due diligence and KYC/AML activities. Likewise, SouthBank allocated substantial additional resources to attract new employees to monitor for suspicious transactions and WestGroup displayed its commitment to substantive compliance by setting up a new department under bank-wide centralized governance to strengthen and accelerate the detection of suspicious transactions and rectify client files.

Leveraged pressure forced firms to implement and make substantial resource commitments. The common denominator of these activities and commitments was the focus on achieving substantive compliance and preventing sanctions. Again, owing to the procedural emphasis of KYC/AML regulations, these activities were primarily focused on retrospectively resolving deficiencies in client files; for instance (re)collecting client information and information on ultimate beneficial ownership. As a result, over $40 \%$ of the resources committed in 2019 were directed at remediation programs, client look-back actions and recovery processes. However, these investments were not intended to remain at the same level over the years, still did not address the underlying causes of noncompliance nor seem to connect KYC/AML with the core business of the organizations. Importantly, firms experienced that the tipping point had been reached, as the requirements for $\mathrm{KYC} /$ AML policy implementation and the associated bureaucracy were considered so stifling 
that it was more attractive to simply not provide any services at all, leading to widespread de-risking of certain clients.

\subsection{The Materialization, Persistence and Remediation of Misconduct}

In the previous section, we described how financial firms responded to rising regulatory pressures for substantive compliance with KYC/AML regulations over a period of 15 years. In this section, we draw on the concepts we have identified and present a model of how noncompliant organizations and regulatory agencies interact in the emergence, persistence and erosion of misconduct. The theoretical model is presented in Figure 4.3. Our model begins when regulatory agencies signal the urgency of adopting and adequately implementing regulatory practices and structures. However, when the regulated firms neglect their oversight responsibilities and signals of noncompliance do not reach senior management, such organizations may respond by systematically disregarding these regulatory cues. Environmental ambiguity with regards to the prioritization by regulatory agencies may result in resource stringency, restricted internal support and competing goals. As a result, regulators may not be able to adequately respond to this negligence (bold arrow in Figure 4.3).

When regulators respond lenient or ambiguous towards noncompliance, rules that are in conflict with core organizational goals and heavily affect managerial discretion are likely to become perceived as illegitimate. Moreover, as noncompliance is primarily framed as a deficiency in the execution of procedural rules (e.g. not detailing or identifying client information correctly), organizations become convinced that these deficiencies require only little attention, resources or priority, and noncompliant practices become increasingly rigid. In other words, when firm-specific feedback is incidental, assurance for remediation is limited and sanctioning following noncompliance is absent, regulatory agencies may inadvertently create a situation in which noncompliance becomes normalized. That is, a history of regulatory leniency and ambiguous communication leads to the emergence of complacency (Box A).

As outlined in our findings, when regulators begin to confront complacency (Box B) through amplifying their coercive pressures (bold arrow in Figure 4.3), there is likely to be much contestation between complacent firms and regulatory agencies. Once complacency has become institutionalized, senior management may become mindless towards regulatory concerns. This mindlessness manifests itself in the underestimation of their operational risks and an overestimation of their degree of compliance. Moreover, when organizations are complacent, remediation is often only triggered reactively by negative feedback rather than proactive introspection. As a result, regulatory agencies may find it increasingly difficult to suppress normalized noncompliance among complacent organizations. Importantly, 


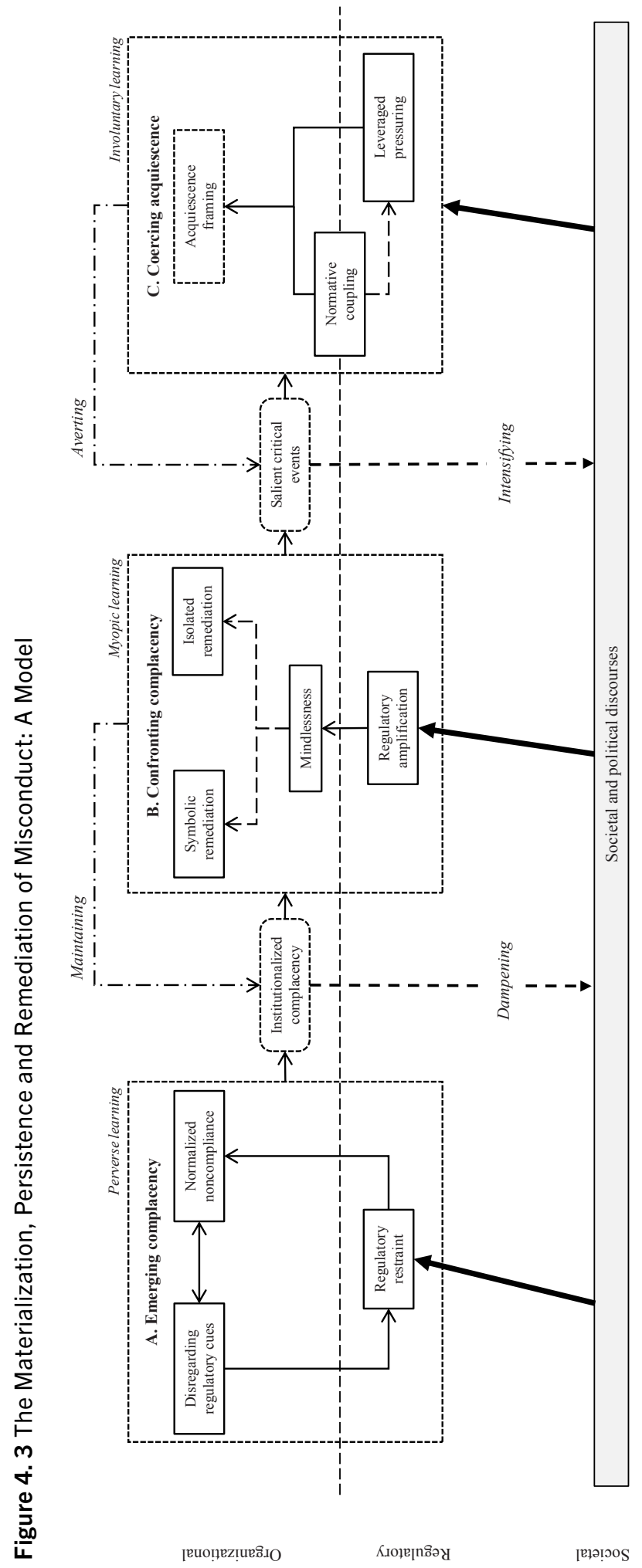


when actual enforcement or sanctioning are not communicated to key audiences, persistent noncompliance leads to only limited social visibility. Furthermore, overt resistance toward coercive pressures may only have a dampened influence on the societal and political discourse around the focal concerns (see "dampening" in Figure 4.3).

In Figure 4.3, we labelled these novel responses as symbolic and isolated remediation. First, firms may only symbolically remediate noncompliance in order to maintain the status quo. This process indicates that firms' corrective efforts are primarily driven to only symbolically meet regulatory requirements while still prioritizing commercial imperatives. Second, remediation is isolated when senior management repeatedly fails to interpret single violations as evidence of wider inadequacy in organizational practices, systems and structures but rather as isolated cases of noncompliance. This myopic stance is then confined to specific client portfolios, divisions and branches. Moreover, we argue that when both symbolic and isolated remediation result in only limited regulatory and social scrutiny, the state of complacency is maintained (see "maintaining" in Figure 4.3), and as a result, noncompliance is likely to persist. Because of the lack of social visibility of noncompliance and the perceived leniency of regulatory enforcement and sanctions, amplified coercive pressures is unlikely to sufficiently offset the perceived benefits (or perceived costs) of noncompliance or legitimize firms' regulatory responsibilities.

As shown in Figure 4.3, complacency may well become effectively challenged as a result of highly publicized events. These salient critical events trigger a process that we termed normative coupling, meaning that regulatory requirements become increasingly value-laden. In addition, by virtue of their public visibility, such critical events may profoundly intensify the political and societal discourse around regulatory noncompliance (see "intensifying" in Figure 4.3). Together, these events function as a significant spike in societal interest in rule-breaking, potentially heightening regulatory and political pressures for good behavior, signaling the possible social and monetary consequences of noncompliance, and increasing rule legitimacy (bold arrow in Figure 4.3).

Following these critical events and subsequent leveraged pressure, senior management is likely to see the need to respond to coercive pressures by publicly displaying its adherence to regulatory requirements by making resource commitments, while primarily aiming to avert any potential criminal sanctions, reputational damage or shareholder unrest that may result from salient critical events (see "averting" in Figure 3). This means that when governmental-mandated rules remain perceived as illegitimate, pointless or ineffective, responsiveness to coercive pressures may be mainly involuntary.

\subsection{Discussion and Conclusion}

In this paper, we set out to address two key questions: Why do organizations persist in engaging in misconduct? How do regulatory agencies achieve substantive remediation? We explored organizational responses to rising regulatory pressures and elaborated a theoretical model of 
how misconduct is created, confronted and eroded. This longitudinal approach complements studies that have previously analyzed in-depth a single incidence of organizational misconduct, yet have not investigated the materializations and persistence of misconduct over time. In this final section, we discuss the implications of our findings for organizational theory.

\subsubsection{Perverse Learning and the Emergence of Complacency: The Role of Social-Control Agents}

Our study offers important insights on the long-standing discussion on how the regulatory environment shapes organizational actions and, specifically, misconduct. Previous research on misconduct adhering to a social-control agent perspective (Clemente \& Gabbioneta, 2017; Dewan \& Jensen, 2020; Mohliver, 2019) emphasized that regulatory agencies are boundedly rational actors (March \& Simon, 1958; Palmer, 2012), must navigate resource and attention constraints (Greve et al., 2010), and are often rife with competing goals and interests (Greenwood et al., 2011; Heese et al., 2016). For instance, Scott (2014) argues that conflicting societal influences (e.g. political, economic, cultural) are mirrored within regulatory agencies, which may lead to role conflicts and eventually motivate regulators to sanction some type of firms, or sanction some types of misbehavior more than others. Although there are indications that such tensions have the potential to impact the enforcing behavior of these actors, how this may impact the materialization of misconduct has not previously been empirically explored.

The literature on organizational learning indicates that initial rule violations may become routinized in the absence of negative outcomes or feedback (Cyert \& March, 1963; Zollo \& Winter, 2002) or when rule-breaking and sanctions are only "loosely coupled" (Lehman \& Ramanujam, 2009; Orton \& Weick, 1990). Extending this line of research, we show that when regulatory scrutiny is absent, or enforcement is limited, organizational learning tends to be perverse. That is, noncompliance, once initiated, persists because the benefits are clear and immediate (e.g. avoiding, delaying or ceasing costly corrective measures), whereas any negative outcome or feedback is ambiguous, postponed or lacking. In our case, regulatory fines were restricted and the visibility of enforcement to outside actors was limited. In such a regulatory environment characterized by enforcement uncertainty, a weak sanctioning system and absent social sanctions (e.g. reputational, legitimacy), the line that separates acceptable from unacceptable behavior may not be clearly demarcated and noncompliance is likely to be widely seen as acceptable.

When regulators are persistently reluctant to sanction noncompliance, they fail to signal the legitimacy of rules and regulations. As a result, organizations come to perceive the allocation of scarce resources and attention to these concerns as justifying non-action. Our findings suggest that regulatory concerns become especially perceived as illegitimate when they are not in the firms' commercial interests (e.g., addressing the concern will take away scarce resources better allocated to other objectives) and because it is not recognized to be a normative objective to adopt (e.g., senior managers do not consider that they have a moral obligation to address this social concern). Although the former is reinforced by the limited 
financial and social costs of noncompliance, the latter touches on the notion that rules that emphasize procedural rather than ethical norms are more likely to be violated (Graffin et al., 2013; Heese et al., 2016; Lehman \& Ramanujam, 2009). In other words, procedural regulations that create bureaucratic 'red tape' and is experienced as disproportionately burdensome are likely to be perceived as illegitimate among regulated firms (Sonenshein, 2016).

Owing to the procedural emphasis of many government-mandated regulations (Edelman, 1992), as is the case with the type of rules we studied, opportunities for flexible managerial interpretation are high. When the flexible interpretation and, consequently, implementation of mandated rules is not regularly guided or corrected, "actions suggested by these interpretations come to be seen as permissible, necessary, and even normal" (Lehman \& Ramanujam, 2009: 650). In other words, these actions, which under unambiguous conditions would be viewed as deviations, become routinized.

Bridging learning research with the literature on the normalization of misconduct (Ashforth \& Anand, 2003; Earle et al., 2010; Vaughan, 1996), our findings thus indicate that when the persistent disregard of regulatory cues is unobtrusively tolerated or not sufficiently corrected by regulatory agencies, noncompliance becomes normalized and (to be perceived as) unresolvable in the long run due to the perceived costs attached to remediation. Such deviations are likely to become embedded in taken-for-granted practices and routines and, consequently, subject to inertia and repeated over time. Because of the perceived illegitimacy and ambiguity of the rules they are violating, organizations are likely to become complacent and they continue under the assumption that regulatory compliance concerns deserve only little attentional resources or priority.

\subsubsection{The Effects of Complacency on Organizational Responsiveness}

Our study also offers important insights on organizational responsiveness to external pressures (Oliver, 1991; Schilke, 2018; Surroca et al., 2013). We do so by elucidating how traits such as complacency, hubris and arrogance engenders resistance to coercive pressures for regulatory compliance. Previous research has linked complacency to a lack of vigilance, attention and awareness (Moray \& Inagakit, 2000), the inability to see, recognize or detect information (Arstad \& Aven, 2017) and constitutes a barrier to adequate responsiveness (Tourish, 2020; Tushman \& Nadler, 1986). Our findings resonate with aspects of previous research and extend the literature on responsiveness by unveiling that complacency, once institutionalized through perverse learning, becomes manifested in a strong force for rigidity and stasis.

Specifically, we find that complacency binds organizations to a set of taken-for-granted noncompliant practices and blinds them to alternative options, thus hindering them from adapting to rising regulatory pressures. When noncompliant practices become routinized, they tend to become enacted mindlessly; that is, with little or no real problem solving or even conscious awareness about their undesirability (Ashforth \& Fried 1988; Weick \& Sutcliffe, 2006). We suggest that this state of mindlessness, as the "thoughtless application of old ways of thinking to new situations" (Rafaeli et al., 2008: 847), blunts the perceived need to re-examine the premises 
that gave rise to the noncompliant practices in the first place, creating a certain "bureaucratic momentum" (Ashforth \& Anand, 2003: 14). This situation is reinforced when regulatory concerns are not prioritized by senior management and do not resonate with their perception of the financial, social and reputational costs of noncompliance. As a result, firms are likely to underestimate their operational risk and overestimate their degree of regulatory compliance.

Previous research has suggested that external events may counteract noncompliance (Desai, 2014; Haunschild et al., 2015). For instance, feedback from regulatory agencies has been shown to trigger a renewed focus on and organizational attention to routines as targets, thereby prompting the remediation of noncompliance. Chandler (2014) emphasizes the importance of such firm-specific critical events (e.g. regulatory audits and enforcement actions) in the adoption and implementation of an ethics and compliance officer position. In contrast, our findings suggest that when regulatory enforcement lacks social visibility, and thus reputational costs, firm-specific events have no significant or lasting effect on firms' behavior. That is, when an issue from the regulatory environment is perceived as illegitimate and there are only negligible economic and social costs of inaction, senior management may allocate only limited attention and resources in response to negative regulatory feedback.

Our analysis further reveals that when remediation of noncompliance is primarily motivated by negative feedback from regulatory agencies, so long as firms continue to perceive these regulatory requirements as illegitimate, organizations remain reluctant to substantially remediate and corrective efforts are at risk of being only symbolic (Boxenbaum \& Jonsson, 2017; Bromley \& Powell, 2012; MacLean \& Behnam, 2010). Issue illegitimacy and the negligible costs of inaction may lead senior managers to simply avoid making decisions about compliance concerns as they "cognitively distract from and actively seek to sustain the status quo" (Mellahi \& Wilkinson, 2010: 535; Tushman \& Nadler, 1986). More specifically, when organizations have a self-interest in not complying (e.g., to avoid costly adaptations to their customer due diligence practices), behavioral invisibility enables them to disguise their noncompliance and to avoid sanctions, such as the loss of legitimacy (Aravind \& Christmann, 2011). Behavioral invisibility thus undermines compliance to the extent that instrumentally driven adopters lack the motivation to comply.

When organizations have become complacent, they tend to search locally for solutions rather than more broadly which makes responsiveness and remediation mostly myopic (Catino, 2013; Levinthal \& March, 1993). Although the deliberate allocation of attention and resources is a critical ingredient for learning from feedback (Argote \& Miror-Spektor, 2011; Zollo \& Winter, 2002), we find that the externally enforced allocation of resources is likely to exhibits the risk of being only temporary. Similar to "organizational oscillation" (Anand et al., 2012; Haunschild et al., 2015), which described the process through which organizations cycle through periods of learning and forgetting, we find that when firms depend on external parties and short-term compliance teams for remediation, accountability and responsibility for remediation is vested in middle management rather than in senior management, and is executed by staff departments rather than core business 
units themselves, knowledge, attention and expertise gradually decline over time and rulebreaking is repeated.

\subsubsection{The Implications of Salient Events on Acquiescence}

The emerging literature on scandals has provided important insights on the responses from organizations (Gillespie \& Dietz, 2009; Schembera \& Scherer, 2017; Pfarrer et al., 2008) as well as from key constituents (Daudigeos et al., 2020; Clemente \& Gabbioneta, 2017; Graffin et al., 2013). However, research has also hinted at their "potential to increase order and stability in society" (Dewan \& Jensen, 2020: 1674). Although we believe that this latter insight has potentially important implications for research on organizational misconduct, it has not yet received empirical examination.

As indicated in our model, organizational noncompliance may persist when firm-specific critical events, such as regulatory enforcement or sanctioning, are perceived as lenient or lack social visibility. Conversely, we find that industry-wide critical events, including highprofile corporate scandals and criminal sanctions, may profoundly intensify the political and societal discourse around noncompliance. Previous research has suggested that these critical events, understood as "contextual dramatic happenings that focus sustained public attention and invite the collective definition or redefinition of societal problems" (Hoffman \& Ocasio, 2001: 414), may have a high degree of resonance with actors in the institutional field (Clemente et al., 2017; Lounsbury et al., 2003), including firms' senior management, regulators and the wider community. We find that such salient critical events can focus attention on the focal issue and, consequently, significantly enhance issue salience of firms' senior management (Bundy et al., 2013; Chandler, 2014; Durand et al., 2019).

Importantly, we contrast previous studies that have emphasized that firm-specific rather than industry-wide critical events determine substantive implementation of regulatory practices and structures (Chandler, 2014). Specifically, regulatory authorities may leverage industry-wide critical events to coerce substantive compliance and resource allocation by both the focal firms and peer organizations. Such strategy of leveraging of critical events to enforce substantial compliance, particularly through stricter and more intrusive monitoring efforts and emphasizing executives' individual legal accountability, is likely to resonate particularly well with firms' senior management, significantly focusing attention and priority (Ocasio, 1997).

Industry-wide critical events provide the opportunity and momentum for regulators for pressuring firms' boards. This process resonates with the work of Kellogg (2011), who showed how the broader societal context can gradually (or even suddenly) present discursive opportunities for actors in the institutional field to compel change. Our study extends this emerging set of ideas by demonstrating that these salient critical events, through heightened regulatory and public scrutiny, may function as discursive opportunity structures (McCammon, 2013) as they provide "salient discourses that are alive and have momentum at a particular point in time" (Cornelissen \& Werder, 2014: 210), legitimizing regulatory mandated practices and structures, and compelling substantive resource commitments and correction efforts. 
Through this process of "acquiescence framing" (Fiss \& Zajac, 2006) firms demonstrate conscious obedience to institutional norms and practices (Oliver, 1991), while primarily aiming to avert any potential criminal sanctions, reputational damage or shareholder unrest that may result from salient critical events. Indeed, in using an acquiescence frame, firms showed they are eager to demonstrate their substantive compliance with regulatory mandates. We show that, in our case, symbolic decoupling between policy and practice may only be a transitory phenomenon (Haack et al., 2012; Tilcsik, 2012), and that "initially symbolic adoption may eventually lead to more substantive implementation" (Wijen, 2105: 312) when strong external incentives (e.g. executives' legal accountability) and monitoring efforts are devised. Moreover, our research suggests that these highly salient critical events function as important social control mechanism for peer organizations.

Specifically, we find due to their saliency, industry-wide critical events may function as effective deterrence signals for others (Dewan \& Jensen, 2020) and as triggers for vicarious learning (Desai, 2014; Madsen, 2009). Firms may learn vicariously from misconduct by peer organizations, particularly when these ethical transgressions have high regulatory and social visibility (Chiu \& Sharfman, 2011; Desai, 2016). Therefore, there is good reason to believe that under heavy and publicized regulatory scrutiny, all organizations (focal firms and their peers) are more likely to follow through on their commitments.

Finally, while it is true that the adoption of practices and structures can be driven primarily by the need to satisfy external demands (Bromley \& Powell, 2012; Rao \& Sivakumar, 1999), the implementation of these practices and structures with "substantive resource commitments is understood to be a ... valid indicator of genuine intent" (Chandler, 2015: 200; Kraatz et al., 2010). However, the demonstration of substantive compliance with regulatory requirements simply in order to prevent future scandals may lead to suboptimal solutions. Responsiveness to coercive pressures is likely to result in involuntary learning and, consequently, a failure to address the underlying norms, beliefs and assumptions that cause persistent noncompliance (Desai, 2014; Rhee \& Haunschild, 2004). Rather than pressuring firms to proactively resolve the underlying causes of noncompliance, overt regulatory pressures and public attention increasingly compels organizations to devote significant resources and attention to resolving past noncompliance. More important, regulatory pressures for the implementation of quality requirements (e.g. collecting and validating client information and information on ultimate beneficial ownership) may only have a tenuous link with the prevention of future money laundering. 
The Persistence of Organizational Misconduct | 111 



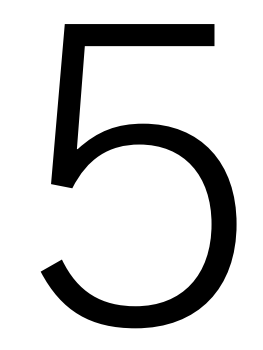

\section{Building Character through Adversity: Organizational Work in Response to Integrity Failure in a Financial Enterprise}

\subsection{Introduction}

Extant research has investigated the processes through which organizations return to 'business as usual' after experiencing disruptive failures, including organizational reintegration (Gillespie et al., 2014; Pfarrer et al., 2008), resilience (Sutcliffe and Vogus, 2003; Williams et al., 2017), and adaptation (Cyert and March, 1963; Kim, 2021). Although these studies have been mainly based on environmental or technological disasters, research suggests that integrity failures (e.g. mismanagement, misconduct, scandals) are especially likely to culminate in a breakdown of shared meaning and overt scrutiny of corporate legitimacy (Gillespie \& Dietz, 2009; Walsh et al., 2019; Wiesenfeld et al., 2008). Organizational scholars have shown that these failures may have a lasting and far-reaching impact on organizations and their constituents (Bundy et al., 2017; Greve et al., 2010; Hersel et al., 2019; Zahra et al., 2005). As such adverse events have the potential to be "character-defining" for organizations (Kraatz et al., 2010), it has become increasingly important to explore the more durable implications of integrity failures even long after the failure has occurred.

Previous versions of this chapter were presented at the 8th Annual University of Edinburgh Business School Paper Development Workshop, March 1, 2021, and at the 37th EGOS Colloquium, July 8-10, 2021 in Amsterdam, The Netherlands. A version of this chapter is under review at Administrative Science Quarterly. 
Organizational failures are change-inducing critical events that have the potential to give rise to latent ideals (Kraatz et al., 2020; Seeger \& Sellnow, 2005) and to significantly redirect or renew the character of organizations (Christianson et al., 2009; Maitlis \& Sonenshein, 2010). Importantly, studies have demonstrated how integrity failures may "create extreme uncertainty and distrust" (Paruchuri et al., 2021: 565) that must be dealt with quickly and in profound ways to restore the trust of important constituents (Bundy \& Pfarrer, 2015; Eberl et al., 2015; Gillespie et al., 2014). Such failures are especially difficult to overcome since they often combine uncertainty about the identity of the organization (Clark et al., 2010; Corley \& Gioia, 2004) with a distrust of its values (Mishina et al., 2012; Love \& Kraatz, 2009). This mixture of identity and values, which Selznick (1957) characterized as "organizational character", creates additional difficulties for organizations wishing to rebuild.

However, the emerging literature on organizational work offers some possible ways forward (Gehman et al., 2013; Kreiner et al., 2015; Lawrence \& Phillips, 2019). For example, Hills, Voronov, and Hinings (2013) have argued that rhetorical history can be used to overcome stigma. Similarly, Coraiola and Derry's (2020) research on U.S. tobacco companies suggest that organizations can successfully defend themselves against moral disapproval by engaging in memory work. Moreover, Walsh and colleagues (2019) explore the identity work by which former members recast a failed organization's identity in positive terms. This emerging body of research offers a promising direction for the research on the organizational efforts to re-establish organizational character.

Scholars have begun to explore the relevant historical sources (Cornelissen et al., 2020; Cuyper et al., 2020) as well as the managerial implications (Kraatz et al., 2010; Sasaki et al., 2019) of organizational character. However, we have yet to achieve a comprehensive understanding of the work that members engage in as they strive to rebuild the character of their organization in the wake of "character-defining" critical events, such as moral failures and crises (Clemente et al., 2017; Hoffman \& Ocasio, 2001). The sparse research that has explored reactions to integrity failures has largely been confined to identifying various types of organizational responses, such as refusals, excuses, justifications, and concessions (Gillespie \& Dietz, 2009; Schembera \& Scherer, 2017; Pfarrer et al., 2008), yet has not examined how such failures provide the impetus for leaders to implement more substantive change. Moreover, despite the recognition that the "past relates to and embodies the character of an organization" (Foster et al., 2020: 11), its unique history and collective memories of a problematic past, as well as its evaluative and behavioral implications for present organizational life, remain empirically understudied (Ravasi et al., 2019; Schultz \& Hernes, 2020). These are important research gaps that we believe warrant empirical examination if we are to better understand the process that organizations go through when rebuilding character in the wake of integrity failures.

By directing our attention to the organizational work members individually or collectively engage in over time as they "construct, maintain, and narrate the idiosyncratic character of [their] organization" (Lawrence \& Phillips, 2019: 124) in the aftermath of an 
integrity failure, we respond to the call for "reinvigorating the study of organizational character" (King, 2015: 167). Our study is guided by the following research question: How do organizations rebuild their character following an integrity failure? To address this question, we gathered longitudinal data from in-depth interviews, field observations and the archives of a European financial enterprise that was separated from its parent company and subsequently brought under public ownership during the 2007-2008 global financial crisis. In probing the puzzle of character rebuilding in the wake of an integrity failure, we construct an empirically grounded process model of how the character of an organization is internally reevaluated, reshaped and anchored.

Based on our findings, we offer several theoretical insights. First, adding to the literature on organizational failures, we extend previous research that has focused on the immediate and more superficial responses to integrity failures (Gillespie et al., 2014; Pfarrer et al., 2008; Schembera \& Scherer, 2017), but have not explored why leaders go beyond "changing surface structures and behaviors" and instead attempt to rebuild the character of their organization (Mishina \& Devers, 2012: 208). We do so by explicating how integrity failures that combine uncertainty over the identity of the organization with a distrust toward its values may coalesce in the need to rebuild character. Second, we add to the emerging literature on organizational work (e.g. Lawrence \& Phillips, 2019) by showing that successfully rebuilding character not only depends on neutralizing organizational policies, practices and narratives that have become perceived as problematic remnants of an undesired organizational self (Pratt \& Kraatz, 2009), but also on the use of rhetorical history and the retrieval of latent values and ideals. Importantly, this twofold "character work" is crucial in in recementing support from key constituents (Ansell et al., 2015; Besharov, 2014; Foster et al., 2020). Third, this study provides key insights regarding the enduring impact of an organization's legacy on present organizational life (Eury et al., 2018; Phillips et al., 2019; Suddaby, 2016; Walsh \& Glynn, 2008), as collective memories of a problematic past, and its behavioral and evaluative implications, embody fundamental elements of an organization's character and may thus critically shape managerial behavior.

\subsection{Theoretical Background}

\subsubsection{Integrity Failures and Organizational Character}

Although existing research has explored the various external environmental and internal causes of organizational failures (Clearfield \& Tilcsik, 2018; Habersang et al., 2018; Mellahi \& Wilkinson, 2004, 2010) there is not yet a clear consensus as to how to define organizational failures. Gillespie and Dietz (2009: 128) provide a reasonably comprehensive definition of failure as "a single major incident, or cumulative series of incidents, resulting from the action (or inaction) of organizational agents that threatens the legitimacy of the organization and has the potential to harm the wellbeing of one or 
more of the organization's stakeholders". Taking this definition, we see that failures can be caused by fatal accidents (e.g. the Challenger Space Shuttle disaster), environmental disasters (e.g. the BP Deepwater Horizon oil spill) and fraud and deceit (e.g. the Volkswagen emission's scandal). Such failures have been shown to be a source of disruption, distrust and uncertainty (Bundy \& Pfarrer, 2015), harmful or threatening for organizations and their constituents (James et al., 2011), and often parts of opaque developments rather than isolated events (Williams et al., 2017). Extant research has explored the various negative consequences of failures, such as a loss of legitimacy, negative profitability, intense negative emotions among key constituents, and even organizational demise (Bundy \& Pfarrer, 2015; Mellahi \& Wilkinson, 2010).

Moreover, scholars view failures as potentially change-inducing with lasting impacts on organizations and their members (Seeger \& Sellnow, 2016; Shepherd \& Williams, 2020). That is, failures may "trigger changes in how organizations represent their logics and raise questions about their focus of attention, sources of authority, norms, legitimacy, and identity" (Clemente et al., 2017: 23). Specifically, organizational scholars have noted that failures "may create a blank slate on which the organization can reinvent itself" (Christianson et al., 2009: 857), as severe failures can "disrupt the status quo, allowing for new assumptions, methods and organizational values to emerge" (Seeger et al., 2005: 92). In some cases, failures have been shown to result in a rejection of the structures, strategies and practices that are perceived as being associated with the event or having caused the event in question (Coombs \& Holladay, 2005).

In this study, we examine a particular type of organizational failure that has the potential to bring about extreme uncertainty and distrust. Scholars have characterized integrity failures as especially damaging as they often reflect "deliberate actions taken by management at any level to deceive, con, swindle, or cheat investors or other key stakeholders" (Zahra et al., 2005: 804). When organizations or its leaders are perceived to be involved in immoral or normatively undesirable conduct, such as in the wake of misconduct or scandals (Greve et al., 2010) or following the adoption of controversial practices (Bednar et al., 2015; Mohliver, 2019), this evokes a "situation wherein the firm's motives, honesty, and/ or character fall short” (Connolly et al., 2016: 2136).

Almost by definition, character is "that which is most central to an organization's being" (King, 2015: 167) and reflects an organization's distinctive commitments and its relationship with its community. As organizations become committed to a particular set of ideals and values, they "fix the assumptions as to the nature of the enterprise, its distinctive aims, methods, and role in the community" (Selznick, 1957: 55). Since character functions as an important focal point for judging and evaluating behavior both within and by organizations (Mishina et al., 2012; Love \& Kraatz, 2009), organizations that persistently uphold their commitments are likely to win admiration for their trustworthiness and reliability. In contrast, organizations that neglect their embraced ethical, regulatory and normative principles are likely to appear opportunistic and unreliable. Since integrity failures signal to constituents that the organization is neither trustworthy nor reliable in its interaction 
with stakeholders, its character is highly likely to become tarnished (Bundy et al., 2021; Connolly et al., 2016; Paruchuri et al., 2021).

Research suggests that when an integrity failure tarnishes the character of an organization, this may lead to a significant breakdown of the social institution in which organizational members have spent much of their time and may impel them to question what is central, distinct and enduring about their organization. For instance, when organizational actors experience disruption of their originally held identity, such as in periods of crisis or following an integrity failure (Jacobs et al., 2020), this may cause severe ambiguity, uncertainty and disidentification among members (Corley \& Gioia, 2004; Elsbach \& Bhattacharya, 2001). Moreover, an organization's tarnished character is likely to spur profound distrust and cynicism towards the values of the organization and may bring about the decay of the relationships that were anchored therein (Harris and Sutton, 1986). These cues must be dealt with immediately and in profound ways to win back trust from important constituents.

\subsubsection{Rebuilding Character through Organizational Work}

Although not explicitly concerned with integrity failures, Selznick (1957) hypothesized that as organizations adapt to critical moments in their life course, they develop a distinctive character, reflecting their core values and its historically accredited commitments. In exploring the process of character formation, existing research in this area has identified the time of founding (Cornelissen et al., 2020; King, 2015) as well as specific sensitive periods (Cuyper et al., 2020) as such character-defining moments. Sensitive periods, during which "the focal entity exhibits high susceptibility to external influences" (Marquis \& Tilcsik, 2013: 195) can occur, for instance, because of changes in leadership, market shifts, or as a result of severe crises. Given the uncertainty and distrust integrity failures often trigger (Connolly et al., 2016; Paruchuri et al., 2021), such failures are likely to function as formative moments for organizational character.

However, rehabilitating the character of failed organizations requires substantive work so that members come to reidentify with their organization and so that the organization regains a vibrant and relevant set of relationships with key constituents. To advance the research on character building following integrity failures, we borrow from the emerging literature on how organizations can actively construct, maintain, and narrate the character of their organization through "organizational work" (Lawrence \& Phillips, 2019). Two lines of inquiry are of relevance for our understanding of the actions members individually and collectively engage in to rebuild the character of their organization: identity work and values work.

First, organizational identity work focusses on the "processes in which individuals engage to create, present, sustain, share, and adapt organizational identity" (Kreiner et al., 2015: 11). Specifically, this work revolves around members' purposeful and reflexive efforts to construct, diffuse, maintain or disrupt their own and others' understanding of what is distinctive, central and enduring about their organization (Kreiner \& Murphy, 2016; 
Watson, 2016). Previous research has suggested that organizational identity work may be particularly important in situations of severe threat or adversity that are characterized by uncertainty and ambiguity (Corley \& Gioia, 2004; Walsh et al., 2019). When they are confronted by threats to their identity (Dutton \& Dukerich, 1991; Tracey \& Philips, 2016), disrupted organizations "can attempt to shape the image and pull it back in alignment with identity" (Gioia et al., 2013: 138). This can be achieved by emphasizing identity characteristics through either public relations initiatives or by engaging with business issues that would help reshape the image of the organization, and consequently, foster identification among dissatisfied members.

Acknowledging the relevance of the past as a basis for such organizational identity work, recent research has seen a growing interest in the use of rhetorical history (Basque \& Langley, 2018; Hatch \& Schultz, 2017) and processes of instrumental remembering and forgetting (Anteby \& Molnár, 2012; Ména et al., 2016). Studies on rhetorical history focuses on "the strategic use of the past as a persuasive strategy to manage key stakeholders of the firm" (Suddaby et al., 2010: 157). This stream of research investigates the ways in which the history of the organization is used strategically as a symbolic resource to emphasize the attributes of an organization's identity that it holds to be important, such values, goals, beliefs and abilities (Ashforth et al., 2008). In contrast, some organizations engage in identity work to obfuscate undesirable elements of its past. Although past actions can be 'naturally' forgotten over time (Casey \& Olivera, 2011; Haunschild et al., 2015), instrumental forgetting can also result from active organizational identity work towards stakeholders.

The second line of inquiry explores the activities through which values are performed in and surrounding organizations. Defined as "the purposeful effort of actors to create, maintain, and disrupt the values of organizations" (Wright et al., 2020: 61), the emerging research on values work draws attention to how values are performed in organizations (Gehman et al., 2013), how values can be evoked strategically to change organizations and institutions (Vaccaro \& Palazzo, 2015) and invoked politically and emotionally to restore them following severe crises (Gutierrez et al., 2010). This latter idea is of relevance here, as values work has been shown to be an important instrument in rediscovering latent values within organizational boundaries and restoring trust among stakeholders in times of adversity. For instance, values work has been shown to lead to the re-articulation of social relations and the promotion of sustainable living conditions in crisis-stricken Greece (Daskalaki et al., 2018), the crafting of 'split-identification' for repairing the identity of the Catholic church grappling with the accusation of child sexual abuse (Gutierrez et al., 2010) and to developing collectively shared honor codes in business schools (Gehman et al., 2013). 


\subsection{Research Setting and Method}

\subsubsection{Empirical Setting}

Our inquiry into how organizations build character through collective experience and respond to integrity failures is grounded in a qualitative, inductive approach that is well suited for developing new theory (Pratt, 2016; Van Maanen, 2011). We chose this approach because the goal of this study was to build theory about a phenomenon that is not well explained by the existing literature. Therefore, we conducted study at "InsCorp" (pseudonym), a major publicly traded financial enterprise located in a Western European country and offers a wide range of financial products and services to both businesses and individuals.

InsCorp represents a particularly interesting case for analysis for a number of reasons. First, InsCorp went through a period of dramatic turmoil during the 2007-2008 global financial crisis. As argued by Clemente et al. (2017: 24), the financial turmoil of the financial crisis was a "critical event that shed a bright light on the previous assumptions, belief systems, and prescriptions that contradicted other institutional logics and higher order values, such as fairness, welfare, and morality". Specifically for InsCorp, a series of events, including the miss-selling of investment insurance products, a series of failed corporate acquisitions, and illiquidity, resulted in InsCorp's parent company finding itself on the brink of bankruptcy. As a result of these events, InsCorp was separated from its parent company and subsequently brought into public ownership. That significantly altered the firm's life-course in the process and created extreme uncertainty and distrust among both organizational members and constituents.

Second, similarly to many other organizational actors who had to seriously rethink their blind adherence to the principles of maximizing shareholder value (Munir, 2011; Sharkey, 2015), the financial crisis gave rise to uncertainty and prompted InsCorp's leadership to make critical choices about previous taken-for-granted practices and norms, and more fundamentally, about "who it wanted to be". In response to these uncertainties, InsCorp has increasingly positioned itself as a socially responsible alternatives to its competitors. Its identity includes pursuing economic values of profit and growth, as well as societal values of environmental sustainability, health, and community welfare. However, given that InsCorp has become publicly owned again, it must manage multiple stakeholder pressures from its financial, environmental and social environments and inevitably operates in an institutionally complex environment.

\subsubsection{Data Collection}

Our qualitative study is based on longitudinal data gathered at InsCorp's headquarter over a period of 12 months, spread over 3 years (2017-2020), complemented by a collection of rich, longitudinal archival material (2000-2020). As we triangulated these three sources of data-in-depth interviews, nonparticipant observations, and archival materials-we compiled an extensive body of textual data across a 13-year time period (See table 5.1). 
This provided us with a dataset as rich and reliable as possible, enabling us to construct an in-depth process model of character building in the wake of integrity failure. As we gathered and processed our data, we were conscious of the confidentiality and sensitivity of our empirical material, notifying our informants about the purpose of data collection. For instance, as a way of member checking, we relayed our interview transcripts to our informants to allow them to correct for possible mistakes and inaccuracies, and contacted some informants to ask follow-up questions to check whether our interpretation of the data matched theirs.

Interviews. The main author conducted 56 semi-structured interviews with InsCorp employees, managers, directors and executives. Informants were selected based on purposive criteria (Miles \& Huberman, 1994). We chose to interview top management members, including board members, executives and policymakers, because they can be considered "key carriers of organizational actorhood" (Bromley \& Sharkey, 2017: 24), expressing and enacting the strategic posture of the firm. However, as other organizational members also represent important agents of organizational work (Lawrence \& Phillips, 2019), we also interviewed rank-and-file employees and managers. The interviews ranged between 60 and 120 minutes in length. Most were recorded and subsequently transcribed verbatim. When presenting the findings, we use codes to indicate the specific informant: we use EX to designate executives, $\mathrm{D}$ for directors, and $\mathrm{M}$ for managers. During these interviews, we initially asked informants to reflect on the financial products and services their organization offered; daily practices, routines and struggles; their perception of their collective identity and values; and potentially emergent tensions between the embraced social and commercial objectives. However, as we started to analyze our data as we collected it, we noticed how many of our informants brought up the global financial crisis and its implications for the organization's strategy and its collective identity. Because we wanted to further explore this interesting yet underexplored phenomenon, we began to look for informants who had personally experienced the crisis and added questions about important historical developments and their experiences of the financial crisis and its aftermath.

Observations. The main author conducted nonparticipant observations to contextualize the interview accounts and provide a richer framework in which to understand how InsCorp works in its daily operations. Field notes were gathered from observing dayto-day interactions and from observing a diverse set of meetings, including corporate responsibility and sustainability interest group meetings, product development meetings, and board and senior management gatherings. Other moments for observation included introductory seminars for new employees. In addition, non-participant observation provided us with ample opportunities for informal conversations with key stakeholders within the organization.

Archival material. We supplemented the interview and observation data with archival data on InsCorp's history, operations, employee policies, and stated mission and values. All this information, including annual reports, public policy statements and press releases, was publicly available on the company's website. The archival material that we collected spanned 
the period 2000-2020 and gave us insights into the various organizational responses the company engaged in in the wake of the crisis and subsequent nationalization. This data was particularly useful in giving meaning to informants' recollections of InsCorp's past. In our findings, we present archival material with an A followed by the year of publication (e.g., A2010 for an archival document from 2010).

Table 5.1 Empirical Material InsCorp

\begin{tabular}{llll}
\hline Interviews & & & \\
\hline & Interviews & Pages & \\
CEO (C) & 3 & 23 & \\
Executives (EX) & 4 & 51 & \\
Directors (D) & 16 & 224 & Total \\
Managers (M) & 20 & 388 & \\
Employees (E) & 16 & 259 & \\
& 59 & 945 & \\
\hline Observational Data & & & \\
\hline & Days & Pages & \\
Daily operations, head office & 12 & 31 & \\
Board meetings & 4 & 8 & \\
CSR board meetings & 3 & 16 & \\
PARP board meetings & 2 & 22 & \\
Miscellaneous meetings & 10 & 30 & \\
& 31 & 107 & \\
\hline Archival Documents & & & \\
Annual reports 2007 - 20219 & Documents & Pages & \\
Corporate magazines 2012-2019 & 13 & 2674 & \\
Employee magazine 2014-2020 & 7 & 445 & \\
General meeting of shareholders minutes & 40 & 797 & \\
Investor relations & 17 & 196 & \\
Miscellaneous & 21 & 594 & \\
Books & 5 & & \\
CEO interviews & 2 & & \\
Company exposition & 2 & & \\
IPO documentation & 1 & & \\
& & & \\
\hline
\end{tabular}

\subsubsection{Data Analysis}

For our qualitative data analysis, we applied the Gioia-methodology and used the standard procedures described in the literature (Gioia et al., 2013). Following this methodology's main tenets, we started to systematically code our data to develop a data structure that contains codes and themes that are increasingly aggregated, abstracted, and theoretically informed. We repeatedly went back and forth among data, emergent theoretical ideas, and previous literature to create a theoretically grounded process model of how organizations 
build character through adversity. Below, we elaborate on each of these stages in turn.

In the first stage of data analysis we engaged in the detailed reading of the collected data material. We started our analysis with the construction of a visual map of critical events (Langley, 1999), bracketing our stream of longitudinal data into separate time periods. This enabled us to develop a longitudinal narrative account. As we analyzed our data and constructed the timeline, we noticed two salient topics: (1) the significance of the financial crisis and its implications for our case organization; and (2) the organization's current identity, values and perceived position in society. Although our initial focus was not specifically directed on the past of InsCorp, the recurrence of this topic in our interview data did prime us to further explore that connection.

During the second stage of data analysis, we began the process of "open coding" (Corbin \& Strauss, 1990). We used the qualitative data analysis software Atlas.ti to code for firstorder empirical topics around themes such as the short-term responses to the crisis and their long-term implications on the organization's identity, its values, and its strategy. Iterating between the literature and reading the texts multiple times, we merged the initial codes to 60 first-order empirical codes.

In the third stage, we used axial coding (Strauss \& Corbin, 1998) to categorize the first-order codes into second-order themes. As we iterated between relevant literature and additional empirical data, we consolidated our initial firs-order codes into higher-level conceptual themes. These themes represented the collective interpretation that took place during the financial crisis ("confrontational interpretation", "reformative interpretation"), immediate organizational responses ("restructuring contentious practices", "retrieving valued historical remnants"), and members' engagement with the past ("renouncing the past", "episodic reproduction of legacy residue"). Moreover, as we started to develop the various processes and relationships between second-order themes, we started to approach important informants to ask follow-up questions and seek further clarifications.

Finally, we clustered these theoretically informed second-order themes in overarching aggregate dimensions. These five dimensions highlight the distinct practices and strategies that InsCorp's members enacted as they adapted their organization, which we termed "experiencing an integrity failure", "neutralizing character work", "accentuating character work" and "legacy engagement". By mapping these aggregate dimensions in parallel to the case history of our organization, we extrapolated three episodes of character formation through the experience of an adverse event: (1) "re-evaluating" (2007-2009), "reshaping" (2011-2015), and "anchoring" (2016-2020). The first episode involved the internal reflection that took place during and just following the crisis. The second episode involved leaders' efforts to reconfigure InsCorp's salient characters cues. During the third episode, this reshaped character became increasingly anchored. Figure 1 represents the data structure that emerged from our analysis of how our case organization built character through adversity, illustrating the first-order categories, the second-order themes, and the aggregate dimensions that served as the foundation for our model. 
$\frac{3}{0}$

\begin{tabular}{|l|l|l|}
\hline Reevaluating & Reshaping & Anchoring \\
\hline
\end{tabular}

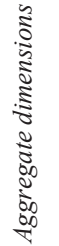
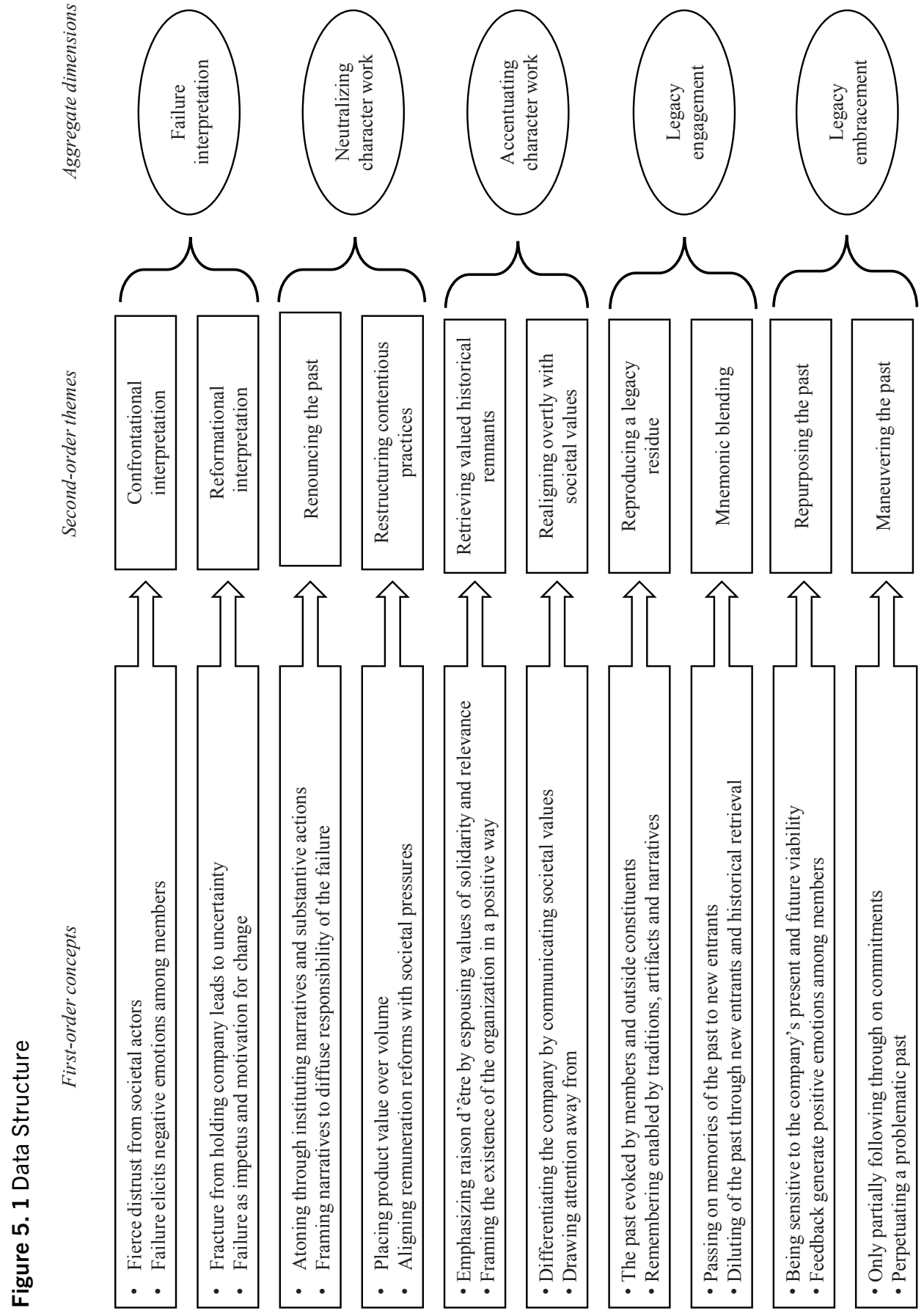


\subsection{Findings}

Our narrative of character rebuilding following an integrity failure begins in the period before the failure. Influenced by a stringent market logic and pressure from its parent company to maximize growth and profit, InsCorp's strategy before the 2007-2008 global financial crisis was primarily aimed at rapidly gaining market share by acquiring smaller competitors. A market logic is associated with goals of efficiency and profit, and that logic's predominance has been recognized across several heavily neo-liberal industries (Munir, 2011). As a strategy manager noted in InsCorp's corporate magazine:

We have to grow faster than our competitors. Incremental change is not enough. Our competitors are committed to growth. If we don't do the same, we risk putting ourselves out of action and we will fall in the rankings. When that happens, we have problems with our costs, with our shareholders and with the labor market [...] because nobody wants to work for a loser (A2007)

Likewise, a senior manager we regularly spoke with recalled: “There was a lot of pressure on the management to perform ... in the sense of revenue and profit-You shouldn't have come up with a different message at that time" (M4). This reflected, as another manager explained, the collectively shared belief that "the sky was the limit" (M8). As the global financial crisis swept through the financial industry, some of the insurance products InsCorp had sold on a massive scale in the past, which were colloquial known as 'usury policies', proved to be defective in various respects (e.g. on transparency regarding cost charges and other product characteristics, and included risks of which the insurer failed to warn, such as considerable stock depreciations, the inability to realize the projected final policy value, unrealistic capital growth projections, and on general terms and conditions regarding costs which many considered to be unfair). As a result of their complexity, hidden costs and the lack of transparency, these controversial products created significant financial losses for the consumers that bought them. InsCorp's CEO later publicly commented on this episode in the firm's life course:

The focus shifted more and more to profit [...] which meant that we were increasingly failing to provide what customers actually needed-We lost sight of the right to exist. And in 2008, that bubble burst very abruptly (EX1)

Our empirical analysis uncovered several mechanisms through which the collective experience of the organizational crisis began to define InsCorp's character. Below, we provide a narrative of our observations of this phenomenon, which is structured around the organizational responses that emerged from our empirical analysis. 


\subsubsection{Phase 1: Reevaluating Organizational Character (2007-2009)}

\subsubsection{Experiencing an Integrity Failure}

The financial crisis and the nationalization that followed led to a 'meaning vacuum' among InsCorp's members. As members attempted to individually and collectively make sense of what had happened to their organization, complemented by signals from various stakeholders, questions emerged about blame, responsibility, identity and, finally, how best to move forward. Two specific types of shared interpretations surfaced as members reflected on the failure and their organization's involvement: a confrontational interpretation and a reformative interpretation.

Confrontational interpretation. Managers explained that as they had not anticipated InsCorp's abrupt split, the failure was experienced as severely confrontational, aptly described by one senior manager: "The demise of our parent company came as a tremendous shock for us ... we didn't see it coming” (M9). During our conversations, we noticed that this interpretation was primarily incited by fierce moral disapproval-among others from the media and politicians-that the firm had failed to adhere to its embraced commitments towards its customers. Interestingly, while the fierce distrust during the financial crisis was primarily directed towards banks, informants experienced that this distrust was also directed at insurance companies, as illustrated in the following interview segments:

I think the public sentiment was really strong directed towards 'banker bashing'. And that also reflected on insurance companies because of their investment insurance products. So whatever we did, we were immediately [verbally] abused and criticized [...] And I think that did put the company under pressure, which led to a lot of uncertainty (M6)

Moreover, the exploitative financial products InsCorp had sold in the past caused a severe loss of trust among customers, as illustrated by the following segment from our data:

With today's knowledge, we can say that the financial industry could [...] have opted for a better balance between customers' interests and the creation of shareholder value [...] The zeitgeist was dominated by profit and value for shareholders. This became almost more important than serving the interests of the customer. As a result, the customer lost trust in [us] (A2010)

This quote aptly illustrates how InsCorp's strategy on maximizing growth and profit had created profound distrust among customers. Exemplifying the sense of drift and decay that had taken place within InsCorp, a senior manager reflected on how the organization had gradually strayed away from its traditional values and principles and elaborated on the distrust that this had evoked:

Our organization was also somewhat rotten. I worked in that sales environment for a while, where we completely lost a sense of reality [...] but there was also much more 
of a cultural thing behind our deterioration [...] modesty, Calvinism, sobriety [...] the principles that we know well in this country [...] we had actually strayed away from those values in a profound way. And that was the case in the whole financial sector, but for us it played out three times as strongly. We screwed up, so we had the sentiment against us (M4)

As employees began to interpret the failure as grounded in opportunism and undesirable behavior, both strong negative emotions-such as embarrassment, shame and guilt-and narratives of blame and accountability emerged: "After the financial crisis and as a result of the societal critique of financial institutions, we had this collective sense of guilt" (A2009). Others expressed their moral disapproval towards InsCorp itself, as emotionally described during a conversation with this senior manager: "I was personally no longer proud after the crisis. Before, I was quite proud for working for a financial firm. And after [the crisis], not at all ... If someone asked where I was working, I would start talking about something else" (M18).

In summing up the shared sentiment that had taken hold within InsCorp in the wake of the failure, a director explained how members "were hurt by everything that had happened ... there was this pain from the investment insurance products, pain from the crisis, pain from how we were being perceived" (D8). However, we also found that this collective sense of shame and loss of trust was accompanied by feelings of humbleness and humility. This is aptly illustrated by the interview segment below:

I was ashamed that we sold these products. When I got home, I thought to myself, 'Is this what we had in mind? That everyone would suffer so many loses?' [...] Only because we are so greedy as a company-You understand? That taught me to become humble and modest. And I also felt the responsibility, but definitely shame as well. Because I did not like that experience-Look, we had to explain to our stakeholders that we caused so many losses. And who was responsible for that? We were (D6)

Reformative interpretation. In addition to the moral disapproval and distrust that the failure had evoked, it was also perceived as profoundly disruptive for InsCorp. As the stability of the organization was at stake, InsCorp's leaders realized that they had to focus primarily on guaranteeing business continuity and solvency as well as regaining market share. For instance, as the crisis progressed, the vigorous focus on cost reduction resulted in several major layoffs cycles. These decisions, while defended as necessary for the firm to survive, created a great deal of uncertainty among employees about job retention and security, for example explained by this manager: "There was a feeling of unrest and fear ... I was looking for something to hold on to, but there is nothing ... I had been working here for so many years, [and] soon my job would no longer exist" (M2).

Consider also one of the defining moments for InsCorp that members frequently shared with us. As InsCorp's holding company had to pay out interim dividend to its shareholders, it had extracted substantial capital from its subsidiaries, effectively "using [InsCorp] as a cash cow" (M13). While we came to the view that these events had united InsCorp's members against "a common external enemy" (M12), the uncertainty they had evoke was overwhelming: 
The organization really had been through a lot-we had been pulled apart quite abruptly and that did have consequences. Specifically for the investment and capital side [...] we lost parts of our business processes and financial resources because of the split [...] That caused enormous unrest among employees. This was an organization where the staff was restless [...] I believe that when the crisis just started [...] there were approximately [...] people working at InsCorp. And now it is less than half of that. And that of course causes enormous unrest in the organization (M20)

Importantly, InsCorp's abrupt split from its parent company caused extreme ambiguity among employees about their organization's identity. During our conversations with managers who had experienced the split from up close, for instance, we noticed that many revealed that they had experienced an extreme 'existential void', as explained by this senior manager:

We had to rediscover ourselves. Who are we? What are we good at? What do we want to do? So [the nationalization] also gave us the opportunity to think about which products we wanted to offer, how we wanted to be in contact with our customers, and how we wanted to be recognized by our environment (M8)

In the wake of the split, leaders acknowledged that substantial reform was vital, both to regain the trust of customers and, maybe as importantly, to strengthen identification among employees who has become uncertain about what InsCorp stood for. For instance, one director recalled: "Ultimately, when we were nationalized, we felt a sense of shame, especially towards our customers-But I also say a certain unity arose. Apparently, we needed a kind of urgency that made us start thinking about these kinds of existential questions" (M19). This uncertainty also functioned as an important impetus for change of a more positive nature.

Under the umbrella of governmental ownership, informants told us, InsCorp's leaders came to acknowledge that they had been given "the opportunity to reinvent [InsCorp]-to make a fresh start" (D10) and "to rethink our identity, our ethics and values, and the way we were going to position ourselves within the financial sector" (EX3). Indeed, the split from the holding company, while traumatic, was simultaneously interpreted as a "true blessing for the firm ... because we regained our independence" (M9). The following segment from InsCorp's corporate magazine illustrates the new reality:

2009 will enter the books as the year in which we were confronted by major social and economic changes [...] In view of this, we must adapt our existing perceptions to a new reality. In this new reality, our business is also experiencing far-reaching changes. By the intervention of the state in our former holding company we continued in 2009 as an independent insurance company (A2009)

Our interpretation of the data suggests that this sense of urgency for change had become widespread within InsCorp, as "everyone was fully aware of the necessity for change ... which made the radical change more comprehensible for us" (M10). For instance, 
during one of our conversations, InsCorp's CEO reflected on the leadership of the parent company before the financial crisis and explained how he experienced the failure as a critical juncture for InsCorp:

I will never forget what he said during my first presentation of my budget for the following year: 'I only look at budgets that give double digit growth'. We had six or seven percent, and I was very good at explaining why that would be really hard work. But all he said to me was, 'If you can't do it, I will find somebody else.' [At] that time I was at a crossroads, and I started to orient myself, that this is not the company where I wanted to work. I could not run the company the way I believed a company should be run. And when the financial crisis started in September 2008, I decided that I wanted to stay on board-I didn't want to let people down, and from that moment on I made the best of it [...] I decided that I wanted to show that the financial sector is a relevant sector, and that we should be proud of it (EX1)

As senior leadership began to communicate this message of change internally, members started to interpret the ongoing failure as a temporary setback in the firm's history from which it would recover, rather than as a threat that would end its existence. Adding to this belief, a senior manager, who had joined the firm just before the financial crisis and had decided to stay on despite the uncertainty that had arisen following the nationalization, summarized these adaptive efforts:

If we are talking about putting the customers' interests first-selling these investment insurances was very symptomatic of the fact that we had really lost touch with our customers. [And] a strategy only aimed at double digit growth and an unbridled drive for profit, is ultimately a dead-end strategy. It ultimately comes together in a focus on the customers [...] and safeguarding our continuity. Both experiences led us to the same conclusion, albeit through two different questions: do we do things with the interests of the customer in mind? And what is our philosophy and vision for the future? (M5)

It is our understanding of the data that the confrontational and reformative interpretations primed InsCorp for change. The distrust towards InsCorp provoked members into interpreting the failure as profoundly confrontational, evoking strongly negative emotions among its members but also making the organization receptive to outside pressures for radical change. The reformative interpretation, in contrast, while grounded in extreme uncertainty and ambiguity over InsCorp's identity, functioned as a springboard for action and energized the responses to fill the existential void that had emerged, or as the CEO indicated during our interaction, "we had to rethink our raison d'être" (EX1). In sum, as the failure led to extreme distrust and uncertainty, members reevaluated the InsCorp's character as "tainted" which mobilized them to reshape it in a profound way. 


\subsubsection{Phase 2: Reshaping Organizational Character (2010-2015)}

\subsubsection{Neutralizing Character Work}

Strengthened by fierce critique from outside constituents, members interpreted the organizational failure as profoundly confrontational, eliciting strongly negative emotions. Simultaneously, the existential void that had emerged as a result of its split provided InsCorp with the opportunity to fundamentally reshape itself. However, leaders understood that to implement credible change and cleanse their organization's tainted character, they had to distance InsCorp from those elements that could be directly linked to the failure. In other words, leadership had to neutralize negative character cues. We termed these efforts as "neutralizing character work", which involved two distinct type of actions: renouncing the past and restructuring contentious practices.

Renouncing the past. InsCorp's $\mathrm{CEO}$ and his senior team began to realize that if they wanted to cleanse their organization's tainted character and instill substantive change, InsCorp had to renounce its problematic past. To advance this process, they acknowledged that they needed to change the way both members and outside actors perceived the firm by instituting narratives. First, leadership understood that to show character, it had to take a stand and take responsibility for past controversial practices, including the widespread sale of exploitative policies. As pressures from regulatory agencies and public interest groups became increasingly pervasive, InsCorp's leadership decided to set in motion a comprehensive compensation initiative. Although informants noted that these efforts were largely ordered by regulatory pressures, the archival material we collected showed how these actions were framed as coming from inside the organization. Nevertheless, this initiative was internally perceived as an important crossroads for InsCorp's members, as explained by a senior manager who had been involved in the compensation process:

This is the most important trajectory of all. If we can't get this [compensation] process right with each other, as an industry, but certainly also as InsCorp, because we are one of the largest insurers-then you can talk about the future as much as you want, but then the question is: 'do we have a future?' [...] And that is my point, never waste a good crisis [...] because we experienced that [crisis] together, we came to the realization that we should never want this again (D5)

One of the stories that we heard told at InsCorp that illustrated of this atoning process was the CEO's decision to make an appearance on the national media and publicly commit to the compensation scheme. While many within the company saw the potential risks of publicly guaranteeing compensation, employees simultaneously experienced this decision as a significant contribution to the atoning process, alleviating a feeling of shame and guilt and it gave rise to a sense of pride in the company. For instance, when asked to reflect on his CEO's action, a manager tellingly explained: 
I have a lot of respect for our CEO. I thought he was very courageous by entering into a dialogue [...] on national television. Obviously, he was connected to the past. I mean, he's been working here for so long that he too-he also had responsibilities back in the days [...] But he did take responsibility, and announced [measures], and then there actually came a period in which we could show that we [were different]-And we meant it. There will be no one here who doubts that (M19)

InsCorp's leadership was determined to follow through on this commitment which, over time, proved fundamental in regaining trust from core stakeholders and setting InsCorp apart from peers that had also sold exploitative policies on a massive scale, as explained by a senior manager: "While this matter was not yet resolved, we were perceived more positively externally, and it actually went better compared to our competitors" (M4). Furthermore, positive feedback on the compensation initiative aided InsCorp in its change efforts and created cohesion within organizational boundaries:

The result of our efforts to offer prospective clients perspective has not gone unnoticed. Our approach can count on increasing appreciation from customers, politicians and even competitors. We see that our competitors are interested in our approach and we feel supported by the letter about the policy on investment insurance policies that the Minister sent to the House of Representatives [...] Proof for us that we are really on our way to becoming the "other insurer" (A2011)

Interestingly, informants characterized the compensation initiatives as an important turning point, as "it symbolized a significant marking point to put the past behind us" (D5) and as a way to "take responsibility to credibly take the next step in our change process" (M11). This purposeful and strategic effort to rhetorically bracket the past facilitated organizational change through constructing a temporal divide between InsCorp's problematic past and its aspired future.

Second, we also discovered that leadership had disseminated subtle framing narratives through their internal and external communication in an effort to diffuse accountability for the failure. One recurrent narrative we encountered in our data was that InsCorp did not need or receive any government support during the financial crisis. Managers repeatedly emphasized that, in contrast its to peers, InsCorp did not receive a capital injection, as noted in its 2009 annual report: "In contrast to a number of other financial institutions, InsCorp did not receive any capital injection by the state ... [and] no guarantees or loans have been provided" (A2009).

Furthermore, some managers went as far as to frame InsCorp's nationalization as completely outside the firm's scope of control by suggesting that its parent company was primarily accountable for the split, as aptly summarized by a commercial director, "In the end, we were drawn into the financial crisis as a result of the actions and culture of our parent company" (D8). Another informant further elaborated on the shared sentiment within the organization that governmental supervision before the crisis had been inadequate: 
You've got to understand that it's not just the insurance companies who are to blameThere was moderate external supervision, the government facilitated [the controversial financial products] in an incredible way and there were no tax alternatives. It had become the perfect storm (D3)

Managers openly argued that rather than being a specific organizational concern, the selling of controversial financial products characterized by a lack of transparency and excessive costs had become normalized throughout the financial industry. That is, managers rationalized the controversial practices by noting that it was facilitated by ineffective governmental regulations and industry incentives:

In the end, mortgages, investment insurances, annuity constructions, you name it, everybody sold these products. The tax regimes were all very production-friendly ... but as a result, the industry entered into a certain sales drive, a 'product push' mentality-people had variable rewards, some [managers] also had bonuses and profit distributions. There were many external incentives that pushed us in that direction. And so there was also a lot of ... pressure to achieve growth and profit (M9)

Restructuring contentious practices. In addition to the atoning and framing actions, InsCorp's leadership understood that if it wanted to regain trust from core constituents it had to profoundly restructure the contentious practices and structures that had given rise to the failure. In other words, to open up space for credible change, some highly institutionalized structures and practices that could be directly associated with the failure situation would have to be replaced. First, as leadership tried to make sense of the failure, they realized that InsCorp had to redesign its financial products and services or to replace them with an alternative range of products, as noted in archival material:

The products and services that we introduce must meet corporate social responsibility criteria with respect to costs, transparency and plain language. This is the only way in which we can regain consumer confidence in the long run (A2009)

A fundamental incentive for this restructuring work was an "increased [regulatory] demand for transparency" (A2011) and pressure on financial firms to reduce the "mentality of pushing financial products on customers" (D8) which had dominated the pre-crisis period. Internal documentation explained that "the focus on excessive costs has resulted in a skeptical attitude towards insurers" (A2014). As a response to this distrust, InsCorp began to critically reflect on its own operations and practices. For instance, a manager reflected on the organization's increasing focus on the societal demand for transparency:

Transparency has become very important ... transparency in terms of costs, but also in terms of communication-We were always very skillful in writing policy terms that were pages long, that no one read and that no one understood. We had to become more transparent about what customers were insured for and they were not insured for (M8) 
An essential step away from a "practice of product push" (D8) was a strategic shift to "a focus on value over volume" (M2), as leadership realized that service with a focus on what customers actually needed rather than promoting financial products was "the only way for an insurance company to distinguish itself from the competition and regain the public's trust" (A2013). In this vein, InsCorp developed a new product development governance structure wherein leadership began to test the activities and objectives against the interests of the customer. New products were presented to customer panels and the wishes expressed by customers were systematically embedded in the product development process at the senior management level.

Second, substantive restructuring also became evident as the organization began to overhaul its remuneration policies in the years following the financial crisis. Reflecting on its perverse effects, InsCorp's leadership noted that the starting point for a restructured remuneration was "a method of reward in which a good balance is guaranteed between customer value, employee involvement and financial results" (A2011). InsCorp started by bringing the compensation of the board in line with the rest of its staff. Importantly, InsCorp's leadership was keen to minimize pay differentials and even capped the remuneration of top management. Our interpretation of the data suggests that this new remuneration system was experienced as an important milestone in the transition to a more customer-oriented organization. The remuneration reforms were particularly salient because they were a strong departure from the organization's past and practices of its parent company. For instance, in our conversations with commercial managers, we were repeatedly told that the ban on commissions for intermediaries. More importantly, these changes aligned with societal and political pressures following the global financial crisis, as explained by a senior manager:

The financial sector always had very extreme bonuses and compensation schemes. On the commercial side, but certainly also on the management side. But for us, those were all option schemes from our past, from our parent company era. We really thought it [variable remuneration] was the wrong signal to the market. We noticed that politics and public sentiment also played a very important role ... InsCorp has been at the forefront of abolishing them. That has also meant that salaries are generally more modest here than in the rest of the financial industry (M4)

The profit-sharing scheme based on profit growth, which had dominated InsCorp before to the financial crisis, was replaced by a remuneration system that focused more on customer-oriented sales by awarding senior management for their performance on client satisfaction and staff engagement, in addition to financial indicators (A2009).

By enacting these renouncing and restructuring actions, leaders were able to construe a somewhat positive collective understanding among members so that confidence in and identification with the organization was sustained. Moreover, these strategies were fundamental in configuring members' collective understanding of how the failure had unfolded. 


\subsubsection{Accentuating Character Work}

Whereas the neutralizing character work was focused on the removal or obfuscation of policies, practices and narratives that had become identified as problematic remnants of the InsCorp's tainted character and defining "who we are not", the accentuation of positive character cues was centered around amplifying latent or dormant organizational values and demonstrating "who we are". The two distinct types of "accentuating character work" we identified-retrieving valued historical remnants and realigning overtly with societal values-were meant to help reframe the existence of the organization in a positive light while also drawing attention to non-tainted aspects of InsCorp.

Retrieving valued historical remnants. Our informants reiterated their belief that the distrust that had emerged towards InsCorp signified the necessity for the company "to [put] emphasis on our insurance operations, products and services and regaining the confidence and trust of our clients" (A2010) by "putting the customers' interests first" (EX1). To substantiate these commitments, leadership realized it had to influence employees' understandings of the importance of the change efforts through strategically retrieving and mobilizing elements of the company's dormant past. Retrieving these latent historical remnants, InsCorp's CEO explained, was meant to confer legitimacy the company, and to provide a clear internal direction for change during times of extreme uncertainty and ambiguity:

While going back to the past is never a good message, I asked myself the question: 'What is our raison d'être?' And that has been my motivation since the crisis. The financial sector has a very clear right to exist, and I wanted to bring that right to exist back into organization (EX1)

Recall how the failure had forced the leadership to re-evaluate InsCorp's character and its raison d'être within the financial industry. Many of our informants told us that the inevitable reevaluation of InsCorp's character led to the recognition among leaders that they had to present and reframe the existence of InsCorp as having positive value for both its members and the wider community. The core elements of the organization's right to exist as an insurance company, as archival documents indicate, were primarily centered around the belief in solidarity and social relevance. As we began to question managers who had been active in these reframing efforts, we were informed that the principles of solidarity and relevance embody "the foundation of what we do and who we are as an insurance company" (D4), is aptly summarized in the following interview segment:

We had to go back to the basics, what it means to be insurer, namely sharing risks and not primarily making a profit. And sharing risks means that we should, in principle, be there for everyone who wants to insure themselves. So we want to be a socially useful and relevant insurer (D11)

Our interpretation of the data suggests that this process of "anchoring in origins" of the firm (Basque \& Langley, 2018) was a response to uncertainty that had emerged as InsCorp was split from its parent company in the wake of the parent's failure. This is illustrated in 
the following statement which was included prominently within the company's corporate magazine:

As an organization, we have the position that we want to and can do things differently. We worked as employees for a company whose parent company fell apart in 2008 . That gives a completely different view of the world. We have learned from that. As an organization, we want to work the way our company started in the $18^{\text {th }}$ century: sharing and bearing risks together, based on guaranteeing mutual trust (A2013)

In 2010, in an effort to support this historical anchoring, InsCorp moved its archives to its head office. We observed in our fieldnotes that artifacts from the company's distant past were placed in glass showcases throughout InsCorp's headquarter. These artifacts, in the form of documents, historical objects and an art collection built up over the years, aimed to demonstrate the company's social involvement and valued history. The purpose behind the creation and showcasing of the art collection and the archival documents was "to make the working environment as inspiring as possible for employees, customers and visitors" (A2015) and to "demonstrate to stakeholders that we are going back to the basics" (EX3). This example of retrieving historical remnants is further illustrated by this fieldnote which describes a senior manager explaining the historical relevance of artifacts displayed throughout the headquarter:

As we walk through the public meeting area, the senior manager points to a historical artifact, a small shield positioned in a glass showcase, displaying a house, a tree and a family, "We went back to our old logo-It's black and white because we want to be efficient and modest. We are not wasteful. So no colors or fancy logo [...] Company X's fancy logo has something distant to it [...] In contrast, our logo must be more accessible. And the logo also shows what we do. In other words, we're going back to the core of why we ever existed, we're 'going back' to the $18^{\text {th }}$ century when we started [...] To cover risks for people who do not want to run them themselves” (Fieldnote)

Retrieving and repurposing these inherited labels from the company's past elicited positive emotions and meaning among employees, and helped them to regain identification with their organization. For instance, informants noted that InsCorp's distant past, with a focus on solidary and social relevance, was "experienced as something to be proud of" (M11) and of which "we like to be reminded" (D2). This narrative of anchoring in the origins of the firm was meant to promote a clear disconnect from the company's problematic recent past and, at the same time, a strong identification with what InsCorp wanted to be in the future, thus aiding the process of periodization, as highlighted in the following interview transcript:

In 2008 the first step was actually taken to put the customer first again. We had to completely abandon that double-digit growth philosophy, we had to go back to the origins of-to our "raison d'être" (M5) 
In summary, the data suggest that this retrieval work helped to increase confidence in the organization's purpose by retrieving and emphasizing its reason for existence. As InsCorp re-evaluated its core characteristics, the organization built a clearer raison d'être and a stronger sense of togetherness among its members.

Realigning overtly with societal values. Although our data suggest that the retrieval of valued historical remnants strengthened identification among members, the efforts described above proved to be insufficient in eroding widespread moral disapproval. More effective in reducing distrust among constituents were attempts by the leadership to shift attention to non-tainted aspects of InsCorp's character. In this vein, the leadership began to enact those societal values that had become salient at that moment in time, more specifically, transparency, corporate responsibility and sustainability. For instance, InsCorp had already engaged in several sustainability topics since the late 2000s and excluded various "sin" sectors from its investment portfolio. As the senior management sought ways to explicitly convey the new approach to avert attention away from the company's problematic past, the company launched a series of marketing campaigns. In constructing these marketing campaigns, InsCorp utilized the various initiatives that had been taken shape within the organization:

Our marketing department has also noticed that all kinds of social initiatives are taking place within the organization. And if you look at our competitors, they don't communicate that much about it [...] The insurance product is just a very homogeneous product, so how do we as InsCorp distinguish ourselves from our competitors? Our marketing department has seen a distinctive character in these sustainability initiatives (M17)

InsCorp understood that if it wanted to differentiate itself from its competitors, it had to define an distinct purpose for InsCorp. InsCorp's leadership realized these initial initiatives could be leveraged to set the company apart and exhibit its distinct character. For instance, pressures from institutional investors had already persuaded InsCorp's asset management division to make considerable and far-reaching advances in its responsible investment practices. As a result, InsCorp started to climb in the national rankings on socially responsible investing. Noteworthy in this regard, while much effort was made to accentuate InsCorp's valued character, many cues were only symbolic and did not substantially affect the core insurance operations of the organization but were rather a tactic to differentiate the current from its undesirable past. For instance, senior management began to search for initiatives and collaborations to explicitly get InsCorp involved in socially-minded partnerships, as explained by this executive:

We recently entered into a joint infrastructure investment program with Firm $\mathrm{X}$, in which we collectively invest in European-wide infrastructural projects. And that is all 'Firm X proof', so sustainable and responsible [... ] The return on it is a bit lower. The return on a green wind farm or green energy, whatever, is lower than the return on 
other infrastructure projects. Ultimately, we accept losing 20 basis points. We accept that, that's fine-If I had lost 1.5 percent, I wouldn't have done it [...] But in this case, we thought it was so strategically attractive to create a positive aura (X2)

Again, this symbolic contrasting of the past was also reflected in InsCorp's renovated headquarters, which had been redesigned to express societal values of environmental sustainability and transparency more explicitly. Our interpretation of the data suggests that members had come to view it as both transparent and open, a clear departure from the past; and as sustainable, which strongly symbolized the direction the firm had taken moving forward. One director who had been part of the team responsible for the renovation explained, "It was a vision, not just an architectural 'tour de force' ... it was a real message, we needed to become a more transparent company" (D5). In examining the archival material, we came to the view that the renovated headquarter gained widespread praise among InsCorp's visitors, employees and community, and was unique in that it was in line with the organization's philosophy of transparency, sustainability and austerity.

\subsubsection{Phase 3: Anchoring Organizational Character (2016-2020)}

\subsubsection{Legacy Engagement}

As a result of the character work leadership engaged in to foster identification among members and reduce distrust from important constituents, it might have been expected that InsCorp would have been able to cleanse its tainted character and return to 'business as usual'. However, despite these efforts our analysis suggests that members continued to labor under their organization's problematic legacy. InsCorp's sustained legacy engagement comprised two distinct activities-episodic reproduction of a legacy residue and mnemonic blending.

Reproducing a legacy residue. Despite InsCorp's efforts to neutralize undesirable remnants and draw attention away from tainted aspects of its character, informants continued to experience recurrent evocations of their organization's problematic recent past. As we began to probe this process of legacy reproduction, we found that the memories of InsCorp's problematic past emanated primarily from various constituents, including customers, politicians, regulators and the media. Informants indicated the profound 'stickiness' of these memories, explained somberly by a senior manager, "[We] are forgiven ... but definitely not forgotten" (M20). For instance, managers stressed how they often felt operating "under intense public scrutiny" (M6), or as explained frustratingly by a senior manager, "We are working in a glass house ... politicians and regulators are looking very critically at us, not always in a fair way" (M8). Illustrative of this enduring scrutiny by outside actors is the following segment of an interview with a commercial manager, who described how a recent acquisition by InsCorp created negative media attention and perpetuated memories of InsCorp's problematic past: 
A trauma from that entire investment saga is still hanging over the industry. Recently we made an acquisition [...] [and] when you look at the reporting about this in the media, [our past] is immediately brought up again-there is this narrative that we cannot be trusted. So there truly is this enduring negative sentiment (M8)

Consistent with these expressions, members felt that InsCorp's character remained ostensibly tainted by ongoing compensation efforts, as a senior manager tellingly explained, "We call it our 'legacy', because it originated from our past ... and because we are still working on it to this day" (M4). Despite the compensation efforts InsCorp's leadership had engaged in, class action lawsuits initiated by dissatisfied customers and interest groups persisted long after the failure had occurred:

That negative sentiment is being sustained by the outside world. The regulator just picks it up again-there are all kinds of interest groups that still conduct class actions lawsuits against insurers [...] Time and again we are confronted with something from our past-that has actually not been the case for a long time. So that sentiment is fueled by a number of parties who have an interest in this narrative (M23)

This quote reflects a shared experience among InsCorp's members; specifically, that the litigations and the negative attention their company received was not only highly confrontational, but also unfair as they believed that InsCorp went beyond what peer firms had done in their compensation efforts. Many noted the remaining ambivalence and even hostility with regards to these efforts. Members made sense of this hostility by noting InsCorp's tainted character was difficult obfuscate as the financial losses for customers had been significant. For instance, a senior manager who had been deeply involved in the compensation initiatives throughout the years explained: "I think we have to realize that we will not get any appreciation for what we were doing ... we should not expect customers to forgive us for having sold them these insurance products [...] as they lost a lot of money" (M17).

We experienced that the taint of InsCorp's problematic past remained a looming challenge in daily organizational life. Our informants explained, for instance, that their organization's past was regularly voiced in the day-to-day interaction with customers: "our past is often evoked when [customers] are dissatisfied with our services and products" (M11). Illustrative of this sentiment was a conversation we had with a commercial manager who recalled a heated exchange with a customer that very day. The manager had been unable to meet the customer's requests because of their policies' restrictions, which caused the latter to scold that InsCorp "had not changed-it would always stay untrustworthy" (M12) before hanging up the phone. Reflecting on this interaction, he noted how common this response was among dissatisfied customers:

The belief that insurers and banks are only here for themselves and for their shareholders, and do not think about their customers [...] is still really endemic-It is 'us versus them' [...] It's also a bit out of dissatisfaction. Customers have to deal with disappointments, 
also from financial products. You sometimes tell them 'no' [...] The truth is, I think that the [negative] framing is still very strong, even ten years later-Just look at all consumer programs, we are continuously referred to as non-transparent. And that image is very difficult to correct (M12)

Stories such as this one highlighted how the episodic reproduction of the company's problematic past elicited strong emotions among both members and key constituents, signaling the enduring effect of InsCorp's past on its present. As we were interested in how these memories were sustained within the organization, we found that memories of the company's problematic past also resided within seniors managers who personally experienced the period building up to the financial crisis. For instance, as we spoke to a director who had been working at InsCorp during the financial crisis, he reflected on how the failure was experienced by many of the directors who participated in InsCorp's central product development working group:

Many of my colleagues on the product development board have all experienced [the crisis]. They were also part of InsCorp ... [And] even though we have compensated for these products and try to do the right thing, we are continuously working against societal perception and sentiment. And that sometimes makes providing [financial services] complicated. That no matter how legally you do it right, the voice of society and the customer-That is really something we have to take into account in everything we do (D8)

Note that how despite efforts to compensate for damages incurred, the leadership was unable to fully repair InsCorp's tainted character. However, this quote also shows that painful memories, when sustained and periodically reproduced by the mnemonic community, forced InsCorp's members to consider ethical and normative principles rather than only legal obligations when making decision. That is, such unsuspected reproduction proved important as it reminded individuals what kind of behavior had tainted their organization's character in the past, as illustrated by the following fieldnote the main author produced during one of the product development meetings. During the meeting, the controversial exploitative policies were brought up, which evoked a sense of unease and angst among the directors present, many of whom had experience InsCorp's failure firsthand:

Director A: I was triggered because you use the word 'usury policy'

Compliance officer C: That's ten years ago

Director A: Apart from not using that word anymore, I can't quite put it into context Compliance officer C: [...] In my role, I have to say that we mention that word often in the context of long-term products [...] retirement products often get this [connotation] [...] All long-term products, wherever you may have to deal with disappointment or certain expectations that do not come true-people will use this word

Director I: There has also been a very negative shroud around our B Division [division selling long-term financial products]

Compliance officer C: But I still have the idea that those concerns are more in relation to care abuses, [and] not in insurances 
Director I:-Only the customer does not make that distinction

Compliance officer $\mathbf{C}$ nods and adds: True, [the customer] does not make that distinction [...] but you're right, the complaints are a lot about disappointment

Director I: Right. And I don't get any complaints at all about our active insurance policies. Really zero. [But] there has been a negative shroud around it. [The regulator] also treated us very badly, in 2014 [...] We were all put in the sin bin-But that should be all history now (Fieldnote)

While this fieldnote excerpt reveals how members harnessed memories of a problematic past to guide decision-making in situations of uncertainty and ambiguity, it also exemplifies how negative mnemonic traces are sustained and periodically evoked by various outside constituents.

Mnemonic blending. As noted above, as InsCorp's mnemonic community continued to remind the company of its problematic past, members of InsCorp continued to experience episodic reproductions of legacy residues. However, our interpretation of the data also suggests that InsCorp attempted to blend these negative mnemonic traces in more positive and workable ways. We noticed, for example, that as InsCorp began to embed its principles of solidarity, relevance and sustainability in their financial products and services, memories of the problematic past became increasingly blended with the more positive emotions associated with InsCorp's reshaped character. For instance, leaders explained that they noticed that employees who applied for and joined the organization did so because they identified with the reshaped character of InsCorp and the principles the company began to espouse and enact. This was expressed proudly during a conversation we had with an executive:

The outside world is beginning to discover that this company is really changing. And we also see that as an employer. Before applying to us, people read about who we are and what we do [...] [We] are increasingly being told that [... our social character, appeals to people. Especially young people, who are more aware than my generation, for example, of the importance of the changes we need to make (EX3)

As we began to talk with members who had joined InsCorp after the financial crisis, we came to the understanding that members who had not personally experienced the financial crisis and the ensuing nationalization of InsCorp shared the belief that, while the lessons learned were relevant and should not be forgotten, the problematic past "was before [our] time ... and we are therefore not to blame for it" (M3), as explained by this new entrant, “... at the moment we are still subjected to that negative framing ... So we have to take that as a starting point, which still hits quite a few nerves for some-[But] at some point you do leave the past behind" (M11). What stood out to us in this context was that the mnemonic traces of InsCorp's problematic past had begun to gradually dilute. Apparently, many of the new members acknowledged the distrust still looming over the industry, but had found much value in InsCorp's reshaped character.

Simultaneously, our data suggest that because they had collectively experienced the failure, senior managers had gained a collective awareness about the frailty of public trust, as 
explained by this director, "Trust can take years to build, and together we have experienced that it can be gone in the blink of an eye ... [So] we had to come a long way ... that was a collective realization" (D5). This collective realization had become endogenously embedded and perpetuated within the organization through various narratives and practices, for instance, through stories and formal ceremonies. One of the stories that we heard told at InsCorp, for instance, how members that joined the organization in the wake of the crisis:

I sometimes hear the stories of men from the board of directors, men who have been in the insurance business for a long time [...] and I sometimes hear the stories of how it used to be [...] that was a time when insurance companies made quite a lot of money, to put it bluntly [...] and there was a lot of excess. At least if you hear those stories, I've never really experienced that personally. When I joined the company in 2007, everyone already felt like: 'it's not going to be easy in the near future'. So I never really experienced that excess. So I think I was brought up very much not to be wasteful. And I think that has really gotten into my DNA. That we really have to be financially prudent, and only make expenditures that lead to something [...] 'no waste' was a theme within our company at one point [...] Back to the focus on the customer [...] Those are all terms that played a role in the early stages of my career (M5)

In a similar vein, we recorded in our fieldnotes that as part of their onboarding process, new employees were required to take part in a ceremony, during which they had to sign the company's code of conduct and were informed about the crisis and subsequent nationalization. During one of these ceremonies, the main author observed how an executive addressed a large group of new employees and noted that, “... InsCorp is the only insurance company that requires its employees to take an oath ... as a way of restoring confidence" (Fieldnote). These practices helped store specific stories, narratives and lessons from the past in the procedural memories of new employees, 'infusing' them with emotions that linked the current organization to its problematic past. Although this example aptly illustrates how members were informed about InsCorp's past, it also demonstrates that members who had joined InsCorp following the failure were socialized in a way that enforced a particular recollection of the past. In this vein, we observed that while InsCorp's corporate museum had a whole section devoted the financial crisis and InsCorp's nationalization, the failure was framed ostensibly as caused by its holding company. These narratives projected an idealized version of the organization but were important is fostering identification among members

\subsubsection{Legacy Embracement}

As InsCorp progressively anchored its reshaped character in its strategy and operational procedures, we began to notice that InsCorp's members talked more and more about the importance of integrating principles of solidarity, social relevance, transparency and sustainability in their financial products and services so that they could reach a wider audience. Simultaneously, our analysis suggests that as InsCorp was forced to continuously engage with its legacy, members began to respond by embracing its problematic past. 
Over time, members made sense of InsCorp's legacy through repurposing the past and maneuvering the past.

Repurposing the past. While the failure that InsCorp experienced was traumatic, our data indicate that confronting it helped the company affirm its character as an organization reshaped to promote solidarity, sustainability and social relevance for both members and its community. The blending process describe above had made members "conscious about [the] company's painful past" (D8) and, as a result, the engagement with InsCorp's legacy was experienced by many as emotional and at times frustrating. Notwithstanding these struggles, many members came to reinterpret the meaning they attributed to InsCorp's failure from something that was very negative, to something that was part of the character of the organization and that could be purposefully used as a strategic asset to demonstrate cherished character traits such as resilience, durability and independence.

For instance, during one meeting between senior managers that the main author observed, a PowerPoint slide deck intended for investors was shown. Interestingly, the presentation began with a sheet that read "never waste a good crisis", followed by the statement that "InsCorp did not receive any (financial) support from the state" when it was nationalized (Fieldnote). This caught our attention, and when questioned as to why management had decided to focus on the crisis, a director explained that, while traumatic, the successful recovery was perceived as a unique selling point that set InsCorp apart from other financial firms and that this was a way to achieve legitimacy (D3)

In other cases, experiences from the financial crisis were purposefully used in shaping InsCorp's corporate strategy. During the time of the research visits, for instance, InsCorp began to refine its strategy, and leadership looked to its collective experience of the crisis for guidance: "As a result of [our] past", one executive explained, "we strongly believe it is important to enable and facilitate customers to take responsible risks and make conscious financial choices" (EX3). To realize this commitment, senior management incorporated principles such as promoting financial self-reliance as core elements of InsCorp's strategy. For instance, in line with the company's principles of solidary, the leadership identified a societal demand for insuring physically demanding occupations:

We consciously insure occupations of which we know in advance that we have to commit additional resources [...] As occupations get physically tougher, you move into a higher hazard class. And for these classes we have to put in extra money to keep them insured [...] And we do that consciously, because we want to be there for all occupations. And that does not apply to all insurance companies. There are also those who only focus on the whitecollar professions [...] [but] we want everyone to be able to be insured. That is something we are proud of (D4)

These examples demonstrate that InsCorp's embraced principles of solidary and relevance became more widely held and deeply rooted over time and generated pride in the organization and helped promote its values among its members. In our conversations, members increasingly articulated both a sense of satisfaction with the principles InsCorp 
had begun to espouse and enact through their character work and admiration that their company had stayed true to its values in spite of the image problems it had suffered.

InsCorp leadership's intent to anchor the character of the organization was aided by feedback from its external environment: "In the process of our development into a customer-oriented and transparent insurer, any awards and prizes received are recognition of the positive changes within the business" (A2017). For instance, consider this quote from a manager who had joined InsCorp only after the crisis:

Let's be honest, we also sold these insurance products with hidden costs in the past. I can't use that word anymore [...] I'm not allowed to say anything about these insurance products at all, and I don't know anything about it either. But we did sell them-and not everyone appreciated that we did. When you talk about image, you still see many reactions about these insurance products in the media. But the share that those investment products now occupy has become smaller. So all the work we've done with regards to compensation and reparation paid off (M7)

Our data indicate that InsCorp's leadership began to leverage this external feedback, through its internal dissemination and external communication, adding credibility to change narratives, reinforcing the appropriateness and rationality of the change and the embraced societal commitments. For instance, during a meeting for all the company's 250 senior managers the main author observed how the CEO explicitly indicated that InsCorp was being "recognized and acknowledged as the most sustainable insurance company in the country ... and perhaps in even in Europe" (Fieldnote). This interpretation was backed by external endorsements of InsCorp's sustainable, corporate responsibility and community practices:

Throughout the year, we were given recognition for our activities in many different areas. We consolidated our number one position as a sustainable investor [...] By conducting a sharper investment policy on labor laws, gender equality and transparency, we improved it [...] and ended the year ahead of other insurers (A2018).

We noticed that members began to interpret this as an affirmation as well as a unique selling point towards InsCorp's customers and shareholders. Importantly, the data suggests that InsCorp's character work helped to increase confidence in the organization's purpose. As InsCorp reevaluated its core characteristics, members were confirmed in their organization's reshaped character, thereby regaining customer trust in the values of the organization and increasing identification with it by employees.

Maneuvering the past. Interestingly, we observed that because the InsCorp's failure had become such a significant part of its character, leadership was forced to continuously maneuver their organization's sticky and rather tenacious problematic past. One of the frustrations we heard expressed several times during our time at InsCorp was grounded in the fact that the company still had "controversial insurance products on the books [...] that are still subject to complaints and lawsuits" (D9). Therefore, proposals for new investment- 
like and long-term financial products elicited strong reactions from key constituents. Illustrative in this regard was the introduction of a new variable pension product that would provide customers with the opportunity to continue to invest after retirement. One of the directors responsible for creating and marketing this financial product explained that this product led to criticism from regulators concerning the lack of transparency of the product, and purposefully made a connection with the company's problematic past:

[...] it was the regulator who gave the sentiment of the 'usury policy' to this product. And I didn't think that was correct because they articulated that as an opinion [...] while the law did provide room for this product. And so [my colleagues] were afraid of the regulators. In the end, I said that if you are afraid of the regulators, involve them in the product development process-And so we did (D3)

This examples illustrates that as "[exploitative policies] are still mentioned in every risk report, quite prominently ... simply because there is still ongoing litigations for unitlinked insurance policies" (M4), managers were continuously confronted with InsCorp's problematic past and thus forced to find ways to navigate it. For instance, in a lengthy discussion during a senior management meeting that the main author observed, the content of the recently drafted firmwide corporate strategy was reviewed. Some attendees questioned why solidarity-an important component of InsCorp's reshaped character-was not included in the strategy:

Compliance officer A: Why is the notion of 'solidarity' mentioned so infrequently [in the corporate strategy] [...] where does solidarity fit in?

Director B: [...] solidarity is a delicate principle

Director C:-There are limits to our solidarity, which is why we don't place it so centrally in [our strategy] [...] There are quite a few risks associated with explicitly articulating solidarity as part of our strategy. This would mean that we always demonstrate solidarity, while that is not always the case [...] 'Solidarity' is a very precarious value, because it is the foundation of what we do, but it is a risk to say that we are always reimburse customers for their losses [...] because if [we] don't want or cannot cover a specific risk, we are not showing solidarity (Fieldnote)

The restraint exhibited by these directors toward this notion of solidarity was initially puzzling to us, given the abuse that members had experienced for having defied this principle in the past and the work that had been done to recover from it. As we probed further, we came to realize that while leadership understood that it was fundamental for InsCorp's existence as insurance company ("[it] is the foundation of what we do"), senior management was also conscious about the challenges that would arise if InsCorp publicly espoused these commitments. Likewise, while InsCorp's leadership had been initially very vocal in its commitments to compensate customers who had purchased a exploitative policy, we noticed that they were simultaneously extremely cautious about the precedent they would create if there were too accommodative in these efforts, as aptly explained by a director: 
There are frequent court rulings [...] And we know that when those statements come through, that an individual statement can become a collective statement [...] and we're not talking about 100 million, we're talking about a lot more. But when it becomes more, it will hit the company [...] the legal entity, in which, in addition to the obligations for those 'usury policy' customers, the pension entitlements of a number of people are. And we will have to disappoint someone somewhere [...] Then there is still a risk of contamination in other business units. And that will go very quickly. So there is also this emerging behavior to include the total number of considerations (D1)

Leadership understood that actually showing their reshaping character in practice would jeopardize the financial solidity of InsCorp. In other words, they had to strategically maneuver InsCorp reshaped character and thus were conscious of the need to manage expectations and only make commitments they were able to follow-through on, as explained by this executive:

We try to tailor our [marketing] campaign to what we actually do. The first version also had the promise that we would compensate everyone who put in a claim [...] We cannot and we will never say that [...] [Because] everyone will come to claim compensation [...] I understand the emotion from society and our customers-But that is a promise we just cannot make [...] So we have fortunately protected ourselves by the fact that we only make commitments that we can live up to (EX2)

Although the external feedback InsCorp received regarding its reshaped character was largely positive, reflecting the recovery of trust from important constituents, decisions such as these also perpetuated InsCorp's contentious legacy. During the period that the main author visited the organization for fieldwork, for instance, InsCorp's board of directors had come under increasing pressure from its shareholders to increase executives' remuneration to be more aligned with the interests of the company. Employees and outside constituents were overwhelmingly critical of about the decision by the board to implement a significant increase in pay, perceiving it as incongruent with the InsCorp's reshaped character. During our conversations, we came to the view that this might represent a movement back to the company's bad old days.

\subsection{A Model of Rebuilding Character through Adversity}

Our findings, summarized in Figure 5.1, outline the re-evaluation that organizational members engaged in the wake of an integrity failure, the main responses in reshaping the character of the organization, and the implications of these efforts as this reshaped character became anchored. In this section, we draw on the concepts we have identified in our findings to present a model of rebuilding character through adversity, showing both how the process unfolds and the relationship between the key concepts. Our model is shown in Figure 5.2. 


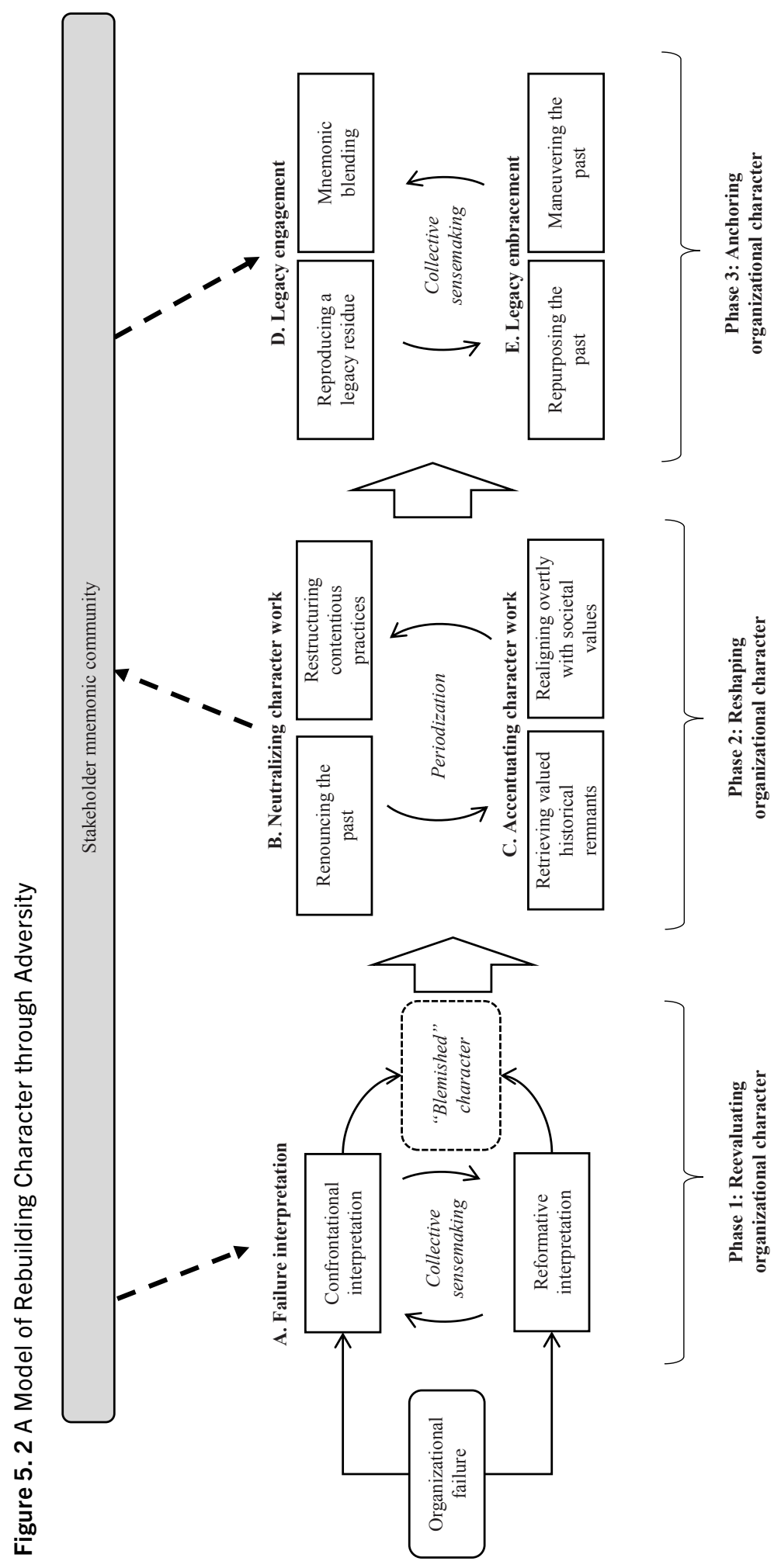


Our model begins from the moment that organizations are confronted with a failure. As members attempt to collectively make sense of the situation, they engage in a process of failure interpretation (See Figure 5.2, box A). Specifically, as happened in our case, an organizational failure can engender several distinct interpretations. First, if members experience fierce distrust and moral disapproval from important constituents, they are likely to perceive their organization and its leaders to be in some way responsible. Moreover, external signals that their organization has not adhered to accepted norms and principles are likely to elicit strongly negative emotions such as embarrassment, shame and guilt. As a result, members may come to interpret the failure as profoundly confrontational. Second, when an integrity failure is accompanied by significant disruptions of daily operations, members are likely to experience extreme uncertainty about the identity of their organization. Although such a disruptive event can be extremely serious for the organization and its members, leaders may come to interpret the failure as potentially reformative. During the process of collective sensemaking, the experience of distrust and uncertainty is likely to lead to an acute reevaluation of organizational character as "blemished".

In the wake of this re-evaluation process, leaders may need to change the way that both members and outside constituents perceive the organization in order for the blemished organization to cope with distrust and uncertainty. As such, members may individually and collectively engage in "character work" to reshape the character of the organization. Leaders may have to neutralize negative character cues by strategically disassociating themselves from those practices, policies and narratives that can be directly linked to the integrity failure. The two types of neutralizing character work (box B) we highlighted are: (1) renouncing the past-the organization seeks to atone for and frame past behaviors by instituting narratives both throughout the organization and towards key constituents; and (2) restructuring contentious practices-the organization seeks to replace practices that have become regarded as disreputable in response to external pressures.

However, the obfuscation of a problematic past may not be enough to instill lasting change within organizational boundaries and regain trust from core stakeholders. Therefore, leaders may also have to accentuate positive character cues to reframe the existence of the organization in a positive light while also drawing attention to non-tainted aspects. Specifically, this accentuating character work (box C) involves: (1) retrieving valued historical remnants-the organization seeks to reinvigorate latent values and beliefs by emphasizing its raison d'être; and (2) overtly realigning with societal values-the organization seeks to distance itself from peer organizations by embracing and enacting those societal values that are salient at that time.

Although the primary purpose of neutralizing character work is to alleviate the distrust toward the organization by influencing the external evaluation of the organization, accentuating character work buttresses the internal renewal efforts and strengthens identification among members. It is our belief that both types of work are essential if organizations want to reshape their character. Neutralizing work and accentuating work occur somewhat concurrently as organizations discard undesired fragments of their past 
and retrieve more valued historical elements. By doing so, organizations can intentionally reconfigure their collective memories and may seek to shape the nature and significance of traces within their mnemonic communities, as indicated by the dotted arrow from box B.

Organizations may need to undergo several cycles of neutralizing and accentuating character work to reshape their characters. However, it is important to note that our model does not assume that reshaping work needs to be successful-if that is even possible-for positive benefits to materialize. As happened in our case, memories of the past are likely to persist and be intentionally sustained by the mnemonic community. Specifically, members may continue to experience legacy engagement, as indicated by the dotted arrow to box D. Specifically, members and external constituents recurrently evoke the past and as such reproduce a legacy residue. In the face of this reproduction, and the challenges this engenders, organizations may respond by mnemonically blending their pasts with positive character cues to dilute memories of the organizations' problematic pasts while also keeping specific memories of the past alive for members

Indeed, a key finding of our study is that memories of a problematic past may be instrumental in upholding reclaimed values and beliefs. Specifically, an organization's character may remain partly stained among core constituents and preserved by the mnemonic community, but if members come to accept the reshaped character of their organization, they are able to come to terms with and accept their past and use it as a guide for future decision-making. Importantly, we found that mnemonic traces connect the organization to its past, "casting a shadow" over present and future organizational actions. Therefore, a problematic past may be anchored in the character of the organization. However, over time, as members continue to collectively make sense of these traces, their legacy is increasingly embraced (box E). Specifically, as the reshaped character becomes anchored in daily practices and is reinforced by external feedback, repurposing a problematic past may lead members to reflect upon and validate the reasons for the organization's existence and its valued societal contributions, imbuing members with a sense of pride in its shared values.

\subsection{Discussion and Conclusion}

Our findings have important implications for organizational theory. First, adding to the literature on responses to organizational failures, we extend existing research that has focused on the immediate and more superficial adaptations to integrity failures, but has not explored why and how organizations respond by rebuilding their character. Second, we add to the literature on organizational work by showing that adaptation following an integrity failure not only relies on discarding organizational elements that have become perceived as undesirable, but also on the use of rhetorical history and the accentuation of latent institutional values and ideals. Third, this study provides key insights on the enduring impact of an organization's legacy on present organizational life, as collective memories of a problematic past, and 
the resulting behavioral and evaluative implications, embody fundamental elements of an organization's character and may thus critically shape managerial behavior.

\subsubsection{The Coalescence of Distrust and Uncertainty: An Impetus for Rebuilding Character}

Why do some integrity failures elicit only symbolic responses, while others lead to changes of a more profound nature? Although extant research has acknowledged that failures are potentially defining moments in the re-formation of organizations (e.g. Christianson et al., 2009), previous studies have primarily focused on the immediate and more superficial responses to integrity failures intended to protect reputation (Gillespie et al., 2014; Pfarrer et al., 2008; Schembera \& Scherer, 2017), yet have not explored why leaders are impelled to go beyond "changing surface structures and behaviors" (Mishina \& Devers, 2012: 208).

Although not explicitly concerned with moral failures, Selznick (1957:59) hypothesized that as organizations adapt in response to critical moments in their life course, they develop a "distinctive unity and character". There is a growing body of research that recognizes the interplay between organizational character and corporate irresponsibility, specifically as it relates to stakeholder responses to behaviors that are perceived as being out of character (Connelly et al., 2016; Bundy et al., 2021; Paruchuri et al., 2021). However, the question why some integrity failures go on the be character-defining for transgressing organizations remains largely overlooked.

The emerging literature on values and emotions is of particular interest in this regard (Creed et al., 2014; Gehman et al., 2013; Kraatz \& Flores, 2015; Wright et al., 2020). For instance, in discussing the origins and emergence of values in organizational life, Kraatz and colleagues (2020:475) note that values are "acquired in the course of experience and revealed over time in their various effects" as organizations follow-through or deviate from them in their actions. Owing to role of values in social evaluation, when organizational members and key constituents come to judge corporate actions as an overt violation of embraced ethical, regulatory and normative principles (e.g. an integrity failure), they are likely to question the underlying character of the organization. Such a "blemished" character (Goffman, 1963: 4) is particularly difficult to overcome since it combines the moral disapproval of the organization with uncertainty about its identity. However, the coalescence of distrust and uncertainty may actually constitute crucial ingredients that precipitate the rebuilding of character.

Our study suggests that the effects of integrity failures can be very significant indeed. When members perceive organizational actions to be consistent with espoused values and ideals, they are more likely to identify with their organization and express positive emotions (Besharov, 2014; Dutton \& Dukerich, 1991). In contrast, members will experience strong negative emotions, including a collective sense of shame and guilt (Creed et al., 2014; Toubania \& Zietsma, 2017), when they perceive that actions are inconsistent with what they believe is central, enduring and distinctive about their organizations. Such negative emotions are likely to be reinforced if and when they perceive their organization in some 
way accountable for the failure. Because constituents use the actions of organizations to make character judgments (Mishina et al., 2012; Love \& Kraatz, 2009), fierce moral disapproval towards the organization followed by an integrity failure is likely to signal to members a significant loss of trust. As negative emotions have been shown "to create particularly powerful impediments for sensemaking and constructive action in turbulent organizational conditions" (Maitlis \& Sonenshein, 2010: 570), the collective sense of shame and guilt leads members to try to make sense of the failure situation. Importantly, and in line with the previous assumption that negative emotions "discipline human behavior by leading people to internalize institutional prescriptions and norms" (Voronov \& Weber, 2016: 459), the prevalence of such negative emotions may lead organizations and their members to become more sensitive to external pressures.

Although failures have been shown to elicit strong negative emotions among members (Creed et al., 2014; Huy et al., 2014), we expect that mere distrust by key constituents is not enough for leadership to engage in radical organizational change. However, our findings suggest that when a failure significantly disrupts organizational viability, operations and routines (e.g. crisis, nationalization, organizational breakdown), this may lead to profound uncertainty and ambiguity among members about the identity of the organization (Clark et al., 2010; Corley \& Gioia, 2004). We found that such disruptive failures raise questions among members about core identity beliefs which, strengthened by fierce moral disapproval by constituents, may lead members to no longer identify with their organization. As members are out of their ordinary, uncertainty about the future of their organization is pervasive, and ambiguity over who they are as a collective is rife, such existential voids provide opportunities for members to contemplate on who they were as an organization, who they have become, and who they want to be, thus functioning as "a blank sheet on which the organization can reinvent itself" (Christianson et al., 2009: 857).

The fundamental insight here is that in the wake of a disruptive integrity failure, distrust and uncertainty are likely to coalesce in a need for profound organizational change. We expect that integrity failures that are merely caused by rogue employees or that lack social salience (Bundy et al., 2013; Eberl et al., 2015) are unlikely to lead to such moral disapproval or identity ambiguity, and thus to elicit radical change. In contrast, we show that the combination of member disidentification and constituents' distrust forces members to collectively make sense of each failure situation and critically reflect on the their organization's past actions, interpreting their organization's character as blemished. This situation can be harnessed as an important "sensitive period" for leaders to reshape their organization's character (Marquis \& Tilcsik, 2013: 195). In addressing this question, new meaning and purpose may be found, and change agents may evoke more positive emotions among organizational members, such as hope, relief, and eventually even pride. Importantly, when these emotions are accompanied by humbleness, humility and openness rather than hubris and arrogance, as we found in our case, members tend to reflect on their own functioning and that greatly increases the motivation to reshape the organization's character. 


\subsubsection{The Role of Character Work in Adapting to Integrity Failure}

Our study also adds to the burgeoning literature on the organizational work members individually and collectively perform as they reconstruct, narrate and maintain the idiosyncratic character of their organization (Cornelissen et al., 2020; Lawrence \& Phillips, 2019; Sasaki et al., 2019). As noted above, research on identity work (Kreiner et al., 2015; Watson, 2016) and values work (Gehman et al., 2013; Vaccaro \& Palazzo, 2015) has provided some significant insight on the discursive, relational and symbolic actions organizational members engage in as they attempt to shape the identity and values of their organization, for instance, through remembering and forgetting (Anteby \& Molnár, 2012), advocacy and valorization (Tracey \& Phillips, 2016) and the strategic use of the past (Basque \& Langley, 2018).

Our study merges these streams of research by identifying a distinct type of organizational work that members perform as they purposefully reconstruct, present and sustain the character of their organizations in response to integrity failures. As these actions are primarily concerned with rebuilding a blemished character with the goal of regaining the trust of key constituents and fostering re-identification among members, we termed this "character work". We identified two types of character work in our findings: neutralizing character cues and accentuating character cues.

First, organizations may engage in accentuating character work by shifting attention to non-blemished aspects of their character. For instance, we found that realigning with important societal values such as corporate responsibility and transparency, while initially perhaps only symbolic in nature, are important signals towards disaffected audiences. In this vein, McDonnell and Cobb (2020: 1031) note that positive character cues "provide ambiguous signals of societal values because they may be interpreted as conformity to social expectations", thus demonstrating adherence to institutional expectations. This overt realignment reminds us that, in times of extreme distrust and uncertainty, organizations may have to turn to their environment for existing elements or strands of meaning, symbols and values to reshape their character so that it provides social cohesion within organizational boundaries and fosters distinctiveness.

Moreover, our study suggests that leaders may present or reframe the existence of their organization as having positive value for its members and community. They do so by retrieving and emphasizing dormant remnants of the organization's valued past. We find that this strategic use of the past (Hatch \& Schultz, 2017; Suddaby et al., 2010) is used to emphasize and reinforce latent values and can be an important instrument to "inspire future courses of action" (Ravasi et al., 2019: 1523) and for signaling authenticity by eliciting "emotive commitments" from diverse stakeholder groups (Zundel et al., 2016: 214). In the wake of the 2007-2008 financial crisis, for instance, InsCorp began to emphasize solidarity and societal relevance, principles that were once core to the organization's functioning but from which it had gradually drifted, to emphasize their fundamental contribution to its customers and community of sharing and bearing risks. This finding corresponds with the study of Tracey and Phillips (2016), who found that adverse events that threaten organizations' viability or existence forces them to reevaluate their raison d'être. 
Our study adds nuance to this idea by showing how disputed organizations may look inward for dormant values and purpose, and invoke those in their efforts to rebuild their character. We find that when this process of introspection is accompanied by recurrent actions and broad recognition by the organization's constituents, members' assumptions about the character of the organization and its value to the wider community are substantiated. In other words, the version of the past that the organization chooses to emphasize reinforces the values of the organization that are unique. In so doing, the unique and distinctive diachronic character of the organization becomes reestablished and reinforced.

Second, leaders' efforts to accentuate previous good deeds or valued character cues may not be enough to erode widespread cynical perceptions of an organization's character. Although organizations may allocate substantive resources toward signaling and enacting important societal values, "one strong negative character cue may be enough to reorganize and reframe the organization's entire history" (Mishina et al., 2012: 470). We find that a more effective approach for leaders would be to direct efforts and resources toward minimizing and obfuscating the negative character cues.

Our study indicates that organizations may have to remove at least parts of their disputed historical "baggage" (Roth \& Kostova, 2003) by publicly discarding taken-forgranted practices and strategies, atoning for or reframing their problematic past in such a way that support from both members and external constituencies is regained. For instance, InsCorp's CEO was initially widely applauded by members for publicly 'taking a stance' by committing to the compensate customers, even though these efforts had already been explicitly ordered by regulatory authorities. Consistent with prior research that has shown that framing is imperative for enabling recovery following adverse events (Kim, 2021; Williams et al., 2017), these types of dissociative actions are crucial in re-establishing the moral character of organizations in the wake of an integrity failure.

Importantly, a core implication of our study is that the accentuation of positive character cues may function as symbolic markers as organizations attempt to regain trust from their constituents (Dutton \& Dukerich, 1991; Gioia et al., 2000). However, accentuating positive cues may only be credible if and when negative character cues have been sufficiently discarded or reframed. We would expect that efforts primarily focused on demonstrating adherence to institutional prescriptions, but that run short of substantially engaging with the consequences of an integrity failure or addressing the contentious past, may come to be perceived as hypocritical (Brunsson, 2002; Carlos \& Lewis, 2018). Therefore, the neutralization and accentuation of negative and positive character cues respectively, as distinct types of character work, have to be performed simultaneously in order to rhetorically bracket the past: what scholars have termed "periodization" (Suddaby \& Foster, 2017; Ybema, 2010), constructing a temporal divide between the organization's problematic past actions and the future it aspires to. 


\subsubsection{The Importance of Legacy for Organizational Character}

Implicit in the "historic turn" in organization and management research is that history matters if we are to understand an organization's present identity, culture and strategies. That is, most organizational institutions have unique historical legacies that are crucial in explaining and understanding aspects of their past, present and future behaviors (Eury et al., 2018; Phillips et al., 2019; Suddaby, 2016; Walsh \& Glynn, 2008). Previous research has suggested that adverse, disruptive or traumatic events in an organization's life course are likely to embody formative elements of its character (Birnholtz et al., 2007; Foster et al., 2020; Sasaki et al., 2019). Enlightened by Ravasi et al.'s (2019: 1547) assertion that "who we have been [as an organization] in the past is relevant to how we understand who we are in the present", we speculated that legacy, whether negative or positive, represents a fundamental aspect of character and, consequently, has important implications for the evaluation of organizational conduct and managerial decision-making. However, to the best of our knowledge, studies that directly connect an organization's contentious legacy to its character remain scarce.

Although organizations may successfully engage in substantive character work to address members' disidentification and constituents' distrust, fully obfuscating a problematic past may-in reality-be impossible. Our findings suggest that by virtue of the inherent stickiness of negative character cues (Mishina et al., 2012; Zolotoy et al., 2019), integrity failures that blemish an organization's character are likely to have enduring behavioral and evaluative implications for the focal organization and its members, even long after the failure has occurred. Specifically, when an integrity failure is highly salient, disruptive and damaging, character work is unlikely to fully cleanse an organization's blemished character and "erase" its problematic past. Instead, we find that memories of a problematic past may be preserved and episodically recalled by those actors that were negatively affected by the failure. Although organizational insiders will experience such legacy reproduction as highly burdensome, tedious, and at some times even upsetting, our findings suggest that this mnemonic community plays a crucial role in maintaining memories of traumatic events, reminding the organization of their irresponsible past behaviors and putting pressure on the firm not to make similar mistakes. We expect that in the absence of a mnemonic community that "knows" about an organization's problematic past that can help to hold the organization accountable for its activities, lessons learned may fade over time and deviant behavior may be repeated (Chandler, 2014; Haunschild et al., 2015).

Simultaneously, and in line with the socially constructed nature of collective memories (Foroughi et al., 2020), while character work is unlikely to be an all-embracing solution for eroding stigma, it can be an important tool in reframing the problematic past in such a way that members come to identify with the organization and accept its contentious legacy. For instance, the narrative that the failure had its roots in external factors rather character deficiencies was blended throughout the organization, facilitating the process of "mnemonic socialization" (Ravasi et al., 2019; Zerubavel, 1996) where new members acquire collective memories as their own. We find that the practices, narratives and artefacts that underlie 
such mnemonic socialization are of key importance because they help to recollect, retell and cultivate an idealized version of the past which allows members to identify with the values and character of the organization, despite its problematic past. Since previous research has acknowledged that "memory processes are crucial in maintaining the integrity of collective identities" (Anteby \& Molnár, 2012: 532), the socialization of reconfigured and idealized collective memories among disidentified or new members may be crucial in legitimating the organization among insiders and in its environment.

Finally, while extant research has explored strategies aimed at reconfiguration or outright forgetting as an instrument to manipulate memories of corporate irresponsibility or misconduct (Coraiola \& Derry, 2019; Mena et al., 2016), our findings suggest that memories of an adverse event can be purposefully framed in a way that sustains members' positive evaluation of their organization's character and core values. Although a problematic past is inherently enduring (Phillips et al., 2019; Suddaby, 2016) organizational leadership may repurpose their legacy and use it as an important strategic resource to foster distinctiveness. In other words, organizations that consciously do not to erase but rather commemorate and blend memories of their problematic past throughout their organization can prevent the repetition of irresponsible behavior. Therefore, our findings add nuance to prior research that has suggested that constitute valuable mnemonic resources (Crawford et al., 2020; Do et al., 2019), by noted that when members are reminded of, they come to collectively understand which actions are in line with the character of their organization and, conversely, which behaviors may constitute out of character acts (Love \& Kraatz, 2009). 



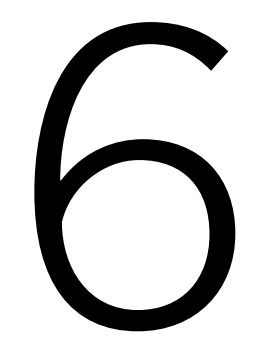

\section{Discussion and Conclusion}

The objective of this dissertation was to conceptually and empirically investigate the complexities, perils and promises of organizational character and integrity. In the Chapter 1 , we formulated the following central research question: "What are the organizational and institutional processes through which organizations (re)form character, sustain integrity and remediate misconduct?" We chose as our empirical setting the financial industry, as we believed its institutional and historical legacy-plus its current opportunities and challenges-make it a compelling context in which to address our central question. To address this question, we formulated four research questions that guided the four consecutive studies presented in this dissertation. Below, we address the central research question by summarizing the key findings and providing responses to the four research questions. After having addressed the central findings, we present the main theoretical contributions of this research. In the remainder of this final chapter we elaborate on the practical implications, research reflections and limitations, and offer suggestions for future research. 


\subsection{Summary of Key Findings}

The first chapter of this dissertation set out the four research questions that would guide the conceptual and empirical inquiries of the individual studies. In the following section, we provide our responses to these research questions and summarize the key findings of each chapter.

\subsubsection{Key Findings Chapter 2: Unpacking the Complexities of Organizational Integrity}

Practitioners and scholars alike increasingly refer to the integrity of organizations, for instance, when they question the trustworthiness, reliability or character of organizational actors following corporate irresponsibility or other misconduct. However, despite significant scholarly attention to individual integrity in relation to employee and leadership behavior (Bauman, 2013; Palanski \& Yammarino, 2007; Simons et al., 2015), there remains ambiguity and inconsistency surrounding how organizational integrity is both conceptualized and used (Dacin et al., 2002; Goodstein, 2015; Selznick, 2000). We asserted that this research gap is problematic in the light of scholars' rising interest in the notion of organizational actorhood (Greenwood et al., 2014; King et al., 2010). Hence, in the second chapter of this dissertation we set out to conceptually flesh out a comprehensive understanding of organizational integrity and elaborate on the challenges that arise as organizations face competing institutional pressures. Therefore, we posed the following research question:

Research Question 1: How is the integrity of organizations affected when they operate under institutional pluralism?

We built on the rich literature on values, organizational identity and institutional pluralism to theorize on the meaning, determinants and challenges of organizational integrity. Recognizing the heterogeneity of values within organizations (Bourne \& Jenkins, 2013), we conceptualized integrity as the wholeness of values espoused by leadership, the values embedded in formal systems and structures and shared among members, and the values enacted in organizational actions. Corresponding to this conceptualization, scholars who have taken a "social actor perspective" of organizational identity (Haslam et al., 2017; King et al., 2010; Whetten \& Mackey, 2002) emphasize "the need for continuity, not just with regard to identity over time but also with regard to the alignment between such identity and the organization's strategies and actions" (Grimes et al., 2019: 821). Since such identities are profoundly values-based, obvious departures from the values inscribed in these identities are likely to evoke perceptions that the organization has compromised its integrity.

In situations of institutional pluralism, in which organizations "operate within multiple institutional spheres" (Kraatz \& Block, 2008: 243), organizations hold multiple institutionally derived identities and, consequently, seemingly contradictory goals, obligations and 
responsibilities. Importantly, whereas we asserted that the wholeness and integration of multiple selves is a key element of integrity, we speculated that organizational actors that face such pluralism are likely to espouse and embed competing values within their boundaries. Such values-based complexity, characterized by "the prevalence of multiple, independent, yet interacting and continuously changing values" (Grimes et al., 2019: 821), has been shown to prescribe diverging courses of action and is thus likely to complicate consistent organizational actions.

Based on the preceding, we theorized on the factors that contribute to the presence or absence of organizational integrity and put forward several propositions. Specifically, we asserted that the integrity of organizations is at risk when leadership only espouses values symbolically to try to secure legitimacy from important institutional constituents. Moreover, when they have not sufficiently internalized espoused values they are less likely to embed them in the formal and informal social structures of the organization. Furthermore, when organizations are unable or unwilling to integrate their multiple valuebased identities, powerful subgroups that do not identify with specific subsets of espoused values may pay less attention to issues that correspond to espoused values, resist enactment of espoused values in practice and will be less likely to adopt practices and structures that support espoused values. Finally, we proposed that when powerful internal subgroups do not identify with a specific subset of espoused values, they are more likely to respond by decoupling embedded from enacted values.

\subsubsection{Key Findings Chapter 3: Character Development and Corporate Responsibility}

By addressing the first research question, we were able to achieve conceptual clarity on the notion of organizational integrity. As we elaborated on the tripartite of values that constitute our conceptualization of integrity as well as on the complexities and perils that arise when organizations face institutional pluralism, we became interested in the intraorganizational processes as they adopt and espouse commitments that ostensibly conflict with existing organizational values, beliefs and identities. For this study, we posed the following question:

Research Question 2: How does the character of organizations develop when they adopt and diffuse commitments to corporate responsibility?

To address this research question, we conducted case studies on two large financial enterprises that had undergone considerable change following the 2007-2008 global financial crisis. Based on in-depth interviews with executives, senior managers and policymakers, we elucidated four steps of character development as organizations adopt commitments to corporate responsibility with their boundaries.

Our findings suggests that when organizations adopt and articulate normative commitments, which we termed stretching, they gradually begin to shape the image of the organization. We found that commitments become evoked as result of a problematic 
past, an envisioned future, and pressure from internal subgroups. The process of stretching resonates with the notion of "values articulation work"; that is, the actions through which purpose and relevant values are constructed and reaffirmed (Gehman et al., 2013). Although values ordinarily exist in a mainly dormant state, we demonstrate that leaders can purposefully retrieve and espouse latent values after critical events to offer members a "bright light" (Hitlin, 2008), provide strategic direction and regain legitimacy from core stakeholders.

We find that when firmwide commitments are made salient internally, tensions between ostensibly contradicting commitments become exposed, leading to a process we termed struggling. This process involves three interrelated dynamics, including the emergence of dilemmas and identity ambiguity. We find that identity ambiguity can be particularly pervasive when commitments are perceived as superficial. To resolve these struggles, we identified various stabilizing practices. These practices include substantive integrative work, through which organization foster an overarching dialogue between subgroups to arrive at a shared understanding and compromise among competing interests, values and needs, routinizing the espoused organizational values into "a sense of collective conscience" (Starkey, 1998: 126), and leaders' internalization of espoused values within themselves, their public behavior and enactment in organizational actions. Importantly, we find that leaders' modelling behaviors and recurrent and public enactment of espoused values and commitments may significantly contribute to "the appearance of cross-temporal consistency" (Kraatz, 2009: 80), through which value commitments become anchored in the character of the organization.

These stabilizing efforts provided the opportunity for further anchoring these commitments in the character of the organization. We termed this process settling. However, at the same time stabilizing efforts that are perceived to be inconsistent with an organization's identity may evoke a sense of organizational sacrilege (Harrison et al., 2009: 255), wherein actions "directly contradict sacred ideals, values, beliefs and so on espoused by the organization". When commitments are perceived to be violated, there is a risk of recurrent struggling and failure of fully diffusing them throughout the organization. We find that as practitioners collectively and repetitively experience and resolve emergent inconsistencies and ambiguities, they develop their own distinct and habitual ways of working. The repetitive nature of this decision-making process eventually led employees and managers alike to gain a collective view of what to expect from each other and from the organization as a whole.

\subsubsection{Key Findings Chapter 4: Complacency and the Normalization of Misconduct}

The findings described above highlight that the adoption of new practices and structures can conflict with existing values, norms and interests. Previous research has shown that these circumstances frequently give rise to resistance within organizational boundaries (Hengst et al., 2020; Huy et al., 2014; Kok et al., 2019), especially when they are in tension 
with core organizational goals (Bromley \& Powell, 2012). We argued in Chapter 2 that such internal contestation can escalate into ongoing and often intractable conflict which, if remaining uncheck, may make the maintenance of organizational integrity difficult.

Specifically intriguing in this regard are organizations that persistently violate values, norms or regulations, despite being repeatedly scrutinized by key audiences for their misbehavior. Although some first-time integrity failures may constitute mere incidental acts, we speculate that the tendency of organizations to persist in rule-breaking and resist regulatory pressures probably results from the interplay between institutional imperfections and character deficiencies (King, 2015; Love \& Kraatz, 2009; Mishina et al., 2012). How these mechanisms may cause the emergence and persistence of misconduct over time remains an empirically understudied topic. We intended to address this research gap, and posed the following research question:

Research Question 3: Why do organizations persist in engaging in misconduct? How do regulatory agencies achieve substantive remediation?

In exploring this question, we undertook three in-depth case studies of noncompliance with anti-money laundering regulations by European financial firms over a 15 -year period (2005-2020). Based on our inductive, qualitative analysis of archival documentation and interviews with regulators, we elucidate three episodes of escalating contestation between offending firms and their regulators.

First, when initial regulatory cues are not corrected or sufficiently enforced by regulatory agencies, noncompliance is at risk of becoming "normalized" (Vaughan, 1996) and (to be perceived as) unresolvable in the long run due to the financial and attentional costs attached to remediation. Importantly, we find that when regulatory scrutiny is absent or enforcement is limited, organizations "learn from noncompliance in a perverse way; namely they learn that it is acceptable" (Greve et al., 2010: 73). Moreover, top managers' inattentiveness to focal regulatory issues is likely become reinforced when regulators frame noncompliance as primarily a deficiency in the procedural execution of administrative norms and rules. When regulatory agencies are lenient towards noncompliance, they fail to address or signal the normativity of rules, and organizations may come to perceive the focal regulations as lacking legitimacy. As a result, noncompliant practices are likely to become subject to inertia and be repeated over time. We describe this process as the emergence of complacency.

Second, consistent with prior findings that complacency may function as a barrier to adequate adaptation and responsiveness (Tourish, 2020; Tushman \& Nadler, 1986), we find that while regulatory agencies may engage in confronting complacency, normalized noncompliant practices are likely to "become taken-for-granted and enacted mindlessly, that is, with little or no real problem solving or even conscious awareness" by the offending organizations (Ashforth \& Anand, 2003: 14). When enforcement actions are lenient and lack visibility, noncompliant organizations will not be sufficiently incentivized to substantially enact costly remediation efforts. Rising coercive pressure by regulatory authorities is thus likely to be met with resistance by noncompliant organizations as they 
purposefully maintain the status quo through isolated and usually temporary remediation. Consequently, organizational learning by complacent organizations is mostly myopic. That is, the symbolic nature of corrective efforts results from an ingrained tendency to strategically search locally rather than more widely as organizations purposefully avoid exposing additional deficiencies with their boundaries.

Finally, we find that salient critical events, such as high profile corporate scandals and criminal sanctions, can profoundly intensify the political and societal discourse around noncompliance and support the efforts of regulatory agencies in what we have termed coercing acquiescence. Together, these critical events led to a significant spike in societal interest in rule-breaking, heightening regulatory and political attention to firm behavior, signaling the possible social and financial consequences of noncompliance, and increasing issue legitimacy and the pressure to change. Importantly, while we find that these salient critical events may be leveraged by regulatory authorities to achieve substantive compliance, the focal rules and regulations may remain regarded as illegitimate, and thus learning tends to be involuntary.

\subsubsection{Key Findings Chapter 5: Character Work in the Wake of Integrity Failures}

Building on the key findings presented above, the final study of this dissertation extends the idea that salient events, such as integrity failures and scandals, are potentially character-defining and may have important and lasting implications for organizations, their members and other key constituents. As Chapter 3 drew some initial attention to the importance of adverse events in identity construction and endurance, we were particularly interested in how organizations rebuild character in the wake of integrity failures. This brought us to the following research question:

Research Question 4: How do organizations rebuild their character following an integrity failure?

To address this research question, we conducted an in-depth case study on a successful European financial enterprise that was nationalized during the 2007-2008 global financial crisis. We drew on rich longitudinal data, including in-depth oral history interviews, field observations and archival material to investigate our case organization's recovery process over time. Based on an inductive, qualitative analysis, we build an empirically grounded process model of how organizations reevaluate, reshape and anchor their character in the wake of integrity failures.

First, we find that a failure may trigger an acute character reevaluation. When members perceive the organization to be in some way responsible for the failure and the conditions leading up to it, strengthened by critique from key audiences, this may elicit strong negative emotions of shame and guilt among members. Simultaneously, when the failure leads to a meaning void, organizational members may come to experience uncertainty over the identity of the organization, but which can function as an important impetus for organizational renewal and bolster a motivation for change. Specifically, we find that when 
an integrity failure combines external distrust towards values of the organization with uncertainty about its identity, this may coalesce in the need to rebuild character.

Second, our findings suggest that following character reevaluation, leaders feel the need to change the way that both organizational members and outside actors perceive the identity and values of the organization. In this character reshaping process, members enact various forms of what we have termed "character work". In this vein, leaders may have to neutralize negative character cues by strategically disassociating themselves from those elements that can be directly linked to the failure through renouncing the past and restructuring contentious practices. We find that the obfuscation of a problematic past is not enough to instill lasting change within organizational boundaries or to regain the trust of core stakeholders. Therefore, leaders may also have to accentuate positive character cues by retrieving valued historical remnants and overtly realigning with societal values. Importantly, this twofold character work is crucial in restoring identification among organizational members and in recementing the support of key audiences.

Finally, while organizations may need to undergo several cycles of character work to rebuild identification among members and regain trust from constituents, we find that members may be forced to engage with their contentious legacy. Specifically, we find that members experience a legacy residue through recurrent evocations of their organization's problematic past. While an organization may remain strained among core constituents and preserved by the mnemonic community, we find that if members come to accept the reshaped character of their organization, they are able to come to terms with and even embrace their problematic legacy to then use it as a guide for decision-making. Therefore, an important finding of our study is that memories of a problematic past may be instrumental in living out reclaimed values and beliefs. As the reshaped character becomes anchored in daily practices and is reinforced by positive external feedback, this process may lead members to reflect upon and validate their organization's societal contributions, imbuing members with a sense of pride in the organization's values and trust in its character.

\subsection{Main Theoretical Contributions}

The previous section summarized the key findings of the four studies presented in this dissertation. Based on these findings, in the following section we elaborate on the five main theoretical contributions that emerged from our studies. In line with the subtitle of this dissertation, these contributions shed light on the complexities, perils and promises of organizational character and integrity.

First, as noted in the introductory chapter of this dissertation, the term "actor" has proliferated spectacularly throughout the organizational and management literature, and has been increasingly connected to collective entities, including groups, organizations and states (Hwang \& Colyvas, 2020; Scott, 2014). Yet despite the growing calls to "re-emphasize 
an organizational level of analysis, and to treat organizations as actors" in their own right (Greenwood et al., 2014: 1207), scholars have only recently begun to conceptually and empirically investigate organizations as distinct social actors (e.g. Ashforth et al., 2020; Bromley \& Sharkey, 2017; Halgin et al., 2018; King et al., 2010). This lacuna is worrisome, we asserted, as organizational actors are capable of being a force for good (Henderson, 2020; Mackey \& Sisodia, 2014), while also being capable of falling prey to a range of maladaptive pathologies and doing tremendous harm (Greve et al., 2010; Hatch \& Schultz, 2002).

To bridge this research gap, this dissertation provides important insights on how organizations as distinct social actors navigate-albeit sometimes without success-their plurality of embraced value-based duties, responsibilities and obligations. To that end, this dissertation broadly adds to the discussion of "the ontological status of organizations as social actors" (King, 2015: 151) by explicating how organizational actors come to be, how they come to represent certain values or beliefs, and how they consequently translate those into action or-in some cases-fail to do so.

Second, this dissertation advances the actorhood perspective by theorizing about organizational integrity. By taking a conceptual approach, this dissertation responds to the observation that "theorizing about [collective] actors benefits from further conceptual specification" (Hwang \& Colyvas, 2020: 575). Unpacking the complexities of organizational integrity is critical, we argued, because organizations as distinct actors are increasingly expected to balance responsiveness to multiple institutional demands while also staying true to their core values and commitments. Building on the burgeoning literatures on values within and surrounding organizations (Besharov, 2014; Gehman et al., 2013; Kraatz et al., 2020) and multiple organizational identities (Ashforth \& Reingen, 2014; Besharov \& Brickson, 2016; Pratt \& Foreman, 2000), we proposed an institutional perspective on organizational integrity. By conceptually separating the distinct forms of values within and surrounding organizations (Bourne \& Jenkins, 2013), we were able to shed light on the pluralism pervasive within many modern corporations and theorize on the issues and challenges that may arise as such organizations are increasingly confronted with competing regulatory, normative and cognitive demands.

Third, we answer calls for "reinvigorating the study of organizational character and actors" (King, 2015: 167) by shedding light on both the formation processes of organizational character as well as its implications for present and future managerial decisionmaking. Although many corporations have become committed to addressing social and environmental concerns, we highlighted that character development is not a straightforward process but rather rife with tensions and conflicts. Therefore, this dissertation contributes to our understanding of the formation process of character (e.g. Cornelissen et al., 2020; Cuyper et al., 2020). However, scholars have not yet examined the "character-defining" critical events in an organization's life course (Clemente et al., 2017; Hoffman \& Ocasio, 2001; Kraatz et al., 2010), nor have they paid attention to the enduring and lasting impact of such events on the character of organizations. By investigating empirically the recovery processes following integrity failures, the findings of this dissertation extends research that 
has examined the more traditional organizational-stakeholder interactions following moral failures (Gillespie et al., 2014; Joshi \& McKendall, 2018; Pfarrer et al., 2008) but that have not paid attention to how such adverse events may function as character-defining moments that has more enduring and far-reaching implications for organizations, their values and beliefs, and their relationships with key stakeholders.

Importantly, the ability to successfully bounce back from integrity failures indicates both the efficacy, sincerity and credibility of the character work in the eyes of key constituents and, correspondingly, the presence of valuable character traits that facilitate adequate recovery such as resilience and responsible adaptability (Williams et al., 2017; Sutcliffe \& Vogus, 2003). Consistent with Selznick's explicit historical perspective on organizational analysis, we extend the research on organizational character by emphasizing the implications of the past on current practices and future actions (Basque \& Langley, 2018; Foroughi et al., 2020; Suddaby et al., 2014). Although the existing literature on organizational character is largely ahistorical (for exceptions, see Sasaki et al., 2019), we build on the notion that "the past relates to and embodies the character of an organization" (Foster et al., 2020), and suggest that the process of remembering, embracing and engaging with a problematic past, while challenging, is fundamental to upholding reclaimed values and commitments, and may even be purposefully and strategically harnessed to foster organizational distinctiveness.

This dissertation adds to the literature on organizational identification (Ashforth et al., 2008; Besharov, 2014; He \& Brown, 2013) by explicating that when leaders show character and find ways to repurpose the past toward more productive ends, members come to identify with the character of the organization and accept its contentious legacy. This deeply affects how they create and implement decisions that are in line with the espoused values of the organization. By identifying the processes through which the past is brought to bear on the present, this dissertation contributes to our knowledge on how and why organizations use their unique history to inform present day decision-making. Furthermore, we might expect that in the absence of a mnemonic community that "knows" about an organization's problematic past-and that can help to hold the organization accountable for its activitieslessons learned may fade over time and misconduct may be repeated (Anand et al., 2012; Haunschild et al., 2015; Mena et al., 2016). Some stakeholders, such as customers, the media and regulators, can thus play a central role in maintaining memories of integrity failures, reminding the focal organization of past controversial practices and putting pressure on others not to make similar mistakes.

Fourth, contributing to the expanding research agenda on the "dark side of organizations" (Vaughan, 1999), this dissertation elucidates the organizational characteristics that enable the materialization and persistence of misconduct (e.g. Greve et al., 2010; Lehman \& Ramanujam, 2009; Palmer, 2012). By drawing on the established literature on organizational learning and responsiveness, we extend the idea that "the same models that predict productivity and organizational citizenship behavior can also foretell organizational misbehavior" (MacLean \& Behnam, 2010: 1517). Consistent with the increasingly influential "normal" organizational wrongdoing perspective (e.g. Palmer, 2012), we believe 
that these theories are necessary because we examined specific types of misconduct in an organizational context that was widespread throughout an industry, and thus, could not be explained by individual or organizational-level factors alone. Importantly, our findings indicate that organizational complexity and managerial inattention prevent internal and external cues from reaching leadership and, consequently, may lead to the materialization of misconduct. In other words, the initial emergence of misconduct is in some cases merely unintentional and mindless.

Notably, although the emergence of misconduct within and by organizations may-in some cases-be unintentional (cf. Goodman et al., 2011; Vaughan, 1999), we simultaneously believe that when organizations continue to violate ethical norms, rules and laws, that is likely to be the result of deficiencies in their characters. Such character deficiencies reflect an absence of moral discipline and self-restraint (Wright \& Goodstein, 2007) and may become manifested in organizations' resistance to institutional demands for responsible conduct (Oliver, 1991; Schilke, 2018; Surroca et al., 2013); specifically, in their tendency to strategically respond to regulatory pressures through myopic, symbolic or temporary remediation. Extending the argument that dominant values within organizations shape issue responses, influence managerial responses to external pressures and serve as anchors that may prevent needed change from occurring (Bansal, 2003; Kraatz et al., 2020; Perkmann \& Spicer, 2014), this dissertation suggests that intensifying regulatory pressures may-in some cases-be futile. Character traits such as complacency, hubris and arrogance inhibit key decision-makers to heed cues of noncompliance and, more importantly, persistently to prioritize commercial imperatives over adherence to societal demands for responsible behavior. Importantly, flagrant integrity failures that fall short of creating extreme uncertainty and distrust, and thus evoke substantive character work, are unlikely to lead to meaningful reductions in undesirable behavior. This final point will be elaborated on in more detail below.

Fifth and finally, in addition to organizational level characteristics, this dissertation also illuminates various institutional processes that may enable the emergence of organizational misconduct. Specifically, the findings contribute to research on misconduct by extending recent studies that investigate how social-control agents attempt to label and curb misconduct (Dewan \& Jensen, 2020; Greve et al., 2010; Heese et al., 2016; Mohliver, 2019), but that to date have not paid any attention to how these actors may inadvertently create or facilitate misconduct. Adding to the research on the "normalization" of misconduct (Ashforth \& Anand, 2003; Earle et al., 2010; Vaughan, 1996), the findings indicate that a long history of regulatory restraint (e.g. few regulatory audits, less enforcement and fewer sanctions) and ambiguity may give rise to complacency and hubris among regulated firms. As a result of such leniency, such undesirable character traits are likely to become seen as acceptable and taken-for-granted, paving the way for the normalization of misconduct.

Since social entities that possess such traits often have inertial or static tendencies (Tourish, 2020; Tushman \& Nadler, 1986), we find that such normalized misconduct becomes especially difficult to reverse, especially when externally mandated rules and norms have become increasingly perceived as illegitimate or enforcement actions lack social visibility. 
When such external processes do not offset the economic benefits of noncompliance, organizations will probably hold on to the status-quo and will abstain from making costly changes in their practices and structures that impede on their core commercial goals. These findings are thus consistent with Vaughan's (2002: 127) assertion that "the ineffectiveness of the regulatory environment becomes part of the causes of corporate misconduct".

An important finding of this dissertation is that industry-wide critical events, such as salient integrity failures and scandals (Clemente et al., 2017; Greve et al., 2010), can bring misconduct and irresponsible behavior to public attention, heighten distrust of the offending organization and, consequently, force organizations and their leadership to become susceptible to institutional pressures for increased ethical conduct and regulatory compliance. This dissertation extends the growing body of organizational literature on scandals and their implications for both offending firms and industry peers (Clemente \& Gabbioneta, 2017; Daudigeos et al., 2020). We do so by extending previous studies that found that firm-specific rather than industry-wide critical events determine substantive implementation of regulatory practices and structures (Chandler, 2014), by illuminating how regulatory agencies may leverage industry-wide critical events to coerce substantive compliance and resource commitments by both the focal firms and their peers. Importantly, we find that the regulatory enforcement and sanctioning in the wake of scandals, by virtue of their social visibility, normative power and emphasis on executive accountability, may function as effective deterrence signals for other noncompliant organizations, offsetting the perceived benefits of noncompliance, and potentially triggering vicarious learning among industry peers. In sum, we show that scandals have the "potential to increase order and stability in society" (Dewan \& Jensen, 2020: 1674).

\subsection{Implications for Practice}

Although the results of this dissertation provide timely theoretical insights into organizational theory, we also think that they have important consequences for policy and practice. In this vein, this dissertation also provides several important implications for leaders to better understand how they can build a valued and respected organizational character and sustain the integrity of their organization and for those actors that are active in the detection, prevention and erosion of misconduct in and by organizations.

First, based on our conceptual work on organizational integrity, we urge leaders and key audiences to be mindful of the diversity and inherent complexity of values within organizations (Kraatz \& Block, 2017). Though modern corporations portray themselves as unitary and integrated entities, in reality they are imbued with a great many valuesbased internal inconsistencies and tensions (Bromley \& Meyer, 2015; Greenwood et al., 2011; Grimes et al., 2019). Therefore, it is critical for leaders to make their espoused commitments, and the values inherent in such commitments, explicit in tangible internal 
processes, practices and governance arrangements, in the services and goods their organization provides and in its interaction with important constituents. The articulation of an aspirational purpose or set of values may be achieved with the best of intentions in mind (Bourne \& Jenkins, 2013), yet leaders should be conscious that new aspirations may directly conflict with the existing values and interests dominant throughout the organization and championed by powerful subgroups, thus inhibiting their enactment and preventing substantive change from occurring. As exemplified by the corporate scandals of at Volkswagen, Parmalat and the like, 'bullshit' is pervasiveness in contemporary society (Frankfurt, 2005) and the espousal of a lofty purpose and ethical principles may function merely as a message to signal symbolic conformity to institutional prescriptions. Therefore, we advise both organizational members and outside audiences to cultivate a healthy dose of cynicism towards the values and beliefs articulated by the corporations we interact with-and to have a keen eye on corporate actions.

Second, as misconduct is widespread in modern organizational life (Greve et al., 2010; Palmer, 2012), the findings provide important implications for organizations that attempt to recover from and adapt to adverse events. Although stigmatizing crises that arise following integrity failures or scandals may create profound uncertainty, ambiguity and distrust within organizational boundaries, leaders can attempt to leverage these salient events to galvanize radical and credible change within their organizations by looking inwards for latent historical elements to rebuild trust among discontented members and other stakeholders. When leaders accompany this process of introspection with recurring actions that ostensibly align with important societal values, assumptions by members and key audiences about an organization's tainted character are obfuscated while its value to the wider community is reinforced.

In contrast, based on our findings we expect that integrity failures that fail to either elicit strong moral disapproval among powerful constituents or create extreme uncertainty among members are unlikely to lead to substantive changes in the character of an organization. Indeed, because scandals and other salient integrity failures often have significant "social costs" (e.g. legitimacy, reputations), such events are particularly important moments for consumers, regulators, activist groups and politicians to enforce good behavior, legitimize administrative rules and achieve substantive compliance. Importantly, while the kneejerk reaction by leaders of transgressing organizations is often to put in motion processes to erase or reconfigure the collective memories of corporate irresponsibility or wrongdoing (Coraiola \& Derry, 2019; Mena et al., 2016), which may be essential to guarantee or preserve trust by constituents in the short term, this dissertation suggests that organizational elites would instead do well to address the taken-for-granted values and norms that gave rise to misconduct in the first place, remember the lessons learned from adversity, to convey their stories and experiences to new employees and make these in tangible core processes, services and goods. Otherwise, we speculate-on the basis of previous research (Chandler, 2014; Haunschild et al., 2015-that misconduct is likely to be repeated. 
Third, an important policy implication of the normalization literature (Ashforth \& Anand, 2003; Earle et al., 2010; Vaughan, 1996) for government officials and nongovernmental organizations seeking collective solutions to ethical problems, this dissertation stresses that persistent restraint in auditing, enforcing and sanctioning may inadvertently signal that nonconforming behavior is to some degree acceptable. Recent regulatory and auditing failures, such as in the case of Wirecard and HSBC, underscore our finding that when organizations persistently get away with misconduct, their bad characters become increasingly rigid and hard to change. Specifically, lenient enforcement mechanisms may pave the way for hubris and complacency among regulated firms, which prevents top management from seeing, perceiving, recognizing or detecting discomforting information in an effective matter and thus hindering adequate responsiveness to an everchanging external environment.

Simultaneously, this dissertation urges regulatory authorities that are tasked with the enforcement of legal requirement to be aware of the local values, norms and history of offending organizations. For governmental authorities responsible for challenging, preventing or reversing noncompliance this means that rather than relying on overt coercive pressure for regulatory compliance, they should first consider how firms perceive the legitimacy of the regulations they are mandated to enforce. Our findings suggest that when firms perceive regulatory requirements and governmental mandates as ambiguous or even illegitimate (Edelman, 1992; Sonenshein, 2016), remediation following negative external feedback is likely to be substandard and at risk of being transitory. Specifically, firms resist substantial implementation of procedural regulations not only because they infringe upon managerial discretion but also because these organizations perceive governmentalmandated rules as demanding inefficient and irrational practices that significantly impede on their commercial priorities. Indeed, normative and coercive pressures from the external environment do not "easily erode long-held managerial prerogatives" (Edelman, 1992: 1535). Therefore, this dissertation suggests regulators that should be conscious that firms remain inherently unwilling to bend to pressures for conformity when such regulatory requirements are in conflict with core business interests and established practices.

Fourth, our findings suggest that governmental agencies should be especially conscious of the implications of the nature of the rules they enforce. Strict enforcement of procedural norms and requirements often comes after a major incident or a long period of noncompliance. Logically, the loss of regulators' trust often leads to an approach in which there is little or no room for interpretation of the requirements by the regulated firm. Although regulators may want to see that firms are making progress in remediation noncompliance, and set detailed, verifiable goals and quality requirements, the disadvantage of this approach is that-in the long term-imposing detailed requirements from the outside leads to reduced ownership. This process may even lead to the process of 'regulatory creep' (Parker, 2006), which can skew the focus of those being regulated away from the key objectives of institutional rules and encourage them to concentrate on the process of demonstrating strict adherence to regulatory requirements, delivering little-if any-additional benefit. 
This process touches on the notion of means-ends decoupling, meaning that while regulatory policies and structures are thoroughly implemented through the organization to avert stringent enforcement or harsh penalties, they have an opaque relationship to intended outcomes (Bromley \& Powell, 2012; Wijen, 2014). Over time, as the relationship between implemented practices and intended outcomes remains uncertain or ambiguous, corporate leaders and employees are likely to become disillusioned and the practices perceived as increasingly illegitimate (MacLean \& Behnam, 2010). Breaking this vicious circle requires both that governments evaluate legislative arrangements and that regulatory authorities regularly review the unintended consequences of supervision, preferably in an open dialogue with those being regulated. Understanding the perspective of the regulated should not stand in the way of independent and rigorous oversight but actually strengthen the effectiveness of supervision. Simple deterrence, in the form of more stringent enforcement, will often fail to produce compliance commitments because it does not directly address the business perceptions about the morality of regulated behavior, especially when regulations emphasize procedural requirements over principles.

\subsection{Research Reflections and Limitations}

Although we laid out some of the methodological considerations in the introductory chapter of this dissertation, we believe that further reflection on our research processes and clarification on their limitations is warranted. As we reflect on the methodological decisions we made and discuss their potential limitations, we also open avenues for future research, which we will discuss in more detail in final section of this dissertation.

First, while the theoretical model developed in Chapter 2 was primarily meant to guide the empirical inquiries in the rest of the research, the propositions we put forth received only little empirical follow-up in the subsequent chapters, but rather functioned as the theoretical background throughout the various studies. Due to the "developmental and formative" nature of qualitative research (Miles \& Haberman, 1994), initial conceptual ideas and propositions may be only of temporary relevance, while captivating hunches and surprises during the data collection may be seized to then be explored in more detail (Saetre \& Van de Ven, 2021). For instance, in Chapter 5 we initially postulated the rather open and broad question of how organizations fail to maintain their self-imposed commitments to corporate responsibility while operating under competing societal pressures. This question gave us room to maneuver, depending on the empirical insights we encountered. As we began the collection of our data and engaged in preliminary analysis for Chapter 3, we noticed that our informants depicted the 2007-2008 global financial crisis, and its aftermath, as a crucial formative period for their organizations and, consequently, present behavior. As we explored these hunches and ideas through conversations with fellow scholars, additional 
interviews and by reading relevant literature, we were intrigued by the notion of character and found its appeal in explaining how adverse events may have enduring implications for organizations, their cultures and their strategies, even long after such events occurred.

Second, the empirical research presented in this dissertation is based on in-depth case studies and, therefore, the insights we have described may raise questions of generalizability-that is, to what extent might the findings described in this dissertation apply to other organizations or industries? According to Gehman and colleagues (2013: 107), the unique theoretical contribution of qualitative studies is "the opportunity to further refine understanding of general phenomena by offering more incisive distinctions than previously available, thereby allowing researchers to see things they could not see before", a process that Tsoukas (2009) termed "heuristic generalization".

Therefore, rather than statistical generalization, the purpose of our case studies was to generalize to theory and provide insights on specific organizational processes and mechanisms that require the iteration between thick description of data through in-depth inquiry and the extant literature. Such theoretical generalization improves our understanding of specific aspects of organizational life by generating "concepts or principles with obvious relevance to some other domain" (Gioia et al., 2013: 24), while simultaneously remaining open to further refinements as future cases are considered. For instance, we coined the term character work to describe the actions that organizations engage in as they rebuild their character following integrity failures. While the concept of character work is empirically grounded and informed by the growing literature on organizational work (e.g. Lawrence \& Phillips, 2019), it remains open for further theoretical development, and clarification of its boundary conditions under various conditions and in other industries.

Third, concerning the design choices made in Chapters 3 and 5, readers might question what made the enterprises that provided access for our inquiries distinctive and "nonprototypical" (Gehman et al., 2013: 107), as this may have shaped the findings reported in this dissertation. Although the process of gaining access to organizations and the confidence of informants was not always straightforward, and at times even awkward and frustrating, there is reason to believe that the organizations that did give permission for repeated research visits, in-depth interviews with high-level executives and observations of day-to-day activities, may have been those organizations that had confidence in their own functioning and were, therefore, more willing to open their doors to academic inquiry. In other words, while we usually do not talk about "selection bias" in qualitative research (Yin, 2015), the case organizations discussed in Chapters 3 and 5 had specific characteristics that made them more willing to accept outside scrutiny.

In contrast, by virtue of the themes we were interested in (e.g. "character", "integrity", "misconduct"), organizations that were reluctant to provide certain types of access to researchers that would have been of particular interest for this dissertation. For instance, some of the financial enterprises we approached declined to participate for reasons, we later discovered, related to boardroom conflicts, internal fraud or widespread regulatory 
noncompliance. This observation underscores the notion that the organization-centric topics we were interested in may, in some cases, be better examined through quantitative methods. On the other hand, the use of in-depth case-studies and ethnographic methods, while less common when studying these themes, has provided the opportunity for unexpected ideas to emerge and to build theory on phenomena we would only be able to observe through immersion. More importantly, the methods we applied in this research gave us the research tools to gain a more fine-grained understanding of the inner workings of organizational actors, the values, beliefs and emotions of people working within them, and their interactions with key stakeholders.

Fourth, owing to the nature of in-depth qualitative research, there is always the danger for academics of 'going native' or, in other words, becoming too involved with the organization or community under study and thus potentially losing objectivity and distance (O'Reilly, 2009). This risk is particularly prevalent when the data collection requires the building of social relationships and the engagement in social interaction with informants over a long period of time. In Chapter 4 and 5, we attempted to counter this limitation by triangulating through using various data sources, including in-depth interviews, field observations, and both internal and external archival material. Despite these efforts, considerable reflexivity and recognition of agency on part of us as researchers remained necessary. Acknowledging the notion that social science is not a value-free endeavor (Sayer, 2011; Suddaby, 2014), we have to be conscious about the choices we make when conducting our research, about how our personal backgrounds, beliefs, preferences and biases shape our questions and interpretations, and consequently, about the narratives we communicate to our readers. The academic department in which I resided during my doctoral studies accommodated a broad range of research themes, ranging from social entrepreneurship to individual resilience and innovation. Although perhaps not immediately apparent, this environment has had a considerable impact on the literature we drew on, on how we interpreted the particularity of our cases and on the narratives we developed.

The choice, for instance, to present the study in Chapter 5 as a 'redemption story', outlining how organizations rebuild character through adversity and become committed to particular set of values and beliefs, meant that we had to forgo alternative empirical trajectories and, consequently, other interpretations of the data. However, extant research has highlighted how organizations may learn (Christianson et al., 2009; Madsen, 2009) or bounce back from crises (Weick \& Sutcliffe, 2015; Williams et al., 2017), making our narrative of how some organizations rebuild character following integrity failures theoretically informed and, we believe, persuasive.

Nevertheless, some critical readers might perceive our narrative as unconvincing or overtly optimistic and may, rightly so, point to the pervasiveness of repeat offenders in modern corporate life. My academic infancy within the school of criminology has made me especially sensitive to much of the hypocrisy and dishonesty inside many of our most powerful corporate institutions-and this has stayed with me ever since. A case in point is in Chapter 4, where we demonstrate how some organizations are actually reluctant to 
rebuild their character and continue to deviate from societal norms and rules. This dualism, between corporations' capacity for both virtuous and vicious behavior, echoes Selznick's recognition of organizational institutions as both economic and technical collectives, aiming to at achieve efficiency, as well as social and value-laden entities whose activities are often important ends in themselves.

Nonetheless, the issues we have discussed above remain valid concerns that require us as researchers to be extra conscious about the subjective portrayals that are presented to us and the interpretations we subsequently make. Having said that, our prolonged immersion within the organizations under study, recurrent interaction with a plethora of members at all levels of the organizations, and a rich set of interviews, and both observational and archival data, gave us sufficient confidence in the validity of our social-scientific account.

Fifth, and related to the previous point, the archival material gathered and analyzed in Chapter four consists primarily of regulatory documents. These documents, including supervisory reports, interviews, and enforcement decisions, were drawn up for regulatory purposes rather than academic research, and drafted by supervisors who had their own goals, interests and preferences in mind and, as a result, inevitably had some degree of "bias". We have attempted to counteract this bias in the data material by combining perspectives of outsider researchers with that of an insider researcher, combining an uninformed view of the empirical setting with that of one with more in-depth knowledge and expertise. More specifically, one of the co-authors was involved in neither the data collection nor the case analysis, but primarily contributed to the process theory development. Such a 'neutral' perspective proved to be valuable because it provided us with an objective view during the analysis by consistently challenging our interpretation of the data. Additionally, during our analysis we purposefully shifted our attention somewhat from focusing exclusively on the practices of offending firms to the interaction between noncompliant organizations and regulatory agencies. To this end, we conducted additional interviews with senior regulatory officers to gain a better understanding of the choices that the regulatory agencies had made over time as the case study organizations persisted in not complying with regulatory requirements and directions.

Finally, while we attempted to correct or reduce the data limitations in Chapter 4, we remained aware of the more fundamental research challenges that emerge by relying primarily on regulatory documentation to understand the misbehavior of organizations. Although a potential solution would have been to gain the perspectives of the offending organizations and complement the archival material with additional interviews or documentation from our case organizations, we were unable to do so due to the confidentiality of our data material. This has had significant implications for addressing our research question and understanding our cases. For instance, because we were restricted to addressing political, legislative and media aspects in our case presentation, a truly multilevel and more indepth study that combined political, regulatory and organizational mechanisms-and their interactions-to understand the materialization and persistence of misconduct was not possible. However, this limitation does suggest opportunities for future research. 


\subsection{Suggestions for Future Research}

Notwithstanding our efforts in this dissertation, research on organizational character and integrity has only recently come of age. As such, we make several suggestions for future research. First, while this dissertation has mainly focused on in-depth case studies, scholars can use the propositions presented in Chapter 2 as input to build theoretical hypotheses on the determinants, constraints and processes of organizational integrity. More specifically, future research could empirically test what organizational and institutional factors contribute to the presence or absence of integrity. Scholars might consider, for instance, what characteristics of executive leadership, board of director structure and employee composition causes or hinders firms' sustained commitments to living out embraced principles. Recent developments in organizational scholarship offer a number of methodical tools that may prove valuable in such endeavor, such as content analysis (Bromley \& Sharkey, 2017), web scraping (Gehman \& Grimes, 2017), and mixed methods (Haunschild et al., 2015), which might allow scholars to capture divergence between espoused, embedded and enacted values. In addition to the financial sector, we would be especially interested in the other sectors that are known for their lofty espousal of ethical principles but where irresponsible behavior and misconduct is pervasive, such as the pharmaceutical, petroleum and automotive industries.

Second, this dissertation suggests that corporate failures, such as misconduct and mismanagement, may function as important critical events (Clemente et al., 2017; Hoffman \& Ocasio, 2001) that can profoundly shape the characters of organizations. However, there remains plenty to empirically investigate with regards to the efficacy and varieties of "character work" in other organizational settings, under varying institutional conditions and following varying types of failures. Specifically, while our findings suggest a more productive and positive pathway to reintegration following integrity failures, existing research has suggested that radical organizational change may also elicit overt resistance (Huy et al., 2014) or conflict (Fiol et al., 2009) within organizational boundaries. We would expect that these tensions may be particularly salient during institutionally enforced organizational changes that are contra-normative in the eyes of members, as leaders that want to instill radical change need to "simultaneous pursue [external] legitimacy and maintain [the] integrity" of their organization (Kraatz, 2009: 73). We speculate that such resistance towards character work may be particularly pervasive within organizations where powerful subgroups or constituents have an interest in maintaining on to the status quo. As this dissertation employs a single-case study design, we would be particularly interested in seeing comparative research that examines how different organizations confronted by the same critical event (e.g. an industry-wide crises or industry scandal) adapt to adversity, the intraorganizational struggles that emerge and, critically, how organizational character changes as a result. 
Third, this dissertation opens uncharted terrain to explore organizational responses to institutional pressures for responsible or ethical conduct. For instance, we have demonstrated that, on the one hand, regulatory restraint may give rise to a type of responsiveness that is more symbolic, isolated and temporary in nature and, on the other hand, that stringent regulatory enforcement after misconduct may lead to an unproductive focus on procedural rules that have an opaque relationship with envisioned outcomes. As this form of decoupling between means and ends is becoming increasingly pervasive in modern organizational life (Bromley \& Powell, 2012; Wijen, 2014), we see opportunities for future research to investigate both the implications of regulatory encroachment in the process of means-ends decoupling over time and the longer-term implications for both firms and their constituents as such a process transpires. We would be particularly interested in organizational responses to rules and regulations that are purely or mainly procedural in nature (Edelman, 1992; Lehman \& Remananjum, 2009) as these often lack normative legitimacy and may thus only be adopted symbolically and are less likely to be fully implemented.

Fourth, although we have examined the behavior and influence of regulatory authorities in "creating and labeling misconduct" (Greve et al., 2010: 55), questions remain as to the specific institutional determinants that shape social-control agent behavior and, consequently, the ways in which this may impact their enforcement behavior. For instance, in addition to previous research that has indicated that regulatory pressures are affected by a combination of internal complexities and fragmentation (Heese et al., 2016) conflicting institutional demands (Greenwood et al., 2011), and the status of the regulated firms (Dewan \& Jensen, 2020), we elucidate in our findings that regulatory authorities may shift their attention and focus as a result of industry-wide critical events, such as crises or legislative adjustments. Especially insightful would be research that examines the effect of corporate scandals (Clemente \& Gabbioneta, 2017; Daudigeos et al., 2020; Graffin et al., 2013), as these have the potential to bring about particularly profound institutional change (Clemente et al., 2017). One fruitful future research direction would be to understand how and why corporate scandals lead to coordinated or uncoordinated processes of practice deinstitutionalization, such as that following the \#MeToo movement or tax evasion revealed by the Panama Papers leaks. This may require a multilevel approach that addresses both the interaction between regulatory agencies and other societal actors, such politicians, the media and social movements, and their subsequent pressure on ingrained, but increasingly undesirable, liminal practices. 



\section{Bibliography}

Albert, S., \& Whetten, D. A. (1985). Organizational identity. In L. L. Cummings \& M.M. Staw (Eds.), Research in organizational behavior (Vol. 7, pp. 263-295). Greenwich, CT: JAI.

Algan, Y., \& Cahuc, P. (2013). Trust and growth. Annual Review of Economics, 5(1), 521-549.

Almandoz, J. (2014). Founding teams as carriers of competing logics: When institutional forces predict banks' risk exposure. Administrative Science Quarterly, 59(3), 442- 473.

Anand, G., Gray, J., \& Siemsen, E. (2012). Decay, shock, and renewal: Operational routines and process entropy in the pharmaceutical industry. Organization Science, 23(6), 17001716.

Ansell, C., Boin, A., \& Farjoun, M. (2015). Dynamics conservatism: How institutions change to remain the same. In M.S. Kraatz (Ed.), Institutions and Ideals: Philip Selznick's Legacy for Organizational Studies (pp. 89-119). Bingley, U.K.: Emerald Group Publishing Limited.

Anteby, M., \& Molnár, V. (2012). Collective memory meets organizational identity: Remembering to forget in firm's rhetorical history. Academy of Management Journal, 55(3), 515-540.

Archer, A. (2017). Integrity and the value of an integrated self. Journal of Value Inquiry, 51, 435-454.

Armanios, D. E., \& Eesley, C. E. (2021). How do institutional carriers alleviate normative and cognitive barriers to regulatory change? Organization Science, 1-24. 
Arstad, I., \& Aven, T. (2017). Managing major accident risk: Concerns about complacency and complexity in practice. Safety Science, 91, 114-121.

Ashforth, B.E., \& Anand, V. (2003). The normalization of corruption in organizations. Research in Organizational Behavior, 25, 1-52.

Ashforth, B.E., \& Fried, Y. (1988). The mindlessness of organizational behaviors. Human Relations, 41(4), 305-329.

Ashforth, B. E., Gibbs, B. W. (1990). The double-edge of organizational legitimation. Organization Science, 1(2), 177-194.

Ashforth, B.E., \& Reingen, P.H. (2014). Functions of dysfunction: Managing the dynamics of an organizational duality in a natural food cooperative. Administrative Science Quarterly, 59(3), 474-516.

Ashforth, B. E., Harrison, S. H., \& Corley, K. G. (2008). Identification in organizations: An examination of four fundamental questions. Journal of Management, 34(3), 325-374.

Ashforth, B. E., Schinoff, B. S., \& Brickson, S. L. (2020). "My company is friendly," "Mine’s a rebel": Anthropomorphism and shifting organizational identity from "what" to "who". Academy of Management Review, 45(1), 29-57.

Avolio, B. J., \& Gardner, W. L. (2005). Authentic leadership development: Getting to the root of positive forms of leadership. The Leadership Quarterly, 16(3), 315-338.

Bakker, E. de (2007). Integrity and cynicism: Possibilities and constraints of moral communication. Journal of Agricultural and Environmental Ethics, 20, 119-136.

Bansal, P. (2003). From Issues to Actions: The Importance of Individual Concerns and Organizational Values in Responding to Natural Environmental Issues. Organization Science, 14(5), 510-527.

Bartkus, B. R., \& Glassman, M. (2007). Do firms practice what they preach? The relationship between mission statements and stakeholder management. Journal of Business Ethics, 83, 207-216.

Basel Committee on Banking Supervision (2016). Sound management of risks related to money laundering and financing of terrorism. Accessed at https://www.bis.org/bcbs/ publ/d353.pdf

Basque, J., \& Langley, A. (2018). Invoking alphonse: The founder figure as a historical resource for organizational identity work. Organization Studies, 39(12), 1685-1708.

Battilana, J. (2006). Agency and institutions: The enabling role of individuals' social position. Organization, 13(5), 653-676.

Battilana, J., \& Dorado, S. (2010). Building sustainable hybrid organizations: The case of commercial microfinance organizations. Academy of Management Journal, 53, 14191440 .

Bauman, D.C. (2013). Leadership and the three faces of integrity. Leadership Quarterly, 24(3), 414-426.

Becker, T. E. (1998). Integrity in organizations: Beyond honesty and conscientiousness. Academy of Management Review, 23(1), 154-161. 
Bednar, M. K., Love, E. G., \& Kraatz, M. S. (2015). Paying the price? The impact of controversial governance practices on managerial reputation. Academy of Management Journal, 58(6), 1740-1760.

Berson, Y., Oreg, S., \& Dvir, T. (2008). CEO values, organizational culture and firm outcome. Journal of Organizational Behavior, 29, 615-633.

Besharov, M. L. (2014). The relational ecology of identification: How organizational identification emerges when individuals hold divergent values. Academy of Management Journal, 57(5), 1485-1512.

Besharov, M. L., \& Brickson, S. L. (2016). Organizational identity and institutional forces: Toward an integrative framework. In M. Pratt, M. Schultz, B. Ashforth, \& D. Ravasi (Eds.), The Oxford Handbook of Organizational Identity (p. 396-416). Oxford University Press: Cambridge.

Besharov, M. L., \& Khurana, R. (2015). Leading amidst competing technical and institutional demands: Revisiting Selznick's conception of leadership. In M.S. Kraatz (Ed.), Institutions and Ideals: Philip Selznick's Legacy for Organizational Studies (p. 5388). Bingley: Emerald Group Publishing Limited.

Beunza, D. Taking the Floor. Models, Morals, and Management in a Wall Street Trading Room. Princeton, NJ: Princeton University Press.

Binder, A. (2007). For Love and Money: One organization's creative and multiple responses to a new funding environment. Theory and Society, 36, 547-571.

Birnholtz, J. P., Cohen, M. D., \& Hoch, S. V. (2007). Organizational character: On the regeneration of Camp Poplar Grove. Organization Science, 18(2), 315-332.

Blair-Loy, M., Wharton, A. S., \& Goodstein, J. (2011). Exploring the relationship between missions statements and work-life practices in organizations. Organization Studies, 32(3), 427-450.

Bökkerink, I., \& Couwenbergh, P. (2020). De Staatsbank: ABN Amro Klem tussen Ambtenaren en Bankiers. Amsterdam: Prometheus.

Boon, V. van der, Couwenbergh, P., Horde, C. de, Lalkens, P., \& Wolzak, M. (2013). De Val van SNS Real. Hoogmoed, het Snelle Geld, en Blinde Ambitie. Amsterdam: Nieuw Amsterdam.

Boston Consulting Group (2018). Staying the course in banking. Accessed at https://imagesrc.bcg.com/Images/BCG-Staying-the-Course-in-Banking-Mar-2017_tcm9-146794. pdf

Bourne, H., \& Jenkins, M. (2013). Organizational values: A dynamic perspective. Organization Studies, 34(4), 495-514.

Bourne, H., Jenkins, M., \& Parry, E. (2019). Mapping espoused organizational values. Journal of Business Ethics, 159, 133-148.

Boxenbaum, E., \& Jonsson, S. (2017). Isomorphism, diffusion and decoupling: Concept evolution and theoretical challenges, in R. Greenwood, C. Oliver, K. Shalin, \& R. Suddaby The SAGE handbook of organizational institutionalism. London, UK: Sage Publications. 
Breakey, H., Cadman, T., \& Sampford, C. (2015). Conceptualizing personal and institutional integrity: The comprehensive integrity framework. In M. Schwartz, H. Harris, \& D. Cromer (Eds.), The Ethical Contribution of Organizations to Society (Research in Ethical Issues in Organizations, Vol. 14), Emerald Group Publishing Limited, Bingley, pp. 1-40

Beemen, O. van (2018). Bier voor Afrika. Amsterdam: Prometheus.

Bromley, P., \& Meyer, J. W. (2015). Hyper-Organization. Global Organizational Expansion. Oxford: Oxford University Press.

Bromley, P., \& Powell, W.W. (2012). From smoke and mirrors to walking the talk: Decoupling in the contemporary world. Academy of Management Annals, 6(1), 483-530.

Bromley, P., \& Sharkey, A. (2017). Casting call: The expanding nature of actorhood in U.S. firms, 1960-2010. Accounting, Organizations and Society, 59, 3-20.

Brunsson, N. (1989). The Organization of Hypocrisy: Talk, Decisions and Actions in Organizations. Chichester, UK: John Wiley and Sons.

Bundy, J., \& Pfarrer, M. D. (2015). A burden of responsibility: The role of social approval at the onset of a crisis. Academy of Management Review, 40(3), 345-369.

Bundy, J., Iqbal, F., \& Pfarrer, M. D. (2021). Reputation in flux: How a firm defends its multiple reputations in response to different violations. Strategic Management Journal, 42, 1109-1138.

Bundy, J., Shropshire, C., \& Buchholtz, A.K. (2013). Strategic cognition and issue salience: Toward an explanation of firm responsiveness to stakeholder concerns. Academy of Management Review, 38(3), 352-376.

Bundy, J., Pfaffer, M. D., Short, C. E., \& Coombs, W. T. (2017). Crises and crisis management: Integration, interpretation, and research development. Journal of Management, 43(6), 1661-1692.

Calhoun, C. (1995). Standing for Something. The Journal of Philosophy, 92(5), 235-260.

Carlos, W. C., \& Lewis, B. W. (2018). Strategic silence: Withholding certification status as a hypocrisy avoidance tactic. Administrative Science Quarterly, 63(21), 130-169

Casey, A. J., \& Olivera, F. (2011). Reflections on organizational memory and forgetting. Journal of Management Inquiry, 20(3), 305-310.

Castro, A., Phillips, N., \& Ansari, S. (2020). Corporate corruption: A review and an agenda for future research" Academy of Management Annals, 14(2), 935-968.

Caza, B. B., Moss, S., \& Vough, H. (2018). From synchronizing to harmonizing: The process of authenticating multiple work identities. Administrative Science Quarterly, 63(4), 703745.

Chandler, D. (2014). Organizational susceptibility to institutional complexity: Critical events driving the adoption and implementation of the ethics and compliance officer position. Organization Science, 25(6), 1722-1743.

Chandler, D. (2015). Why institutions matter: Stakeholder attention to organizational ethics commitments." In M.S. Kraatz (Ed.), Institutions and Ideals: Philip Selznick's Legacy for Organizational Studies (p. 199-233). Bingley, UK: Emerald Group Publishing Limited. 
Charmaz, K. (2006). Constructing ground theory: A practical guide through qualitative analysis. Thousand Oaks, CA: Sage.

Chiu, S.-C., \& Sharfman, M. (2011.) Legitimacy, visibility, and the antecedents of corporate social performance: An investigation of the instrumental perspective. Journal of Management, 37, 1558-1585.

Christianson, M. K., Farkas, M. T., Sutcliffe, K. M., \& Weick, K. E. (2009). Learning through rare events: Significant interruptions at the Baltimore \& Ohio Railroad Museum. Organization Science, 20(5), 846-860.

Clark, B. R. (1956). Organizational Adaption and Precarious Values: A Case Study. American Sociology Review, 327-336.

Clark, P., \& Rowlinson, M. (2004). The treatment of history in organization studies: Towards an 'historic turn'? Business History, 46(3), 331-352

Clark, S. M., Gioia, D. A., Ketchen, D. J., \& Thomas, J. B. (2010). Transitional identity as a facilitator of organizational identity change during a merger. Administrative Science Quarterly, 55, 397-438.

Clearfield, C., \& Tilcsik, A. (2018). Meltdown: Why Our Systems Fail and What We Can Do About It. London, UK: Penguin Group.

Clemente, M., \& Gabbioneta, C. (2017). How does the media frame corporate scandals? The case of German newspapers and the Volkswagen diesel scandal. Journal of Management Inquiry, 26(3), 1-16.

Clemente, M., Durand, R., \& Roulet, T. (2019). The recursive nature of institutional change: An Annales School perspective. Journal of Management Inquiry, 26(1), 17-31.

Coffee, J.C. (2006). Gatekeepers: The professions and corporate governance. Oxford, UK: Oxford University Press.

Cohen, M. D. (2007). Reading Dewey: Reflections on the study of routine. Organization Studies, 28(5), 773-786.

Cohn, A., Fehr, E., \& Maréchal, M. A. (2014). Business culture and dishonesty in the banking industry. Nature, 516, 86-89.

Coleman, J.W., \& Ramos, L.L. (1998). Subcultures and deviant behavior in the organizational context. Research in the Sociology of Organizations, 15, 3-34.

Collins, J. C., \& Porras, J. I. (1994). Building Your Company's Vision. Harvard Business Review, September-October 1996.

Colquitt, J. A., \& Rodell, J. B. (2011). Justice, trust, and trustworthiness: A longitudinal analysis integration three theoretical perspectives. Academy of Management Journal, 54(6), 1183-1206.

Connelly, B. L., Ketchen, D. J., Gangloff, K. A., \& Shook, C. L. (2016). Investor perceptions of CEO successor selection in the wake of integrity and competence failures: A policy capturing study. Strategic Management Journal, 37, 2135-2151. 
Coombs, T. W., \& Holladay, S. J. (2005). An exploratory study of stakeholder emotions: Affect and crises. In N. M. Ashkanasy, W. J. Zerbe, \& C. E. J. Härtel (Ed.) The Effect of Affect in Organizational Settings (Research on Emotion in Organizations, Vol. 1, pp. 263-280), Emerald Group Publishing Limited, Bingley,

Coraiola, D. M., \& Derry, R. (2020). Remembering to forget: The historic irresponsibility of U.S. Big Tobacco. Journal of Business Ethics, forthcoming.

Corbin, J., \& Strauss, A. (1990). Grounded theory research: Procedures, canons, and evaluative criteria. Qualitative Sociology, 13, 3-21.

Cording, M., Harrison, J. S., Hoskisson, R. E., Jonsen, K. (2014). Walking the talk: A multistakeholder exploration of organizational authenticity, employee productivity, and postmerger performance. Academy of Management Perspectives, 28(1), 38-56.

Corley, G. C., \& Gioia, D. A. (2004). Identity ambiguity and change in the wake of a corporate spin-off. Administrative Science Quarterly, 49(2), 173-208.

Cornelissen, J. P., Akemu, O., Jonkman, J. G. F., \& Werner, M. D. (2020). Building character: The formation of a hybrid organizational identity in a social enterprise. Journal of Management Studies. doi:10.1111/joms.12640.

Cornelissen, J. P., Haslam, S. A., \& Werner, M. D. (2016). Bridging and integrating theories on organizational identity: A social interactionist model of organizational identity formation and change. In M. G. Pratt, M. Schultz, Ashforth, B. E., \& Ravasi, D. (Eds.), The Oxford Handbook of Organizational Identity (p. 200-216). Oxford, UK: Oxford University Press.

Correira, M.M. (2014). Political connections and SEC enforcement. Journal of Accounting and Economics, 57, 241-261.

Cox, D., La Caze, M., \& Levine, M. P. (2018). Integrity and the fragile self. New York, NY, USA: Routledge.

Crawford, B., Coraiola, D. M., \& Dacin, M. T. (2021). Painful memories as mnemonic resources: Grand Canyon Dories and the protection of place. Strategic Organization.

Creed, W. E. D., Hudson, B. A., Okhuysen, G. A., \& Smith-Crowe, K. (2014). Swimming in a sea of shame: Incorporating emotion into explanations of institutional reproduction and change. Academy of Management Review, 39(3), 275-301.

Crilly, D., Zollo, M., \& Hansen, M.T. (2012). Faking it or muddling through? Understanding decoupling in response to stakeholder pressures. Academy of Management Journal, 55(6), 1429-1449.

Cyert, R. M., \& March, J. G. (1963). A Behavioral Theory of the Firm. Malden, MA: Blackwell Publishers.

Dacin, T.M., Goodstein, J., \& Scott, W.R. (2002). Institutional Theory and Institutional Change: Introduction to the Special Research Forum. Academy of Management Journal, 45(1), 45-57.

Daskalaki, M., Fotaki, M., \& Sotiropoulou, I. (2019). Performing values practices and grassroots organizing: The case of solidarity economy initiatives in Greece. Organization Studies, 40(11), 1741-1765. 
Daudigeos, T., Roulet, T., \& Valiorgue, B. (2020). How scandals act as catalysts of fringe stakeholders' contentious actions against multinational corporations. Business \& Society, 59(3), 387-418

Deephouse, D. L., \& Suchman, M. (2008). Legitimacy in organizational institutionalism. In R. Greenwood, C. Oliver, R. Suddaby, \& K. Sahlin-Andersson (Eds.), The SAGE Handbook of Organizational Institutionalism (p. 49-77). Thousand Oaks, CA/London: Sage.

Cuyper, L. de, Clarysse, B., \& Phillips, N. (2020). Imprinting beyond the founding phase: How sedimented imprints develop over time. Organization Science, 31(6), 1579-1600.

Desai, V.M. (2014). The impact of media information on issue salience following other organizations' failures. Journal of Management, 40(3), 893-918.

Desai, V.M. (2016). Under the radar: Regulatory collaborations and their selective use to facilitate organizational compliance. Academy of Management Journal, 59(2), 636-657.

Dewan, Y., \& Jensen, M. (2020). Catching the big fish: The role of scandals in making status a liability. Academy of Management Journal. 63(5), 1652-1678.

DiMaggio P.J., \& Powell, W.W. (1983). The iron cage revisited: Institutional isomorphism and collective rationality in organizational field. American Sociology Review, 48(2), 147160.

Do, B., Lyle, M. C. B., \& Walsh, I. J. (2019). Driving down memory lane: The influence of memories in a community following organizational demise. Organization Studies, 40(9), 1307-1329.

Drori, G. S., Meyer, J. W., \& Hwang, H. (2009). Global Organization: Rationalization and Actorhood as Dominant Scripts. Research in the Sociology of Organizations, 27, 17-43.

Durand, R., Hawn, O., \& Ioannou, I. (2019). Willing and able: A general model organizational responses to normative pressures. Academy of Management Review, 44(2), 299-320.

Dutton, J. E., \& Dukerich, J. M. (1991). Keeping an eye on the mirror: Image and identity in organizational adaptation. Academy of Management Journal, 34(3), 517-554.

Earle, J.S., Spicer, A., \& Peter, K.S. (2010). The normalization of deviant organizational practices: Wage arrears in Russia, 1991-98. Academy of Management Journal, 53(2), 218-237.

Eberl, P., Geiger, D., \& Assländer, M. S. (2015). Repairing trust in an organization after integrity violations: The ambivalence of organizational rule adjustments. Organization Studies, 36(9), 1205- 1235.

Ebrahim, A., Battilana. J., \& Mair, J. (2014). The Governance of Social Enterprises: Mission Drift and Accountability Challenges in Hybrid Organizations. Research in Organizational Behavior, 34, 81-100.

Edelman, L.B. (1992). Legal ambiguity and symbolic structures: Organizational mediation of Civil Rights Law. American Journal of Sociology, 97(6), 1531-1576.

Ehrenhard, M. L., \& Fiorito, T. L. (2018). Corporate values of the 25 largest European banks: Exploring the ambiguous link with corporate scandals. Journal of Public Affairs, 18(1), e1700 
Elsbach, K. D., \& Bhattacharya, C. B. (2001). Defining who you are by what you're not: Organizational disidentification and the National Rifle Association. Organization Science, 12(4), 393-413

European Commission (2019) Report on the assessment of recent alleged money laundering cases involving EU credit institutions. Accessed at https://eur-lex.europa.eu/legalcontent/EN/ALL/?uri=COM:2019:373:FIN

Eury, J. L., Kreiner, G. E., Trevino, L. K., \& Gioia, D. A. (2018). The past is not dead: Legacy identification and alumni ambivalence in the wake of the Sandusky Scandal at Penn State. Academy of Management Journal, 61(3), 826-856.

Fenergo (2020). Another fine mess. A global research report on financial institution fines and enforcement actions. Accessed at https:/www.fenergo.com/resources/reports/ another-fine-mess-global-research-report-financial-institution-fines.html

Ferraro, F., Etzion, D., \& Gehman, J. (2015). Tackling grand challenges pragmatically: Robust action revisited. Organization Studies, 36(3), 363-390.

Fiol, C. M., Pratt, M. G., \& O’Connor, E. J. (2009). Managing intractable identity conflicts. Academy of Management Review, 34(1), 32-55.

Fiss, P.C., \& Zajac, E.J. (2006). The symbolic management of strategic change: Sensegiving via framing and decoupling. Academy of Management Journal, 49(6), 1173-1193.

Fligstein, N., \& McAdam, D. (2011). Toward a general theory of strategic action fields. Sociological Theory, 29(1), 1-26.

Fombrun, C. J. (1996). Reputation: Realizing value from the corporate image. Boston: Harvard Business School.

Foroughi, H., Coraiola, D. M., Rintamäki, J., Mena, S., \& Foster, W. M. (2020). Organizational memory studies. Organization Studies, 41(12), 1725-1748.

Foster, W. M., Coraiola, D. M., Quinn-Trank, C., \& Bastien, F. (2020). Unpacking organizational re-membering. In K. Bruce (Eds.), Elgar Handbook of Research on Management and Organizational History (pp. 256-274). Cheltenham, UK: Edward Elgar Publishing Limited.

Frankfurt, H. G. (2005). On Bullshit. Princeton, NJ: Princeton University Press.

Gabbioneta, C., Greenwood, R., Mazzola, P., \& Minoja, M. (2013). The influence of the institutional context on corporate illegality. Accounting, Organizations and Society, 38, 484-504.

Gallagher, J.A., \& Goodstein, J. (2002). Fulfilling institutional responsibilities in health care: Organizational ethics and the role of missions discernment. Business Ethics Quarterly, 12(4), 433-450.

Gangloff, K.A., Connelly, B.L., \& Shook, C.L (2016). Of scapegoats and signals: Investor reactions to CEO succession in the aftermath of wrongdoing. Journal of Management, 42(6), 1614-1634.

Gavetti, G., \& Levinthal, D. (2000). Looking forward and looking backward: Cognitive and experiential research. Administrative Science Quarterly, 45, 113-137. 
Gavetti, G., Greve, H.R., Levinthal, D.A., \& Ocasio, W. (2012). The behavioral theory of the firm: Assessment and Prospects. Academy of Management Annals, 6(1), 1-40.

Geertz, C. (1973). The Interpretation of Cultures: Selected Essays. NY: Basic Books, Inc.

Gehman, J., Trevino, L. K., \& Garud, R. (2013). Values work: A process study of the emergence and performance of organizational values practices. Academy of Management Journal, 56(1), 84-112.

George, G., Howard-Grenville, J., Joshi, A., \& Tihanyi, L. (2016). Understanding and tackling societal grand challenges through management research. Academy of Management Journal, 59(6), 1880-1895.

Gillespie, N. \& Dietz, G. (2009). Trust repair after an organization-level failure. Academy of Management Review, 34(1), 127-145.

Gillespie, N., Dietz, G., \& Lockey, S. (2014). Organizational reintegration and trust repair after an integrity violation: A case study. Business Ethics Quarterly, 24(3), 371-410.

Gioia, D. A., Patvardhan, S. D., Hamilton, A. L., \& Corley, K. G. (2013). Organizational identity formation and change. Academy of Management Annals, 7, 123-193

Gioia, D. A., Schultz, M., \& Corley, K. G. (2000). Organizational identity, image, and adaptive instability. Academy of Management Review, 25(1), 63-81.

Gioia, D. A., Corley, K. G., \& Hamilton, A. L. (2013). Seeking qualitative rigor in inductive research: Notes on the Gioia methodology. Organizational Research Methods, 16(1), 1531.

Glaser, B., \& Strauss, A. (1967). The discovery of grounded theory: Strategies for qualitative research. New York: Aldine de Gruyter.

Glynn, M. A. (2000). When Cymbals Become Symbols: Conflict over Organizational Identity within a Symphony Orchestra. Organization Science, 11, 285-298.

Glynn, M.A. (2008). Beyond constraint: How institutions enable identities. In R. Greenwood, C. Oliver, K. Sahlin, \& R. Suddaby (Eds.), The SAGE handbook of organizational institutionalism (pp. 413-430). London, UK: SAGE Publications.

Goffman, E. (1963). Stigma: Notes on the management of spoiled identity. Englewood Cliffs, NJ: Prentice-Hall.

Golant, B. D., Sillince, J. AA., Harvey, C., \& Maclean, M. (2015). Rhetoric of stability and change: The organizational identity work of institutional leadership. Human Relations, 68(4), 607-631.

Gonin, M., Palazzo, G., \& Hoffrage, U. (2012). Neither bad apple nor bad barrel: How the societal context impacts unethical behavior in organizations. Business Ethics: A European Review, 21(1), 31-46.

Goodman, P. S., Ramanujam, R., Carroll, J. C., Edmondson, A. C., Hofmann, D. A., \& Sutcliffe, K. M. (2011). Organizational errors: Directions for future research. Research in Organizational Behavior, 31, 151-176. 
Goodstein, J. (2015). Philip Selznick and the Problems of Organizational Integrity and Responsibility. In M.S. Kraatz (Ed.), Institutions and Ideals: Philip Selznick's Legacy for Organizational Studies (p. 175-197). Bingely: Emeral Group Publishing Limited.

Goodstein, J., \& Potter, (1999). Beyond Financial Incentives: Organizational ethics and organizational integrity. HEC Forum, 11(4), 293-305.

Graham, J. R., Grennan, J., Harvey, C. R., \& Rajgopal, S. (2016). Corporate culture: The interview evidence. 27th Annual Conference on Financial Economics and Accounting Paper, Columbia Business School Research Paper No. 16-49, Duke I\&E Research Paper No. 2016-33, Available at SSRN: https://ssrn.com/abstract=2805602 or http://dx.doi. org/10.2139/ssrn.2805602

Gray, G.C., \& Silbey, S.S. (2014). Governing inside the organization: Interpreting regulation and compliance. American Journal of Sociology, 120(1), 96-145.

Greenwood, R., \& Hinings, C. R. (1996). Understanding Radical Organizational Change: Bringing together the Old and the New Institutionalism. Academy of Management Review, 21(4), 1022-1054.

Greenwood, R., Hinings, C. R., \& Whetten, D. (2014). Rethinking Institutions and Organizations. Journal of Management Studies, 51(7), 1206-1220.

Greenwood, R., Oliver, C., Lawrence, T. B., \& Meyer, R. E. (2017). The SAGE Handbook of Organizational Institutionalism. Thousand Oaks, CA/London: Sage.

Greenwood, R., Raynard, M., Kodeih, F., Micelotta, E., \& Lounsbury, M. (2011). Institutional complexity and organizational responses. Academy of Management Annals, 5(1), 317371.

Greve, H. R., \& Rao, H. (2012). Echoes of the past: Organizational foundings as sources of an institutional legacy of mutualism. American Journal of Sociology, 118(3), 635-675.

Grimes, M. G., Williams, T. A., \& Zhao, E. Y. (2019). Anchors aweigh: The sources, variety, and challenges of mission drift. Academy of Management Review, 44(4), 819-845.

Grøgaard, B., \& Colman, H. L. (2016). Interpretive frames as the organization's "mirror": From espoused values to social integration in MNEs. Management International Review, 56(2), 171-194.

Gruys, M.L., Stewart, S.M., Goodstein, J., Bing, M.N., \& Wicks, A.C. (2008). Values Enactment in Organizations: A Multi-Level Examination. Journal of Management, 34(4), 806-843.

Gutierrez, B., Howard-Grenville, J., \& Scully, M. A. (2015). The faithful rise up: Split identification and an unlikely change effort. Academy of Management Journal, 53(4), 673-699

Haack, P., Schoeneborn, D., \& Wickert, C. (2012). Talking the talk, moral entrapment, creeping commitment? Exploring narrative dynamics in corporate responsibility standardization. Organization Studies, 33(5-6), 815-845.

Habersang, S., Küberling-Jost, J., Reihlen, M., \& Seckler, C. (2018). A process perspective on organizational failure: A qualitative meta-analysis. Journal of Management Studies, 56(1), 19-56. 
Halgin, D. S., Glynn, M. A., \& Rockwell, D. (2018). Organizational Actorhood and the Management of Paradox: A Visual Analysis. Organization Studies, 1-20.

Hallett, T., \& Ventresca, M.J. (2006). Inhabited institutions: Social interactions and organizational forms in Gouldner's Patterns of Industrial Bureaucracy. Theory and Society, 35, 213-236.

Hambrick, D. C., \& Mason, P. A. (1984). Upper Echelons: The Organization as a Reflection of its Top Managers. Academy of Management Review, 9, 193-290.

Harrison, S. H., Ashforth, B. E., \& Corley, K. G. (2009). Organizational sacralization and sacrilege. In A. P. Brief \& B. M. Staw (Eds.), Research in Organizational Behavior (pp. 225-254). Oxford, U.K.: Elsevier.

Haslam, S. A., Cornelissen, J. P., \& Werner, M. D. (2017). Metatheories and metaphors of organizational identity: Integrating social constructionist, social identity, and social actor perspectives within a social interactionist model. International Journal of Management Reviews, 19, 318-336.

Hatch, M. J., \& Schultz, M. (2002). The dynamics of organizational identity. Human Relations, 55(8), 989-1018.

Haunschild, P.R., \& Rhee, M. (2004). The role of volition in organizational learning: The case of automotive product recalls. Management Science, 50(11), 1545-1560.

Haunschild, P.R., Polidoro, F., \& Chandler, D. (2015). Organizational oscillation between learning and forgetting: The dual role of serious errors. Organization Science, 26(6), $1682-1701$.

He, H., \& Brown, A. D. (2013). Organizational identity and organizational identification: A review of the literature and suggestions for future research. Group \& Organization Management, 38(1), 3-35.

Heese, J., Krishnan, R., \& Moers, F. (2016). Selective regulator decoupling and organizations' strategic responses. Academy of Management Journal, 59(6), 2178-2204

Henderson, R. (2020). Reimagining Capitalism: How Business Can Save the World. New York City, NY: Penguin Books Ltd.

Hersel, M.T., Helmuth, C.A., Zorn, M.L., Shropshire, C., \& Ridge, J.W. (2019). The corrective actions organizations pursue following misconduct: A review and research agenda. Academy of Management Annals, 13(2), 547-585.

Heugens, P. M. A. R., \& Scherer, A. G. S. (2010). When Organization Theory met Business Ethics: Toward Further Symbioses. Business Ethics Quarterly, 20(4), 643-672.

Heugens, P. M. A. R., Kaptein, M., \& Van Oosterhout, J. (2008). Contracts to communities: A processual model of organizational virtue. Journal of Management Studies, 45(1), $100-121$.

Hills, S., Voronov, M., \& Hinings, C. R. B. (2013). Putting new wine in old bottles: Utilizing rhetorical history to overcome stigma associated with a previously dominant logic. In Lounsbury, M. and Boxenbaum, E. (Ed.) Institutional Logics in Action, Part B (Research in the Sociology of Organizations, Vol. 39 Part B), Emerald Group Publishing Limited, Bingley, pp. 99-137. 
Hinings, C. R., Thibault, L., Slack, T., \& Kikulis, L. M. (1996). Values and organizational structure. Human Relations, 49, 885-916.

Hitlin, S. (2008). Moral selves, evil selves: The social psychology of conscience. New York: Palgrave MacMillan

Hoffman, A. J., \& Ocasio, W. (2001). Not all events are attended equally: Toward a middlerange theory of industry attention to external events. Organization Science, 12(4), 414434.

Hofstede, G. (1998). Attitudes, values and organizational culture: Disentangling the concepts. Organizations Studies, 19, 477-492.

Howell, A., Kirk-Brown, A., \& Cooper, B. K. (2012). Does Congruence between Espoused and Enacted Organizational Values Predict Affective Commitment in Australian Organizations? The International Journal of Human Resource Management, 23(4), 731747.

Huberts, L. (2014). The Integrity of Governance: What it is, what we know, what is done, and where to go. Hampshire: Palgrave Macmillan.

Huisman, W. (2001). Tussen winst en moraal. Achtergronden van regelnaleving en regelovertreding door ondernemingen. Den Haag: Boom Juridische Uitgevers.

Huy, Q. N., Corley, K. G., \& Kraatz, M. S. (2014). From support to mutiny: Shifting legitimacy judgements and emotional reactions impacting the implementation of radical change. Academy of Management Journal, 57(6), 1650-1680.

Hwang, H., \& Colyvas, J. A. (2020). Ontology, levels of society, and degrees of generality: Theorizing actors as abstractions in institutional theory. Academy of Management Review, 45(3), 570-595.

Ibarra, H., \& Barbulescu, R., (2010). Identity as narratives: Prevalence, effectiveness, and consequences of narrative identity work in macro work role transitions. Academy of Management Review, 35(1), 135-154.

International Monetary Fund (2010). The making of good supervision: Learning to say "no". Accessed at The Making of Good Supervision : Learning to Say "No" (imf.org)

Jacobs, C. D., Kreutzer, K., \& Vaara, E. (2020). Political dynamics in organizational identity breach and reconstruction: Findings from the crisis in UNICEF Germany. Academy of Management Journal, forthcoming.

James, E. H., Wooten, L. P., \& Dushek, K. (2011). Crisis management: Informing a new leadership research agenda. Academy of Management Annals, 5(1), 455-493

Jonson, K., Galunic, C., Weeks, J., \& Braga, T. (2015). Evaluating Espoused Values: Does Articulating Values Pay Off? European Management Journal, 33, 332-340.

Joshi, M., \& McKendall, M. (2018). Responses to the discovery of unethical acts: An organizational identity and reputations perspective. Business \& Society, 57(4), 706-741.

Kabanoff, B., \& Daly, J. (2000). Values espoused by Australian and US organizations. Applied Psychology, 49(2), 284-314. 
Kabanoff, B., Waldersee, R., \& Cohen, M. (1995). Espoused values and organizational change themes. Academy of Management Journal, 38(4), 1075-1104.

Kacmar, K. M., \& Tucker, R. (2016). The moderating effect of supervisor's behavioral integrity on the relationship between regulatory focus and impression management. Journal of Business Ethics, 135(1), 87-98

Kaptein, M. (2019). The moral entrepreneur: A new component of ethical leadership. Journal of Business Ethics, 156, 1135-1150

Kaptein, M., \& Wempe, J. (2002). The Balanced Company. Oxford: Oxford University Press.

Kedia, S., Rajgopal, S. (2011). Do the SEC's enforcement preferences affect corporate misconduct? Journal of Accounting and Economics, 51, 259-278.

Kellogg, K.C. (2011). Hot lights and cold steel: Cultural and political toolkits for practice change in surgery. Organization Science, 22(2), 482-502.

Kim, S. (2021). Frame restructuration: The making of an alternative business incubator amid Detroit's crisis. Administrative Science Quarterly, 1-53.

King, B. G. (2015). Organizational actors, character, and Selznick's theory of organizations. In M. S. Kraatz (Ed.), Institutions and Ideals: Philip Selznick's Legacy for Organizational Studies (p. 149-174). Bingley, UK: Emerald Group Publishing Limited.

King, B. G., Felin, T., \& Whetten, D. A. (2010). Perspective - finding the organization in organizational theory: A meta-theory of the organization as a social Actor. Organization Science, 21, 290-305.

Kish-Gephart, J. J., Harrison, D. A., \& Treviño, L. K. (2010). Bad apples, bad cases, and bad barrels: Meta-analytic evidence about sources of unethical decisions at work. Journal of Applied Psychology, 95(1), 1-31.

Kok, A. M., Bakker, F. G. de, \& Groenewegen, P. (2019). Sustainability struggles: Conflicting cultures and incompatible logics. Business \& Society, 58(8), 1496-1532.

Kostova, T., \& Roth, K. (2002). Adoption of an organizational practice by subsidiaries of multinational corporations: Institutional and relational effects. Academy of Management Journal, 45(1), 215-233.

Kraatz, M. S. (2009). Leadership as institutional work: A bridge to the other side. In T. B. Lawrence et al. (Eds.), Institutional Work: Actors and Agency in Institutional Studies of Organizations (pp. 59-91). Cambridge: Cambridge University Press.

Kraatz, M.S., \& Block, E.S. (2008). Organizational Implications of Institutional Pluralism. In R. Greenwood, C. Oliver, R. Suddaby, \& K. Sahlin-Andersson (Eds.), The SAGE Handbook of Organizational Institutionalism (p. 243-275). Thousand Oaks, CA/London: Sage.

Kraatz, M. S., \& Block, E. S. (2017). Institutional pluralism revisited. In R. Greenwood, C. Oliver, T. Lawrence, \& Meyer R. (Eds.), The Sage Handbook of Organizational Institutionalism. London: Sage Publications. London: SAGE Publications.

Kraatz, M.S., \& Flores, R. (2015). Reinfusing values. In M.S. Kraatz (Ed.), Institutions and Ideals: Philip Selznick's Legacy for Organizational Studies (pp. 353-381). Bingley, UK: Emerald Group Publishing Limited. 
Kraatz, M. S., \& Moore, J. H. (2002). Executive migration and institutional change. Academy of Management Journal, 45(1), 120-143.

Kraatz, M. S., Phillips. N., \& Tracey, P. (2016). Organizational identity in institutional theory: Taking stock and moving forward. In M. G. Pratt, M. Schultz, B. E. Ashforth, \& D. Ravasi (Eds.), The Oxford Handbook of Organizational Identity (p. 353-373). Oxford: Oxford University Press.

Kraatz, M. S., Ventresca, M. J., \& Deng, L. (2010). Precarious values and mundane innovations: Enrollment management in American liberal arts colleges. Academy of Management Journal, 53(6), 1521-1545.

Kraatz, M. S., Flores, R., \& Chandler, D. (2020). The value of values for institutional analysis. Academy of Management Annals, 14(2), 474-512.

Kreiner, G. E., \& Murphy, C. (2016). Organizational identity work. In M. Pratt, M. Schultz, B. E. Ashforth, \& D. Ravasi (Eds.), The Oxford handbook of organizational identity (pp. 276-293). Oxford, UK: Oxford University Press.

Kreiner, G., Hollensbe, E., Sheep, M., Smith, B., \& Kataria, N. (2015). Elasticity and the dialectic tensions of organizational identity: How can we hold together while we're pulling apart? Academy of Management Journal, 58, 981-1011.

Krygier, M. (2012). Philip Selznick. Ideals in the World. Stanford, CA: Stanford University Press.

Langley, A. (1999). Strategies for theorizing from process data. Academy of Management Review, 24(4), 691-710.

Lawrence, T. B., \& Phillips, N. (2019). Constructing organizational life. How social-symbolic work shapes selves, organizations, and institutions. Oxford, UK: Oxford University Press.

Lawrence, T. B., Leca, B., \& Zilber, T. B. (2013). Institutional work: Current research, new directions and overlooked issues. Organization Studies, 34(8), 1023-1033.

Leaver, M. P., \& Reader, T. W. (2019). Safety culture in financial trading: An analysis of trading misconduct investigations. Journal of Business Ethics, 154, 461-481.

Lehman, D.W., \& Ramanujam, R. (2009). Selectivity in organizational rule violations. Academy of Management Review, 34, 634-657.

Lehman, D.W., Cooil, B., \& Ramanujam, R. (2019). The effects of rule complexity on organizational noncompliance and remediation: Evidence from restaurant health inspections. Journal of Management, 1-33.

Lencioni, P. M. (2002). Making your Values mean Something. Harvard Business Review, 80, 113-117.

Leopold, J., Cormier, A., Templon, J., Warren, T., Singer-Vine, J., Pham, S., Holmes, R., Ghorayshi, A., Sallah, M., Kozyreva, T., \& Loop, E. (2020). The FinCen Files. Accessed at: FinCEN Files Show Criminals Moved Billions As Banks Watched (buzzfeednews. com)

Leroy, H., Palanski, M.E., \& Simons, T. (2012). Authentic leadership and behavioral integrity as drivers of follower commitment and performance. Journal of Business Ethics, 107, 255-264. 
Lockwood, T. C. (2013). Habituation, habit and character in Aristotle's Nicomachean Ethics. In T. Sparrow \& A. Hutchinson (Ed.), A History of Habit (pp. 19-36). Lanham, MD: Lexington Books.

Lounsbury, M., Ventresca, M., \& Hirsch, P.M. (2003). Social movements, field frames and industry emergence: A cultural-political perspective on U.S. recycling. Socio-Economic Review, 1, 71-104.

Love, E. G., \& Kraatz, M. S. (2009). Character, conformity, or the bottom line? How and why downsizing affected corporate reputation. Academy of Management Journal, 52(2), 314-335.

Lowe, K. B., Cordery, J., \& Morrison, D. (2004). A model for the attribution of leader integrity: Peeking inside the black box of authentic leadership. Paper presented at the 2004 Gallup Leadership Institute conference, Lincoln, NE

Lyon, T. P., Maxwell, J. W. (2011). Greenwashing: Corporate environmental disclosure under threat of audit. Journal of Economics \& Management Strategy, 20(1), 3-41.

Maak, T. (2008). Undivided corporate responsibility: Towards a theory of corporate integrity. Journal of Business Ethics, 82, 353-368.

Mackey, J., \& Sisodia, R. (2013). Conscious Capitalism: Liberating the Heroic Spirit of Business. Cambridge, MS: Harvard Business Press.

MacLean, T.L., \& Behnam, M. (2010). The dangers of decoupling: The relationship between compliance programs, legitimacy perceptions, and institutionalized misconduct. Academy of Management Journal, 53(6), 1499-1520.

Madsen, P.M. (2009). These lives will not be lost in vain: Organizational Learning from disaster in U.S. coal mining. Organization Science, 20(5), 861-875.

Maitlis, S., \& Sonenshein, S. (2010). Sensemaking in crisis and change: Inspiration and insights of Weick (1988). Journal of Management Studies, 47(3), 551-580.

Mandis, S. G. (2013). What Happened to Goldman Sachs: An Insider's Story of Organizational Drift and Its Unintended Consequences. Cambridge, MS: Harvard Business Review Press.

March, J.G., \& Simon, H.A. (1958). Organizations. New York: John Wiley \& Sons.

March, J.G., \& Olsen, J.P. (1975). The uncertainty of the past: Organizational learning under ambiguity. European Journal of Political Research, 3(2), 147-171.

March J. G., \& Olsen, J. P. (2004). The logic of appropriateness. In R. E. Goodin (Ed.), The Oxford Handbook of Political Science (pp. 479-493). Oxford: Oxford University Press.

Margolis, J.D., \& Walsh, J. (2003). Misery Loves Company: Rethinking Social Initiatives by Business. Administrative Science Quarterly, 48, 268-305.

Marquis, C., \& Lounsbury, M. (2007). Vive la résistance: Competing logics and the consolidation of U.S. community banking. Academy of Management Journal, 50(4), 799-820.

Marquis, C., \& Tilcsik, A. (2013). Imprinting: Toward a multilevel theory. Academy of Management Annals, 7(1), 193-243. 
McCammon, H. (2013). Discursive opportunity structure. In Snow DA, Della Porta D, Klandermans B, McAdam D, eds. The Wiley-Blackwell Encyclopedia of Social and Political Movements (Willey-Blackwell, Oxford)

McDonnell, M., \& Cobb, J. A. (2020). Take a stand and keep your seat: Board turnover after social movement boycotts. Academy of Management Journal, 63(4), 1028-1053.

McFall, L. (1987). Integrity. Ethics, 98, 5-20.

McWilliams, A., \& Siegel, D. (2001). Corporate social responsibility: A theory of the firm perspective. Academy of Management Review, 26(1), 117-127.

Mellahi, K., \& Wilkinson, A. (2004). Organizational failure: A critique of recent research and a proposed integrative framework. International Journal of Management Reviews, 5/6(1), 21-41.

Mellahi, K., \& Wilkinson, A. (2010). Managing and coping with organizational failure: Introduction to the Special Issue. Group \& Organization Management, 35(5), 531-541

Mena, S., Rintamäki, J., Fleming, P., \& Spicer, A. (2016). On the forgetting of corporate irresponsibility. Academy of Management Review, 41, 720-738.

Meyer, J. W., \& Bromley, P. (2013). The worldwide expansion of 'organization'. Sociology Theory, 31(4), 366-389.

Meyer, J.W., \& Rowan, B. (1977). Institutionalized organization: Formal structure as myth and ceremony. American Journal of Sociology, 83(2), 340-363.

Miles, M. B., \& Huberman, A. M. (1994). Qualitative Data Analysis. An Expanded Sourcebook. Thousand Oaks, CA: SAGE Publications.

Misangyi, V.F., Weaver, G.R., \& Elms, H. (2008). Ending corruption: The interplay among institutional logics, resources, and institutional entrepreneurs. Academy of Management Review, 33(3), 750-770.

Mishina, Y., \& Devers, C. E. (2012). On being bad: Why stigma is not the same as a bad reputation. In M. L. Barnett, \& T. G. Pollock (Ed.) The Oxford Handbook of Corporate Reputation. Oxford, UK: Oxford University Press.

Mishina, Y., Block, E. S., \& Mannor, M. J. (2012). The path dependence of organizational reputation: How social judgement influences assessments of capability and character. Strategic Management Journal, 33(5), 459-477.

Mishina, Y., Dykes, B.J., Block, E.S., \& Pollock, T.G. (2010). Why “good” firms do bad things: The effects of high aspirations, high expectations, and prominence on the incidence of corporate illegality. Academy of Management Journal. 53(4), 701-722.

Mohliver, A. (2019). How misconduct spreads: Auditors' role in the diffusion of stockoption backdating. Administrative Science Quarterly. 64(2), 310-336.

Moray, N., \& Inagaki, T. (2000). Attention and complacency. Theoretical Issues in Ergonomics Science, 1(4), 354-365.

Morrell, K. M., Loan-Clarke, J., \& Wilkinson, A. J. (2004). Organizational change and employee turnover. Personnel Review, 33(2), 161-173. 
Munir, K. A. (2011). Financial crisis 2008-2009: What does the silence of institutional theorists tell us? Journal of Management Inquiry, 20(2), 114-117.

Murphy, C., Patvardhan, S., \& Gehman, J. (2017). Moral accounting by organizations: A process study of the U.S. Financial Crisis Inquiry Commission. Journal of Management Inquiry. 26(3):303-325.

Muzio, D., Faulconbridge, J.R., Gabbioneta, C., \& Greenwood, R. (2016). Bad barrels and bad cellars: A boundaries perspective on professional misconduct. In: Organizational Wrongdoing: Cambridge Companions to Management. Cambridge, MA: Cambridge University Press

Narduzzo, A., Rocco, E., \& Warglien, M. (2000). Talking about routines in the field. In G. Dosi, R. R. Nelson, and S. G. Winter (Eds.), The Nature and Dynamics of Organizational Capabilities (pp. 27-50). Oxford: Oxford University Press.

Nohria, N., \& Ghoshal, S. (1994). Differentiation Fit and Shared Values: Alternatives for Managing Headquarters-Subsidiary Relations. Strategic Management Journal, 15, 491 502.

Obermayer, B., \& Obermaier, F. (2016). Panama Papers: Breaking the Story of How the Rich and Powerful Hide their Money. London, UK: Oneworld Publications.

Ocasio, W. (1997). Towards an attention-based view of the firm. Strategic Management Journal, 18(1), 187-206.

Oliver, C. (1991). Strategic responses to institutional processes. Academy of Management Review, 16(1), 145-179.

Oliver, C. (1992). The antecedents of deinstitutionalization. Organization Studies, 13(4), 563-588.

Orton J.D., \& Weick, K.E. (1990). Loosely coupled systems: A reconceptualization. Academy of Management Review, 15(2), 203-223.

O’Reilly, K. (2009). Key Concepts in Ethnography. London, UK: SAGE Publications Ltd.

Orts, E. W., \& Smith, N. C. (2017). The Moral Responsibility of Firms. Oxford University Press.

Ostroff, C., Shin, Y., \& Kinicki, A. J. (2005). Multiple perspectives of congruence: Relationships between value congruence and employee attitudes. Journal of Organizational Behavior, 26, 591-623.

Ouchi, W. G. (1980). Markets, bureaucracies, and clans. Administrative Science Quarterly, 25, 129-141.

Pache, A., \& Santos, F. (2010). When Worlds Collide: The Internal Dynamics of Organizational Responses to Conflicting Institutional Demands. Academy of Management Journal, 35, 455-479.

Pache, A., \& Santos, F. (2013). Inside the Hybrid Organization: Selective Coupling as a Response to Competing Institutional Logics. Academy of Management Journal, 56(4), 972-1001. 
Page, S. (2006) Path dependence. Quarterly Journal of Political Science, 1(1), 87-115.

Paine, L. S. (1994). Managing for organizational integrity. Harvard Business Review, MarchApril.

Palanski, M. E., \& Yammarino, F. J. (2007). Integrity and Leadership: Clearing the Conceptual Confusion. European Management Journal, 25(3), 171-184.

Palanksi, M. E., Kahai, S., \& Yammarino, F. J. (2010). Team Virtue and Performance: An Examination of Transparency, Behavioral Integrity, and Trust. Journal of Business Ethics, 99, 201-216.

Palmer, D. (2008). Extending the process model of collective corruption. Research in Organizational Behavior, 28, 107-135.

Palmer, D. (2012). Normal organizational wrongdoing. Oxford University Press, Oxford, UK.

Palmer, D. (2017). Institutions, institutional theory and organizational wrongdoing. In: The SAGE Handbook of Organizational Institutionalism.

Park, B., \& Rogan, M. (2019). Capability reputation, character reputation, and exchange partners' reactions to adverse events. Academy of Management Journal, 62(2), 553-578.

Parker, C. (2006). The 'compliance' trap: The moral message in responsive regulatory enforcement. Law \& Society Review, 40(3), 591-622.

Parry, K. W., \& Proctor-Thomson, S. B. (2002). Perceived integrity of transformational leaders in organizational settings. Journal of Business Ethics, 35, 75-96

Parsons, T. (1956). A sociological approach to the theory of organizations. Administrative Science Quarterly, 1, 63-85.

Paruchuri, S., Han, J.-H., \& Prakash, P. (2021). Salient expectations? Incongruence across capability and integrity signals and investor reactions to organizational misconduct. Academy of Management Journal, 64(2), 562-586.

Palazzo, G., Krings, F., \& Hoffrage, U. (2012). Ethical blindness. Journal of Business Ethics, $109,323-338$.

Palermo, T., Power, M., \& Ashby, S. (2017). Navigating institutional complexity: The production of risk culture in the financial sector. Journal of Management Studies, 54(2), $154-181$.

Perkmann, M., \& Spicer, A. (2014). How emerging organizations take form: The role of imprinting and values in organizational bricolage. Organization Science, 25(6), 15731877.

Perrow, C. (1999). Normal Accidents: Living with High-Risk Technologies. Princeton, NJ: Princeton University Press.

Pfarrer, M. D., DeCelles, K. A., Smith, K. G., \& Taylor, M. S. (2008). After the fall: Reintegration the corrupt organization. Academy of Management Review, 33(3), 730749.

Phillips, R., Schrempf-Stirling, J., \& Stutz, C. (2019). The past, history, and corporate social responsibility. Journal Business Ethics, 166, 203-213. 
Pratt, M.G. (2016). Crafting and selecting research questions and contexts in qualitative research. In K. Elsbach \& R. Kramer's (Eds.), The Handbook of Qualitative Organizational Research (pp. 177-185). New York: Taylor \& Francis/Routledge.

Pratt, M. G., \& Foreman, P. O. (2000). Classifying managerial responses to multiple organizational identities. Academy of Management Review, 25(1), 18-42.

Pratt, M.G., \& Kraatz, M.S. (2009). E pluribus unum: Multiple identities and the organizational self. In J. Dutton, \& L.M. Roberts (Eds.), Exploring Positive Identities and Organizations (p. 385-410). Mahwah, NJ: Lawrence Erlbaum and Associates.

Quinn, R. E., \& Rohrbaugh, J. (1981). A competing values approach to organizational effectiveness. Public Productivity Review, 5(2), 122-140.

Raaijmakers, A.G.M., Vermeulen, P.A.M., Meeus, M.T.H. \& Zietsma, C. (2015). I need time! Exploring pathways to compliance under institutional complexity. Academy of Management Journal, 58(1), 85-110.

Radoynovska, N., Ocasio, W., \& Laasch, O. (2020). The emerging logic of responsible management: Institutional pluralism, leadership, and strategizing. In O. Laasch, R. Suddaby, R. E. Freeman, \& D. Jamali (Eds.), Research Handbook of Responsible Management (p. 420-437). Cheltenham, UK: Edward Elgar Publishing Limited.

Rafaeli, A., Sagy, Y., \& Derfler-Rozin, R. (2008). Logos and initial compliance: A strong case of mindless trust. Organization Science, 19(6), 845-859.

Raffaelli, R., \& Glynn, M. A. (2014). Turnkey or tailored? Relational pluralism, institutional complexity, and the organizational adoption of more or less customized practices. Academy of Management Journal, 57(2), 541-562.

Raffaelli, R., \& Glynn, M. A. (2015). What's so Institutional About Leadership? Leadership Mechanisms of Value Infusion. In M.S. Kraatz (Ed.), Institutions and Ideals: Philip Selznick's Legacy for Organizational Studies (p. 283-316). Bingely: Emeral Group Publishing Limited.

Rao, H., \& Sivakumar, K. (1999). Institutional sources of boundary-spanning structures: The establishment of investor relations departments in the Fortune 500 industrials. Organization Science, 10(1), 27-42.

Ravasi, D., Rindova, V., \& Stiglliani, I. (2019). The stuff of legend: History, memory, and the temporality of organizational identity reconstruction. Academy of Management Journal, 62(5), 1523-1555

Reijngoud, T. (2009). Het Nieuwe Bankieren. De Duurzame Oplossing van Bankier Peter Blom. Utrecht: Kosmos Uitgevers.

Rhee, M., \& Haunschild, P.R. (2006). The liability of good reputation: A study of product recalls in the U.S. automobile industry. Organization Science, 17, 101-117.

Rokeach, M. (1973). The Nature of Human Values. New York: The Free Press.

Roth, K., \& Kostova, T. (2003). Organizational coping with institutional in transition economies. Journal of World Business, 38, 314-330.

Saetre, A. S., \& Van de Ven, A. H. (2021). Generating theory by abduction. Academy of Management Review, In-Press. 
Sasaki, I., Ravasi, D., \& Micelotta, E. R. (2019). Family firms as institutions: Cultural reproduction and status maintenance among multi-centenary Shinise in Kyoto. Organization Studies, 40(6), 1-39.

Sayer, A. (2011). Why Things Matter to People: Social Science, Values and Ethical Life. Cambridge, NJ: Cambridge University Press.

Schein, E.H. (1985). Organizational Culture and Leadership. San Francisco, CA: Jossey-Bass.

Schembera, S., Scherer, A. G. (2017). Organizational strategies in the context of legitimacy loss: Radical versus gradual responses to disclosed corruption. Strategic Organization, 15(3), 301-337.

Scherer, A.G., \& Palazzo, G. (2007). Toward a Political Conception of Corporate Responsibility: Business and Society seen from a Habermasian Perspective. Academy of Management Review, 32(4), 1096-1120.

Schilke, O. (2018). A micro-institutional inquiry into resistance to environmental pressures. Academy of Management Journal, 61(4), 1431-1466.

Schilling, J., \& Kluge, A. (2009). Barriers to organizational learning: An integration of theory and research. International Journal of Management Reviews, 11(3), 337-360.

Schuh, A. M., \& Miller, G. M. (2006). Maybe Wilson was right: Espoused values and their relationship to enacted values. International Journal of Public Administration, 29(9), 719-741.

Schultz, M., \& Hernes, T. (2013). A temporal perspective on organizational identity. Organization Science, 24(1), 1-21.

Schultz, M., \& Hernes, T. (2020). Temporal interplay between strategy and identity: Punctuated, subsumed, and sustained modes. Strategic Organization, 18(1), 106-135.

Schwartz, S. H. (1999). A theory of cultural values and some implications for work. Applied Psychology: An International Review, 48(1), 23-47

Scott, R.W. (2014). Institutions and organizations. Thousand Oaks, CA: Sage.

Seeger, M. W., \& Sellnow, T. L. (2016). Narratives of crises. Telling stories of ruin and renewal. Stanford, CA: Stanford University Press.

Seeger, M. W., Ulmer, R. R., Novak, J. M., \& Sellnow, T. (2005). Post-crisis discourse and organizational change, failure and renewal. Journal of Organizational Change Management, 18(1), 78-95.

Selznick, P. (1949). TVA and the Grass Roots; A Study in the Sociology of Formal Organization. Berkeley: University of California Press.

Selznick, P. (1957). Leadership in administration: A sociological interpretation. New York: Harper \& Row, Publishers.

Selznick, P. (1992). The moral commonwealth: Social theory and the promise of community. Berkeley, CA: University of California Press.

Selznick, P. (1996). Institutionalism "Old" and "New”. Administrative Science Quarterly, 41(2), 270-277. 
Selznick, P. (2000). On Sustaining Research Agendas: Their Moral and Scientific Basis: An Address to the Western Academy of Management. Journal of Management Inquiry, 9(3), 277-282.

Selznick, P. (2008). A Humanist Science: Values and Ideals in Social Inquiry. Stanford, CA: Stanford University Press.

Shepherd, D. A., \& Sutcliffe, K. M. (2015). The use of anthropomorphizing as a tool for generating organizational theories. Academy of Management Annals, 9(1), 97-142.

Shepherd, D. A., \& Williams, T. (2020). Entrepreneurship responding to adversity: Equilibrating adverse events and disequilibrating persistent adversity. Organization Theory, 1, 1-25.

Simons, T. (2002). Behavioural integrity: The perceived alignment between managers' words and deeds as a research focus. Organization Science, 13(1), 18-35.

Simons, T., Leroy, H., Collewaert, V., \& Masschelein, S. (2015). How leader alignment of words and deeds affects followers: A meta-analysis of behavioral integrity research. Journal of Business Ethics, 132, 831-844

Simpson, S.S. (2002). Corporate crime, law, and social control. Cambridge, UK: Cambridge University Press.

Smart, J. J. C., \& Williams, B. (1973). Utilitarianism: For and Against. Cambridge, UK: Cambridge University Press.

Smets, M., Jarzabkowski, P., Burke, G. T., \& Spee, P. (2015). Reinsurance trading in Llyod's of London: Balancing conflicting-yet-complementary logics in practice. Academy of Management Journal, 58(3), 932-970.

Smit, J. (2012). De Prooi. Blinde Trots Breeks ABN Amro. Amsterdam: Prometheus.

Smith, D., \& Elliott, D. (2007). Exploring the barriers to learning from crisis. Management Learning, 38(5), 519-538.

Smith, W. K., \& Besharov, M. L. (2019). Bowing before dual gods: How structured flexibility sustains organizational hybridity. Administrative Science Quarterly, 64(1), 1-44.

Smith, W. K., \& Lewis, M. W. (2011). Toward a Theory of Paradox: A Dynamic Equilibrium Model of Organizing. Academy of Management Review, 36(2), 381-403.

Smith, W.K., Gonin, M., \& Besharov, M.L. (2013). Managing Social-Business Tensions: A Review and Research Agenda for Social Enterprises. Business Ethics Quarterly, 23(3), 407-442.

Solinger, O. N., Jansen, P. G. W., Cornelissen, J. P. (2020). The emergence of moral leadership. Academy of Management Review, 45(3), 504-527.

Solomon, Robert C. (1999). A Better Way to Think About Business: How Personal Integrity Leads to Corporate Success. Oxford, UK: Oxford University Press.

Solomon, R. (2004). Aristotle, Ethics and Business Organizations. Organization Studies, 25(6), 1021-1043. 
Sonenshein, S. (2016). How corporations overcome issue illegitimacy and issue equivocality to address social welfare: The role of the social change agent. Academy of Management Review, 41(2), 349-366.

Srivastra, S., \& D. L. Cooperrider (1988). Introduction: The urgency for executive integrity, in S. Srivastra (ed.), Executive Integrity: The Search for High Human Values in Organizational Life (pp. 1-28). San Francisco, Jossey-Bass.

Starkey, K. (1998). Durkheim and the limits of corporate culture: Whose culture? Which Durkheim. Journal of Management Studies, 35(2), 125-136.

Starkey, K. (2015). The strange absence of management during the current financial crisis. Academy of Management Review, 40(4), 652-663.

Steele, C. W. J., \& King, B. G. (2011). Collective intentionality in organizations: A metaethnographic of identity and strategizing. In S.R. Thye, \& E.J. Lawler (Ed.) Advances in Group Processes (Advances in Group Processes, Vol. 28), Emerald Group Publishing Limited, Bingley, pp. 59-95.

Strauss, A., \& Corbin, J. (1998). Basics of qualitative research: Techniques and procedures for developing grounded theory. Thousand Oaks, CA: SAGE.

Stumpf, J. (2016). From the CEO: Perspective on the Sept. 8 settlement announce. Accessed at: From the CEO: Perspectives on today's settlement announcement (wf.com)

Suchman, M. C. (1995). Managing Legitimacy: Strategic and Institutional Approaches. Academy of Management Review, 20, 571-610.

Suddaby, R. (2014). Editor's comments: Why theory? Academy of Management Review, 39(4), 407-411.

Suddaby, R. (2016). Toward a historical consciousness: Following the historic turn in management thought. Management, 19, 46-60.

Suddaby, R., \& Foster, W. M. (2017). History and organizational change. Journal of Management, 43(1), 19-38.

Suddaby, R., Foster, W. M., \&, Trank, C. Q. (2010). Rhetorical history as a source of competitive advantage. Advances in Strategic Management, 27, 147-173.

Suddaby, R., Foster, W. M., \& Quinn-Trank, C. (2016). Re-membering: Rhetorical history as identity work. In M. G. Pratt, M. Schultz, B. E. Ashforth, \& D. Ravasi (Eds.), The Oxford handbook of organizational identity (pp. 297-316). New York: Oxford University Press.

Surroca, J., Tribó, J. A., \& Zahra, S. A. (2013). Stakeholder pressure on MNEs and the transfer of socially irresponsible practices to subsidiaries. Academy of Management Journal, 56(2), 549-572.

Sutcliffe, K. M., \& Vogus, T. J. (2003). Organizing for resilience. In K. S. Cameron, J. E. Dutton, \& R. E. Quinn, Positive Organizational Scholarship: Foundations of a New Discipline (pp. 94-110). San Francisco, CA: Barrett-Koehler.

Swanson, D. L. (1999). Toward an Integrative Theory of Business and Society: A Research Strategy for Corporate Social Performance. Academy of Management Review, 24(3), 506-521. 
Tayan, B. (2019). The Wells Fargo cross-selling scandal. Rock Center for Corporate Governance at Stanford University Closer Look Series: Topics, Issues and Controversies in Corporate Governance.

The Economist (2020). How Wirecard fooled most of the people all of the time. Accessed at https://www.economist.com/finance-and-economics/2020/06/25/how-wirecardfooled-most-of-the-people-all-of-the-time

Thornton, P. H., Ocasio, W., \& Lounsbury, M. (2012). The Institutional Logics Perspective: A New Approach to Culture, Structure and Process. New York: Oxford University Press.

Tilcsik, A. (2010). From ritual to reality: Demography, ideology, and decoupling in a postCommunist government agency. Academy of Management Journal, 53(6), 1474-1498.

Tollefsen, D. (2002). Organizations as true believers. Journal of Social Philosophy, 33(3), 395-410.

Toubiana, M., \& Zietsma, C. (2017). The message is on the wall? Emotions, social media, and the dynamics of institutional complexity. Academy of Management Journal, 60(3), 922-953

Tourish, D. (2020). Towards an organisational theory of hubris: Symptoms, behaviours and social fields within finance and banking. Organization, 27(1), 88-109

Tracey, P., \& Phillips, N. (2016). Managing the consequences of organizational stigmatization: Identity work in a social enterprise. Academy of Management Journal, 59(3), 740-765.

Trevino, L. K., \& Youngblood, S. A. (1990). Bad apples in bad barrels: A causal analysis of ethical decision-making behavior. Journal of Applied Psychology, 75(4), 378-385

Tsoukas, H. (2009). Craving for generality and small-N studies: A Wittgensteinian approach towards the epistemology of the particular in organization and management studies. In D. A. Buchanan \& A. Bryman (Eds.), The SAGE handbook of organizational research methods (p. 285-301). Los Angeles: Sage.

Tsoukas, H. (2018). Strategy and virtue: Developing strategy-as-practice through virtue ethics. Strategic Organization, 16(3), 323-351.

Tushman, M., \& Nadler, D. (1986). Organizing for innovation. California Management Review, 28(3), 74-92.

Vaccaro, A., \& Palazzo, G. (2015). Values against violence: Institutional change in societies dominated by organized crime. Academy of Management Journal, 58(4), 1075-1101.

Van Maanen, J. (2011). Tales of the Field: On Writing Ethnography. Chicago, United States of America: The University of Chicago Press.

Vaughan, D. (1996). The Challenger Launch Decision: Risky Technology, Culture and Deviance at NASA. Chicago, IL: University of Chicago Press.

Vaughan, D. (1999). The dark side of organizations: mistake, misconduct, and disaster. Annual Review of Sociology, 25, 271-305.

Voronov, M., \& Weber, K. (2016). The heart of institutions: Emotional competence and institutional actorhood. Academy of Management Review, 41(3), 456-478. 
Voss, G. B., Cable, D. M., \& Voss, Z. G. (2000). Linking organizational values to relationships with external constituents: A study of non-profit professional theatres. Organization Science, 11(3), 330-347.

Waddock, S. (2012). Resilience and integrity: Fundamental to system integrity. Resilience: A Journal of Strategy and Risk. PwC US.

Waddock, S. A., Bodwell C., \& Graves, S. B. (2002). Responsibility: The new business imperative. Academy of Management Executive, 16(2), 132-148.

Waeger, D., \& Weber, K. (2019). Institutional complexity and organizational change: An open polity perspective. Academy of Management Review, 44(2), 1-24.

Wakefield, A., \& Fleming, J. (2009). The SAGE dictionary of policing. London, UK: SAGE Publications.

Walsh, I. J., \& Glynn, M. A. (2008). The way we were: Legacy organizational identity and the role of leadership. Corporate Reputation Review, 11, 262-276.

Walsh, I. J., Pazzaglia, F., \& Ergene, E. (2019). Loyal after the end: Understanding organizational identification in the wake of failure. Human Relations, 72(2), 163-187.

Watson, T. J. (2016). Organizational identity and organizational identity work as valuable analytical resources. In M. Pratt, M. Schultz, B. E. Ashforth, \& D. Ravasi (Eds.), The Oxford Handbook of Organizational Identity (pp. 123-139). Oxford, UK: Oxford University Press.

Weaver, G., Trevino, L., \& Cochran, L. (1999). Integrated and decoupled corporate social performance: Management commitments, external pressures, and corporate ethics practices. Academy of Management Journal, 42(5), 539-552.

Weick, K. E. (2013). Donald Palmer: Normal organizational wrongdoing: A critical analysis of theories of Misconduct in and by organizations. Administrative Science Quarterly, 58(2), 292-295.

Weick, K. E., \& Sutcliffe, K. M. (2006). Mindfulness and the quality of organizational attention. Organization Science, 17(4), 514-524.

Weick, K. E., \& Sutcliffe, K. M. (2015). Managing the Unexpected: Sustained Performance in a Complex World. Hoboken, NJ: John Wiley \& Sons.

Westphal, J. D., \& Zajac, E. J. (2001). Decoupling policy from practice: The case of stock repurchase programs. Administrative Science Quarterly, 46(2), 202-228.

Whetten, D. A. (2006). Albert and Whetten revisited: Strengthening the concept of organizational identity. Journal of Management Inquiry, 15, 219-234.

Whetten, D. A., \& Mackey, A. (2002). A social actor conception of organizational identity and its implications for the study of organizational reputation. Business \& Society, 41(4), 393-414.

Whetten, D., Foreman, P., \& Dyer, W. G. (2014). Organizational identity and family business. In L. Melin, M. Nordqvist, P. Sharma (Eds.), The SAGE Handbook of Family Business (pp. 340-363). London: SAGE. 
Wiesenfeld, B. M., Wurthmann, K. A., \& Hambrick, D. C. (2008). The stigmatization and devaluation of elites associated with corporate failures: A process model. Academy of Management Review, 33(1), 231-251.

Williams, T. A., Gruber, D. A., Sutcliffe, K. M., Shepherd, D. A., \& Zhao, E. Y. (2017). Organizational response to adversity: Fusing crisis management and resilience research streams. Academy of Management Annals, 11(2), 733-769.

Wijen, F. (2014). Means versus ends in opaque institutional fields: Trading off compliance and achievement in sustainability standard adoption. Academy of Management Review, 39(3), 302-323.

Wolfe, D. M. (1988). Is there integrity in the bottom line: Managing obstacles to executive integrity, in S. Srivastra (Ed.), Executive Integrity: The Search for High Human Values in Organizational Life (p. 140-171). Jossey-Bass, San Francisco.

Worden, S. (2003). The role of integrity as a mediator in strategic leadership: A recipe for reputational capital. Journal of Business Ethics, 46, 31-44.

Wright, T. A., \& Goodstein, J. (2007). Character is not "dead" in management research: A review of individual character and organization-level virtue. Journal of Management, 33(6), 928-958.

Wright, A. L., Irving, G., \& Thevatas, K. S. (2020). Professional values and managerialist practices: Values work by nurses in the emergency department. Organization Studies, $1-22$.

Wright, C., \& Nyberg, D. (2017). An inconvenient truth: How organizations translate climate change into business as usual. Academy of Management Journal, 60, 1633-1661.

Yamak, S., Nielsen, S., \& Escribá-Esteve, A. (2014). The role of external environment in upper echelons theory: A review of existing literature and future research directions. Group \& Organization Management, 39(1), 69-109.

Ybema, S. (2010). Talk of change: Temporal contrasts and collective identities. Organization Studies, 31(4), 481-503.

Yin, R. K. (2003). Case study research: Design and methods. Thousand Oaks, CA: Sage Publication, Inc.

Yin, R. K. (2015). Qualitative Research from Start to Finish. New York City, NY: The Guilford Press.

Zahra, S. A., Priem, R. L., \& Rasheed, A. A. (2005). The antecedents and consequences of top management fraud. Journal of Management, 31(6), 803-828.

Zavyalova, A., Pfarrer, M. D., Reger, R. K., \& Shapiro, D. L. (2012). Managing the message: The effects of firm actions and industry spillovers on media coverage following wrongdoing. Academy of Management Journal, 55, 1079-1101

Zerubavel, E. (1996). Social memories: Steps to a sociology of the past. Qualitative Sociology, 19, 283-299.

Zhao, E. Y., Fisher, G., Lounsbury, M., \& Miller, D. (2017). Optimal distinctiveness: Broadening the interface between institutional theory and strategic management. Strategic Management Journal, 38, 93-113. 
Zollo, M., \& Winter, S.G. (2002). Deliberate learning and evolution of dynamic capabilities. Organization Science, 13, 339-351.

Zolotoy, L., O'Sullivan, D., \& Klein, J. (2019). Character cues and contracting costs: The relationship between philanthropy and the cost of capital. Journal of Business Ethics, 154, 497-515.

Zundel, M., Holt, R., \& Popp, A. (2016). Using history in the creation of organizational identity. Management \& Organizational History, 11(2), 211-235. 
Bibliography | 201 



\section{Summary: On the Moral Side of Enterprise}

One of the most intriguing aspects of modern business is that organizations have become social actors, equivalent in many respects to human actors. In acknowledging organizations as social actors, we have come to recognize their capacity for responsibility, moral agency, and purposive action. This understanding is reflected in our tendency to attribute human qualities, traits and behaviors to collective entities; for instance, when we evaluate firms as virtuous for addressing pressing social and environmental challenges. Conversely, we are inclined to question the moral character and integrity of firms in the wake of misbehavior. Importantly, because of their attributed "actorhood", organizations are increasingly expected to cope with a multiplicity of institutionally derived roles, obligations and duties. Consequently, leaders of modern organizations are finding that value creation by the business and the values, norms and rules of the societies in which they operate are intertwined-in complex and often perilous ways.

However, scholars have not yet developed a comprehensive theory that explains why organizational actors come to embody a particular set of values, beliefs and interests, how they actively translate those into actions toward stakeholders, and why they persistently stay true to self-imposed commitments or, in some cases, stray away from them in profound ways. Much extant organizational theory is predominantly interested in processes and phenomena at a micro-level or macro-level, ignoring the origins, distinctive features and inner workings of organizational actors themselves. We argue that this research 
gap is troubling, considering that organizations as unique social actors are increasingly becoming the subject of moral scrutiny, in both everyday and academic discourse.

In this dissertation, we address the complexities, perils, and promises of organizational character and integrity. Specifically, we study the processes through which organizations form character, sustain or fail to maintain integrity and remediate misconduct. We believe that providing insight on these organizational phenomena is crucial, both for the academic debate on the moral responsibility of collective entities and for those institutional actors seeking solutions to ethical and social challenges. This dissertation includes four studiesone conceptual and three empirical-in which we address these matters in the context of the financial industry.

The purpose of Chapter $\mathbf{2}$ is to provide conceptual clarity on the notion of organizational integrity. Despite considerable scholarship on individual integrity, particularly as it relates to leadership behavior, there is still much ambiguity and inconsistency surrounding integrity at the collective level. In that chapter, we review the literature on integrity and theorize about its meaning and as building blocks, as and also the challenges for organizations in maintaining their integrity. Building on the scholarly work on organizational values and identity, we conceptualize integrity as the 'wholeness' of values espoused by leadership, the values embedded in formal structures and shared by members, and the values enacted in organizational actions. Importantly, as many modern organizations operate within an increasingly pluralistic institutional landscape, we acknowledge the heterogeneity of values within organizations and the challenges this inevitably presents fo maintaining integrity. Based on our conceptual model and, the associated propositions, we examine the application of integrity in the subsequent empirical studies.

In Chapter 3 we build on our propositions and explore how the character of organizations develop when corporate leaders espouse their commitment to addressing social concerns. When organizations adopt such commitments, for instance concerning corporate responsibility, business ethics and sustainability, they admit new responsibilities and objectives within their boundaries that may ostensibly conflict with the embedded values, identities and interest. We conducted case studies at two major financial firms that have become increasingly committed to corporate social responsibility. Based on in-depth interviews with executives, senior managers, and policymakers, we find that the development of character over time involves a collective process of negotiation, compromise, and conflict over values, beliefs and interests through which espoused commitments become anchored in the character of the organization.

In the Chapter 4 we investigate why organizations persistently violate accepted ethical, normative or regulatory principles (termed integrity failure). Although some integrity failures may be unintentional or brought about by isolated individuals, we speculate 
that the tendency of organizations to persist in tolerating such failures is the result of the interaction between flaws in the character of the organization and imperfections in the institutional system in which the organization is embedded. The latter assumption requires us to recognize and include the actions (or inactions) of social control agents in our empirical analyses. In that chapter, we conduct three case studies into financial firms that repeatedly violated anti-money laundering regulations over a 15 -year period. We are particularly interested in the role of regulatory agencies in the materialization and persistence of rule violations. Based on our analysis of archival material and interviews with regulators, we find that when procedural rules are experienced as commercially restrictive and/or ambiguous, firms are likely to perceive such rules as illegitimate. At the same time, we find that if regulators do not punish violations of procedural rules, the undesirability of rule violations is inadequately signaled which may inadvertently lead to its "normalization". Together, these processes tend to lead firms into complacency. We find that the restraint and poor visibility of enforcement induce complacent firms to deliberately maintain the status quo. However, regulators can use salient critical events to signal both the immorality and the organizational consequences of rule violations and enforce substantive remediation.

In Chapter 5, we build on our earlier observation that critical events in an organization's life course, such as integrity failures, have the potential to be character-defining. To examine how organizations adapt to integrity failure, we conduct an ethnographic study of a European financial firm that was nationalized during the 2007-2008 financial crisis. We find that integrity failures that combine profound uncertainty over the identity of the organization with a distrust towards its values may coalesce in an impetus for leadership to rebuild the character of their organization. This study reveals that successfully rebuilding character not only relies on neutralizing the policies, practices and narratives that have become perceived as problematic remnants of an undesirable organizational self, but also on the use of rhetorical history and the retrieval of latent values and ideals. Importantly, although this twofold character work is crucial in recementing identification and trust from key constituents, fully obfuscating memories of a problematic past may indeed be extremely difficult or impossible. We find that while a blemished character will have enduring behavioral and evaluative implications for the organization and its members, a problematic legacy can-with skill and genuine commitment-be purposefully and strategically harnessed to foster organizational distinctiveness.

The results of this dissertation contribute to both organizational theory and practice. Whereas scholars have been focused primarily on social phenomena above or below the organization-level line of sight, this dissertation reinvigorates the academic debate on the "actorhood" of modern organizations. Based on our studies on organizational integrity and character, we show that the latent values of an organizational institution may systematically affect its ability to learn and adapt to external changes, but can be 
purposefully deployed after moral failure to guide the organization in a better direction. In addition, by illuminating the processes that enable the materialization, persistence and remediation of misconduct, this dissertation provides important insights on the growing scholarly interest in the "dark side of organizations". This dissertation also offers practical implications for leaders on how to maintain the integrity of their organizations and to rebuild character in the aftermath of moral adversity, as well as for those actors responsible for detecting, preventing, and eradicating misconduct within and by organizations. Finally, this dissertation opens new avenues for future research on the plurality of values within organizations, character and integrity, and the role of social-control agents in both preventing and combating "normalized" misconduct.. 


\section{Samenvatting: Over de Morele Kant van Ondernemen}

Misschien wel het belangrijkste sociale feit van de moderne tijd is dat organisaties sociale actoren zijn geworden, die in veel opzichten gelijkwaardig zijn aan menselijke actoren. Door organisaties als sociale actoren te erkennen, onderkennen we hun vermogen tot verantwoordelijkheid, morele daadkracht (moral agency) en doelgerichte actie. Dit inzicht komt tot uiting in onze neiging om menselijke kwaliteiten, eigenschappen en gedragingen toe te schrijven aan collectieve entiteiten, bijvoorbeeld wanneer we bedrijven beoordelen als deugdzaam voor het aanpakken van sociale vraagstukken en milieuproblemen. We zijn tegelijkertijd geneigd om het morele karakter en de integriteit van bedrijven in twijfel te trekken wanneer zij zich misdragen. Vanwege hun toegeschreven "actorschap" (actorhood) wordt van bedrijven in toenemende mate verwacht dat zij een veelheid aan maatschappelijke rollen en verplichtingen vervullen. Bijgevolg komen de bestuurders van moderne ondernemingen er steeds meer achter dat het creëren van waarde door de onderneming en de waarden, normen en regels van de samenlevingen waarin zij actief is, met elkaar verweven zijn-zij het op een complexe en vaak uitdagende manier.

Wetenschappers hebben echter nog geen samenhangende theorie ontwikkeld die verklaart waarom organisaties bepaalde waarden, overtuigingen en belangen belichamen, hoe zij deze actief omzetten in acties jegens stakeholders, en waarom zij trouw blijven aan zelfopgelegde verbintenissen (self-imposed commitments) of, in sommige gevallen, er op een fundamentele manier van afdwalen. Veel van de bestaande organisatietheorieën zijn voornamelijk 
geïnteresseerd in processen en fenomenen op een meer micro- of macroniveau, en negeren de oorsprong, de onderscheidende kenmerken en de innerlijke werking van de organisatorische actor (organizational actor) zelf. Wij stellen dat deze leegte in het onderzoek verontrustend is, gezien het feit dat organisaties als unieke sociale actoren steeds meer het onderwerp worden van morele kritiek, zowel in het dagelijks taalgebruik als in het academisch discours.

In dit proefschrift behandelen we de complexiteit, perikelen en beloften van organisatorisch karakter en integriteit. Meer specifiek bestuderen we de processen waardoor organisaties karakter vormen, integriteit behouden en wangedrag herstellen. Wij geloven dat het verschaffen van inzicht in deze organisatorische fenomenen van cruciaal belang is, zowel voor het academische debat over de morele verantwoordelijkheid van collectieve entiteiten als voor die maatschappelijke actoren die oplossingen zoeken voor ethische en sociale problemen. Dit proefschrift omvat vier studies (één conceptuele en drie empirische) waarin we deze kwesties aan de orde stellen in de context van de financiële sector.

Het doel van Hoofdstuk 2 is conceptuele helderheid te verschaffen over het begrip organisatorische integriteit (organizational integrity). Ondanks een aanzienlijke hoeveelheid wetenschappelijk onderzoek over de integriteit van leiders is er nog steeds een grote mate van ambiguïteit en inconsistentie rond integriteit op het collectieve niveau. In dit hoofdstuk bespreken we de literatuur over integriteit en theoretiseren we de betekenis en de bouwstenen ervan, evenals de uitdagingen voor organisaties bij het handhaven van hun integriteit. Voortbouwend op de wetenschappelijke literatuur over waarden en identiteit, conceptualiseren we integriteit als de 'heelheid' (wholeness) van waarden die door het leiderschap worden omarmd (espoused), de waarden die in formele structuren zijn ingebed en door leden worden gedeeld (embedded), en de waarden die in acties van de organisatie tot uiting komen (enacted). Aangezien moderne organisaties in een steeds meer pluralistisch landschap (institutional pluralism) opereren, erkennen wij de heterogeniteit van waarden binnen organisaties en de uitdagingen die dit kan betekenen voor het handhaven van integriteit. Op basis van ons conceptuele model en de bijbehorende stellingen, onderzoeken we de toepassing van integriteit in de empirische studies.

In Hoofdstuk 3 bouwen wij onze stellingen verder uit en onderzoeken wij hoe het karakter van organisaties zich ontwikkelt wanneer bedrijfsleiders hun betrokkenheid bij het aanpakken van sociale problemen uitspreken. Wanneer organisaties dergelijke verbintenissen aangaan, bijvoorbeeld met betrekking tot maatschappelijk verantwoord ondernemen, bedrijfsethiek en duurzaamheid, laten zij binnen hun grenzen nieuwe verantwoordelijkheden en doelstellingen toe die ogenschijnlijk in strijd kunnen zijn met de ingebedde waarden, identiteiten en belangen. We voeren casestudies uit bij twee grote financiële ondernemingen die zich steeds meer zijn gaan inzetten voor maatschappelijk 
verantwoord ondernemen. Op basis van diepte-interviews met leidinggevenden, senior managers en beleidsmakers stellen we vast dat de ontwikkeling van het karakter in de loop van de tijd een collectief proces van onderhandeling, compromissen en conflicten over waarden, overtuigingen en belangen inhoudt, waardoor aangegane verplichtingen in het karakter van de organisatie worden verankerd.

In Hoofdstuk 4 onderzoeken we waarom organisaties herhaaldelijk ethische, normatieve en wettelijke regels overtreden (integriteitsschendingen). Hoewel sommige integriteitsschendingen onbedoeld kunnen zijn, speculeren we dat de neiging van organisaties om te volharden in dergelijke schendingen het resultaat is van de wisselwerking tussen fouten in het karakter van de organisatie en onvolkomenheden in het institutionele systeem waarin de organisatie opereert. Deze laatste veronderstelling vereist dat we het optreden (of niet-optreden) van sociale controleurs (social-control agents) erkennen en in onze empirisch analyses opnemen. In dit hoofdstuk voeren we drie casestudies uit van financiële ondernemingen die over een periode van 15 jaar herhaaldelijk antiwitwas regelgeving hebben overtreden. Op basis van archiefmateriaal en interviews met toezichthouders, stellen we vast dat wanneer procedurele regels als commercieel beperkend en dubbelzinnig worden ervaren, bedrijven deze regels als onwettig zullen beschouwen. Tegelijkertijd blijkt uit ons onderzoek dat als toezichthouders niet straffend optreden tegen overtredingen van dergelijke procedurele regels, de onwenselijkheid ervan onvoldoende wordt gecommuniceerd en niet-naleving wordt "genormaliseerd". Deze processen tezamen leiden ertoe dat bedrijven zelfgenoegzaam (complacent) worden. Wij stellen vast dat de terughoudendheid en verborgenheid van handhaving zelfgenoegzame bedrijven ertoe bewegen doelbewust de status quo in stand te houden. Toezichthouders kunnen echter gebruik maken van kritieke gebeurtenissen (salient critical events) om zowel immoraliteit als de gevolgen van regelovertredingen te communiceren en zodoende ingrijpende verbeteringen af te dwingen.

In Hoofdstuk 5 bouwen we voort op onze eerdere observatie dat kritieke gebeurtenissen in de levensloop van een organisatie, zoals integriteitsschendingen, in potentie karakterbepalend kunnen zijn. Om te onderzoeken hoe organisaties zich aanpassen aan een integriteitsschending, voeren we een etnografisch onderzoek uit bij een Europese financiële onderneming die tijdens de financiële crisis van 2007-2008 is genationaliseerd. We stellen vast dat integriteitsschendingen die een diepe onzekerheid over de identiteit van de organisatie combineren met een wantrouwen tegenover haar waarden, kunnen samenvloeien in een impuls voor het leiderschap om het karakter van hun organisatie te hervormen. Het met succes hervormen van karakter berust niet alleen op het neutraliseren van beleid, praktijken en verhalen die als problematische overblijfselen van een ongewenst “organisatorische zelf” (organizational self) worden ervaren, maar ook op het terughalen en benadrukken van latente waarden en idealen. Hoewel dit tweeledige karakterwerk (character work) van cruciaal belang is voor het terugwinnen van vertrouwen onder 
stakeholders, laat dit onderzoek zien dat het volledig verdoezelen van herinneringen aan een problematisch verleden uiterst moeilijk kan zijn. Wij stellen vast dat, hoewel een aangetast karakter blijvende implicaties zal hebben voor de organisatie en haar leden, een problematische erfenis (problematic legacy) doelgericht en strategisch kan worden aangewend om het onderscheidend vermogen van de organisatie te bevorderen.

De resultaten van dit proefschrift leveren een bijdrage aan zowel de organisatietheorie als de praktijk. Terwijl wetenschappers zich voornamelijk hebben gericht op sociale fenomenen boven of onder het organisatieniveau, geeft dit proefschrift een nieuwe impuls aan het academische debat over het "actorschap" van de moderne organisatie. Op basis van onze studies over organisatorische integriteit en karakter tonen wij aan dat de (latente) waarden van een organisatie haar vermogen om te leren en zich aan te passen aan veranderende omstandigheden systematisch kunnen beïnvloeden en doelgericht kunnen worden ingezet om de organisatie in de juiste richting te sturen na moreel falen. We belichten hiermee ook de processen die de materialisatie, persistentie en remediëring van wangedrag mogelijk maken en verschaffen daarmee belangrijke inzichten in de groeiende wetenschappelijke aandacht voor de "donkere kant van organisaties". Dit proefschrift biedt ook praktische implicaties voor leiders hoe zij de integriteit van hun organisaties kunnen handhaven en een karakter kunnen opbouwen in de nasleep van tegenspoed, evenals voor die actoren die actief zijn in het opsporen, voorkomen en uitroeien van wangedrag in en door organisaties. Bovendien opent dit proefschrift nieuwe wegen voor vervolgonderzoek naar de pluraliteit van waarden binnen organisaties, karakter en integriteit, en de rol van sociale controleurs bij het voorkomen en bestrijden van "genormaliseerd" wangedrag. 


\section{About the Book}

One of the most intriguing aspects of modern business is that corporations have become social actors, similar in many respects to human actors. In an era when corporate scandals and misconduct often raise questions about the moral character and integrity of organizations, leaders are increasingly finding that value creation by the business and the values, norms and rules of the societies in which they operate are intertwined-albeit in complex and often perilous ways. In On the Moral Side of Enterprise, Timo Fiorito explores the complexities, perils and promises of organizational character and integrity. Timo's rich account shows that although some financial enterprises are able to successfully adapt to and, in some cases, even realize profound positive change following moral failures, corporations that have fallen prey to dysfunctional processes tend to repeatedly violate their institutional responsibilities. This scholarly work provides important contributions to organizational theory and offers insights for anyone looking to build a stronger organizational character and preserve the integrity of the broader system in which corporations are embedded.

Timo Fiorito (1990) obtained a MSc in Criminology and a MSc in Public Administration, both from the Vrije Universiteit Amsterdam. Timo conducted his doctoral research at the Entrepreneurship and Technology Management (ETM) department of the University of Twente. His research, in collaboration with De Nederlandsche Bank, deals with corporate responsibility and misconduct, organizational institutionalism, governance, values and related institutional processes. 
One of the most intriguing aspects of modern business is that corporations have become social actors, similar in many respects to human actors. In an era when corporate scandals and misconduct often raise questions about the moral character and integrity of organizations, leaders are increasingly finding that value creation by the business and the values, norms and rules of the societies in which they operate are intertwinedalbeit in complex and often perilous ways. In On the Moral Side of Enterprise, Timo Fiorito explores the complexities, perils and promises of organizational character and integrity. Timo's rich account shows that although some financial enterprises are able to successfully adapt to and, in some cases, even realize profound positive change following moral failures, corporations that have fallen prey to dysfunctional processes tend to repeatedly violate their institutional responsibilities. This scholarly work provides important contributions to organizational theory and offers insights for anyone looking to build a stronger organizational character and preserve the integrity of the broader system in which corporations are embedded.

Timo Fiorito (1990) obtained a MSc in Criminology and a MSc in Public Administration, both from the Vrije Universiteit Amsterdam. Timo conducted his doctoral research at the Entrepreneurship and Technology Management (ETM) department of the University of Twente. His research, in collaboration with De Nederlandsche Bank, deals with corporate responsibility and misconduct, organizational institutionalism, governance, values and related institutional processes.

\section{UNIVERSITY \\ OF TWENTE.}

